\title{
Dietary components and cardiovascular risk markers : effects of tocotrienols, beta-glucan and plant stanol esters
}

Citation for published version (APA):

Kerckhoffs, D. A. J. M. (2003). Dietary components and cardiovascular risk markers : effects of tocotrienols, beta-glucan and plant stanol esters. [Doctoral Thesis, Maastricht University]. Maastricht University. https://doi.org/10.26481/dis.20030321 dk

Document status and date:

Published: 01/01/2003

DOI:

10.26481/dis.20030321dk

Document Version:

Publisher's PDF, also known as Version of record

\section{Please check the document version of this publication:}

- A submitted manuscript is the version of the article upon submission and before peer-review. There can be important differences between the submitted version and the official published version of record. People interested in the research are advised to contact the author for the final version of the publication, or visit the DOI to the publisher's website.

- The final author version and the galley proof are versions of the publication after peer review.

- The final published version features the final layout of the paper including the volume, issue and page numbers.

Link to publication

\footnotetext{
General rights rights.

- You may freely distribute the URL identifying the publication in the public portal. please follow below link for the End User Agreement:

www.umlib.nl/taverne-license

Take down policy

If you believe that this document breaches copyright please contact us at:

repository@maastrichtuniversity.nl

providing details and we will investigate your claim.
}

Copyright and moral rights for the publications made accessible in the public portal are retained by the authors and/or other copyright owners and it is a condition of accessing publications that users recognise and abide by the legal requirements associated with these

- Users may download and print one copy of any publication from the public portal for the purpose of private study or research.

- You may not further distribute the material or use it for any profit-making activity or commercial gain

If the publication is distributed under the terms of Article $25 \mathrm{fa}$ of the Dutch Copyright Act, indicated by the "Taverne" license above, 
Dietary Components and Cardiovascular Risk Markers:

Effects of Tocotrienols, $\beta$-Glucan and Plant Stanol Esters 


\section{fứin}

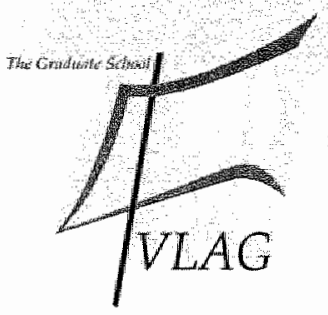

The studies presented in this thesis were performed at the Nutrition and Toxicology Research Institute Maastricht (NUTRIM), which participates in the Graduate School VLAG (Food Technology, Agrobiotechnology. Nutrition and Health Sciences) accredited by the Royall Netherlands Academy of Arts and Sciences.

Production: Datawyse, Universitaire Pers Maastricht Cover design: Daniëlle Kerckhoffs

(C) Daniëlle Anna Johannes Maria Kerckhoffs, Venlo 2003 ISBN 90-9016633-5 


\section{Dietary Components and Cardiovascular Risk Markers:}

\section{Effects of Tocotrienols, $\beta$-Glucan and Plant Stanol Esters}

\section{Proefschrift}

ter verkrijging van de graad van doctor aan de Universiteit Maastricht, op gezag van de Rector Magnificus, Prof. Dr. A.C. Nieuwenhuijzen Kruseman, volgens het besluit van het College van Decanen, in het openbaar te verdedigen op vrijdag 21 maart 2003 om 14.00 uur

$$
\text { door }
$$

Daniëlle Anna Johannes Maria Kerckhoffs geboren op 6 juni 1970 te Maastricht 


\section{Promotores:}

Prof. Dr. Ir. R.P. Mensink

Prof. Dr. G. Hornstra

\section{Beoordelingscommissie:}

Prof. Dr. Ir W.H.M Saris (voorzitter)

Prof. Dr. A. Bast

Prof. Dr. T.W.A de Bruin

Prof. Dr. M.H. Hofker

Dr. Ir. P.L. Zock (Wageningen Universiteit)

Financial support by the Netherlands Heart Foundation for the publication of this thesis is gratefully acknowledged. 
Aan mijn vader

Ter nagedachtenis aan mijn moeder

Voor Ron 



\section{Contents}

\section{Chapter 1}

General introduction

\section{Chapter 2}

A critical review of the effects on the human serum lipoprotein profile of $\beta$-glucan, soy protein and isoflavones, plant sterols and stanols, garlic and tocotrienols

\section{Chapter 3}

Effects of a tocotrienol-rich fraction from rice bran oil on serum lipoproteins, markers for cholesterol synthesis and absorption, and hemostatic parameters in hypercholesterolemic subjects

\section{Chapter 4}

The effects of $\beta$-glucan from oat bran in bread and cookies or orange juice on serum lipoproteins in mildly hypercholesterolemic subjects

\section{Chapter 5}

The effects of plant stanol esters, oat $\beta$-gllucan and pravastatin on plasma lipid-soluble antioxidants in subjects with increased serum cholesterol concentrations

\section{Chapter 6}

C-reactive protein and interleukin-6 in mildly and hypercholesterolemic subjects: effects of plant stanol esters and pravastatin, and relationships with plasma antioxidants

\section{Chapter 7}

General discussion

Summary

Samenvatting

Dankwoord

Curriculum Vitae

List of publications 


\section{Chapter}

General introduction 


\section{General introduction}

Coronary heart disease (CHD) is a principal cause of morbidity and mortality in Western societies. Multiple risk factors have been identified that contribute to the development of CHD, such as clgarette smoking, hypertension, diabetes mellitus, obesity, physical inactivity, hemostatic markers and an unfavorable lipoprotein profile. At present, it is clear that high concentrations of total or low-density lipoprotein (LDL) cholesterol in the blood are potent risk factors for CHD (1), whereas elevated concentrations of high-density lipoprotein (HDL) cholesterol or a low LDL (or total) to $\mathrm{HDL}$ cholesterol ratio may protect against $\mathrm{CHD}(2,3)$.

The formation of oxidized LDL in the intima of vessel walls, which may lead to endothelial cell damage, also plays a crucial role in de development of CHD. Oxidation of LDL can stimulate the expression of pro-inflammatory cytokines and adhesion molecules, which may result in the formation of lipid-filled foam cells, which in turn may lead to the development of atherosclerotic plaque. Antioxidants that inhibit LDL oxidation may therefore protect against disease processes in which endothelial dysfunction is involved (4).

The composition of the diet is of importance in modifying an unfavorable serum lipoprotein profile and thereby the risk of CHD. This has not only led to general dietary advices, but also to the development of specific foods and food components that may improve the serum lipoprotein profile.

In this chapter, the dietary components, tocotrienols, $\beta$-glucan and plant stanol esters are briefly introduced. Then, special attention is given to lipid-soluble antioxidants and inflammation, and to the dietary lipid and lipoprotein metabolism. Finally, the last part of this chapter provides the outline of the thesis.

\section{Dietary components}

Our critical review described in Chapter 2 addresses in detail the effects of several dietary components, such as tocotrienols, $\beta$-glucan and plant stanol esters on serum lipids and lipoproteins. For this reason, these compounds will only be briefly introduced in the next paragraphs.

\section{Tocotrienols}

The term vitamin $E$ is a generic description for the four subtypes $(\alpha, \beta, \gamma$ and $\delta)$ of tocopherols and corresponding tocotrienols, which consist of a chromanol ring 
connected to a phytyl side chain. These four forms are based on the number and pasition of methyl groups on their chromanol ring. The tocotrienols differ from the tocopherols in having a phytyl side chain that contains three double bonds (5). Most vegetable oils contain tocopherols. They are more abundant in the human diet than the tocotrienols, which are especially found in palm oil and rice bran oil $(6,7)$.

Unlike tocopherols, which do not affect serum lipoproteins (8), the tocotrienols have been suggested to lower serum LDL cholesterol concentrations by reducing the activity of 3-hydroxy-3-methylglutaryl-coenzyme A (HMG-CoA) reductase, the ratelimiting enzyme in the endogenous cholesterol synthesis (9-12). The possible mechanism of action may be a reduced HMG-COA reductase protein synthesis rate and an increased degradation rate (13). It has been proposed that $\delta$-tocotrienol and $\gamma$-tocotrienol are more effective than $\alpha$-tocotrienol in inhibiting HMG-CoA reductase, whereas $\beta$-tocotrienol has a very low effect $(11,14)$.

Results of human studies, however, about the effects of tocotrienols from palm oil on serum lipids and lipoproteins, but also on platelet function, are conflicting (15-21). In 1997, Qureshi et al. (22) suggested that tocotrienols from rice bran oil possess even a greater hypocholesterolemic activity than tocotrienois from palm oil $(16,17)$. Rice bran oil is especially rich in $\gamma$-tocotrienol. Besides, they postulated that these promising effects could be ascribed to two novel subtypes of tocotrienols, which were isolated from rice bran oil and identified as desmethyl $\left(P_{21}\right)$ and didesmethyl $\left(P_{25}\right)$ tocotrienols. Based on these findings, our first study described in Chapter 3 was designed to compare the effects of a tocotrienol-rich fraction from rice bran oil with those of pravastatin, an HMG-CoA reductase inhibitor, on serum lipoproteins, markers for cholesterol synthesis and absorption and on hemostatic function in hypercholesterolemic volunteers on a cholesterol-lowering diet.

\section{$\beta$-Glucan}

Dietary fibers can be divided into two classes as based on their water solubility. Unlike water-insoluble fibers, most soluble fibers appear to lower serum total cholesterol concentrations mainly by lowering LDL cholesterol (23). in fact, results of a meta-analysis of 12 trials (24) indicated that a daily intake of $3 \mathrm{~g}$ of soluble fiber from oat products resulted in a modest decrease of total cholesterol concentrations of about $0.13 \mathrm{mmol} / \mathrm{L}$. This effect was positively related with initial serum total cholesterol concentrations.

It has been demonstrated that this hypocholesterolemic effect of oat products could be ascribed to their soluble fiber component, $\beta$-glucan (25). Oat $\beta$-glucan is a nonstarch polysaccharide composed of $\beta-(1 \rightarrow 4)$-linked glucose units separated every two to three units by a single $\beta-(1 \rightarrow 3)$-linked glucose $(26)$. Also $\beta$-glucan from 
barley $(27,28)$ or yeast $(29)$ has been shown to exert hypocholesterolemic effects in humans. The exact mechanism of action of oat $\beta$-glucan and other soluble fibers is not clear yet. $A$ possible explanation may be a decreased bile acid reabsorption and thereby an increased hepatic conversion of cholesterol to bile acids caused by fiber binding or by an increased viscosity of the intestinal contents $(30,31)$.

in 1997, the U1.S. Food and Drug Administration (FDA) approved a health claim on food products that a diet high in soluble fiber from whole oats (oat bran, oatmeal and oat flour) and low in saturated fat and cholesterol may reduce the risk of heart disease $(32,33)$." It was concluded that at least $3 \mathrm{~g}$ of $\beta$-glucan from oats should be consumed per day to achieve a clinically relevant reduction in serum total cholesterol concentration (32): By introducing a wide range of staple food products, compliance with this dietary guideline would be greatly improved. Our second study described in Chapter 4 was therefore designed to examine the effects of $\beta$-glucan from oat bran incorporated into bread and cookies on serum lipids and lipoproteins in mildly hypercholesterolemic subjects. Since no effects were found in this trial, we further investigated the effects of food processing and the food matrix. For this, our third trial, also described in Chapter 4 , was designed to study whether the same source and amount of oat $\beta$-glucan as in our second study would lower serum cholesterol concentrations when given with orange juice.

\section{Plant stanol esters}

Plant sterols are mostly found in vegetable oils, nuts, cereals and beans, and are consumed in Western countries in a daily amount of about 160 to $360 \mathrm{mg}$ (34): The human body can not synthesize these components and therefore they are derived only from the diet. The most abundant plant sterols in nature are campesterol, $\beta$ sitosterol and stigmasterol, which are structurally related to cholesterol but differ in side chain configuration. Saturation of plant sterols with hydrogen leads to the formation of plant stanols, such as campestanol and sitostanol, which are less abundant in the human diet than plant sterols (34). For incorporation into food products, plant sterols and stanols are often esterified with fatty acids to improve their fat solubility. It should be noted that $1.6 \mathrm{~g}$ of esterified plant sterols or stanols provide about $1 \mathrm{~g}$ of plant sterols or stanols and $0.6 \mathrm{~g}$ of fatty acids. This is often described as ' $1 \mathrm{~g}$ plant sterols (or stanols) provided as its fatty acid esters" or " $1 \mathrm{~g}$ plant sterol (or stanol) esters'.

It is well established that plant sterols and stanols have cholesterol-lowering properties. Based on a meta-analysis of 14 studies, Law (35) concluded that about 2 $\mathrm{g}$ of plant sterols or stanols lowered serum LDL cholesterol concentrations by 9 to $14 \%$. There were no further significant decreases at higher doses. Plant sterols and 
stanols lower cholesterol absorption since they can easily displace intestinal cholesterol from the micelles due to their higher hydrophobicity (36). This reduction results in a compensatory increase in endogenous cholesterol synthesis (37), but also in a higher LDL-receptor expression (38). The net overall effect is that plant sterols or stanols lower serum cholesterol concentrations. Not all plant sterols, however, are powerful cholesterol-lowering components. in contrast to the 4desmethylsterols, like sitosterol and campesterol, 4,4-dimethylsterols from sheanut oil, such as $\alpha$-amyrin and lupeol, do not affect serum lipid and lipoprotein concentrations (39).

Food products that contain plant sterols or stanols are effective in various population groups, including children, and also in combination with cholesterol-lowering diets or drugs. In addition, these cholesterol-lowering agents do not seem to have adverse effects as shown by extensive safety evaluation studies (36). However; plant sterols and stanols also lower plasma concentrations of lipid-soluble components other than cholesterol, such as vitamin $\mathbb{E}$ and other antioxidants (40). In the present thesis, attention is not only given to the effects of plant stanol esters on plasma lipid-soluble antioxidants (Chapter 5), but also to their effects on inflammatory parameters (Chapter 6). Information about the effects of other cholesterol-lowering agents than the plant sterols and stanols on plasma antioxidants in humans is limited. Therefore we also examined the effects of oat $\beta$-glucan and pravastatin on plasma lipid-soluble antioxidants (Chapter 5).

\section{Lipid-soluble antioxidants}

Antioxidants may protect against damage by oxygen free radicals, which are oxygen species containing one or more unpaired electrons. The oxygen free radicals are produced in the human body by normal metabolic processes, but an excess of these species can damage membranes and lipoproteins through lipid peroxidation. They are thought to play a role in pathological processes, like atherosclerosis, cancer and aging. Oxidized $L D L$, but not native $L D L$, may damage the vascular endathelium. The prevention of LDL oxidation may therefore protect against atherosclerosis (4).

A lipid-soluble antioxidant that has attracted interest in the protection against LDL oxidation is vitamin $E$. It has been hypothesized to protect the human body from cell damage that can lead to cardiovascular disease and cancer. However, five recent intervention trials (41-45) showed no favorable effects of vitamin E supplementation. Also the role of carotenoids in reducing the risk for cancer, cardiovascular and agerelated eye diseases has gained much attention lately. Next to their function as 
precursors for vitamin A (retinol), these lipid-soluble antioxidants may reduce the damage from free radicals. Foods rich in carotenoids include green and yellow to deep-red vegetables and fruits. The carotenoids $\beta$-carotene, $\alpha$-carotene, lycopene, lutein and $\beta$-cryptoxanthin are most frequently found in the human diet $(46,47)$. Despite an inverse association between $\beta$-carotene intake or plasma $\beta$-carotene concentrations and the risk of lung cancer and cardiovascular disease $(48,49)$, three randomized trials (50-52) did not demonstrate a reduction in risk of lung cancer or cardiovascular disease after $\beta$-carotene supplementation. Inverse relationships were found between lycopene consumption and the risk for prostate cancer (53-55) and between dietary intakes of carotenoids and the risk of age-related macular degeneration $(56,57)$. This disease is characterized by deterioration of the macula (the yellow spot at the center of the human retina), which contains the yellowpigmented carotenolds, lutein and zeaxanthin (58).

\section{Inflammation}

The vascular endothelium, which forms a barrier between the circulating blood and the surrounding tissues, plays an important role in the regulation of lipid breakdown, vascular tone platelet adhesion and aggregation "coagulation, fibrinolysis, inflammation and immune responses (59-61). Damage of endothelial cells may lead to changes in normal endothelial function, which is a critical event in the development of atherosclerosis. Several risk factors for artherosclerotic cardiovascular disease including cigarette smoking, hypertension and hypercholesterolemia appear to promote endothelial dysfunction. Oxidized LDL particles play a key role in the vascular endothelial cell damage.

Oxidation of LDL may result in the expression of pro-inflammatory cytokines, such as interleukin (IL) - 1 , tumor necrosis factor- $\alpha$ (TNF- $\alpha$ ) and IL-6 $(62,63)$. In turn, IL-6 may induce the hepatic synthesis of the acute phase reactant Creactive protein (CRP) $(64,65)$. These markers of inflammation can be measured in the plasma. Atherosclerosis is generally believed to be an inflammatory disease. In fact, CRP and IL-6 were significant predictors of the risk of future cardiovascular events in healthy women (66). An early event in inflammation, which is stimulated by the proinflammatory cytokines including $\mathrm{L}_{-1}-1$ and $\mathrm{TNF}-\alpha$, is the endothelial adhesion of circulating leucocytes and their migration between the endothelial cells. After migration, the monocytes become macrophages, which accumulate oxidized LDL particles to become lipid (cholesteryl esters)- filled foam cells. In turn, release of growth factors and cytokines may stimulate the proliferation and endothelial 
transmigration of smooth muscle cells. Also platelets may adhere and aggregate at the same sites. The foam cells together with T-lymphocytes and smooth muscle cells may become fatty streak within the intima of the artery wall. Eventually, this can lead to the development of fibrous plaque (67).

Endothelial adhesion molecules may participate in the pathogenesis of atherosclerosis. Elevated concentrations of the soluble adhesion molecules in the blood appear to be useful markers of endothelial cell darnage (60). The adhesion molecules are divided into two families, the selectins and the immunoglobulin superfamily (IGSF). The selectins mediate the initial rolling of leucocytes on the vascular endothelium. L-selectin is located on all leucocytes: After activation, Pselectin appears on the cell surface of platelets, whereas E-selectin is found on endothelial cells. The selectins are mediators for adhesion between leucocytes and the endothelium and between leucocytes and platelets in the blood. Intercellular adhesion molecule (ICAM)-1 and vascular cell adhesion molecule (VCAM)-1 are members of the IGSF family that are expressed on endothelial cells and mediate the firm adherence and subsequent transendothelial migration of circulating leucocytes (68).

In short, oxidation of LDL can stimulate the expression of pro-inflammatory cytokines. This may increase endothelial adhesion and migration of leucocytes, and macrophage formation, which may result in lipid accumulation, which in turn may lead to the development of atherosclerotic plaque.

\section{Dietary lipid and lipoprotein metabolism}

The liver plays a crucial role in the regulation of serum lipid and lipoprotein concentrations. It synthesizes lipoproteins, which are released into the circulation, and removes them from the blood. Bile salts are also formed by the liver from cholesterol and are needed for the formation of mixed micelles in the intestine to transport lipids through the unstirred water layer adjacent to the intestinal cells. More than $95 \%$ of the bile salts are re-absorbed in the terminal ileum and are then transported through the portal blood to the liver for re-secretion into bile. This process is called the enterohepatic circulation. Cholesterol homeostasis is maintained by balancing cholesterol absorption and endogenous cholesterol synthesis with the removal of bile salts and biliary cholesteral from the body (69).

Blood lipids are transported by lipoproteins. These water-soluble particles are composed of a hydrophobic core filled with triacylglycerols and cholesteryl esters, and a surface monolayer containing polar phospholipids, unesterified cholesterol and 
specific proteins called apolipoproteins (apo). Five major classes of lipoproteins are found: chylomicrons, very low-density lipoproteins (VLDL), intermediate-density lipoproteins (DDL), low-density lipoproteins (LDL); and high-density lipoproteins (HDL). These lipoproteins are classified on the basis of their density. The major classes also differ in size and composition. LDL is the main carrier of cholesterol and contains about $70 \%$ of the total amount of serum cholesteral $(70,71)$.

The transport of blood lipids throughout the body is a complex and dynamic process. In brief, lipoprotein metabolism can be divided into three pathways (Figure 1): a) the exogenous transport pathway, which comprises the transport of lipids by chylomicrons from the intestine to peripheral tissues and the liver, b) the endogenous transport pathway, involving the metabolism of the liver-derived lipoproteins, and $c$ ) reverse cholesterol transport, which includes the transport of lipids from peripheral tissues to the liver (70-73):

\section{The exogenous transport pathway}

Dietary triacylglycerols are digested in the intestine by pancreatic lipase into predominantly free fatty acids and monoacylglycerols. After absorption by enterocytes, the monoacylglycerols are re-esterified with free fatty acids within the intestinal mucosal cells to form new triacylglycerols, whereas $75 \%$ of the dietary, biliary and newly synthesized cholesterol is esterified with fatty acids. ATP binding cassette transporters $(A B C)$ play a role in mediating the efflux of unesterified cholesterol from enterocytes back into the intestinal lumen (72). The triacylglycerols, together with cholesteryl esters, are packed into chylomicrons $(69,74)$. Nascent chylomicrons, which contain apo B48, A-I and A-IV, first enter the mesenteric lymph and are then transported through the thoriac duct into the blood circulation. In the circulation, the chylomicrons take up apo C-ll. Subsequently chylomicron triacylglycerols are hydrolyzed by lipoprotein lipase (LPL) into free fatty acids and glycerol. LPL acts at the side of the capillary endothelium surface, and uses apo C-II as a cofactor: Free fatty acids are taken up from the circulation by peripheral tissues and subsequently stored as triacylglycerols or used as fuel. During lipolysis, some surface components, such as phospholipids, cholesterol and apolipoproteins, are transferred to HDL particles. The remaining cholesteryl ester-enriched particles, which are called chylomicron remnants, take up apo E from HDL and are removed from the circulation by the hepatic remnant (apo E) receptor through endocytosis as demonstrated in animais $(70,71)$. 


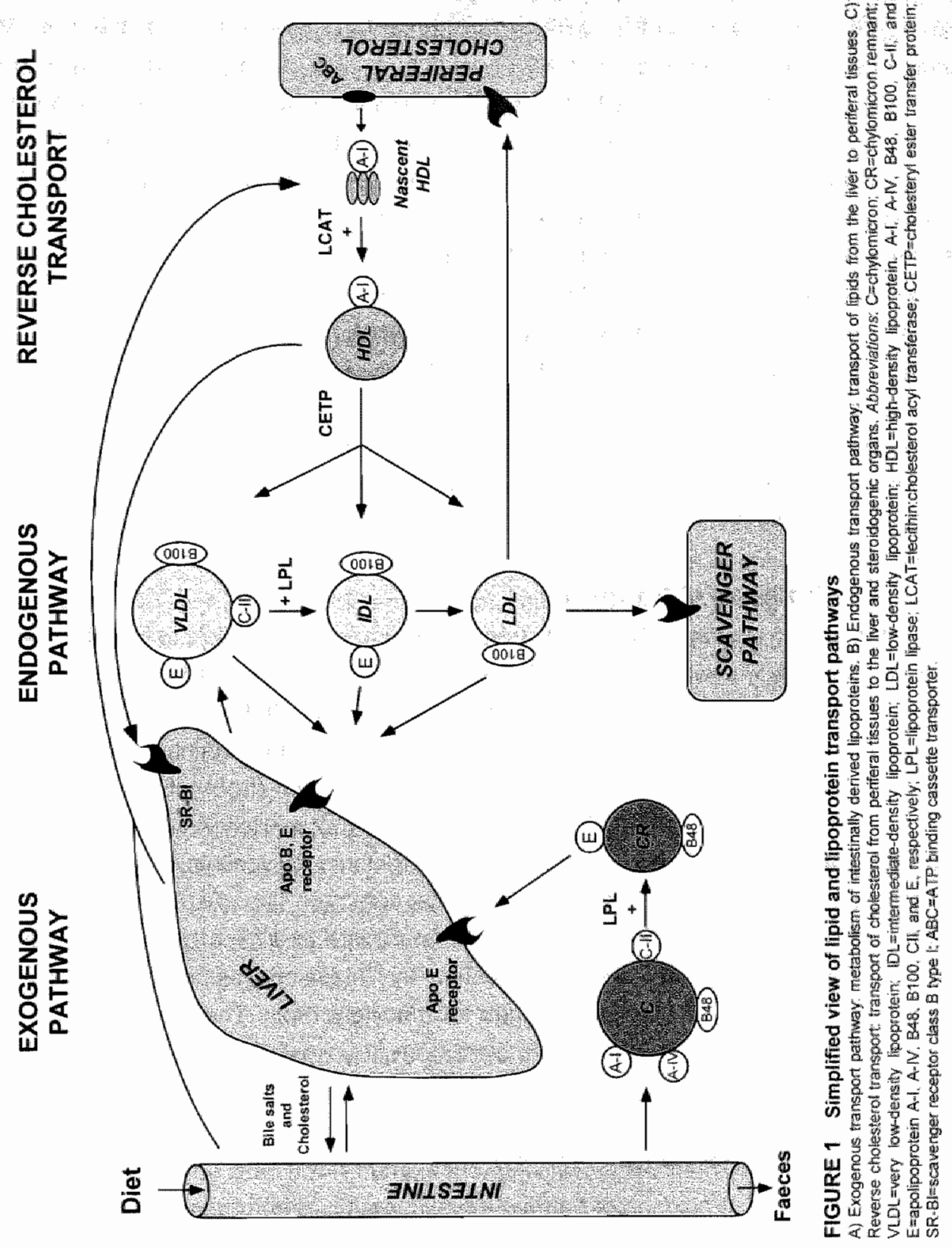




\section{The endogenous transport pathway}

The liver synthesizes and secretes VLDL particles into the circulation. These lipoproteins contain predominantly triacylglycerols, small amounts of cholesterol, and apo $\mathrm{B} 100, \mathrm{C}$-ll and $\mathrm{E}$. VLDL particles distribute triacylglycerols from the liver to peripheral tissues for storage or fuel. Like chylomicrons, VLDL triacylglycerols are hydrolyzed by LPL and its cofactor apo C-ll, resulting in the formation of VLDL remnants, also called intermediate-density lipoproteins (IDL). In tum, these cholesteryl ester-rich lipoproteins are in part removed from the circulation through the binding of apo $E$ by the LDL or (apo $B, E$ ) receptor on the surface of the liver, or converted into LDL. Cholesterol-rich LDL particles contain apo B100, which is recognized by hepatic and extrahepatic $L D L$ receptors. The hepatic $L D L$ receptors are responsible for the clearance of approximately $70 \%$ of plasma $\operatorname{LDL}(70,71,75)$.

Plasma $L D L$ is also removed by pathways independent of the $L D L$ receptor, called the scavenger pathway. In the vascular endothelium, oxidatively modified LDL is removed by the scavenger receptors found on the surfaces of macrophages, which become cells loaded with cholesteryl esters, the so-called foam cells. This could accelerate the development of atheroscierotic plaque (76).

\section{Reverse cholesterol transport}

The transport of cholesterol by HDL from peripheral tissues back to the liver and steroidogenic organs, which uses cholesterol for synthesis of lipoproteins, bile acids, vitamin $D$ and steroid hormones, is referred to as reverse cholesterol transport. The liver and intestine secrete nascent HDL particles, which contain mainly phospholipids and apo A-I. Nascent HDL particles accept unesterified (free) cholesterol from peripheral tissues through the ATP binding cassette transporter ( $A B C$ ). In turn, free cholesterol is esterified with a fatty acid in the plasma by lecithin:cholesterol acyl transferase (LCAT), which uses apo $\mathrm{A}-1$ as a cofactor. The resulting cholesteryl esters are removed from the newly formed mature HDL particies by two pathways. First, mature HDL transfers cholesteryl esters by cholesteryl ester transfer protein (CETP) to VLDL, $1 D L$, or LDL in exchange for triacylglycerols. The cholesteryl esterenriched particles are subsequently removed from the circulation by the liver through the LDL receptor. Secondly, the cholesteryl esters in the mature HDL are returned to the liver and steroidogenic organs, such as adrenals, ovary and testes, through the scavenger receptor class B type I (SR-BI) $(72,73)$. 


\section{Outline of the thesis}

The present thesis describes the effects of the dietary components, tocotrienols, $\beta$ glucan and plant stanol esters on cardiovascular risk markers in subjects with increased serum cholesterol concentrations. For comparison with a lipid-lowering drug, effects of pravastatin are also discussed in this thesis.

\section{Serum lipids and lipoproteins}

In Chapter 2, we have critically reviewed the literature from the last decade about the effects of the dietary components, $\beta$-glucan, soy protein, isoflavones, plant sterols and stanols, garlic, and tocotrienols on the human lipoprotein profile. In our first study described in Chapter 3, we have compared the effects of a tocotrienol-rich fraction from rice bran oil with those of pravastatin on serum lipids and lipoproteins, and on markers for cholesterol synthesis and absorption in hypercholesterolemic subjects on a cholesterol-lowering diet. The lipid-lowering drug, pravastatin, is an HMG-CoA reductase inhibitor, which inhibits the endogenous cholesterol synthesis. Like statins, tocotrienols have been suggested to inhibit the activity of HMG-CoA reductase (912). Chapter 4 focuses on the results of our second and third study on the effects of $\beta$-glucan from oat bran un different food matrices. For this, the second study examined the effects of $\beta$-glucan from oat bran administered in bread and cookies on serum lipoproteins in mildly hypercholesterolemic subjects, whereas the third study presents the effects of the same source and amount of oat $\beta$-glucan when given with orange juice.

\section{Plasma lipid-soluble antioxidants}

Chapter 5 reports the effects on plasma lipid-soluble antioxidant concentrations as examined not only in our third trial with oat $\beta$-glucan, but also in a subpopulation of our first study that received either placebo or pravastatin treatment "as well as in a study using plant stanol esters.

\section{Hemostatic and inflammatory parameters}

The study described in Chapter 3 addressed not only the effects of a tocotrienol-rich fraction from rice bran oil as compared with pravastatin on the serum lipoprotein profile, but also the effects on hemostatic function. Chapter 6 describes the effects on inflammatory parameters, $C$-reactive protein and interleukin- 6 , as examined in the subpopulation of our first study that received either placebo or pravastatin treatment as well as in the study in which plant stanol esters were used. Furthermore, we have studied the relationships between these markers of inflammation and plasma lipid- 
soluble antioxidants in a cross-sectional study group of subjects with increased cholesterol concentrations.

Finally, Chapter 7 discusses the main findings and implications of the in this thesis described studies. 


\section{References}

1. Law MR Lowering heart disease risk with cholesterol reduction: evidence from observational studies and clinical trials. Eur Heart J Supplements 1999; 1 S3-S8.

2. Shaten $B J$, Kuller $L H$, Neaton JD. Association between baseline risk factors, cigarette smoking, and CHD mortality after 10.5 years. Prev Med 1991:20:655-69.

3. Castelli WP. Anderson K, Wilson PWF, Levy D. Lipids and risk of coronary heart disease: the Framingham study. Ann Epidemiol $1992 ; 2: 23-8$.

4. Berry EM. The effects of nutrients on lipoprotein susceptibility to oxidation. Curr Opin Lipidal 1992;3:5-11.

5. Hunt SM, Groff JL. Advanced nutrition and human metabolism. St Paul: West Publishing Company, 1990.

6. Kayden $\mathrm{HJ}_{\mathrm{s}}$ Traber MG. Absorption, lipoprotein transport, and regulation of plasma concentrations of vitamin $E$ in humans. J Lipid Res 1993:34:343-58.

7. Qureshi $A A_{1}$, Mo $H$, Packer $L$, Peterson DM. Isolation and identification of novel tocotrienols from rice bran with hypocholesterolemic, antioxidant, and antitumor properties. لAgric Food Chem 2000;48:3130-40.

8. Kesaniemi YA, Grundy SM. Lack of effect of tocopherol on plasma lipids and lipoproteins in man. Am J Clin Nutr 1982;36:224-8.

9. Qureshi AA, Burger WC, Peterson DM, Elson CE. The structure of an inhibitor of cholesterol biosynthesis isolated from barley. J Biol Chem 1986;261:10544-50.

10. Qureshi AA, Qureshi N, Hasler-Rapacz JO, et al. Dietary tocotrienols reduce concentrations of plasma cholesterol, apolipoprotein $\mathrm{B}$, thromboxane $\mathrm{B}_{2}$, and platelet factor 4 in pigs with inherited hyperlipidemias. Am J Clin Nutr 1991;53:1042S-6S.

11. Pearce BC, Parker RA, Deason ME, Qureshi AA, Wright JJK. Hypocholesterolemic activity of synthetic and natural tocotrienols. J Med Chem 1992;35:3595-606.

12. Khor HT, Ng TT. Effects of administration of $\alpha$-tocopherol and tocotrienols on serum lipids and liver HMG CoA reductase activity. Int J Food Sci Nutr 2000;51:S3-S11.

13. Parker RA, Pearce BC, Clark RW, Gordon DA, Wright J.JK. Tocotrienols regulate cholesterol production in mammalian cells by post-transcriptional suppression of 3 hydroxy-3-methylglutaryl coenzyme A reductase. J Biol Chem 1993;268:11230-8.

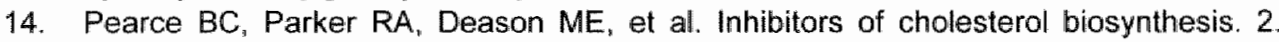
Hypocholesterolemic and antioxidant activilies of benzopyran and tetrahydronaphthalene analogues of the tocotrienols. J Med Chem 1994;37:526-41.

15. Tan DTS, Khor HT, Low WHS, Ali A, Gapor A. Effect of a palm-oil-vitamin $E$ concentrate on the serum and lipoprotein lipids in humans. Am J Clin Nutr 1991;53:1027S-30S.

16. Qureshi AA, Qureshi $\mathbb{N}$, Wright JJK, et al. Lowering of serum cholesteral in hypercholesterolemic humans by tocotrienols (palmvitee) Am $₫$ Clin Nutr $1991,53: 1021 \mathrm{~S}-6 \mathrm{~S}$.

17. Qureshi AA, Bradlow $B A_{n}$ Brace $L_{n}$ et al. Response of hypercholesterolemic subjects to administration of tocotrienols. Lipids 1995;30:1171-7.

18. Wahlqvist ML, Krivokuca-Bogetic $Z$, Lo CS, Hage B, Smith R, Lukito W. Differential serum responses of tocopherols and tocotrienols during vitamin supplementation in hypercholesterolaemic individuals without change in coronary risk factors. Nutr Res 1992:12:S181-S201.

19. Tomeo AC, Geller M, Watkins TR, Gapor A. Bierenbaum ML. Antioxidant effects of tocotrienols in patients with hyperlipidemia and carotid stenosis. Lipids 1995;30:1179. 83. 


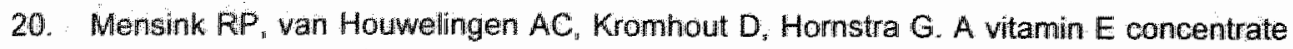
rich in tocotrienols had no effect on serum lipuds, lipoproteins, or platelet function in men with mildly elevated serum lipid concentrations. Am $\mathbb{J}$ Clin Nutr 1999:69:213-9.

21. O' Byrne D, Grundy $S$, Packer $L$, et al. Studies of $L D L$ oxidation following $\alpha-$ or $\delta-$ tocotrienyl acetate supplementation of hypercholesterolemic humans. Free Radiac Biol Med 2000,29;834-45.

22. Qureshi AA. Bradlow BA, Salser WA, Brace LD. Novel tocotrienols of rice bran modulate cardiovascular disease risk parameters of hypercholesterolemic humans. I Nutr Biochem 1997:8,290-8

23. Anderson JW, Deakins DA, Floore TL, Smith BM, Whitis SE. Dietary fiber and coronary heart disease. Crit Rev Fd Sci Nutr 1990;29:95-147.

24. Ripsin CM, Keenan JM, Jacobs DR, et al Oat products and lipid lowering: a metaanalysis. JAMA 1992;267:3317-25.

25. Braaten JT, Wood PJ, Scott FW, et al. Oat B-glucan reduces blood cholesterol concentration in hypercholesterolemic subjects. Eur J Clin Nutr 1994;48:465-74.

26. Bell $\mathrm{S}$, Goldman VM, Bistrian BR, Arnold AH, Ostroff $G$, Forse RA. Effect of $\beta$-glucan from oats and yeast on serum lipids. Crit Rev Food Sci Nutr 1999;39:189-202.

27. Mcintosh GH, Whyte J, McArthur R, Nestel PJ. Barley and wheat foods: influence on plasma cholesterol concentrations in hypercholesterolemic men. Am J Clin Nutr 1991;53:1205-9.

28. Bourdon I, Yokoyama W, Davis $P$, et al. Postprandial lipid, glucose, insulin, and cholecystokinin responses in men fed barley pasta enriched with B-glucan. Am J Clin Nutr 1999,69:55-63.

29. Nicolosi R, Bell SJ, Bistrian BR, Greenberg I, Forse RA, Blackburn GL. Plasma lipid changes after supplementation with $\beta$-glucan fiber from yeast. Am $J$ Cin Nutr 1999:70:208-12

30. Lund EK, Gee JM, Brown JC, Wood PJ, Johnson IT. Effect of oat gum on the physical properties of the gastrointestinal contents and on the uptake of D-galactose and cholesterol by rat small intestine in vitro. $\mathrm{Br} J$ Nutr 1989;62:91-101.

31. Beer $M U$, Arrigoni $E$, Amadò $R$. Effects of oat gum on bload cholesterol levels in healthy young imen. Eur J Clin Nutr 1995:49:517-22.

32. Food labeling: health claims; oats and coronary heart disease. Food and Drug Administration, HHS. Proposed rule. Fed Regist 1996;61:296-313.

33. FDA Talk Paper. FDA allows whole oat foods to make health claim on reducing the risk of heart disease. January 1997. World Wide Web: http://www.cfsan.fda.gov/ /rd/tpoats.html (accessed 27 April 2001).

34. Ling $\mathrm{WH}_{1}$ Jones $\mathrm{PJH}$. Minireview dietary phytosterols: a review of metabolism, benefits and side effects. Life Sci 1995; 57:195-206.

35. Law M. Plant sterol and stanol margarines and health. BMJ 2000;320:861-4

36. Plat J, Mensink RP. Effects of plant sterols and stanols on lipid metabolism and cardiovascular risk. Nutr Metab Cardiovasc Dis 2001;11:31-40.

37. Miettinen TA, Gylling $H$. Regulation of cholesteral metabolism by dietary plant sterols. Curr Opin Lipidol 1999;10:9-14.

38. Plat J, Mensink RP. Effects of plant stanol esters on LDL receptor protein expression and on LDL receptor and HMG-CoA reductase mRNA expression in mononuclear blood cells of healthy men and women. FASEB J 2002;16:258-60.

39. Sierksma A, Weststrate JA, Meijer GW. Spreads enriched with plant sterols, either esterified 4,4-dimethylsterols or free 4-desmethylsterols, and plasma total- and LDLcholesterol concentrations. Br J Nutr 1999;82:273-82. 
40. Plat J, Kerckhoffs DAJM, Mensink RP. Therapeutic potential of plant sterols and stanols. Curr Opin Lipidol 2000;11:574-6.

41. Virtamo J, Rapola $J M$, Ripatti $S$, et al. Effect of vitamin E and beta carotene on the incidence of primary nonfatal myocardial infarction and fatal coronary heart disease. Arch Intern Med 1998;158:668-75.

42. Stephens NG, Parsons $A$, Schofield PM, et al. Randomised controlled trial of vitamin $E$ in patients with coronary disease: Cambridge Heart Antioxidant Study (CHAOS). Lancet $1996 ; 347: 781-6$.

43. GISSI-Prevenzione Investigators (Gruppo Italliano per to Studio della Sopravvivenza nell'Infarto miocardico). Dietary supplementation with $\mathrm{n}-3$ polyunsaturated fatty acids and vitamin $\mathrm{E}$ after myocardial infarction: results of the GISSI-Prevenzione trial. Lancet 1999;354:447-55.

44. The Heart Outcomes Prevention Evaluation Study Investigators. Vitamin E supplementation and cardiovascular events in high-risk patients. $N$ Engl $J$ Med 2000;342:154-60.

45. Collaborative Group of the Primary Prevention Project (PPP). Low-dose aspirin and vitamin $E$ in people at cardiovascular risk: a randomised trial in general practice. Lancet 2001;357:89-95.

46. Rock CL. Carotenoids: biology and treatment. Pharmacol Ther 1997;75:185-97.

47. Parker RS. Bioavailabilty of carotenoids. Eur J Clin Nutr 1997;51:S86-S90.

48. van Poppel G, Goldbohm RA. Epidemiologic evidence for $\beta$-carotene and cancer prevention. Am J Clin Nutr 1995;62:1393S-402S.

49. Christen WG, Buring JE, Manson JE, Hennekens CH. Beta-carotene supplementation: a good thing, a bad thing, or nothing? Curr Opin Lipidol 1999;10:29-33.

50. The Alpha-Tocopherol , Beta Carotene Cancer Prevention Study Group. The effect of vitamin $E$ and beta carotene on the incidence of lung cancer and other cancers in male smokers. N Engl J Med 1994;330:1029-35.

51. Omenn GS, Goodman GE, Thornquist MD, et al. Effects of a combination of beta carotene and vitamin $A$ on lung cancer and cardiovascular disease. $N$ Engl $J$ Med 1996;334:1150-5.

52. Hennekens $\mathrm{CH}$, Buring JE, Manson JE, et al. Lack of effect of long-term supplementation with beta carotene on the incidence of malignant neoplasms and cardiovascular disease. N Engi J Med 1996;334:1145-9.

53. Giovannucci E, Ascherio A, Rimm EB, Stampfer MJ, Colditz GA, Willett WC. Intake of carotenoids and retinol in relation to risk of prostate cancer. J Natl Cancer Inst 1995;87:1767-76.

54. Gann PH, Ma J, Giovannucci E, et al. Lower prostate cancer risk in men with elevated plasma lycopene levels: results of a prospective analysis. Cancer Res 1999:59:122530.

55. Norrish AE, Jackson RT, Sharpe SJ, Skeaff CM. Prostate cancer and dietary carotenoids. Am J Epidemiol 2000;151:119-23.

56. Eye Disease Case-Control Study Group. Antioxidant status and neovascular agerelated macular degeneration. Arch Ophthalmol 1993;111:104-9.

57. Seddon JM, Ajani UA, Sperduto RD, et al. Dietary carotenoids, vitamin $A, C_{\text {, }}$ and $E_{\text {, }}$ and advanced agle-related macular degeneration. Eye Disease Case-Control Study Group. JAMA 1994:272:1413-20.

58. Handelman GJ. The evolving role of carotenoids in human biochemistry. Nutrition 2001:17:818-22.

59. Vaughan CJ, Murphy MB, Buckley BM. Statins do more than just lower cholesterol. Lancet 1996;348:1079-82. 
60. Vogel RA, Corrett MC, Gellman \&. Cholesterol cholesteroll lowering, and endothelial tunction. Prog Cardiovase Dis 1998;41:117-36.

61. White CM. Pharmacological effects of HMG-CoA reductase inhibitors other than lipoprotein modulation: J Clin Pharmacol 1999:39:111-8.

62. Libby P. Aikawa M. Schönbeck U. Cholesterol and atherosclerosis. Biochim Biophys Acta 2000:1529:299-309.

63. Patrick L, Uzick M. Cardiovascular disease: C-reactive protein and the inflammatory disease paradigm: HMG-COA reductase inhibitors, alpha-tocopherol, red yeast rice, and ollve ofl polyphenols. A review of the literature. Altern Med Rev 2001:6:248-71.

64. Tracy RP. Inflammation markers and coronary heart disease. Curr Opin Lipidal $1999,10: 435-41$.

65. Yudkin JS, Kumari $M$, Humphries SE, Mohamed-Ali $V$. Inflammation, obesity, stress and coronary heart disease: is interleukin-6 the link? Atherosclerosis 2000;148:209-14.

66. Ridker PM, Hennekens $\mathrm{CH}_{1}$ Buring JE, Rifail N. C-reactive protein and other markers of inflammation in the prediction of cardiovascular disease in women. $N$ Engl $J$ Med $2000 ; 342 ; 836-43$.

67. Ross R. The pathogenesis of atherosclerosis: a perspective for the $1990 \mathrm{~s}$. Nature 1993:362:801-9.

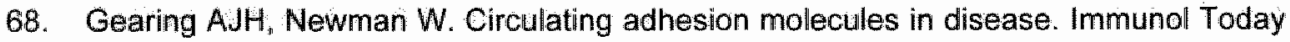
$1993: 14 ; 506-12$.

69. Dawson PA Rudel LL. Intestinal cholesterol absorption. Curr Opin Lipidol $1999 ; 10: 315-20$.

70. Breslow JL. Apolipoprotein genetic variation and human disease. Physiol Rev $1988 ; 68: 85-132$.

71. Kris-Etherton PM, Krummel D, Russell ME, et al. The effect of diet on plasma lipids, lipoproteins, and coronary heart disease. J Am Diet Assoc 1988;88:1373-400.

72. von Eckardstein $A$, Nofer $J-R$, Assmann $G$. High density lipoproteins and arteriosclerosis. Role of cholesterol efflux and reverse cholesterol transport. Arteriascler Thromb Vasc Biol 2001:21:13-27.

73. Kwiterowich $\mathrm{PO}$. The metabolic pathways of high-density lipoprotein, low-density lipoprotein, and triglycerides: a current review. Am J Cardiol 2000;86:5L-10L.

74. van Greevenbroek MMJ, de Bruin TWA. Chylomicron synthesis by intestinal cells in vitro and in vivo. Atherosclerosis 1998;141:S9-S16.

75. Olson RE. Discovery of the lipoproteins, their role in fat transport and their significance as risk factors. J Nutr 1998; $128: 4395-43 S$.

76. Ross R. Atherosclerosis - an inflammatory disease. N Engl J Med 1999;340:115-26. 


\section{Chapter}

\section{A critical review of the effects on the human serum lipoprotein profile of $\beta$-glucan, soy protein and isoflavones, plant sterols and stanols, garlic and tocotrienols}

Daniëlle AJM Kerckhoffs ${ }^{1,2}$, Fred Brouns ${ }^{2,3}$, Gerard Hornstra ${ }^{2}$ and Ronald $\mathbb{P}$ Mensink $^{1,2}$

${ }^{1}$ Department of Human Biology and ${ }^{2}$ Nutrition and Toxicology Research Institute Maastricht (NUTRIM), Maastricht University, Maastricht, The Netherlands, and "at present Cerestar Vilvoorde R\&D Centre, Vilvoorde, Belgium

Based on: The Journal of Nutrition 2002;132:2494-505. 


\section{Abstract}

The effects of $\beta$-glucan, soy protein, isoflavones, plant sterols and stanols, garlic and tocotrienols on serum lipoproteins have been of great interest the last decade. From a critical review of the literature, it appeared that recent studies found positive as well as no effects of $\beta$-glucan from oats on serum $L D L$ cholesterol concentrations. These conflicting results may suggest that the cholesterol-lowering activity of products rich in oat $\beta$-glucan depends on factors, such as its viscosity in the gastrointestinal tract, the food matrix and/or food processing. The effects of $\beta$-glucan from barley or yeast on the lipoprotein profile are promising, but more human trials are needed to further substantiate these effects. It is still not clear whether the claimed hypocholesterolemic effects of soy can be attributed solely to the isoflavones. Several studies found no changes in serum LDL cholesterol concentrations after consumption of isolated soy isoflavones (without soy protein), indicating that a combination of soy protein and isoflavones may be needed for eliciting a cholesterollowering effect of soy. Therefore, the exact (combination of) active ingredients in soy products need to be identified. The daily consumption of $2-3 \mathrm{~g}$ of plant sterols or stanols reduces LDL cholesterol concentrations by $9-14 \%$. It has been demonstrated that functional foods enriched with plant sterols and stanols are effective in various population groups, and in combination with cholesterol-lowering diets or drugs. Whether garlic or garlic preparations can be used as a lipid-lowering agent, is still uncertain. It is important to characterize the active components in garlic and their bioavailability after ingestion. It is not very likely that tocotrienols from palm oil or rice bran oil have favorable effects on the human serum lipoprotein profile. 


\section{Introduction}

Coronary heart disease (CHD) is a major health problem in developed countries. Many studies have now shown that elevated concentrations of total or LDL cholesterol in the blood are powerful risk factors for $\mathrm{CHD}$ (1), whereas high concentrations of HDL cholesterol or a low LDL (or total) to HDL cholesterol ratio may protect against $\mathrm{CHD}(2,3)$.

The composition of the human diet plays an important role in the management of lipid and lipoprotein concentrations in the blood. Reduction in saturated fat and cholesterol intake has traditionally been the first goal of dietary therapy in lowering the risk for cardiovascular disease (4). This may reduce blood total cholesterol concentrations by $\sim 3 \%$ (step | diet) or $6 \%$ (step II diet) in free-living subjects (5). In recent years, however, the possible hypocholesterolemic effects of several dietary components, such as $\beta$-glucan, soy protein, isoflavones, plant sterols and stanols, garlic and tocotrienols, have attracted much interest. In fact, foods, pills and capsules rich in these ingredients are on the market in many countries and may be the basis for new functional foods.

The purpose of this article is to review critically the literature from the last decade about the effects of these dietary components on blood lipids and lipoproteins in humans. The possible mechanisms by which these components may affect lipid and lipoprotein metabolism will also be briefly addressed.

\section{Oat products and $\beta$-glucan}

During the last couple of decades, much attention has been given to the role of dietary fibers in the control of lipid and lipoprotein metabolism. Dietary fibers include a variety of plant substances, mainly nonstarch polysaccharides and lignins, which are resistant to digestion by digestive enzymes. They can be classified into two groups based on water solubility. In contrast to water-insoluble fibers, most soluble fibers may lower plasma total cholesterol by a specific effect on LDL cholesterol (6). HDL cholesterol or triacylglycerol concentrations are in generai not affected.

Severall mechanisms of action for the hypochalesterolemic effect of soluble fibers have been suggested that may depend on the type of fiber. Soluble fibers may increase the binding of bile acids in the intestinal lumen, which leads to a decreased enterohepatic circulation of bile acids and a subsequent increase in the hepatic conversion of cholesterol to bile acids $(7,8)$. Another suggested mechanism is that 
the increased viscosity of the food mass in the small intestine because of soluble fibers leacls to the formation of a thick unstirred water layer, adjacent to the mucosa. This layer may act as a physical barrier to reduce the absorption of nutrients and bile acids $(9,10)$. Furthermore, soluble fibers may reduce the rate of glucose absorption leading to a lower glycemic response and lower insulin concentrations. This latter may result in a reduced hepatic cholesterol synthesis $(6,8)$. Finally, it has been shown in animals that production of short-chain fatty acids, such as acetate (11) and propionate (12) after fermentation of soluble fibers by colonic bacteria, inhibits hepatic cholesterol synthesis.

A rich source of soluble fiber is oats. In the early 1960s, De Groot et al. (13) were the first to demonstrate that a daily consumption of $300 \mathrm{~g}$ of bread containing $140 \mathrm{~g}$ of rolled oats for $3 \mathrm{wk}$ resulted in an 11\% decrease serum total cholesterol concentrations in men. A meta-analysis by Ripsin et al. (14), in which 12 trials were included; found that a daily intake of $\sim 3 \mathrm{~g}$ of soluble fiber from oat products for $18 \mathrm{~d}$ to 3 mo resulted in a modest reduction of total cholesterol concentrations of $\sim 0.13$ mmol/L. This reduction was the greatest in men and women with the highest initial total cholesterol concentrations.

Braaten et all. (15) have now demonstrated that the cholesterol-lowering effect of oat products could be attributed to their main soluble fiber component, $\beta$-glucan. In this study (15), decreases in LDL cholesterol concentrations of $10 \%$ were found in hypercholesterolemic men and women who consumed daily for $4 \mathrm{wk} 7.2 \mathrm{~g}$ of oat gum containing $5.8 \mathrm{~g}$ of $\beta$-glucan mixed with a noncarbonated drink or with water. The amount of $\beta$-glucan provided by the oat gum is equivalent to the amount found in $\sim 70$ $\mathrm{g}$ of oat bran. $\beta$-glucan from oats is a nonstarch polysaccharide composed of $\beta$ $(1 \rightarrow 4)$-linked glucose units separated every two to three units by a single $\beta-(1 \rightarrow 3)$ linked glucose (8). Oat $\beta$-glucan is often referred to as mixed linkage $\beta$-glucan (16) (Figure 1).

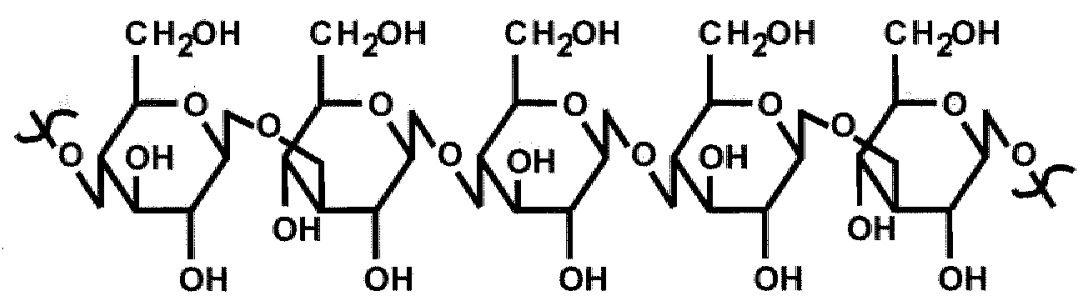

FIGURE 1 Chemical structure of $\beta$-glucan from oats

(1-Gitucan from oats is a nonstarch polysaccharide composed of $p(1,-\ldots, 4)$-linked glucose units separated every two to three units by angle $\beta \sim(1 \rightarrow 3)$-linked glucose $(8)$. Oat $\beta$-glucan is often referred to as mixed linkage $\beta$-glucan (116). 
On January 21, 1997, the U.S. Food and Drug Administration (FDA) approved a health claim on food products that "a diet high in soluble fiber from whole oats (oat bran, oatmeal and oat flour) and low in saturated fat and cholesterol may reduce the risk of heart disease." The FDA concluded that at least $3 \mathrm{~g} / \mathrm{d}$ of $\beta$-glucan from oats should be consumed to achieve a clinically relevant reduction in serum total cholesterol concentrations $(17,18)$.

Many of the previous studies did not provide information on the $\beta$-glucan content of their experimental products, but, in general, the studies carried out during the last 10 $y$ did. In these studies, to be discussed below, $\beta$-glucan was derived from oats (10, $15,19-25)$, barley $(26,27)$ or yeast $(28)$.

Davidson et al. (19) found in hypercholesterolemic men and women consuming a National Cholesterol Education Program (NCEP) step I diet, a decrease in serum LDL cholesterol concentrations of 10,16 and $12 \%$ with increasing doses of $3.6,4.0$ and $6.0 \mathrm{~g}$ of $\beta$-glucan from $84 \mathrm{~g}$ of oatmeal, or from 56 or $84 \mathrm{~g}$ of oat bran, respectively. Surprisingly, the highest dosage of $\beta$-glucan led to an intermediate hypocholesterolemic response. As such, a dose-response effect was not established. Oat bran and oatmeal were incorporated into hot cereals, low-fat muffins and low-fat shakes, which were consumed for 6 wk. Uusitupa et al. (20) examined the effects of $\beta$-glucan from oat bran on serum lipids and lipoproteins in mildly to moderately hypercholesterolemic men and women. During the study, subjects followed an American Heart Association (AHA) step I diet. The estimated intake of oat bran. which was mostly consumed with juice yogurt, porridge or a dessert, ranged from 20 to $66 \mathrm{~g} / \mathrm{d}$ and provided $3.3-11.0 \mathrm{~g}$ of $\beta$-glucan. After an intervention of $8 \mathrm{wk}$, serum LDL cholesterol concentrations were nonsignificantly lowered by $3 \%$. After 4 wk, however, LDL cholesterol concentrations were significantly lowered by $6 \%$. Subjects who consumed at least $6.9 \mathrm{~g}$ of $\beta$-glucan showed the greatest decline in serum LDL cholesterol concentrations, which was $8 \%$ after 4 wk and $4 \%$ after $8 w k$; again, only the reductions at 4 wk were significant. Based on these findings, it was suggested that the hypocholesterolemic effect of $\beta$-glucan from oat bran might diminish with time. Uusitupa et al. (29), therefore, investigated whether this attenuation could be explained by changes in the synthesis and/or absorption of cholesterol. However, no changes after 4 and $8 \mathrm{wk}$ were found in the cholesterol-standardized serum concentrations of cholesterol precursors, which reflect the endogenous cholesterol synthesis, and in those of cholestanol and plant sterols, which reflect the intestinal absorption of cholesterol. Behall et al. (23) supplemented the diet of mildly hypercholesterolemic men and women for 5 wk with $50-75 \mathrm{~g} / \mathrm{d}$ of two different oat 
fiber extracts, in which the amount of $\beta$-glucan was either low or high. The background diet provided $0.8 \mathrm{~g} / \mathrm{d}$ of $\beta$-glucan and the two fiber extracts $0.8-1.2$ or $5.1-7.6 \mathrm{~g} / \mathrm{d}$ of $\beta$-glucan. Plasma LDL cholesterol concentrations decreased -15 and $21 \%$ from prestudy values, respectively. The $7 \%$ difference in LDL cholesterol between subjects who consumed the low and high $\beta$-glucan diets was not statistically significant but the $6 \%$ difference in total cholesterol was. The oat fiber extract was given in a variety of food products including muffins, cakes, brownies, waffles, gelatins, yogurts, spaghetti sauces and meat loaf. Furthermore, Önning et al. (24) found that daily consumption of $750 \mathrm{~mL}$ of aat milk, devoid of insoluble fiber, but providing $3.8 \mathrm{~g} / \mathrm{d}$ of $\beta$-glucan for $5 \mathrm{wk}$ lowered serum LDL cholesterol by $6 \%$ in moderately hypercholesterolemic men. The oat preparation consisted of $50 \%$ commercial oat flakes and $50 \%$ heat-treated, dry-milled oat bran. The insoluble fibers were separated by decanting.

Mackay and Ball (21) did not demonstrate in hypercholesterolemic men and women consuming a low-fat diet a decline in plasma LDL cholesterol concentrations after a daily intake of $55 \mathrm{~g}$ of two different types of oat bran providing low amounts of either 1.9 or $3.0 \mathrm{~g}$ of $\beta$-glucan for $6 \mathrm{wk}$. Unlike in most other studies, however, plasma HDL cholesterol concentrations increased after both doses of $\beta$-glucan. Oat bran was given in a variety of food products, such as muffins, porridge, pancakes and scones. Törrönen et al. (22) alsa did not observe a decrease in serum LDL cholesterol concentrations after consumption of $37-75 \mathrm{~g} / \mathrm{d}$ of an oat bran concentrate providing, respectively, $5.6-11.2 \mathrm{~g} / \mathrm{d}$ of $\beta$-glucan for 8 wh in mildly to moderately hypercholesterolemic men. A dose of $11 \mathrm{~g} / \mathrm{d}$ of $\beta$-glucan from the oat bran concentrate is equivalent to the amount provided by $\sim 170 \mathrm{~g}$ of oat bran. The oat bran concentrate, which was produced by removing nonfiber compounds by milling in a cold-water suspension, was incorporated into bread. During the baking and frozen storage of bread, the $\beta$-glucan content as well as its molecular weight were unchanged. As already mentioned, soluble fibers, such as $\beta$-glucan, seem to increase the viscosity of the intestinal contents, leading to an increased unstirred water layer adjacent to the mucosa. Törönen et al. (22) suggested that the lack of effect in their study could be attributable to a poor solubility of $\beta$-glucan, which may have prevented an increase in the viscosity in the intestine. Beer et al. (10) investigated the effects of daily intake of $14.4 \mathrm{~g}$ of oat gum containing $9 \mathrm{~g}$ of $\beta$ glucan, which was served in an instant whip, on the serum lipid and lipoprotein profile in normocholesterolemic men. This daily dosage of oat gum containing $62 \% \beta$-glucan is equivalent to $\sim 150 \mathrm{~g}$ of oat bran. After a treatment period of $2 \mathrm{wk}$, serum concentrations of total cholesterol, $L D L$ cholesterol and triacylglycerol were unaffected, whereas the HDL cholesterol concentration rose. The investigators 
suggested that the attenuation of the cholesterol-lowering effect might be explained by the low solubility and moderate molecular weight of the oat gum, and, therefore, a low viscosity in the intestine.

A recent study of Lovegrove et al. (25) was conducted to investigate the effects of the minimal recommended dose by the FDA of $3 \mathrm{~g} / \mathrm{d}$ of $\beta$-glucan on fasting lipoproteins. and postprandial triacylglycerols. In this study, men and women with mild to moderate hypercholesterolemia consumed cereals with low-fat yogurt or low-fat milk that provided for a treatment period of $8 \mathrm{wk} 20 \mathrm{~g} / \mathrm{d}$ of al bran concentrate, which consisted of $3 \mathrm{~g} / \mathrm{d}$ of $\beta$-glucan. No changes were found in fasting plasma concentrations of total cholesterol, LDL cholesterol and triacylglycerol, whereas a decline in concentrations of HDL cholesterol was observed. There was no beneficial effect of $3 \mathrm{~g} / \mathrm{d}$ of $\beta$-glucan from oat bran concentrate on postprandial plasma triacylglycerol responses, which were measured at the start of the study and at the end of the treatment period.

Two studies have reported the effects on plasma lipoproteins of $\beta$-glucan from barley. Mclntosh et al. (26) demonstrated that plasma LDL cholesterol concentrations were lowered by $7 \%$ in mildly hypercholesterolemic men, who consumed $\sim 170 \mathrm{~g}$ of barley containing $8 \mathrm{~g} / \mathrm{d}$ of $\beta$-glucan for $4 \mathrm{wk}$. Barley bran was incorporated into bread, spaghetti and cookies, whereas barley flakes were given in muesli. Bourdon et al. (27) examined the postprandial cholesterol and triacylglycerol responses in men to two different pastas that were made from either barley flour enriched with 3 -gluican during processing or barley flour naturally high in $\beta$-glucan. Both pastas provided $5 \mathrm{~g}$ of $\beta$-glucan and were served as a part of a low-fat meal. The postprandial plasma cholesterol concentrations were lowered at 30 min and at $4 \mathrm{~h}$ after the $\beta$-gllucancontaining meals. No favorable effects were found on postprandial plasma triacylglycerol responses.

Like oats and barley, yeast (Saccharomyces cerewisiae) from bakeries or breweries is also a rich source of $\beta$-glucan. The yeast contains $85 \%$ of $\beta$-glucan after processing, which is composed of a $\beta-(1 \rightarrow 6)$-branched- $\beta-(1 \rightarrow 3)$-linked linear glucose polysaccharide. In contrast to $\beta$-glucan from oat products, yeast-derived $\beta$ glucan has a low viscosity, and its solubility in water is low. Therefore, it does not gel when added to liquids ( 8 ). Nicolasi et al. (28) were the first to report that an intake of $15 \mathrm{~g} / \mathrm{d}$ of 3 -glucan from yeast mixed in orange juice for $8 \mathrm{wk}$ in hypercholesterolemic obese men tended to lower plasma concentrations of LDL cholesterol by $8 \%$, whereas those of HDL cholesterol tended to increase by $9 \%$. Plasma triacylglycerol concentrations were unaffected. As already discussed, it has been suggested that 
the high water solubility and high viscosity of the $\beta$-glucan from oats may be of importance for its cholesterol-lowering effect $(9,10)$. Unlike oat $\beta$-glucan, yeastderived $\beta$-glucan has a low viscosity, and its solubility in water is low. Still, this type of $\beta$-glucan may lower serum LDL cholesterol concentrations. It is, therefore, not likely that the mechanism of action of yeast-derived $\beta$-glucan can be explained by the increased intestinal viscosity and must be due to other mechanisms, such as binding of the soluble fiber to bile acids, reduced serum insulin concentrations or increased production of short-chain fatty acids (8).

In short, recent studies showed positive as well as no effects of oat $\beta$-glucan on LDL cholesterol. One of the suggested mechanisms of action of oat $\beta$-glucan is that it increases intestinal viscosity. If true, the food matrix of the oat products may influence the viscosity and bioavailability in the gastrointestinal tract. To explain the abserved discrepancies, therefore, it is necessary to further clarify the hypocholesterolemic mechanism of the different $\beta$-glucan preparations. In addition, more human trials are needed to confirm the potentially favorable effects of $\beta$-glucan from barley or yeast on the lipid and lipoprotein profiles.

\section{Soy protein and isoflavones}

There is great interest in the beneficial effects on the plasma lipid and lipoprotein profiles of soy protein, a component of traditional Asian foods. Also, in Western diets, various types of soy protein-containing products, such as soybeans, soymilk, tofu (soybean curd), tempeh (a cake of cooked soybeans), miso (soybean paste) and soy sauce, are used. Based on a review of 26 studies, Carroll (30) concluded that replacement of $13-20 \%$ of total energy from dietary animal protein by soy protein for 3-6 wk reduced total cholesterol concentrations by $-20 \%$ in men and women with hypercholesterolemia. The soy protein diets had no effect on HDL cholesterol concentrations, whereas triacylglycerol concentrations tended to decrease, especially in subjects with hypertriglyceridemia. The effects of soy protein diets on plasma lipids and lipoproteins in men and women with normal cholesterol concentrations were less consistent. More moderate cholesterol reductions ranging from 1 to $12 \%$ occurred in normocholesterolemic subjects. Carroll (30), therefore, suggested that men and women with hypercholesterolemia were more responsive to soy protein diets than normocholesterolemic persons.

In a meta-analysis of 38 trials, Anderson et al. (31) investigated the effects of soy protein on serum lipid concentrations in men and women. Soy protein was used in 
the form of isollated soy protein or textured soy protein. In most of the studies, the control and soy-containing diets differed by $<10 \%$ in amounts of total fat and saturated fat. It was estimated that an average consumption of $47 \mathrm{~g} / \mathrm{d}$ soy protein, in place of animal protein lowered total cholesterol, LDL cholesterol and triacylglycerol concentrations by $-9 \%(0.60 \mathrm{mmol} / \mathrm{L}), 13 \%(0.56 \mathrm{mmo} / \mathrm{L})$, and $11 \%(0.15 \mathrm{mmol} / \mathrm{L})$, respectively. No changes were found in serum HDL cholesterol concentrations. The changes in serum total and LDL cholesterol concentrations, however, depended upon the initial serum total cholesterol concentration. Men and women with normal cholesterol concentrations $(<5.17 \mathrm{mmol} / \mathrm{L}$ ) and those with mild hypercholesterollemia (5.17-6.59 mmol/L) both had nonsignificant decreases of -3 and $4 \%$, respectively. In contrast, men and women with moderate hypercholesterolemia $(6.70-8.61 \mathrm{mmol} / \mathrm{L})$ had significant reductions of $\sim 7 \%$ and those with severe hypercholesterolemia (> $8.66 \mathrm{mmol} / \mathrm{L}$ ) had marked decreases of $-20 \%$. Changes in LDL cholesterol concentrations followed a similar pattern. Thus, as already mentioned by Carroll (30), the cholesterol-lowering effects of soy protein were greatest in persons with the highest initial cholesterol concentrations.

The possible mechanisms of the hypocholesterolemic effect of soy protein have been thoroughly described in several reviews (32-35). Based on studies with cell cultures, animals or humans, suggested mechanisms include increases in LDL receptor activity, increases in the synthesis and fecal excretion of bile acids, and a suppression of cholesterol absorption. Furthermore. Forsythe (36) suggested that in animals, the hypocholesterolemic effect of soy protein results from increases in plasma thyroxine concentrations. In humans, however, results of hormonal thyroid status were inconsistent (34).

On October 26, 1999, the U.S. FDA $(37,38)$ approved a health claim that "25 $\mathrm{g}$ of soy protein a day, as part of a diet low in saturated fat and cholesterol, may reduce the risk of heart disease." Of interest is which component of the soy proteincontaining products in the diet may be responsible for the observed changes in blood lipids. It has been suggested that phytoestrogens, or plant estrogens, found in soy may account for $60-70 \%$ of the effects seen (31). The phytoestrogens genistein and daidzein, known as isoflavones, are structurally related to the mammalian estrogen, estradiol (39) (Figure 2). The hypocholesterolemic effects of soy phytoestrogens could be explained by their weak estrogenic activity through binding of isoflavones to estrogen receptors $(35,39,40)$. In general, $L D L$ cholesterol increases and HDL cholesterol decreases in postmenopausal women because of a decline in estrogen. Postmenopausal administration of a low dose of conjugated estrogens of $0.625 \mathrm{mg} / \mathrm{d}$ 
for 3 mo indeed lowered concentrations of LDL cholesterol by $15 \%$ and increased those of HDL cholesterol by $16 \%$ (41). If phytoestrogens actually contribute to the effects of soy on plasma lipids, it is noteworthy that the meta-analysis of Anderson et al. (31) did not suggest any effect of soy on HDL cholesterol.

\section{Estrogen}<smiles>CC12CCC3c4ccc(O)cc4CCC3C1CCC2O</smiles>

\section{Isoflavones}<smiles>O=c1c(-c2ccc(O)cc2)coc2cc([GeH3])ccc12</smiles><smiles>O=C1C(c2ccc(O)cc2)=CCc2cc(O)ccc21</smiles><smiles>COc1ccc(-c2coc3cc(O)cc(O)c3c2=O)cc1</smiles>

Biochanin A<smiles>COc1ccc(-c2coc3cc(O)ccc3c2=O)cc1</smiles>

Formononetin

\section{FIGURE 2 Chemicall structures of isoflavones}

The isotlavones, which are structurally related to the estrogen, estradiol, include genistein and daidzein and their methyl ether derivatives biochanin $A$ and formononetin, respectively (40). Genistein and daidzein are predominantly present in soy, whereas red clower contains also higher amounts of biochanin $A$ and formononetin. After ingestion, biochanin $A$ and formononetin can be conwerted to genistein and daidzein, respectively $(58)$. 
The effects of isoflavones on serum lipids and hoproteins are, however: controversial. Several studies have reported a cholesterolilowering effect of soy isoflavones. In these studies, triacylglycerol concentrations were unchanged. Ciassidy et al. (42) demonstrated that plasma total cholesterol concentrations were lowered by $9 \%$ in premenopausal women who consumed $60 \mathrm{~g} / \mathrm{d}$ of textured soy protein containing $45 \mathrm{mg}$ of conjugated isoflavones for $1 \mathrm{mo}$. The textured soy protein was incorporated into various food items including bologna, chicken casserole and vegetable curry. Because of small sample size, $L D L$ cholesterol $\mathrm{HDL}$ cholesterol and triacylglycerol concentrations could not be measiured. Potter et al. (43) showed that an intake of $40 \mathrm{~g} / \mathrm{d}$ of isolated soy protein consisting of 56 or $90 \mathrm{mg}$ of isoflavones for 6 mo decreased plasma non-HDL ( $L D L+V L D L)$ cholesterol and increased HDL cholesterol concentrations in hypercholesterolemic postmenopausal women consuming a NCEP step I diet. Isolated soy protein was given in a variety of food products, such as breads, muffins, drinks, milks and soups. Another finding in this study was that the concentration of mononuclear cell LDL receptor $M R N A$, which is related to that in the liver (44), rose after consumption of both doses of soy isoflavones, indicating an up-regulation of hepatic LDL receptor activity. Also, Washburn et al. (45) observed that consumption of $20 \mathrm{~g}$ of soy protein powder containing $34 \mathrm{mg} / \mathrm{d}$ of phytoestrogens for 6 wk decreased serum LDL cholesterol concentrations $7 \%$ in perimenopausal, normocholesterolemic women. The powders were mixed in various ways with milk, orange juice, yogurt or cereals. Crouse et al. (46) also suggested that the cholesterol-lowering effect of soy protein depends on its content of isoflavones. In their study, moderately hypercholesterolemic men and women consuming a NCEP step I diet consumed a beverage with $25 \mathrm{~g}$ of isolated soy protein, which provided $3,27,37$ or $62 \mathrm{mg} / \mathrm{d}$ of isoflavones for $9 \mathrm{wk}$. The virtually isoflavone-depleted soy protein ( $3 \mathrm{mg}$ isaflavones) as well as isolated soy protein containing only $27 \mathrm{mg}$ isoflavones had no favorable effects on the plasma lipid and lipoprotein profile. Isolated soy protein with the highest isoflavone content $(62 \mathrm{mg})$ reduced $\mathrm{LDL}$ cholesterol concentrations $6 \%$. After consumption of isollated soy protein providing $37 \mathrm{mg}$ of isoflavones, however, decreases in LDL cholesterol concentrations of $8 \%$ were found only in the men and women with the highest initial LDL cholesterol concentrations. Similarly. Teixeira et al. (47) demonstrated that an intake of $20 \mathrm{~g} / \mathrm{d}$ of isolated soy protein containing a low content of isoflavones (38 mg) reduced plasma total and non-HDL (LDL + VLDL) cholesterol concentrations in moderately hypercholesterolemic men consuming an NCEP step I diet by 2 and $3 \%$, respectively. At intakes of 30,40 or $50 \mathrm{~g}$ of isolated soy protein providing 57,76 or 95 mg of isoflavones, plasma non-HDL cholesterol concentrations declined by 3,2 and $5 \%$ respectively. Also, plasma total cholesterol concentrations were significantly 
lowered, except on the diet providing $40 \mathrm{~g}$ of isolated soy protein. The isolated soy proteins were incorporated into various baked products and ready-to-mix beverages, which were consumed for 6 wk. Another study by Takatsuka et al. (48) examined the effects of soymilk on serum lipids in premenopausal, normolipidemic Japanese women. The investigators observed that dailly consumption of $-350 \mathrm{~mL}$ soymilk, which provided $15 \mathrm{~g}$ soy protein and $96 \mathrm{mg}$ of isoflavones, for $60 \mathrm{~d}$ decreased serum total cholesterol concentrations $5 \%$. Very recently, Wangen et al. (49) found that plasma LDL cholesterol concentrations in normocholesterolemic and mildly hypercholesterolemic postmenopausal women were lowered $7 \%$ after a daily intake of $85 \mathrm{~g}$ of isolated soy protein beverage powder containing a high isoflavone content (132 mg) for $93 \mathrm{~d}$. A lower dose of soy isoflavones ( $65 \mathrm{mg}$ ) had no effects on plasma lipids and lipoproteins. Another very recent trial $(50)$ demonstrated that in postmenopausal women with moderate hypercholesterolemia, the use of $42 \mathrm{~g} / \mathrm{d}$ of isolated soy protein powder providing $80 \mathrm{mg}$ of isoflavones for $12 \mathrm{wk}$ lowered plasma LDL cholesterol concentrations by $0.3 \mathrm{mmol} / \mathrm{L}$ compared with $42 \mathrm{~g}$ of isolated soy protein without isoflavones. Surprisingly, the decrease in LDL cholesterol due to 42 $\mathrm{g} / \mathrm{d}$ of milk protein did not differ from isolated soy protein powders that were mixed with juice, water or soup.

Not all studies have reported a hypocholesterolemic effect of isoflavones. Gooderham et al. (51) showed that plasma total and HDL cholesterol concentrations did not change in normocholesterolemic men who consumed $60 \mathrm{~g}$ of an isolated soy protein supplement providing $131 \mathrm{mg} / \mathrm{d}$ of isoflavones for $28 \mathrm{~d}$. These findings were confirmed by Nestel et al. (52), who investigated the effects of a daily intake of $80 \mathrm{mg}$ isolated soy isoflavones (tablet) for 5-10 wk on plasma lipids in a study with postmenopausal and perimenopausal women. Furthermore, Jenkins et al. (53) demonstrated that daily consumption of breakfast cereals containing $36 \mathrm{~g}$ of soy protein and $168 \mathrm{mg}$ of isoflavones for $3 \mathrm{wk}$ had no beneficial effects on serum lipids and lipoproteins in a trial with hyperlipidemic men and postmenopausal women. Another trial by Simons et al. (54) examined the effects of a tablet of $80 \mathrm{mg} / \mathrm{d}$ of soy isoflavones, as part of a diet low in saturated fat and cholesterol, on the plasma lipid and lipoprotein profile in postmenopausal women with normal lipid concentrations. After treatment for $8 \mathrm{wk}$, plasma lipid and lipoprotein concentrations were not affected. In a recent study by Hsu et al. (55), there were no changes in the plasma lipoprotein profile of postmenopausal women after a daily intake of $150 \mathrm{mg}$ of pure isoflavones for $6 \mathrm{mo}$. This study, however, lacked a control group. Also, four trials with isolated isoflavones from red clover did not demonstrate a cholesterol-lowering effect (56-59). Isoflavones from red clover differ from soy in that red clover contains 
not only the isoflavones genistein and daidzein, which are predominantly present in soy, but also high amounts of the isoflavone precursors biochanin $\mathrm{A}$ and formononetin (Figure 2). After ingestion of isoflavones by humans, these compounds are converted to genistein and daidzein, respectively (58). Samman et al. (56) observed that consumption of tablets containing $86 \mathrm{mg} / \mathrm{d}$ of isoflavones from red clover for -2 mo did not influence plasma lipids in premenopausal normocholesterolemic women. Another study by Nestel et al. (57) also reported no effects of tablets containing 40 or $80 \mathrm{mg} / \mathrm{d}$ of red clover isoflavones for 5 wk on plasma lipids in postmenopausal women. Similarly. Howes et al. (58) showed that the lipoprotein profile was not affected by tablets containing 45 or $90 \mathrm{mg} / \mathrm{d}$ of isoflavones from red clover for 4 wk by postmenopausal women with mild to moderate hypercholesterolemia. A 6-mo trial by Clifton-Bligh et al. (59) showed that serum LDL cholesterol concentrations were not changed after daily consumption of $28.5,57$ or $85.5 \mathrm{mg}$ of isoflavones from red clover in postmenopausal women. A possible shortcoming of this study was that it was not placebo-controlled: In addition, an 8-wk trial by Hodgson et al. (60) with tablets providing $55 \mathrm{mg}$ of isoflavones from subterranean clover did not report beneficial effects on serum lipids and lipoproteins in men and postmenopausal women. Like red clover, subterranean clover contains the isoflavones predominantly present in soy (genistein and daidzein) as well as the isoflavones biochanin $\mathrm{A}$ and formononetin.

Based on the inconsistent findings about the effects of isoflavones on lipids and lipoproteins, it remains uncertain whether isoflavones are responsible for the proposed hypocholesterolemic effects of soy. In several studies, serum lipoprotein concentrations were unaffected by consumption of isolated soy isoflavones (without soy protein) indicating that both soy protein and isoflavones may be needed to elicit a cholesterol-lowering effect. Furthermore, in most of the studies that reported a lack of effect, isoflavones isolated from soy or from red clover were given in tablet form. In general, results among studies with soy products are variable, although it should be noted that the most consistent cholesterol-lowering effects have been found in subjects with high plasma cholesterol concentrations. Also, other components in soy may be hypocholesterolemic. Lovati et al. $(61,62)$ observed in studies with cell cultures that a $7 \mathrm{~S}$ globulin fraction from soybeans enhanced the activity of the LDL receptor, suggesting that this component may be a cholesterol-lowering agent. The $7 S$ globulin is a major storage protein of soybeans. In contrast to in vitro media, however, soy protein is completely digested in vivo. Accordingly, we assume that this $7 S$ globulin will not be absorbed intact from the human intestine. Thus, its role in vivo remains speculative. Other components present in soy, such as various amino acids, 
fiber, saponins or a combination of components, have also been postulated to be active compounds (32). It seems, therefore, important to identify the active components in soy products and to identify population groups who may benefit from them. Because various commercial soy proteins and soy-based products differ markedly in composition, it is difficult to substantiate that soy protein intake leads to a reduction in blood cholesterol concentrations. Rather, evidence should be obtained on specific soy protein sources or soy-based products to support consumer benefit claims.

\section{Plant sterols and stanols}

At present, a variety of food products enriched with plant sterols and stanols are on the market in many countries. For incorporation into foods, plant sterols and stanols are often esterified with fatty acids to improve their fat solubility. One gram of plant sterols or stanols is equivalent to $-1.6 \mathrm{~g}$ of esterified plant sterols or stanols. This is often referred to as $1 \mathrm{~g}$ plant sterols (or stanols) provided as its fatty acid esters or 1 $\mathrm{g}$ plant sterol (or stanol) esters. Plant sterols, of which campesterol, $\beta$-sitosterol and stigmasterol are the most abundant in nature, are structurally related to cholesterol, but they have a different side-chain configuration. Saturation of the sterols with hydrogen leads to the formation of plant stanols, such as campestanol and sitostanol (63) (Figure 3).

Because the human body can not synthesize plant sterols, these components are derived only from the diet. They are usually present in vegetable oils, nuts, cereals and beans, and are consumed in Western diets in an amount of $\sim 160$ to $360 \mathrm{mg} / \mathrm{d}$ (63). Plant stanols are less abundant in these dietary sources than plant sterols. Compared with cholesterol, plant sterols and stanols are absorbed less and their biliary excretion is faster. Consequently, their serum levels are very low. The different plant sterols and stanols are not equally absorbed. This was demonstrated in a study by Heinemann et al. (64) in which the intestinal absorptions of cholesterol and different plant sterols and stanols were compared in healthy men, using an intestinal perfusion technique over a $50-\mathrm{cm}$ segment of the upper jejunum. Absorptions of cholesterol, campestanol, campesterol, stigmasterol and sitosterol were $33,13,10,5$ and $4 \%$, respectively. Absorption of sitostanol is minimal. 


\section{Cholesterol}

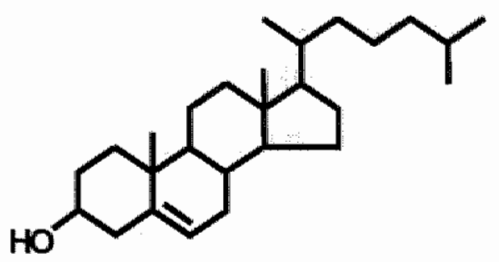

\section{Plant sterols $\stackrel{\text { Saturation }}{\longrightarrow}$ Plant stanols}<smiles>CC(C)C(C)CCC(C)C1CCC2C3CC=C4CC(O)CCC4(C)C3CCC12C</smiles><smiles>CCC(CCC(C)C1CCC2C3CC=C4CC(O)CCC4(C)C3CCC12C)C(C)C</smiles>

Sitosterol<smiles>CCC(C=CC(C)C1CCC2C3CC=C4CC(O)CCC4(C)C3CCC12C)C(C)C</smiles><smiles>CC(C)C(C)CCC(C)C1CCC2C3CCC4CC(O)CCC4(C)C3CCC12C</smiles><smiles>CCC(CCC(C)C1CCC2C3CCC4CC(O)CCC4(C)C3CCC12C)C(C)C</smiles>

\section{FIGURE 3 Chemical structures of plant sterols and stanols}

The plant sterols, campesteral, sitosterol and stigmasterol are struchurally related to cholesterol but they vary in sicle chain. Saturation of these plant sterols with hydrogen leads to the formation of the plant stanols" campestanol and silostanol. Note that saturation of stigmasterol also leads to the formation of silostancil(63). 
Plant sterols and stanols have a greater affinity for micelles than cholesterol because of theil greater hydrophobicity. Therefore, they can easily displace intestinal cholesterol from the micelles, reducing intestinal cholesterol absorption (65). This reduction results in a compensatory increase in endogenous cholesterol synthesis (66) and in higher LDL-receptor expression (67). The net overall effect is that circulating $L D L$ cholesterol concentrations are lowered after consumption of plant sterol or stanol-containing foods.

Ikeda et al. (68) assumed that the cholesterol-lowering action is the greatest for the least absorbable plant sterols. Because the absorbability of sitostanol is lower than that of campestanol (64), a greater hypocholesterolemic effect can be expected after consumption of plant stanol ester mixtures in which the amount of sitostanol is higher than that of campestanol. However, daily consumption of $2-4 \mathrm{~g}$ of two different plant stanol ester mixtures consisting of different proportions of sitostanol and campestanol reduced serum concentrations of LDL cholesterol to the same extent (69-71). Furthermore "it was demonstrated in men and women with ileostomies that plant sterol and stanol esters at doses of $1.5 \mathrm{~g} / \mathrm{d}$ for $3 \mathrm{~d}$ reduced intestinal cholesterol absorption similarly (72). In fact, serum LDL cholesterol concentrations were lowered similarly after a daily intake of $-2 \mathrm{~g}$ of plant sterol or stanol esters for $4 \mathrm{wk}$ in hypercholesterolemic men and women consuming a low-fat diet (73).

It is not necessary to consume plant stanols at each meal or simultaneously with dietary cholesterol to obtain the maximal cholesterol-lowering effect (74). In the study with normocholesterolemic and mildly hypercholesterolemic men and women (74), daily intake for 4 wk of $2.5 \mathrm{~g}$ of plant stanols once at lunch was as effective in lowering serum LDL cholesterol concentrations as when divided over three meals $10.42 \mathrm{~g}$ at breakfast, $0.84 \mathrm{~g}$ at lunch, and $1.25 \mathrm{~g}$ at dinner, proportional to the dietary cholesterol intake). This indicates that replacement of intestinal cholesterol from the micelles is not the only mechanism by which plant stanols lower LDL cholesterol. Plant sterols and stanols are effective when consumed as part of a diet low in fat and cholesterol (69, 75). Thus, not only dietary cholesterol but also biliary cholesterol absorption in the intestine is suppressed. Additionally, plant sterols and stanols are effective in combination with cholesterol-lowering drugs such as statins (76).

Not all plant sterols are potent cholesterol-lowering agents. Sierksma et al. (77) showed that plasma lipid and lipoprotein concentrations were not affected in men and women after daily intake for $3 \mathrm{wk}$ of $3.3 \mathrm{~g}$ of 4,4-dimethylsterols from sheanut oil, such as $\alpha$-amyrin and lupeol, which were incorporated into spreads. These findings were consistent with their previous study (78). Because the molecular structures of 4,4-dimethylsterols are less comparable with cholesterol than those of the 
hypocholesterolemic 4-desmethylsterols, like sitosterol and campestero, a possible explanation for the lack of effect of 4,4-dimethylsterols could be that they do not displace intestinal cholesterol from the micelles.

In a recent meta-analysis of 14 studies, Law (79) concluded that $\sim 2 \mathrm{~g}$ of plant sterols or stanols lowered serum LDL cholesterol concentrations by $9-14 \%$. Little or no effect was observed on HDL cholesterol or triacylglycerol concentrations. There were no further significant decreases in serum LDL cholesterol concentrations at higher doses. In most of the included studies, plant sterols or stanols were added to margarine and in the other trials, these compounds were incorporated into mayonnaise, olive oil or butter. However, these components are also effective in lowfat products $(80,81)$.

Currently, the U.S. FDA has under review two requests for the allowance of a health claim for plant sterols and stanols. This far, the agency has concluded that "based on the totality of the publicly available scientific evidence, plant sterol and stanol esters may reduce the risk of CHD" (82). A final decision is expected in 2002.

In general, plant sterols and stanols have no adverse effects as demonstrated in extensive safety evaluation studies (65). However, the absorption of fat-soluble components other than cholesterol, such as vitamins and antioxidants, might be

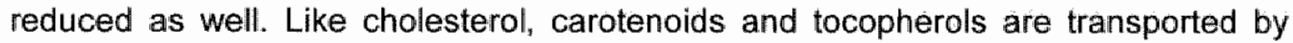
lipoproteins. Because the number of LDL particles decreases in the circulation after consumption of plant sterols or stanols, the plasma concentrations of carotenoids and tocopherols also decrease. For this reason, these antioxidants are often standardized to plasma lipid concentrations. Recently, we summarized the results from randomized placebo-controlled trials about the effects of plant sterols or stanols on $\alpha$-plus $\beta$-carotene and $\alpha$-tocopherol concentrations (83). The absolute plasma concentrations of $\alpha$-plus $\beta$-carotene as well as of $\alpha$-tocopherol decreased after plant sterol or stanol intake. After standardization to LDL cholesterol, however, $\alpha$ tocopherol concentrations were not affected, whereas those of $\alpha$-plus $\beta$-carotene were still reduced in almost all trials. Note that levels of carotenoids and tocopherols were still within the normal ranges. Plasma concentrations of retinol (vitamin A), 25hydroxy-vitamin $D$ and vitamin $K$ were unaffected by dietary plant sterols and stanols.

Thus, the efficacy of plant sterols and stanols as cholesterol-lowering agents has been well established. Extensive safety evaluation studies have not revealed any adverse effects. However, more information should be obtained if consumption of plant sterols and stanols, and of functional foods in general, may cause unexpected side effects in the longer term. Because plant sterols and stanols can displace 
cholesterol from the intestinal micelles, they can reduce intestinal cholesterol absorption. Although this reduction increases endogenous cholesterol synthesis and LDL-receptor expression, the net overall effect is that serum LDL cholesterol concentrations are lowered by $9-14 \%$ after consumption of $-2-3 \mathrm{~g}$ of plant sterols or stanols. No further decreases occur at higher doses. Functional foods enriched with plant sterols or stanols are effective in various population groups of all ages, including children $(84,85)$, and also in combination with cholesterol-lowering drugs.

\section{Garlic}

A large number of intervention trials with garlic (Allium sativum) have been published. Allicin, which causes the characteristic garlic odor, is believed to be the active lipidlowering compound in garlic (Figure 4). Through crushing, cutting or chewing the garlic clove, the enzyme allinase comes into contact with the adorless alliin, which is then converted into allicin. Approximately $3.7 \mathrm{mg}$ of allicin can be produced from $1 \mathrm{~g}$ of crushed raw garlic $(86,87)$. The mechanisms underlying the possible lipid-lowering action of garlic are not well understood. Animal studies have suggested that garlic supplemented diets may inhibit the synthesis of cholesterol and fatty acids in the iiver (88).

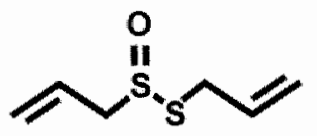

FIGURE 4 Chemical structure of allicin from garlic

Allicin is believed to be the active lipid-lowering compound in garlic. After crushing, cutting or chewing the garlic clove, the enzyme allinase acts an alliin to produce allicin $(86,87)$.

Although the results from two earlier meta-analyses $(89,90)$ suggested a hypocholesterolemic effect of garlic, they did not provide strong evidence for the usefuness of garlic as a hypocholesterolemic agent because of methodological shortcomings of many of the studies included. Not all the included trials provided information about the subjects' dietary intakes and body weights, or about the comparability of the smell or taste of the placebo and garlic preparations. In the meta-analysis performed by Warshafsky et al. (89), only 5 randomized, placebocontrolled trials of the 28 identified trials were included. The authors suggested that a cholesterol-lowering effect of $\sim 9 \%(0.59 \mathrm{mmol} / \mathrm{L})$ could be achieved by a daily consumption of $-1.5-3 \mathrm{~g}$ of fresh garlic for 2-6 mo. According to the second meta- 
analysis of 16 trials (90), garlic, in powder or non-powder form, consumed for $1-3 \mathrm{mo}$, reduced serum total cholesterol concentrations $12 \% \quad(0.77 \mathrm{mmol} / \mathrm{L})$. After consumption of nonpowdered garlic preparations, serum total cholesterol concentrations declined by $15 \%(0.99 \mathrm{mmol} / \mathrm{L})$, whereas a daily dose of $600-900 \mathrm{mg}$ of dried garlic powder, in which the allicin content was standardized, lowered cholesterol $8 \%(0.51 \mathrm{mmol} / \mathrm{L})$. A dose of $600-900 \mathrm{mg}$ of dried garlic powder is equivalent to $1.8-2.7 \mathrm{~g}$ of fresh garlic. Based on data from eight trials with dried garlic powder preparations (600-900 mg/d), serum triacylglycerol concentrations decreased by $13 \%$, whereas HDL cholesterol concentrations were not affected.

Neil et al. (91) performed a 6-mo trial with 115 men and women to investigate the effect of a daily intake of $900 \mathrm{mg}$ of dried allicin-standardized garlic powder on serum cholesterol concentrations. Plasma lipids and lipoproteins were not affected. When they included the results of this study in their previous meta-analysis $(90)$, the overall cholesterol-lowering effect of garlic was reduced to $0.65 \mathrm{mmol} / \mathrm{L}$. The authors of a subsequent meta-analysis (92) excluded 9 of the 16 trials in the meta-analyses of Silagy and Neil (90), which were not placebo-controlled, blind or involved normocholesterolemic subjects, and included 5 new trials. This recent meta-analysis suggested that garlic, used as allicin-standardized garlic powder $(600-900 \mathrm{mg} / \mathrm{d})$, garlic oil or spray-dried garlic, for 2-10 mo reduced total cholesterol concentrations $\sim 4-6 \%(0.41 \mathrm{mmol} / \mathrm{L})$ in hypercholesterolemic persons, which is much smaller than the effects reported in previous meta-analyses (89-91).

In the most recent meta-analysis of 45 studies, Ackermann et al. (93) concluded that garlic decreased total cholesterol concentrations $\sim 0.19 \mathrm{mmol} / \mathrm{L}$ after an intervention of 4-6 wk and $0.44 \mathrm{mmol} / \mathrm{L}$ after 8-12 wk, whereas no changes were observed after 20-24 wk. This may suggest that the effect is transient. The decreases in LDL cholesterol and triacylglycerol concentrations paralleled those in total cholesterol concentrations. HDL cholesterol concentrations were unchanged. in 22 included trials, dehydrated alliin-standardized $(1.3 \mathrm{~g} / 100 \mathrm{~g})$ garlic preparations were used. The ather studies tested preparations that were standardized to a minimum of $0.3 \%$ allicin and $4.6 \mathrm{mg}$ of alliin per supplement or used various nonstandardized garlic preparations.

Over the last $3 y$, six well designed trials (94-99) did not confirm the favorable effects of garlic on lipid and lipoprotein concentrations. These studies were all randomized, double-blinded, placebo-controlled experiments. Thus, Isaacsohn et al. (94) investigated the effects of a daily dose of $900 \mathrm{mg}$ allicin-standardized garlic powder on plasma lipids and lipoproteins in moderately hypercholesterolemic men and 
women. After 12 wk, plasma concentrations of total, LDL and HDL cholesterol, and of triacylglycerol were not affected. These findings were confirmed by Berthold et al. (95) who examined the effects of a daily dose of garlic oil of $10 \mathrm{mg}$, which corresponds to $\sim 4-5 \mathrm{~g}$ of fresh garlic, for 12 wk on serum lipoproteins in a study of moderately hypercholesterolemic men and women. In addition, they performed a fecal balance and a double-isotope continuous feeding method at the end of each 12-wk treatment to measure cholesterol absorption and synthesis, which remained unchanged during the study. Another study by Superko and Krauss (96) showed no effects of a daily dose of $900 \mathrm{mg}$ allicin-standardized garlic powder for 12 wk on plasma lipoproteins, LDL and HDL subclass distribution or postprandial triacylglycerols in hypercholesterolemic subjects. Similarly, Zhang et al. (97) demonstrated that the plasma lipoprotein profile of trained male runners with a low coronary risk profile who used $12.3 \mathrm{mg}$ garlic oil daily for $16 \mathrm{wk}$ did not change. The study by Gardner et al. (98) also did not demonstrate any reduction in lipids and lipoproteins. In this study, a daily dose of 500 or $1000 \mathrm{mg}$ allicin-standardized garlic powder was given for $12 \mathrm{wk}$ to moderately hypercholesterolemic men and women. Zhang et al. (99) also did not find favorable effects of garlic oil capsules delivering daily $8.2 \mathrm{mg}$ of allyl sulfide, a derivative of allicin, for $11 \mathrm{wk}$ in men and women at low risk for $\mathrm{CHD}$. Compared with men, however, the women had increased plasma HDL cholesterol concentrations. The investigators suggested that any beneficial effect of garlic on plasma lipids might differ between men and women.

In contrast, a recently published trial (100) showed that in mild to moderate hypercholesterolemic men and women consuming a low-fat diet for $12 \mathrm{wk}$, an enteric-coated garlic powder supplement decreased plasma LDL cholesterol concentration $7 \%$. Because of the instability of allicin, most preparations are designed to produce allicin enzymatically from alliin after consumption, and contain fixed amounts of allin and allinase. However, allinase can be deactivated in the stomach (93). In the study of Kannar et al. (100), however, enteric-coated tablets, which were standardized to produce $9.6 \mathrm{mg} / \mathrm{d}$ of allicin, were used to protect the enzyme alliinase from deactivation by the low gastric $\mathrm{pH}$. This may lead to an adequate enzymatic production of allicin from allin in the intestinal tract after consumption.

In summary, the usefuiness of garlic as an effective lipid-lowering agent is still a matter of dispute. Apart from one trial (100), other very recent trials have not shown such effects. Allicin has been suggested to be one of the major sulfur-rich components in garlic that may contribute to its hypocholesterolemic effect. The reason for the lack of effect of garlic on the lipid and lipoprotein profile in recent well 
designed studies is unclear. It is possible that the allicin release from the garlic preparations, despite standardization, was not optimal (99). Garlic preparations are often designed to release allicin enzymatically from alliin after consumption. It seems that the enzyme alliinase quickly denaturates at a low gastric pH (93). However, allicin and some of its metabolites, such as ajoene and diallyl disulfide (DADS), have never been found in human blood after consumption of garlic products, including enteric-coated products that protect the enzyme alliinase against deactivation by stomach acid. Furthermore, aged garlic extract (AGE) products contain no alliin or allicin. S-allylcysteine (SAC), which is a major water-soluble organosulfur compound in $A G E$, can be measured in the blood. For this reason, the stable SAC present in AGE could be a hypocholesterolemic active agent as suggested in some animal and human trials $(87,88)$. Another possible explanation for the lack of effect could be that other components, such as saponins (101), may account for the lipid-lowering properties of garlic. Future studies should try to characterize the possible active constituents and their availability after ingestion as well as to elucidate the mechanism to explain the possible favorable effects of garlic on lipids and lipoproteins.

\section{Tocotrienols}

Tocopherols and tocotrienols are two subgroups of the vitamin $E$ family, which consist of a chromanol ring attached to a phytyl side chain. The tocotrienols differ only from the tocopherols in that their phytyl side chain contains three double bonds. The $\alpha-, \beta-, \gamma$ - and $\delta$-tocopherols and corresponding tocotrienols are based on the number and position of methyl groups on their chromanol ring (102) (Figure 5). Tocopherols are commonly found in most vegetable oils. The tocotrienols are less abundant in nature than the tocopherols, but are present in palm oil and rice bran oil $(103,104)$.

The tocopherals, of which $\alpha$-tocopherol has the greatest vitamin $E$ activity, have no effects on plasma concentrations of total, LDL, HDL and VLDL cholesterol, and triacylglycerol (105). Unlike tocopherols, tocotrienols have been suggested to lower cholesterol concentrations in the blood, possibly because of an inhibition of the activity of 3-hydroxy-3-methylglutaryl-coenzyme A (HMG-CoA) reductase, the ratelimiting enzyme in endogenous cholesterol synthesis, as demonstrated in animals (106-109). The mechanism of this inhibitory action by tocotrienols may involve a reduced HMG-COA reductase protein synthesis rate and an increased dlegradation 
rate as found in human hepatoma HepG2 cells (110). The different tocotrienol subtypes seem to possess various degrees of hypocholesterolemic activity: 8 Tocotrienol and $\gamma$-tocotrienol were claimed to be more active than $\alpha$-tocotrienol in inhibiting HMG-COA reductase, whereas $\beta$-tocotrienol has a very low effect (108, 111).<smiles>[R3]c1c([R2])c2c(c([R7])c1O)CC[C@@](C)(CCC[C@H](C)CCC[C@H](C)CCCC(C)C)O2</smiles>

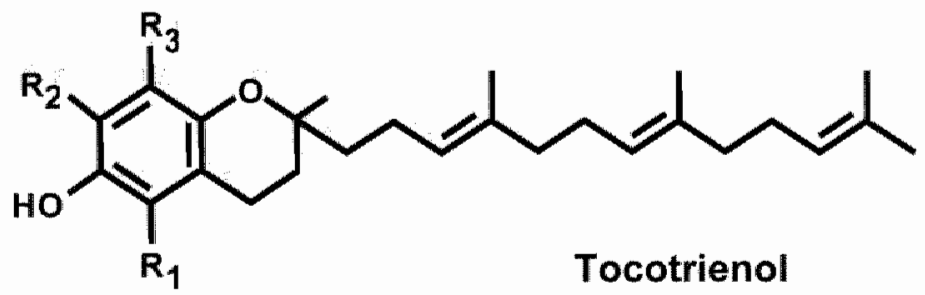

\begin{tabular}{llll} 
Compound & $\mathbf{R}_{\mathbf{1}}$ & $\mathbf{R}_{\mathbf{2}}$ & $\mathbf{R}_{\mathbf{3}}$ \\
\hline$\alpha$-Tocopherol / $\alpha$-Tocotrienol & $\mathrm{CH}_{3}$ & $\mathrm{CH}_{3}$ & $\mathrm{CH}_{3}$ \\
$\beta$-Tocopherol / $\beta$-Tocotrienol & $\mathrm{CH}_{3}$ & $\mathrm{H}$ & $\mathrm{CH}_{3}$ \\
$\gamma$-Tocopherol $/ \gamma$-Tocotrienol & $\mathrm{H}$ & $\mathrm{CH}_{3}$ & $\mathrm{CH}_{3}$ \\
$\delta$-Tocopherol / $\delta$-Tocotrienol & $\mathrm{H}$ & $\mathrm{H}$ & $\mathrm{CH}_{3}$
\end{tabular}

FIGURE 5 Chemical structures of tocopherols and tocotrienols

The tocotrienols differ from the tocopherols in that they have unsaturated phytyl side chains. $R_{1} R_{2}$ and $R_{3}$ are rest-groups on the chromanol ring. Four subtypes of tocopherols and corresponding tocotrienols have been identified as: $\alpha-(6,7,8$-trimethyl), $\beta m(5,8$-dimethyl), $\gamma(7,8-d i m e t h y l)$ and $\delta$-(8-methyl) based on the number and position of methyl groups on the chromanal ring (102). 
Results concerning the effects of tocotrienols from palm oil on circulating lipids and lipoproteins in humans are not consistent. The studies published by Tan et al. (112) and Qureshi et al. $(113,114)$ have shown a hypocholesterolemic effect of tocotrienols from palm oil in men and women. In these studies, no changes were found in serum HDL cholesterol and triacylglycerol concentrations. Tan et al. (112) demonstrated that daily ingestion of a tocotrienol-rich fraction from palm oil resulted in lowered serum concentrations of LDL cholesterol in both normocholesterolemic and hypercholesterolemic men and women. A shortcoming of this study, however, is that they did not use a control group. Qureshi et al. (113) conducted a study in which hypercholesterolemic men and women used $200 \mathrm{mg}$ of a tocotrienol-rich fraction from palm oil containing 30-40 mg of $\alpha$-tocopherol, 24-30 $\mathrm{mg}$ of $\alpha$-tocotrienol, 70-80 $\mathrm{mg}$ of $\gamma$-tocotrienol and $50-60 \mathrm{mg}$ of $\delta$-tocotrienol per day. After 4 wk, serum LDL cholesterol concentrations tended to be $8 \%$ lower. When 3 poor responders of 15 participants in the tocotrienol group were excluded from the statistical analysis; a significant $28 \%$ decrease was found. The validity of excluding these subjects from the statistical analysis, however, is doubtful. Daily supplementation with $200 \mathrm{mg}$ of the specific $\gamma$-tocotrienol fraction from palm oil to the three poor responders and four new hypercholesterolemic subjects for 4 wk decreased LDL cholesterol $27 \%$. The authors suggested that $\gamma$-tocotrienol might be the most effective cholesterol-lowering compound in palm oil. Note, however, that these changes of the $\gamma$-tocotrienol group were not compared with those of a control group. Another trial by Qureshi et al. (114) also demonstrated a $13 \%$ decline in serum LDL cholesterol concentrations after the daily supplementation with a tocotrienol-rich fraction from paim oil, which consisted of $40 \mathrm{mg}$ of $\alpha$-tocopherol, $48 \mathrm{mg} \alpha$-tocotrienol, $112 \mathrm{mg}$ of $\gamma$-tocotrienol and $60 \mathrm{mg}$ of $\delta$ tocotrienol for $4 \mathrm{wk}$ in men and women with hypercholesterolemia consuming an AHA step I diet. When $200 \mathrm{mg}$ of $\gamma$-tocotrienol from palm oil per day was given for 4 wk, serum total cholesterol concentrations declined by $13 \%$.

In contrast, various other research groups did not find any change in the serum lipid and lipoprotein profile after supplementation with tocotrienols from palm oil. In the study of Wahllquist et al. (115), men and women with hypercholesterolemia used supplements containing a tocotrienol-rich fraction from palm oil in increasing doses from $60,120,180$ up to $240 \mathrm{mg} / \mathrm{d}$. Each dose was given for $4 \mathrm{wk}$ and consisted of $30 \%$ of $\alpha$-tocopherol, $23 \%$ of $\alpha$-tocotrienol, $31 \%$ of $\gamma$-tocotrienol and $16 \%$ of $\delta$ tocotrienol. No changes were found in serum concentrations of total, LDL and HDL cholesterol, or triacylgiycerol. These findings were confirmed by Tomeo et al. (116) who examined the effects of daily supplementations with a tocotrienol-rich fraction from palm oil in increasing doses from 224, 280 up to $336 \mathrm{mg}$ for 18 mo on serum lipids and lipoproteins in hyperlipidemic men and women with carotid atherosclerosis. 
Each dose of the tocotrienol-rich fraction from palm oil contained $29 \%$ a-tocopherol and $71 \% \gamma^{\prime}$ plus $\alpha$-tocotrienols. Furthermore, Mensink et al. (117) found no changes in serum lipid and lipoprotein concentrations in mildly hypercholesterolemic men who received supplements containing a tocotrienol-rich fraction from palm oil consisting of $83 \mathrm{mg}$ of $\alpha$-tocopherol, $40 \mathrm{mg}$ of $\alpha$-tocotrienol, $5 \mathrm{mg}$ of $\beta$-tocotrienol, $68 \mathrm{mg}$ of $\gamma$ tocotrienol and $25 \mathrm{mg}$ of $\delta$-tocotrienol per day for 6 wk. $0^{*}$ Byrne et al. (118) supplemented hypercholesterolemic men and women with $250 \mathrm{mg}$ of purified $\alpha-, \gamma$, or 8 -tocotrienyl acetates from palm oil per day for $8 \mathrm{wk}$ in addition to an AHA step I diet. Serum lipid and lipoproteins were not affected.

In a review of animal and human studies using different supplements containing variable compositions of the tocotrienol-rich fraction from palm oil, Qureshi et al. (119) tried to explain the controversial effects of tocotrienols from palm oil by suggesting that the most effective supplements provided $15-20 \% \alpha$-tocopherol and $-60 \% \gamma$ - (and $\delta$-) tocotrienol, whereas the less effective supplements consisted of $\geq$ $30 \% \alpha$-tocopherol and $45 \% \gamma-$ (and $\delta$-) tocotrienol. They postulated that the cholesterol-lowering action of the tocotrienols might be attenuated by $\alpha$-tocopherol, as shown in chickens (119). In contrast, other studies with HepG2 cells (120) or rats (121) demonstrated that $\alpha$-tocopherol did not decrease the activity of $\gamma$-tocotrienol.

Like palm oil, rice bran oil is a rich source of tocotrienols, especially $\gamma$-tocotrienol, which is claimed to be the most hypocholesterolemic agent (122). In 1997, Qureshi et al. (123) suggested that the cholesterol-lowering effect of tocotrienols from rice bran oil were even more encouraging than the effects seen in their previous studies with tocotrienols from palm oil $(113,114)$. They postulated that these promising effects could be attributed to two new types of tocotrienols, which were isolated from rice bran oil and identified as desmethyl $\left(P_{21}\right)$ and didesmethyl $\left(P_{25}\right)$ tocotrienols (104, 123). Daily consumption of $-200 \mathrm{mg}$ of a novel tocotrienol-rich fraction from rice bran oil, which contained $12 \mathrm{mg}$ of $\alpha$-tocopherol, $25 \mathrm{mg}$ of $\alpha$-tocotrienol, $42 \mathrm{mg}$ of $\gamma$ tocotrienol, $20 \mathrm{mg}$ of $\delta$-tocotrienol, $9 \mathrm{mg}$ of d-tocotrienol, $34 \mathrm{mg}$ of $\mathrm{P}_{25}$-tocotrienol, 36 $\mathrm{mg}$ of unidentified tocopherols and tocotrienols, and $20 \mathrm{mg}$ of sterols and triacylglycerol for 4 wk reduced serum LDL cholesterol concentrations by $23 \%$ in hypercholesterolemic men and women who were consuming a NCEP step I diet. Serum HDL cholesterol and triacylglycerol concentrations were stable throughout the study (123).

In summary, despite the positive results of Qureshi et al. $(113,114,123)$, the claimed hypocholesterolemic effect of tocotrienols from either palm oil or rice bran oil is highly controversial. In fact, except for Tan et al. (112) who conducted a study that was not well controlled, no other research groups have been able to confirm the findings of 
Qureshi and his colleagues. It is therefore not very likely that tocotrienols have a cholesterol-lowering effect for the general population.

\section{Conclusions}

Diet plays a major role in reducing the risk of CHD. This has led to the search for specific foods and food components that may help to improve the serum lipoprotein profile. In this respect, we have focused this review on the effects of different food: components that have received much attention for the last $10 \mathrm{y}$.

The studies about the effects of $\beta$-glucan from oats on the lipoprotein profile showed positive as well as no effects on LDL cholesterol. Not only the viscosity in the gastrointestinal tract, but also the food matrix and/or food processing may influence the cholesterol-lowering potential of $\beta$-glucan from oats. Like oats, yeast and barley are also rich in $\beta$-glucan, but the chemical structure and characteristics of yeastderived $\beta$-glucan differ from $\beta$-glucan from oats and barley. It is not clear yet whether $\beta$-glucan from yeast acts in a similar way as $\beta$-glucan from oats or barley. Those issues raise the question whether each food enriched with a proven bioactive compound, or each food of which the bioactive compound or mode of administration is not certain, such as for soy and garlic, needs to be tested before being put on the market. Discrepant and unexpected results, however, may be better explained if we gain more insight into mechanisms of action. In fact, such knowledge may even be helpfull in predicting the cholesterol-lowering potential of a food.

Furthermore, it is important to bear in mind that some people may be more responsive to a dietary component and may benefit more from dietary changes tham other people. The focus of this study was on effects of dietary components on serum lipoproteins in groups of subjects. Genetic and environmental factors that render groups or individuals more or less responsive should be identified.

It is also important to monitor not only the effects of food components on the lipoprotein profile but also on other aspects of health because animal studies suggest that garlic preparations may inhibit atheroscleratic plaques formation, despite a lack of effect on plasma lipids (124). The cholesterol-lowering effects of soy isoflavones, for instance, which are structurally related to estradiol, are explained by their weak estrogenic activity through binding of isoflavones to estrogen receptors. Postmenopausal women who use estrogens generally have lower rates of 
cardiovascular disease than those who are not supplemented. However, estrogens at high doses can have adverse effects, such as thrombotic complications, but may still have beneficial effects on serum LDL cholesterol concentrations. To our knowledge, however, such adverse effects have never been shown for phytoestrogens. Another example is that the plant sterols and stanols not only lower serum lipoprotein levels but also plasma levels of the fat-soluble carotenoids. These effects, however, may not be clinically important:

In conclusion, it is important to document the cholesterol-lowering effect of a functional food ingredient " and its mechanism " under various conditions, such as in combination with cholesterol-lowering diets or drugs, and in different population groups. Attention should be paid not only to beneficial but also to potentially adverse health effects. 


\section{References}

1. Law MR. Lowering heart disease risk with cholesterol reduction: evidence from observational studies and clinical trials. Eur Heart J Supplements 1999;1:S3-S8.

2. Shaten $B d$, Kuller $\mathrm{LH}$, Neaton JD. Association between baseline risk factors, cigarelte smoking, and CHD mortality after 10.5 years. Prev Med 1991;20:655-69.

3. Castelli WP. Anderson $K$, Wilson PWF, Levy D. Lipids and risk of coronary heart disease: the Framingham study. Ann Epidemiol 1992;2:23-8.

4. Expert Panel on Detection, Evaluation, and Treatment of High Blood Cholesterol in Adults. Executive summary of the third report of the National Cholesterol Education Program (NCEP) Expert Panel on Detection, Evaluation, and Treatment of High Blood Cholesterol in Adults (Adult Treatment Panel II). JAMA 2001;285:2486-96.

5. Tang IL, Armitage JM, Lancaster T, Silagy CA, Fowler GH, Neill HA. Systematic review of dietary intervention trials to lower blood total cholesterol in free-living subjects. BMJ $1998 ; 316: 1213-20$.

6. Anderson JW, Deakins DA, Floore TL, Smith BM, Whitis SE. Dietary fiber and coronary heart disease. Crit Rev Fd Sci Nutr 1990:29:95-147.

7. Glore $S_{n}$ van Treeck $D$, Knehans $A W$, Guild $M$. Soluble fiber and serum lipids: a literature review. J Am Diet Assoc 1994;94:425-36.

8. Bell S, Goldman VM, Bistrian BR, Arnold AH, Ostroff G, Forse RA. Effect of $\beta$-glucan from oats and yeast on serum lipids. Crit Rev Food Sci Nutr 1999;39:189-202.

9. Lund EK, Gee JM, Brown JC, Wood PJ, Johnson IT. Effect of oat gum on the physical properties of the gastrointestinal contents and on the uptake of D-galactose and cholesterol by rat small intestine in vitro. Br J Nutr 1989;62:91-101.

10. Beer MU, Arrigoni E, Amadò R. Effects of oat gum on blood cholesterol levels in healthy young men. Eur J Clin Nutr 1995;49:517-22.

11. Bridges SR, Anderson JW, Deakins DA, Dillon DW, Wood CL. Oat bran increases serum acetate of hypercholesterolemic men. Am J Clin Nutr 1992;56:455-9.

12. Wright RS, Anderson JW, Bridges SR. Propionate inhibits hepatocyte lipid synthesis. Proc Soc Exp Biol Med 1990;195:26-9.

13. De Groot AP, Luyken R, Pikaar NA. Cholesterol-lowering effect of rolled oats. Lancet 1963;2:303-4.

14. Ripsin $\mathrm{CM}_{0}$ Keenan JM, Jacobs DR, et al. Oat products and lipid lowering: a metelanalysis. JAMA 1992;267:3317-25.

15. Braaten JT, Wood PJ, Scott FW, et al. Oat $\beta$-glucan reduces blood cholesterol concentration in hypercholesterolemic subjects. Eur J Clin Nutr 1994;48:465-74.

16. World Wide Web: http://www.brennenmedical.com/complex.html (accessed June 6, 2001).

17. Food labeling: health claims; oats and coronary heart disease. Food and Drug Administration, HHS. Proposed rule. Fed Regist 1996;61:296-313.

18. FDA Talk Paper. FDA allows whole oat foods to make health claim on reducing the risk of heart disease. January 1997. World Wide Web: http://www.cfsan.fda.gov/ /rd/tpoats html (accessed 27 April 2001).

19. Davidson $\mathrm{MH}$, Dugan LD, Burns JH, Bova J, Story $K$, Drenman $K B$. The hypocholesterolemic effects of $\beta$-glucan in oatmeal and oat bran. A dose-controlled study. JAMA 1991;265:1833-9.

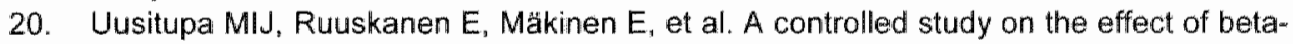
glucan-rich oat bran on serum lipids in hypercholesterollemic subjects: relation to apolipoprotein E phenotype. J Am Coll Nutr 1992;11:651-9. 
21. Mackay S, Ball MJ. Do beans and oat bran add to the effectiveness of a low-fat diet? Eur J Cin Nutr 1992;46:641-8.

22. Töroônen $R$, Kansanen $L$, Uusitupa $M_{\text {, }}$ et al. Effects of an oat bran concentrate on serum lipids in free-living men with mild to moderate hypercholesterolaemia. Eur J Clin Nutr 1992;46:621-7.

23. Behall KM, Scholfeld DJ, Hallfisch J. Effect of beta-glucan level in oat fiber extracts on blood lipids in men and women. J Am Coll Nutr 1997:16:46-51.

24. Onning G, Wallmark A, Persson M, Akesson B. Elmstahl S, Oste R. Consumption of oat milk for 5 weeks lowers serum cholesterol and LDL cholesterol in free-living men with moderate hypercholesterolemia. Ann Nutr Metab 1999;43:301-9.

25. Lovegrove JA, Clohessy A, Milon $H$, Williams $C M$. Modest doses of $\beta$-glucan do not reduce concentrations of potentially atherogenic lipoproteins. Am $J$ Clin Nutr $2000 ; 72: 49-55$.

26. Mclntosh GH, Whyte J, McArthur R, Nestel PJ. Barley and wheat foods: influence on plasma cholesterol concentrations in hypercholesterolemic men. Am J Clin Nutr 1991:53:1205-9.

27. Bourdon I, Yokoyama W, Davis $P$, et al. Postprandial lipipd, glucose, insulin, and cholecystokinin responses in men fed barley pasta enriched with $\beta$-glucan. Am $\mathrm{J}$ Clin Nutr 1999;69:55-63.

28. Nicolosi $R$, Bell SJ, Bistrian BR, Greenberg I. Forse RA, Blackburn GL. Plasma lipid changes after supplementation with $\beta$-glucan fiber from yeast. Am $\mathrm{J}$ Clin Nutr 1999;70:208-12.

29. Uusitupa MI, Miettinen TA, Sarkkinen ES, Ruuskanen E, Kervinen K, Kesäniemi YA. Lathosterol and other non-cholesterol sterols during treatment of hypercholesterolaemia with beta-glucan-rich oat bran. Eur J Clin Nutr 1997;51:607-11.

30. Carroll KKK. Review of clinical studies on cholesterol-lowering response to soy protein. $J$ Am Diet Assoc 1991;91:820-7.

31. Anderson JW, Johnstone BM, Cook-Newell ME. Meta-analysis of the effects of soy protein intake on serum lipids. N Engl J Med 1995;333:276-82.

32. Potter SM. Overview of proposed mechanisms for the hypocholesterolemic effect of soy. J Nutr 1995;125:606S-11S.

33. Potter SM. Soy protein and serum lipids. Curr Opin Lipidol 1996;7:260-4.

34. Potter SM. Soy protein and cardiovascular disease: the impact of bioactive components in soy. Nutr Rev 1998;56:231-5.

35. Lichtenstein AH. Soy protein, isoflavones and cardiovascular disease risk. J Nutr 1998; 128:1589-92.

36. Forsythe III WA. Soy protein, thyroid regulation and cholesterol metabolism. I Nutr 1995; $125: 619 \mathrm{~S}-23 \mathrm{~S}$.

37. Food labeling: health claims; soy protein and coronary heart disease. Food and Drug Administration, HHS. Final rule. Fed Regist 1999;64:57700-33.

38. FDA Talk Paper. FDA approves new health claim for soy protein and coronary heart disease. 1999. World Wide Web: http://www.cfsan.fda.gov/ /rd/tpsoypr2.html (accessed June 12, 2001).

39. Tikkanen MJ, Adlercreutz $\mathrm{H}$. Dietary soy-derived isoflavone phytoestrogens-Could they have a role in coronary heart disease prevention? Biochem Pharmacol 2000;60:1-5.

40. Kurzer MS, Xu X. Dietary phytoestrogens. Annu Rev Nutr 1997;17:353-81.

41. Walsh BW, Schiff I, Rasner B, Greenberg L, Ravnikar V, Sacks FM. Effects of postmenopausal estrogen replacement on the concentrations and metabolism of plasma lipoproteins. N Engl| J Med 1991;325:1196-1204. 
42. Cassidy $A$, Bingham $S$, Setchell $K$. Biological effects of isoflavones in young women: importance of the chemical composition of soya bean products. $\mathrm{Br} J \mathrm{Nutr} 1995,74.587$ 601.

43. Potter $S M$, Baum JA, Teng $H_{3}$ Stillman RJ, Shay NF, Erdman Jr JW. Soy protein and isoflavones: their effects on blood lipids and bone density in postmenopausal women. Am J Clin Nutr 1998;68:1375S-9S.

44. Powell EE, Kroon PA. Low density lipoprotein receptor and 3-hydroxy-3-methylglutaryl coenzyme A reductase gene expression in human mononuclear leukocytes is regulated coordinately and parallels gene expression in human liver. I Clin Invest $1994: 93: 2168-74$.

45. Washburn S, Burke GL, Morgan T: Anthony M. Effect of soy protein suppiementation on serum lipoproteins, blood pressure, and menopausal symptoms in perimenopausal women. Menopause 1999;6:7-13.

46. Crouse III JR, Morgan T, Terry JG, Ellis J, Vitolins M, Burke GL. A randomized trial comparing the effect of casein with that of soy protein containing varying amounts of isoflavones on plasma concentrations of lipids and lipoproteins. Arch Intern Med 1999;159:2070-6.

47. Teixeira SR, Potter SM, Weigel R, Hannum S, Erdman Jr JW, Hasler CM. Effects of feeding 4 levels of soy protein for 3 and $6 \mathrm{wk}$ on blood lipids and apolipoproteins in moderately hypercholesterolemic men. Am J Clin Nutr 2000;71:1077-84.

48. Takatsuka $N$, Nagata $C$, Kurisu $Y$, Inaba $S$, Kawakami $N$, Shimizu $H$. Hypocholesterolemic effect of soymilk supplementation with usual diet in premenopausal normolipidemic Japanese women. Prev Med 2000;31:308-14.

49. Wangen KE, Duncan AM, Xu $X$, Kurzer MS. Soy isoflavones improve plasma lipids in normocholesterolemic and mildly hypercholesterolemic postmenopausall women. Am $J$ Clin Nutr 2001;73:225-3\%.

50. Gardner CD, Newell KA, Cherin R, Haskell WL. The effect of soy protein with or without isoflavones relative to milk protein on plasma lipids in hypercholesterolemic postmenopausal women. Am J Clin Nutr 2001;73:728-35.

51. Gooderham MH, Adlercreutz H, Ojala ST, Wähälä $K$, Holub BJ. A soy protein isolate rich in genistein and daidzein and its effects on plasma isoflavone concentrations, platelet aggregation, blood lipids and fatty acid composition of plasma phospholipid in normal men. J Nutr 1996;126:2000-6.

52. Nestel PJ, Yamashita $T$. Sasahara $T$, et al. Soy isoflavones improve systemic arterial compliance but not plasma lipids in menopausal and perimenopausal women. Arterioscler Thromb Vasc Biol 1997;17:3392-8.

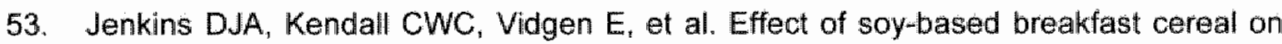
blood lipids and oxidized low-density lipoprotein. Metabolism 2000;49:1496-1500.

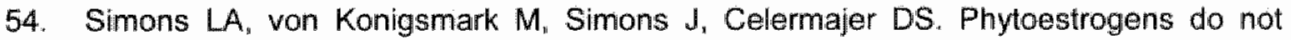
influence lipoprotein levels or endothelial function in healthy, postmenopausal women. Am J Cardiol 2000;85:1297-1301.

55. Hsu CS, Shen WW, Hsueh YM, Yeh SL. Soy isoflavone supplementation in postmenopausal women. Effects on plasma lipids, antioxidant enzyme activities and bone density. J Reprod Med 2001;46:221-6.

56. Samman $S$, Lyons Wall PM, Chan GS, Smith S.J. Petocz P. The effect of supplementation with isoflavones on plasma lipids and oxidisability of low density lipoprotein in premenopausal women. Atherosclerosis 1999;147:277-83.

57. Nestel P. . Pomeroy S, Kay S, et al. Isoflavones from red clover improve systemic arterial compliance but not plasma lipids in menopausal women. J Clin Endocrinol Metab 1999;84:895-8. 
58. Howes JB, sullivan $D$, Lai $N$, et al. The effects of dietary supplementation with isoflavones from red clover on the lipoprotein profiles of past menopausal women with mild to moderate hypercholesterolaemia. Atherosclerosis 2000;152:143-7.

59. Clifton-Bligh PB, Baber RJ, Fulcher GR, Nery ML, Moreton T. The effect of isoflavones extracted from red clover (Rirnostil) on lipid and bone metabolism. Menopause $2001 ; 8: 259-65$

60. Hodgson $\mathrm{JM}_{*}$ Puddey $1 \mathrm{~B}$, Beilin $\mathrm{LJ}$, Mori TA, Croft KD. Supplementation with isoflavonoid phytoestrogens does not alter serum lipid concentrations: a randomized controlled trial in humans: J Nutr 1998:128:728-32.

61. Lovati MR, Manzoni C, Corsini A, Granata A, Fumagalli $R_{t}$, Sirtori CR. 7 S Globulin from soybean is metabolized in human cell cultures by a specific uptake and degradation system. J Nutr 1996, 126:2831-42.

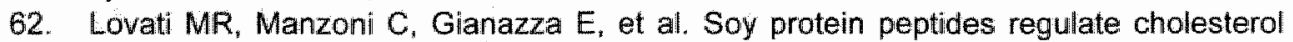
homeostasis in Hep $\mathrm{G} 2$ cells. Nutr 2000;130:2543-9.

63. Ling WH, Jones PJH. Minireview of dietary phytosterols: a review of metabolism, benefits and side effects. Life Sci 1995;57:195-206.

64. Heinemann $T$, Axtmann $G$, von Bergmann $K$. Comparison of intestinal absorption of cholesterol with different plant sterols in man. Eur J Clin Invest 1993;23:827-31.

65. Plat J, Mensink RP. Effects of plant sterols and stanols on lipid metabolism and cardiovascular risk. Nutr Metab Cardiovasc Dis 2001;11:31-40.

66. Miettinen TA, Gylling H. Regulation of cholesterol metabolism by dietary plant sterols: Curr Opin Lipidol 1999;10:9-14.

67. Plat J, Mensink RP. Effects of plant stanol esters on LDL receptor protein expression and on LDL receptor and HMG-CoA reductase mRNA expression on mononuclear blood cells of healthy men and women. FASEB J 2002;16:258-60.

68. Ikeda $I$, Tanaka $K$, Sugano $M_{0}$ Vahouny $G V$, Gallo $L L$. Inhibition of cholesterol absorption in rats by plant sterols. J Lipid Res 1988;29:1573-82.

69. Hallikainen MA, Uusitupa MIJ. Effects of 2 low-fat stanol ester-containing margarines on serum cholesterol concentrations as part of a low-fat diet in hypercholesterolemic subjects. Am J Clin Nutr 1999;69:403-10.

70. Gylling $H$, Miettinen TA. Cholesterol reduction by different plant stanol mixtures and with variable fat intake. Metabolism 1999:48:575-80.

71. Plat J, Mensink RP. Vegetable oil based versus wood based stanol ester mixtures: effects on serum lipids and hemostatic factors in non-hypercholesterolemic subjects. Atherosclerosis 2000;148:101-12.

72. Normén L. Dutta $P$, Lia $A$, Andersson $H$. Soy steral esters and $\beta$-sitostanol ester as inhibitors of cholesterol absorption in human small bowel. Am J Clin Nutr 2000;71:908 13.

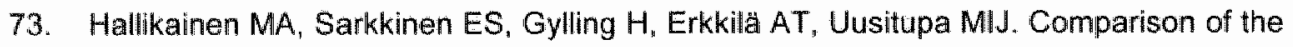
effects of plant sterol ester and plant stanol ester-enriched margarines in lowering serum cholesterol concentrations in hypercholesterolaemic subjects on a low-fat diet. Eur J Cin Nutr 2000;54:715-25.

74. Pllat J, van Onselen ENM, van Heugten MMA, Mensink RP. Effects on serum lipids, lipoproteins and fat soluble antioxidant concentrations of consumption frequency of margiarines and shortenings enriched with plant stanol esters. Eur $J$ Clin Nutr $2000 ; 54671-7$.

75. Jones PJH, Ntanios FY, Raeini-Sarjaz M, Vanstone CA. Cholesterol-lowering efficacy of a sitostanol-containing phytosterol mixture with a prudent diet in hyperlipidemic men. Am $J$ Clin Nutr 1999;69:1144-50. 
76. Blair SN, Capuzzil DM, Gottheb SO, Nguyen T, Morgan JM, Cater NB. Incremental reduction of serum total cholesterol and low-density lipoprotein cholesterol with the addition of plant stanol ester-containing spread to statin therapy: Am J Cardiol $2000 ; 86: 46-52$

77. Sierksma A, Weststrate JA, Mejjer GW. Spreads enriched with plant sterols, either esterified 4,4-dimethylsterols or free 4-desmethylsterols, and plasma total- and LDLcholesterol concentrations. Br J Nutr 1999;82:273-82.

78. Weststrate JA, Meijer GW. Plant sterol-enriched margarines and reduction of plasma total- and LDL-cholesterol concentrations in mormocholesterolaemic and mildy hyperchalesterolaemic subjects. Eur J Clin Nutr 1998:52:334-43.

79. Law M. Plant sterol and stanol margarines and health. BMU 2000;320:861-4.

80. Ostlund Jr RE, Spilburg CA, Stenson WF. Sitostanol administered in lecithin micelles potently reduces cholesterall absorption in humans. Am J Clin Nutr 1999;70:826-31.

81. Mensink RP, Ebbing $S_{\text {, Lindhout } M}$ "Plat $J$, van Heugten MMA. Effects of plant stanol esters supplied in low-fat yoghurt on serum lipids and lipoproteins, non-cholesterol sterols and fat soluble antioxidant concentrations. Atherosclerosis 2002:160:205-13.

82. Food labelling: health claims; plant sterol/stanol esters and coronary heart disease. Food and Drug Administration, HHS. Interim final rule. Fed Regist 2000;65:54685-739.

83. Plat $\mathbb{J}$, Kerckhoffs DAJM, Mensink RP. Therapeutic potential of plant sterols and stanols. Curr Opin Lipidol 2000;11:571-6.

84. Tammi A, Rönnemaa T, Gylling $H_{3}$ et al. Plant stanol ester margarine lowers serum total and low-density lipoprotein cholesterol concentrations of healthy children: the STRIP project. Special Turku Coronary Risk Factors Intervention Project. J Pediatr 2000;136:503-10.

85. Vuorio AF, Gylling $H$, Turtola $H$, Kontula $K_{*}$ Ketonen $P$, Miettinen TA. Stanol ester margarine alone and with simvastatin llowers serum cholesterol in families with familial hypercholesteralemia caused by the FH-North Karelia mutation. Arteriascler Thromb Vasc Biol 2000;20:500-6.

86. Agarwall KC. Therapeutic actions of garlic constituents. Med Res Rev 1996;16:111-24.

87. Amagase $H$, Petesch $B L$, Matsuura $H$, Kasuga $S$, Itakura $Y$. Intake of garlic and its bioactive components. J Nutr 2001:131:955S-62S.

88. Yeh $Y$, Liu L. Cholesterol-lowering effect of garlic extracts and organosulfur compounds: human and animal studies. I Nutr 2001;131:989S-93S.

89. Warshafsky S, Kamer RS, Sivak SL. Effect of garlic on total serum cholesterol. A metaanalysis. Ann Intern Med 1993;119:599-605.

90. Silagy C, Neil A. Garlic as a lipid lowering agent-a meta-analysis. J R Coll Physicians Lond 1994;28:39-45.

91. Neil HAW, Silagy CA, Lancaster T, et al. Garlic powder in the treatment of moderate hyperlipidaemia: a controlled trial and meta-analysis. J R Coll Physicians Lond $1996 ; 30: 329-34$.

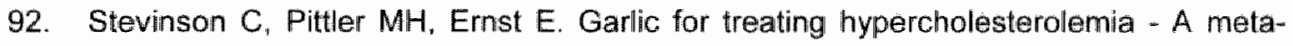
analysis of randomized clinical trials. Ann Intern Med 2000;133:420-9.

93. Ackermann RT, Mulrow CD, Ramirez G, Gardner CD, Morbidoni L. Lawrence VA. Garlic shows promise for improving some cardiovascular risk factors. Arch Intern Med 2001; 161:813-24.

94. Isaacsohn JL, Moser M, Stein EA, et al. Garlic powder and plasma lipids and lipoproteins: a multicenter, randomized, placebo-controlled trial. Arch Intern Med $1998 ; 158: 1189-94$. 
95. Berthold HK, Sudhop $T$, von Bergmann $K$. Effect of a garlic oil preparation on serum lipoproteins and cholesterol metabolism: a randomized controlled trial. JAMA $1998 ; 279: 1900=2$.

96. Superko HR, Krauss RM. Garlic powder, effect on plasma lipids, postprandial lipemia, low-density lipoprotein particle size, high-density lipoprotein subclass distribution and lipoprotein(a). J Am Coll Cardiol 2000;35:321-6.

97. Zhang $X \mathrm{XH}_{\text {, Lowe }} \mathrm{D}_{\text {. }}$ Gilles $\mathrm{P}_{\text {" }}$ et al. A randomized trial of the effects of garlic oil upon coronary heart disease risk factors in trained male runners. Blood Coagul Fibrinolysis $2000,11: 67-74$.

98. Gardner $C D$, Chatterjee LM, Carlson JJ. The effect of a garlic preparation on plasma lipid levels in moderately hypercholesterolemic aduits. Atherosiclerosis 2001;154:21320.

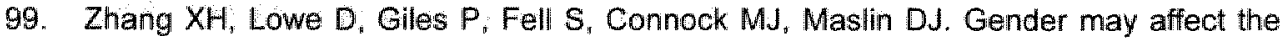
action of garlic oil on plasma cholesterol and glucose llevels of normal subjects. J Nutr $2001: 131: 1471-8$.

100. Kannar D. Wattanapenpaiboon $\mathbb{N}$, Savige GS, Wahlqvist ML. Hypocholesterolemic effect of an enteric-coated garlic supplement. J Am Coll Nutr 2001;20:225-31.

101. Matsuura $H$. Saponins in garlic as modifiers of the risk of cardiovascular disease. J Nutr 2001;131:1000S-5S:

102. Hunt SM, Groff JL. Advanced nutrition and human metabolism. St. Paul: West Publishing Company, 1990.

103. Kayden HJ, Traber MG. Absorption, lipoprotein transport, and regulation of plasma concentrations of vitamin $E$ in humans. $J$ Lipid Res 1993:34:343-58.

104. Qureshi AA, Mo H. Packer L, Peterson DM. Isolation and identification of novel tocotrienols from rice bran with hypocholesterolemic, antioxidant, and antitumor properties. J Agric Food Chem 2000;48:3130-40.

105. Kesaniemi YA, Grundy SM. Lack of effect of tocopherol on pllasma lipids and lipoproteins in man. Am J Clin Nutr 1982;36:224-8.

106. Qureshi AA, Burger WC, Peterson DM Elson CE. The structure of an inhibitor of cholesterol biosynthesis isolated from barley. J Biol Chem 1986;261: 0544-50.

107. Qureshi AA, Qureshi N, Hasler-Rapacz JO, et al. Dietary tocotrienols reduce concentrations of plasma cholesterol, apolipoprotein $\mathrm{B}$, thromboxane $\mathrm{B}_{2}$, and platelet factor 4 in pigs with inherited hyperlipidemias. Am J Clin Nutr 1991;53:1042S-6S.

108: Pearce BC, Parker RA, Deason ME, Qureshi AA, Wright JJK. Hypocholesterolemic activity of synthetic and natural tocotrienols. J Med Chem 1992;35:3595-606.

109. Khor HT, Ng TT. Effects of administration of $\alpha$-tocopherol and tocotrienols on serum lipids and liver HMG CoA reductase activity. Int J Food Sci Nutr 2000;51:S3-S11.

110. Parker RA, Pearce, BC, Clark RW, Gordon DA, Wright JJK. Tocotrienols regulate cholesterol production in mammalian cells by post-transcriptional suppression of 3 hydroxy-3-methylglutaryl coenzyme A reductase. J Biol Chem 1993;268:11230-8.

111. Pearce BC, Parker RA, Deason $M E_{n}$ et al. Inhibitors of cholesterol biosynthesis. 2 . Hypocholesterolemic and antioxidant activities of benzopyran and tetrahydronaphthalene analogues of the tocotrienols. J Med Chem 1994;37:526-41.

112. Tan DTS, Khor HT, Low WHS, Ali A, Gapor A. Effect of a palm-oil-vitamin $E$ concentrate on the serum and lipoprotein lipids in humans. Am $J$ Clin Nutr $1991 ; 53: 1027 \mathrm{~S}-30 \mathrm{~S}$.

113. Qureshi AA, Qureshi $N$, Wright JJK, et al. Lowering of serum chollesterol in hypercholesterolemic humans by tocotrienols (palmvitee). Am $J$ Clin Nutr 1991:53:1021S-6S. 
114. Qureshi AA, Bradlow BA, Brace $L$, et al. Response of hypercholesterolemic subjects to administration of tocotrienols. Lipids $1995,30: 1171-7$.

115. Wahlqvist ML, Krivokuca-Bogetic $Z$, Lo CS, Hage $B$, Smith $R$, Lukito W. Differential serum responses of tocopherols and tocotrienols during vitamin supplementation in hypercholesterolaemic individuals without change in coronary risk factors. Nuti Res 1992;12:S181-S201.

116. Tomeo AC, Geller $M_{\sharp}$ Watkins TR, Gapor $A$, Bierenbaum ML. Antioxidant effects of tocotrienols in patients with hyperlipidemia and carotid stenosis. Lipids $1995,30: 1179$. 83.

117. Mensink RP, van Houwelingen AC, Kromhout D, Hornstra G. A vitamin E concentrate rich in tocotrienols had no effect on serum lipids, lipoproteins, or platelet function in men with mildly elevated serum lipid concentrations. Am J Clin Nutr 1999;69:213-9.

118. On Byrne D, Grundy S, Packer L, et all. Studies of LDL oxidation following $a-y-$ or $\delta$ tocotrienyl acetate supplementation of hypercholesterolemic humans. Free Radiac Biol Med 2000;29:834-45.

119. Qureshi AA, Pearce BC, Nor RM, Gapor A, Peterson DM, Elson GE. Dietary aw tocopherol attenuates the impact of $\gamma$-tocotrienol on hepatic 3-hydroxy-3-methylglutaryl coenzyme A reductase activity in chickens. J Nutr 1996:126:389-94.

120. Theriault A, Wang Q, Gapor A, Adeli K. Effects of $\gamma$-tocotrienol on apoB synthesis, degradation, and secretion in HepG2 cells. Arterioscler Thromb Vasc Biol 1999;19:70412.

121. Watkins $T$, Lenz $P$, Gapor $A$, Struck $M$, Tomeo A, Bierenbaum M, y-Tocotrienol as a hypocholesterolemic and antioxidant agent in rats fed atherogenic diets. Lipids $1993: 28: 1113-8$.

122. Rukmini $C$. Raghuram TC. Nutritional and biochemical aspects of the hypolipidemic action of rice bran oil: a review. J Am Coll Nutr 1991;10:593-601.

123. Qureshi AA, Bradlow BA, Salser WA, Brace LD. Novel tocotrienols of rice bran modulate cardiovascular disease risk parameters of hypercholesterolemic humans. J Nutr Biochem 1997;8:290-8.

124. Efendy JL, Simmons DL, Campbell $\mathrm{GR}$, Campbell JH. The effect of the aged garlic extract, "Kyolic", on the development of experimental atherosclerosis. Atherosclerosis 1997:132:37-42. 



\section{Chapter}

Effects of a tocotrienol-rich fraction from rice bran oil on serum lipoproteins, markers for cholesterol synthesis and absorption, and hemostatic parameters in hypercholesterolemic subjects

Daniëlle AJM Kerckhoffs ${ }^{1,2}$ "Ronald $P$ Mensink ${ }^{1,2}$, Tjerk WA de Bruin ${ }^{3}$, Elke A Trautwein $^{4}$, Fred Brouns ${ }^{2,5}$ and Gerard Hornstra ${ }^{2}$

${ }^{1}$ Department of Human Biology and ${ }^{2}$ Nutrition and Toxicology Research Institute Maastricht (NUTRIM), Maastricht University, Maastricht, ${ }^{3}$ Department of Internal Medicine, University Hospital Maastricht, Maastricht, ${ }^{4}$ at present Unilever Research, Vlaardingen, The Netherlands, and ${ }^{5}$ at present Cerestar Vilvoorde R\&D Centre, Vilvoorde, Belgium

Submitted for publication 


\section{Abstract}

Background: Tocotrienols have been reported to lower LDL cholesterol concentrations by reducing HMG-CoA reductase activity and to improve some hemostatic parameters. Results of human studies, however, are conflicting.

Objective: To compare the effects of a tocotrienol-rich fraction from rice bran oil (TRF-RBO) with those of pravastatin (an HMG-CoA reductase inhibitor) on serum lipoproteins, markers for cholesterol synthesis and absorption, and hemostatic function in hypercholesterolemic subjects.

Design: In a randomized, double-blind, placebo-controlled parallel trial, 33 men and 38 women followed a cholesterol-lowering diet for three weeks. For the next six weeks, participants continued their diets and consumed placebo $(n=24)$, pravastatin (40 $\mathrm{mg} / \mathrm{d}, n=23$ ) or TRF-RBO ( $42 \mathrm{mg} / \mathrm{d}, n=24$ ) capsules that provided daily 13.44 $\mathrm{mg} a$-tocopherol, $0.64 \mathrm{mg} \beta$-tocopherol, $7.32 \mathrm{mg} \gamma$-tocopherol, $1.12 \mathrm{mg} \delta$-tocopherol, $3.96 \mathrm{mg} \alpha$-tocotrienol, $<0.32 \mathrm{mg} \beta$-tocotrienol, $14.4 \mathrm{mg} \gamma$-tocotrienol and $0.64 \mathrm{mg} \delta$ tocotrienol.

Results: Compared with the control group, no statistically significant effects of TRFRBO were found on serum lipoproteins or markers for cholesterol synthesis (lathosterol) and absorption (campesterol). In the pravastatin group, however, LDL cholesterol decreased by $1.83 \pm 0.18 \mathrm{mmol} / \mathrm{L}$ or $32.2 \pm 2.9 \%$ versus changes in the placebo group of $-0.02 \pm 0.08 \mathrm{mmol} / \mathrm{L}(P<0.001)$ and in the TRF-RBO group of -0.23 $\pm 0.10 \mathrm{mmol} / \mathrm{L}(P<0.001)$. Lathosterol declined with pravastatin by $0.59 \pm 0.07$ umol $/ \mathrm{mmol}$ cholesterol or $44.3 \pm 3.9 \%$ versus changes in the placebo $(P<0.001)$ and TRF-RBO group $(P<0.001)$. Campesterol increased with pravastatin by $0.51 \pm$ $0.09 \mu \mathrm{mol} / \mathrm{mmol}$ cholesterol or $16.1 \pm 2.8 \%$ versus the change in the placebo group $(P=0.005)$. Neither TRF-RBO nor pravastatin did affect $\mathrm{TXB}_{2}$ production of platelets in clotting blood, or WWF and factor VIIc activities, or factor VIlla and fibrinogen concentrations.

Conclusions: TRF-RBO supplements did not affect cholesterol metabolism or hemostatic parameters in hypercholesterolemic subjects. 


\section{Introduction}

Vitamin $E$ is a generic term for tocopherols and tocotrienols, which consist of a chromanol ring linked to a phytyl side chain. The four forms $(\alpha, \beta, \gamma$ and $\delta$ ) of tocopherols and corresponding tocotrienols are based on the number and position of methyl groups on their chromanol ring. The tocotrienols differ from the tocopherols in having an unsaturated phytyl tail (1).

Epidemiological data (2) have suggested that tocopherols may reduce the risk of coronary heart disease, possibly due to a protective effect of tocopherols on oxidation of LDLs (3). Animal studies have further demonstrated that tocotrienols decreased diet-induced atherosclerotic lesions (4). Unlike tocopherols (5), tocotrienols may protect against atherosclerosis beyond their antioxidant properties through lowering of cholesterol concentrations as demonstrated in various animal species (6-8). This effect may be mediated through post-transcriptional inhibition of the activity of 3-hydroxy-3-methylglutaryl-coenzyme A (HMG-CoA) reductase, the rate limiting enzyme in the biosynthesis of cholesterol $(7,9)$. In this respect, $\delta$ tocotrienol and $\gamma$-tocotrienol, that lack 5-methyl substitution in the chromanol ring, may be more potent than $\alpha$-tocotrienol, whereas $\beta$-tocotrienol has only a limited effect (7). Also, cholesterol synthesis and apolipoprotein B secretion were reduced after treatment of HepG2 cells with $\gamma$-tocotrienol (10). Human studies, however, about the effects of tocotrienol supplementation on serum lipoprotein concentrations have provided conflicting results. A tocotrienol-rich fraction from palm oil (Palmvitee) decreased cholesterol concentrations in some human studies (11-13), whereas others (14-17) have reported no beneficial effects on the lipoprotein profile.

Tocotrienols from rice bran oil appear to be even more effective in lowering cholesterol concentrations in humans $(18,19)$ and animals $(20-22)$. In addition, favorable effects have been found on platelet function after supplementation with a tocotrienol-rich fraction from rice bran oil (18). These promising effects have been ascribed to two novel tocotrienols, which have been isolated from rice bran oil and identified as desmethyl $\left(P_{21}\right)$ and didesmethyl $\left(P_{25}\right)$ tocotrienols (18-20). Also, rice bran oil contains a higher amount of $\gamma$-tocotrienol than palm oil (23). On the basis of these findings, the major aim of the present study was to investigate the effects of a tocotrienol-rich fraction from rice bran oil (TRF-RBO) an serum lipids and lipoproteins and on markers for cholesterol synthesis and absorption in subjects with hypercholesterolemia on a cholesterol-lowering diet. Effects were compared with those of pravastatin, an HMG-CoA reductase inhibitor. Finally, changes in some hemostatic parameters were examined. 


\section{Subjects and methods}

\section{Subjects}

Volunteers with hypercholesterolemia were recruited among the general population of Maastricht and surroundings by posters in public buildings and through advertisements in local newspapers and on local television or from a patient population at the Department of Internal Medicine (University Hospital Maastricht. The Netherlands). All subjects were given a detailed description of the study before they gave their written informed consent. Sewenty-two volunteers were selected for the study according to the following inclusion criteria: aged between 40 and $70 y$, stable body weight (weight gain or loss below $3 \mathrm{~kg}$ in the past three months), body mass index (BMI) below $30 \mathrm{~kg} / \mathrm{m}^{2}$, diastollic blood pressure below $95 \mathrm{mmHg}$ systolic blood pressure below $160 \mathrm{mmHg}$, serum concentrations of total cholesterol above $7.0 \mathrm{mmol} / \mathrm{L}$ and of triacylglycerol below $4.5 \mathrm{mmol} / \mathbb{L}$ for subjects who did not use lipidlowering drugs, no pregnancy or breast-feeding. no glucosuria or proteinuria, no history of coronary heart disease, no history of kidney, liver or muscle diseases, no malignancy in the past five years, and no use of medication known to affect hemostasis. Subjects who were treated with lipid-lowering medication could also participate, but had to stop their therapy two weeks before the start of the study. Blood donation or participation in another biomedical trial was not allowed within 4 weeks before the start of the study or during the study.

The study protocol was approved by the Ethics Committee of the Maastricht University. One woman withdrew in the fourth week of the study because of muscle cramps possibly due to pravastatin treatment. All other seventy-one volunteers, 33 men and 38 women, completed the study. Men had a mean age of $54 \pm 1$ (SEM) y. a mean body weight of $84.5 \pm 1.8 \mathrm{~kg}$, a mean height of $1.78 \pm 0.01 \mathrm{~m}$, and a mean BMI of $26.5 \pm 0.4 \mathrm{~kg} / \mathrm{m}^{2}$. The mean age of women was $58 \pm 1 \mathrm{y}$. They had a mean weight of $69.3 \pm 1.5 \mathrm{~kg}$, a mean height of $1.65 \pm 0.01 \mathrm{~m}$, and a mean BM\| of $25.4 \pm 0.5$ $\mathrm{kg} / \mathrm{m}^{2}$. Mean diastolic blood pressure was $81 \pm 1 \mathrm{mmHg}$ in men, and $79 \pm 1 \mathrm{mmHg}$ in women. The mean systolic blood pressure was $133 \pm 2 \mathrm{mmHg}$ in men, and $128 \pm 2$ $\mathrm{mmHg}$ in women. None of the subjects had glucosuria or proteinuria. The eight men and ten women, who used lipid-lowering drugs, stopped their statin therapy two weeks before the start of the trial. At day 0 of the study, mean fasting concentrations of serum total cholesterol and triacylglycerol in men were $7.40 \pm 0.16 \mathrm{mmol} / \mathrm{L}$ and $1.51 \pm 0.11 \mathrm{mmol} / \mathrm{L}$, respectively. In women, these values were $7.58 \pm 0.12 \mathrm{mmol} / \mathrm{L}$ and $1.13 \pm 0.09 \mathrm{mmol} / \mathrm{L}$, respectively. One woman used medication known to lower blood pressure. Seven men and six women were smokers. Two women used oral contraceptives and twenty-one women were postmenopausal. 


\section{Experimental design}

The study was a randomized, double-blind, placebo-controlled parallel trial. During the study period of nine weeks, all subjects followed a cholesterol-lowering diet according to the Dutch dietary guidelines (24), in which the intake of fat is 30-35 percent of energy $(\mathrm{En} \%)$ and of saturated fat plus trans fatty acids maximal $10 \mathrm{En} \%$. The daily cholesterol intake was restricted to a maximum level of $300 \mathrm{mg}$. This diet is comparable with a National Cholesterol Education Program (NCEP) step I diet (25). Before the start of the study, subjects had to fill in a food frequency list to estimate their habitual intakes of energy and nutrients for the last four weeks. These food frequency lists were immediately checked by a registered dietician in the presence of the subjects. On the basis of the subjects' current dietary habits, individual instructions were given to achieve adherence to the recommended diet. In addition, the subjects together with their partners, if the participant did not usually prepare the diner at home, met in small groups for information about cholesterol-lowering dietary therapy. A recipe booklet with background information about the dietary guidelines was also provided. During the study, each subject visited a dietician once a week.

During the first three weeks of the experiment (run-in period), all subjects only used the cholesterol-lowering diet. Thereafter, the subjects were randomly divided into three treatment groups, stratified for age and gender. For the next six weeks, the three groups also had to take daily five capsules. The placebo group consumed daily four placebo capsules for TRF-RBO, two after supper and two just before bedtime, each consisting of $400 \mathrm{mg}$ of corn oil containing $4.92 \mathrm{mg}$ tocopherols and tocotrienols (1.64 mg $\alpha$-tocopherol, $0.04 \mathrm{mg} \beta$-tocopherol, $1.00 \mathrm{mg} \gamma$-tocopherol, $0.12 \mathrm{mg} \delta$ tocopherol, $0.56 \mathrm{mg} \alpha$-tocotrienol, $<0.08 \mathrm{mg} \beta$-tocotrienol, $1.48 \mathrm{mg} \gamma$-tocotrienol, 0.08 $\mathrm{mg} \delta$-tocotrienol; Table 1) plus one placebo capsule for pravastatin (cellulose micro cristallinun $\mathrm{Ph}$ 102) just before bedtime. The second group took daily four placebo capsules for TRF-RBO, two after supper and two just before bedtime, plus one pravastatin capsule (Bristol-Myers Squibb, The Netherlands) of $40 \mathrm{mg}$ just before bedtime. The third group used daily four TRF-RBO capsules, two after supper and two just before bedtime, each consisting of $400 \mathrm{mg}$ of corn oil containing $10.38 \mathrm{mg}$ tocopherols and tocotrienols $(3.36 \mathrm{mg} \alpha$-tocopherol, $0.16 \mathrm{mg} \beta$-tocopherol, $1.83 \mathrm{mg}$ $\gamma$-tocopherol, $0.28 \mathrm{mg} \delta$-tocopherol, $0.99 \mathrm{mg} \alpha$-tocotrienol, $<0.08 \mathrm{mg} \beta$-tocotrienol, $3.60 \mathrm{mg} \gamma$-tocotrienol, $0.16 \mathrm{mg} \delta$-tocotrienol; Table 1) plus one placebo capsule for pravastatin just before bedtime. The volunteers received their number-coded capsules from the pharmacy of the University Hospital Maastricht at weeks 3 and 6 of the study. Compliance was determined by counting the remaining capsules that were collected at the end of the treatment period. TRF-RBO capsules and placebo capsules for TRF-RBO as well as data on their compositions were provided by 
Bionutrics-Lipogenics, Phoenix, USA. Since only results for the total amount of tocopherols and tocotrienols in the capsules were provided and not for their individual isomers, capsules from the same batch were also analyzed by the Novartis Central Analytics, Basel, Switzerland. According to chemical analysis in Basel, the placebo capsules contained more tocopherols and tocotrienols. The presence of the so-called didesmethyl $\left(P_{25}\right)$ tocotrienol (18-20) could not be demonstrated by the laboratory from Basel, although a standard was available ( $d, 1-P_{25}$, Procyon Pharmaceuticals).

\section{TABLE 1}

Composition of the placebo capsules for TRF-RBO and TRF-RBO capsules (mg/capsule) ${ }^{1}$

\begin{tabular}{|c|c|c|c|c|}
\hline & \multicolumn{2}{|c|}{ Placebo capsule } & \multicolumn{2}{|c|}{ TRF-RBO capsule } \\
\hline & Basel & Phoenix & Biasiel & Phoenix \\
\hline a-Tocopherol & 1.64 & & 3.36 & \\
\hline$\beta$-Tocopheral & 0.04 & & 0.16 & \\
\hline$\gamma$-Tocopheral & 1.00 & & 1.83 & \\
\hline 8-Tocopheral & 0.12 & & 0.28 & \\
\hline Sum Tocopherols & 2.80 & 1.40 & 5.63 & 6.00 \\
\hline$a-T o c o t r i e n o l$ & 0.56 & & 0.99 & \\
\hline$\beta$-Tacotrienal & $<0.08$ & & $<0.08$ & \\
\hline$\gamma$-Tocotrienall & 1.48 & & 3.60 & \\
\hline 8 -Tocotrienol & 0.08 & & 0.16 & \\
\hline Sum Tocotrienols & 2.12 & $\| .12$ & 4.75 & 6.00 \\
\hline
\end{tabular}

'For six weeks, the subjects had to take daily four placebo capsules for TRF-RBO or four TRF-RBO capsules. TRF.RBO capsules and placebo capsules for TRF-RBO as well as data on their compositions were provided by Bionutrics-Lipogenics, Phoenix, USA. Foll analysis of the different isomers, capsules from the same batch were also analyzed by the Nowartis Central Analytics. Basel. Switzerland. The presence of the so-called didesmethyl $\left(\mathrm{P}_{\mathrm{z}}\right)$ tocotrienol (18-20) could not be demonstrated by the laboratory from Basel, although a standard was avaitable (d, $1-\mathrm{P}_{28}$. Procyon Phamaceuticals). TRF-RRB, tocotrienol-rich fraction from rice bran oil.

The subjects were urged not to change their smoking and drinking habits, level of physical activity, and use of oral contraceptives throughout the experiment. Furthermore, they were not allowed to use vitamin-supplements during the study. The participants were only allowed to use filtered or instant coffee, as unfiltered coffee may increase serum concentrations of cholesterol and triacylglycerol (26). They recorded in diaries any signs of illness, medication used, menstrual phase, alcohol consumption and any deviations from the study protocol. 
Body weight without shoes and heavy clothes was recorded every week. In ordier to estimate each subjects' intake of energy and nutrients throughout the study, subjects recorded their food intake for the last four weeks by filling in food frequency lists at the end of the run-in period and at the end of the treatment period. Food frequency lists were checked by a registered dietician in the presence of the subjects.

\section{Blood sampling}

The volunteers fasted overnight, did not use alcohol the previous day and did not smoke on the morning before blood sampling. Venous blood samples were taken between $8.00 \mathrm{~h}$ and $11.00 \mathrm{~h} \mathrm{AM}$ at day 0 and at weeks 2 and 3 (run-in period), and at weeks $4,5,8$ and 9 (treatment period). Blood was sampled from a forearm vein using vacutainers under minimal stasis with the participant in a supine position for at least 5 minutes. The vacutainers were kept at room temperature before and after blood sampling. All venipunctures were generally done by the same person, in the same room, and mostly at the same time of the day.

First, $10 \mathrm{ml}$ blood was collected in a serum tube (CORVAC; Sherwood Medical, St. Louis, USA) for measurements of total cholesterol, HDL cholesterol and triacylglycerol at day 0 , weeks $2,3,4,5,8$ and 9, for analyses of apolipoprotein (apo) A-I, apo B, lipoprotein(a) $(L p(a))$ and markers for cholesterol synthesis and absorption at weeks $2,3,8$ and 9 , and for determination of liver and kidney enzymes and $\mathrm{C}$-reactive protein at day 0 and week 9 . At least one hour after venipuncture, serum was obtained by centrifuging at $2000 \times \mathrm{g}$ for $30 \mathrm{~min}$ at $4{ }^{\circ} \mathrm{C}$, which was stored at $-80^{\circ} \mathrm{C}$.

For analyses of hemostatic parameters at weeks $2,3,8$ and $9,5 \mathrm{ml}$ blood was collected in a tube (Diatube $\mathrm{H}$, Diagnostica Stago, Asnières-sur-Seine, France) containing a mixture of citrate theophylline, adenosine and dipyridamole (CTAD). After centrifuging at $2000 \times \mathrm{g}$ for $30 \mathrm{~min}$ at room temperature within one hour after venipuncture, the midportion of the plasma was taken. Plasma samples were snapfrozen in liquild nitrogen and stored at $-80^{\circ} \mathrm{C}$.

Thereafter, $10 \mathrm{ml}$ blood was collected in an EDTA tube (Sherwood Medical, Ballymoney, Northern Ireland) for determination of hematologic parameters at weeks 3 and 9.

Finally, a $10 \mathrm{ml}$ serum tube was filled and then placed in a warm water bath at 37.5 ${ }^{\circ} \mathrm{C}$ for exactly one hour. Serum was obtained by centrifuging at $2000 \mathrm{xg}$ for $30 \mathrm{~min}$ at $4{ }^{\circ} \mathrm{C}$. The serum samples were frozen in liquid nitrogen and stored at $-80^{\circ} \mathrm{C}$ for measurement of thromboxane $B_{2}\left(T \times B_{2}\right)$ concentrations at weeks $2,3,8$ and 9 . 


\section{Analyses}

\section{Lipids and hipoproteins}

Concentrations of total cholesterol (CHOD-PAP method; Monotest cholesterol, Boehringer Mannheim GmbH, Mannheim, Germany). HDL chalesterol (precipitation method by adding a mixture of phosphotungstic acid and magnesium ions to the sample, and CHOD-PAP method; Monotest cholesterol, Boehringer Mannheim $\mathrm{GmbH}$, Mannheim, Germany) and triacylglycerol with correction for free glycerol (GPO-Trinder, Sigma Diagnostics, St. Louis, USA) were measured in serum enzymatically. Concentrations of LDL cholesterol were calculated with the Friedewald equation (27). The coefficients of variation within runs for serum total cholesterol, HDL cholesterol and triacylglycerol were $1.2 \%, 4.7 \%$, and $3.0 \%$, respectively. For all analyses, the samples from one subject were analyzed within one run at the end of the trial.

Apo A-1 and apo B concentrations in serum were analyzed using an immunoturbidimetric method with anti-apo $A-1$ antiserum from sheep and anti-apo $B$ antiserum from rabbits (Uni-kit apo A-1 and Uni-kit apo $B_{i}$ Hoffmann-La Roche, Basel, Switzerland). The concentration of $L p(a)$ in serum was determined by using an enzyme linked immonosorbent assay (ELISA) (TintElyze $B p(a)$, Biopool $A B$, Umeå, Sweden). The coefficients of variation within runs for apo $A-1$, apo $B$ and $L p(a)$ were $2.4 \%, 4.0 \%$ and $10.2 \%$, respectively. Before analyses, samples of weeks 2 and 3 (run-in period) as well as of weeks 8 and 9 (treatment period) were pooled.

\section{Markers for cholesterol synthesis and absorption}

Before analyses of markers for cholesterol synthesis (lathosterol) and absorption (campesterol), serum samples obtained at weeks 2 and 3 (run-in period) and at weeks 8 and 9 (treatment period) were pooled. Methods have recently been described in detail (28). Briefly, $5 \beta$-cholestan- $3 \alpha$-ol was added to the samples and used as an internal standard for quantification of lathosterol, campesterol and sitosterol. Another internal standard, $5 \alpha$-cholestane, was used to determine the amaunt of cholesterol. After saponification of the sample with $10 \mathrm{M}$ ethanolic $\mathrm{KOH}$, the unsaponifiable components were extracted with hexane and separated as trimethylsilylethers on a gas chromatograph (GC 8000 Top, Carlo Erba, ThermoQuest Italia S.p.A., Milan, Italy).

\section{Hemostatic variables}

Serum and plasma samples of the run-in period (weeks 2 and 3 ) and of the treatment period (weeks 8 and 9) were pooled before analyses of $\mathrm{TXB}_{2}$ production of the 
platelets in clotting blood and blood coagulation parameters: The TX $\mathrm{B}_{2}$ concentration in serum was analyzed using an enzyme immunoassay kit (Cayman Chemical Company, Ann Arbor, USA). The von Willebrand Factor (NWF) and factor VII coagulant (factor $\mathrm{V} / \mathrm{l} \mathrm{c}$ ) activities were expressed as a percentage of a standard pool plasma obtained from 50 healthy volunteers, 25 men and 25 women with a mean age of $30 \mathrm{y}$. The VWF activity in plasma was analyzed by an enzyme linked immunosorbent assay (ELISA) (29). Factor Vllc activity in plasma was measured with a clotting test as described by van Dam-Mieras et al. (30): A clotting assay was used for analysis of activated factor VII (factor VIla) (31) in plasma (STACLOT VIlla-rTF, Diagnostica Stago , Asnières-sur-Seine, France). Plasma fibrinogen was determined according to the method of Clauss (32). The coefficients of variation within runs for $\mathrm{TxB}_{2}$, WWF, factor VIIc, factor VIla and fibrinogen were $9.5 \%, 6.9 \%, 1.2 \%, 1.5 \%$ and $3.7 \%$, respectively.

\section{Safety parameters}

Serum samples for analyses of liver and kidney enzymes (total bilirubin, asparagineaminotransferase (ASAT), alanine-aminotransferase (ALAT), alcalic phosphatase, $\gamma$ glutamyl transpeptidase $(\gamma-G T)$ and creatinine), and C-reactive protein were determined at the Department of Clinical Chemistry, University Hospital Maastricht, Maastricht, The Netherlands (Beckman Synchron CX7 Clinical Systems, Beckman Instuments, Inc., Brea, USA). Various hematologic parameters (white blood cell count, percentages and numbers of lymphocytes, mononuclear cells and granulocytes, red blood cell count, hemoglobin concentration, hematocrit, mean corpuscular volume, mean corpuscular hemoglobin, mean corpuscular hemoglobin concentration, red cell distribution width, platelet count and mean platelet volume) were determined using a Coulter Counter (Coulteri MD Series, Coulter Corporation, Hialeah, Florida). None of these safety parameters were affected by the three treatments (data not shown).

\section{Statistics}

The power of this experimental design to detect a difference in serum LDL concentrations of $0.35 \mathrm{mmol} / \mathrm{L}$ between two treatments was $80 \%$. The results of the 71 out of 72 participants who completed the study were included in the analyses. Since one subject from the placebo group, four subjects from the pravastatin group and two subjects from the TRF-RBO group were prescribed during the study to use prostaglandin synthetase inhibitors known to affect the $\mathrm{TXB}_{2}$ production of the platelets in clotting blood, the data of these participants were excluded from the 
analyses of serum $T \times B_{2}$. The responses to treatment were calculated for each subject as the difference between values obtained at the end of the treatment period (means of values of weeks 8 and 9) and the run-in period (means of values of weeks 2 and 3). Differences in changes between the three treatment groups were analyzed by one-factor analysis of variance (ANOVA). The significance level was corrected for three group comparisons to one third of the customary $5 \%$, using the Bonferroni multi comparison method. Therefore, a value of $P<0.0167$ was considered significant. At the end of the run-in period, all measured variables were not significantly different between the three groups (one-factor ANOVA). Because changes in concentrations of Lp(a), liver and kidney enzymes (total billirubin, ASAT, ALAT, alcalic phosphatase. $\gamma$-GT and creatinine) and C-reactive protein were not normally distributed; these changes were analyzed with the non-parametric Kruskal-Wallis test. Normally distributed variables are presented as means \pm SEM and non-normally distributed values as medians with ranges in parentheses. All statistical analyses were performed with StatView 5.0.

\section{Results}

\section{Dietary intake and body weight}

The placebo group consumed daily on average $3.74 \pm 0.07$ (range 2.71-4.00) placebo capsules for TRF-RBO and $0.95 \pm 0.01$ (range $0.83-1.00$ ) placebo capsules for pravastatin. In the pravastatin group, the mean daily intake of placebo capsules for TRF-RBO was $3.91 \pm 0.03$ (range 3.62-4.19) and of pravastatin capsules $0.96 \pm$ 0.01 (range $0.83-1.00$ ). The TRF-RBO group used daily $3.81 \pm 0.05$ (range 2.95 4.17) TRF-RBO capsules and $0.95 \pm 0.02$ (range $0.69-1.00$ ) placebo capsules for pravastatin.

As shown in Table 2, the decrease in the percentage of energy from total fat of $2.4 \pm$ $0.8 \mathrm{En} \%$ in the pravastatin group was significantly different from the increase of $0.3 \pm$ 0.6 En\% in the TRF-RBO group $(P=0.010)$. Changes in the intake of energy and of other nutrients did not significantly differ between the three groups. Body weights did not significantly change during the treatment period (placebo group, $-0.3 \pm 0.2 \mathrm{~kg}$; pravastatin group, $-0.5 \pm 0.1 \mathrm{~kg}$; TRF-RBO group, $-0.2 \pm 0.2 \mathrm{~kg}$ ). 


\section{TABLE 2}

The average daily intake of energy and nutrients during the study

\begin{tabular}{lccc}
\hline & Placebo group & Pravastatin group & TRF-RBO gro \\
\hline Energy (MUJ/d) & & & \\
$\quad$ Run-in & $8.7 \pm 0.4$ & $8.9 \pm 0.4$ & $9.1 \pm 0.5$ \\
Treatment & $8.6 \pm 0.4$ & $8.4 \pm 0.4$ & $8.4 \pm 0.4$ \\
Change & $-0.1 \pm 0.2$ & $-0.4 \pm 0.2$ & $-0.7 \pm 0.3$ \\
Protein (En\%) & & & \\
Run-in & $16.9 \pm 0.4$ & $17.3 \pm 0.5$ & $16.5 \pm 0.5$ \\
Treatment & $16.7 \pm 0.4$ & $17.0 \pm 0.5$ & $16.2 \pm 0.4$ \\
Change & $-0.2 \pm 0.4$ & $-0.3 \pm 0.4$ & $-0.2 \pm 0.4$
\end{tabular}

Fat $(E n \%)$

Run-in

Treatment

Change

SFA (En\%)

Run-in

Treatment

Change

MUFA (En\%)

Run-in

Treatment

Change

PUFA (En\%)

Run-in

Treatment

Change

Carbohydrates (En\%)

Rum-in

Treatment

Change

Alcohol (En\%)

Rum-in

Treatment

Change
$30.7 \pm 0.9$

$29.5 \pm 1.0$

$-1.2 \pm 0.7$

$10.1 \pm 0.4$

$9.9 \pm 0.4$

$-0.2 \pm 0.4$

$10.9 \pm 0.4$

$10.5 \pm 0.5$

$-0.5 \pm 0.4$

$7.5 \pm 0.3$

$7.0 \pm 0.3$

$-0.4 \pm 0.3$

$47.1 \pm 0.9$

$48.3 \pm 0.8$

$\$ .2 \pm 0.7$

$4.9 \pm 0.7$

$5.0 \pm 0.8$

$0.2 \pm 0.4$
$30.9 \pm 0.9$

$28.5 \pm 1.0$

$-2.4 \pm 0.8^{2}$

$10.6 \pm 0.5$

$9.3 \pm 0.5$

$-1.3 \pm 0.5$

$10.8 \pm 0.4$

$10.1 \pm 0.5$

$-0.7 \pm 0.4$

$7.3 \pm 0.3$

$7.1 \pm 0.3$

$-0.2 \pm 0.3$

$47.9 \pm 1.1$

$49.7 \pm 1.1$

$1.9 \pm 0.8$

$3.3 \pm 1.1$

$4.2 \pm 1.0$

$0.8 \pm 0.7$
$3.8 \pm 0.9$

$3.4 \pm 0.8$

$30.1 \pm 0.9$

$30.4 \pm 0.8$

$0.3 \pm 0.6$

$10.2 \pm 0.5$

$10.0 \pm 0.4$

$-0.2 \pm 0.3$

$10.6 \pm 0.5$

$10.6 \pm 0.4$

$0.1 \pm 0.3$

$7.2 \pm 0.3$

$7.6 \pm 0.3$

$0.4 \pm 0.3$

$49.0 \pm 1.3$

$49.4 \pm 1.2$

$0.4 \pm 0.7$

$-0.4 \pm 0.5$ 


\section{TABLE 2 Continued}

Cholesterol (mg/d)

Run-in
Treatment
Change

$$
\begin{array}{r}
195 \pm 11 \\
186 \pm 11 \\
-9 \pm 7
\end{array}
$$$$
211 \pm 16
$$$$
196 \pm 13
$$$$
176 \pm 9
$$$$
185 \pm 10
$$$$
-35 \pm 12
$$$$
-11 \pm 10
$$

Dietary fiber ( $\mathrm{g} / \mathrm{MJ})$

\section{Run-ín \\ Treatment}

change

Vitamin E (mg/d)
$3.3 \pm 0.1$

$3.4 \pm 0.1$

$0.1 \pm 0.1$
$3.3 \pm 02$

$3.5 \pm 0.2$

$0.2 \pm 0.1$
$3.4 \pm 0.2$

$3.4 \pm 0.2$

$0.0 \pm 0.1$
Run-in

Treatment

Change
$13.7 \pm 0.8$

$12.9 * 0.7$

$-0.8 \pm 0.6$
$14.4 \pm 1.0$

$13.2 \pm 0.9$

$-1.2 \pm 0.5$
$13.9 \pm 0.8$

$13.5 \pm 0.6$

$-0.4 \pm 0.7$

\footnotetext{
"Values are means \pm SEM. Seventy-one wolunteers followed a cholesterol-lowering diet for three weeks (run-in period). For the next six weeks (treatment period), subjects continued their diets and consumed placebo ( $n=$ 24). pravastatin ( $40 \mathrm{mg} / \mathrm{d}, n=23$ ) or TRF-RBO (42 mg/d, $n=24$ ) capsules. Food intake was calculated from a food frequency list filled in at the end of each period. TRF-RBO, tocotrienol-rich fraction from rice bran oil; SFA, saturated fatty acids; MUFA, monounsaturated fatty acids; PUFA, polyunsaturated fatty acids.

${ }^{2}$ Significantly different from the TRF-RBO group: ${ }^{2} P<0.017$.
} 


\section{Lipids and lipoproteins}

Serum total cholesterol concentrations rose by $0.05 \pm 0.09 \mathrm{mmol} / \mathrm{L}$ in the placebo group, and decreased by $1.85 \pm 0.18 \mathrm{mmol} / \mathrm{L}$ or $24.8 \pm 2.2 \%$ in the pravastatin group and by $0.11 \pm 0.10 \mathrm{mmol} / \mathrm{L}$ in the TRF-RBO group (Table 3 ). The reduction in serum total cholesterol concentrations in the pravastatin group was significantly different from the changes in both the placebo $(95 \%$ confidence interval $(\mathrm{Cl})$ for the difference in changes between the two groups: -2.29 to $-1.52 \mathrm{mmol} / \mathrm{L} ; P<0.001)$ and TRF-RBO group ( $95 \% \mathrm{Cl}$ for the difference: -2.14 to $\left.-1.33 \mathrm{mmol} / \mathrm{L}_{;} P<0.001\right)$. Changes in total cholesterol were not significantly different between the TRF-RBO and placebo groups $(95 \% \mathrm{Cl}$ for the difference: -0.44 to $0.11 \mathrm{mmol} / \mathrm{L} ; P=0.355)$. In the pravastatin group, a comparable decrease was found in LDL cholesterol concentrations $(-1.83 \pm 0.18 \mathrm{mmol} / \mathrm{L}$ or $-32.2 \pm 2.9 \%)$, which was significantly different from the slight change of $-0.02 \pm 0.08 \mathrm{mmol} / \mathrm{L}$ in the placebo group $(95 \% \mathrm{Cl}$ for the difference: -2.21 to $-1.43 \mathrm{mmol} / \mathrm{L} ; P<0.001$ ) and of $-0.23 \pm 0.10 \mathrm{mmol} / \mathrm{L}$ in the TRF-RBO group $(95 \% \mathrm{Cl}$ for the difference: -2.01 to $-1.19 \mathrm{mmol} / \mathrm{L} ; P<0.001)$. Changes in LDL cholesterol were not significantly different between the TRF-RBO and placebo groups $(95 \% \mathrm{Cl}$ for the difference: -0.49 to $0.05 \mathrm{mmol} / \mathrm{L} ; P=0.229$ ). The decrease in the pravastatin group of $0.38 \pm 0.08 \mathrm{mmol} / \mathrm{L}$ or $24.7 \pm 4.2 \%$ in triacylglycerol was also significantly different from the change of $0.10 \pm 0.07 \mathrm{mmol} / \mathrm{L}$ in the placebo group $(95 \% \mathrm{Cl}$ for the difference: -0.70 to $-0.27 \mathrm{mmol} / \mathrm{L} ; P<0.001$ ) and of $0.05 \pm 0.13 \mathrm{mmol} / \mathrm{L}$ in the TRF-RBO group $(95 \% \mathrm{Cl}$ for the difference: -0.74 to $-0.12 \mathrm{mmol} / \mathrm{L} ; P=0.003$ ). The increase in HDL concentrations in the pravastatin group of $0.16 \pm 0.03 \mathrm{mmol} / \mathrm{L}(16.3 \pm 3.1 \%)$ tended to be higher than that of $0.02 \pm$ $0.04 \mathrm{mmol} / \mathrm{L}$ in the placebo group $(95 \% \mathrm{Cl}$ for the difference: 0.04 to $0.24 \mathrm{mmol} / \mathrm{L} ; P$ $=0.023)$, but not than that of $0.10 \pm 0.05 \mathrm{mmol} / \mathrm{L}$ in the TRF-RBO group $(95 \% \mathrm{Cl}$ for the difference: -0.07 to $0.18 \mathrm{mmol} / \mathrm{L} ; P=0.324$ ). The total to HDL cholesterol ratio in the pravastatin group declined by $2.78 \pm 0.31$ or $34.3 \pm 2.6 \%$, which was significantly different from the changes in both the placebo $(-0.15 \pm 0.21 ; 95 \% \mathrm{Cll}$ for the difference: -3.38 to $-1.88 ; P<0.001)$ and TRF-RBO group $(-0.18 \pm 0.30 ; 95 \% \mathrm{Cl}$ for the difference: -3.46 to $-1.73 ; P<0.001$ ).

Changes in serum apo B concentrations (pravastatin vs. placebo group: $95 \% \mathrm{Cl}$ for the difference, -469 to $-310 \mathrm{mg} / \mathrm{L}, P<0.001$; pravastatin vs. TRF-RBO group: $95 \%$ $\mathrm{Cl}$ for the difference, -434 to $-278 \mathrm{mg} / \mathrm{L}, P<0.001$ ) paralleled those in $\mathrm{LDL}$ cholesterol, whereas apo $A-I$ and $L p(a)$ concentrations remained unchanged in the three groups. 


\section{TABLE 3}

Effects of TRF-RBO or pravastatin supplementation on serum lipid and lipoprotein concentrations"

\begin{tabular}{|c|c|c|c|c|}
\hline & Placebo group & Pravastatin group & TRF-RBO giroup & \\
\hline \multicolumn{5}{|l|}{ Total cholesterol (nmol/l) } \\
\hline Run-n & $7.14 \pm 0.18$ & $739 \pm 120$ & $7.42 \pm 0.20$ & \\
\hline Treatment & $7.19 \pm 0.15$ & $5.54 \pm 0.21$ & $7.31 \pm 0.20$ & \\
\hline Change & $0.05 \pm 0.09$ & $-1.85 \pm 0.18^{2.3}$ & $-0.11 \pm 0.10$ & \\
\hline \multicolumn{5}{|l|}{ LDL cholesterol (mmollL) } \\
\hline Run-in & $5.16 \pm 0.18$ & $5.67 \pm 0.22$ & $5.61 \pm 0.20$ & \\
\hline Treatment & $5.15 \pm 0.16$ & $3.83 \pm 0.23$ & $5.37 \pm 0.19$ & \\
\hline Change & $-0.02 \pm 0.08$ & $-1.83 \pm 0.18^{2.3}$ & $-0.23 \pm 0.10$ & \\
\hline \multicolumn{5}{|l|}{ HDL cholesterol (mmol/L) } \\
\hline Run-in & $1.38 \pm 0.14$ & $1.08 \pm 0.12$ & $1.15 \pm 0.12$ & \\
\hline Treatment & $1.40 \pm 0.13$ & $1.24 \pm 0.12$ & $1.25 \pm 0.16$ & \\
\hline Change & $0.02 \pm 0.04$ & $0.16 \pm 0.03$ & $0.10 \pm 0.05$ & \\
\hline \multicolumn{5}{|l|}{ Triacylglycerol (mmol/L) } \\
\hline Run-in & $1.31 \pm 0.17$ & $1.40 \pm 0.12$ & $1.46 \pm 0.18$ & \\
\hline Treatment & $1.41 \pm 0.20$ & $1.01 \pm 0.10$ & $1.51 \pm 0.19$ & \\
\hline Change & $0.10 \pm 0.07$ & $-0.38 \pm 0.08^{2.4}$ & $0.05 \pm 0.13$ & \\
\hline \multicolumn{5}{|c|}{ Total to HDL cholesterol ratio } \\
\hline Run-in & $6.59 \pm 0.70$ & $8.34 \pm 0.89$ & $8.35 \pm 1.00$ & \\
\hline Treatment & $6.44 \pm 0.68$ & $5.57 \pm 0.74$ & $8.17 \pm 1.06$ & \\
\hline Change & $-0.15 \pm 0.21$ & $-2.78 \pm 0.31^{2,3}$ & $-0.18 \pm 0.30$ & \\
\hline \multicolumn{5}{|l|}{ Apolipoprotein A-l (mg/L) } \\
\hline Rum-in & $1501 \pm 72$ & $1470 \pm 43$ & $1496 \pm 52$ & \\
\hline Treatment & $1536 \pm 67$ & $1511 \pm 40$ & $1546 \pm 62$ & \\
\hline Change & $35 \pm 19$ & $42 \pm 21$ & $50 \pm 20$ & \\
\hline Apolipoprotein B (mg/L) & & & & ? \\
\hline Run-in & $1416 \pm 40$ & $1530 \pm 40$ & $1509 \pm 47$ & \\
\hline Treatment & $1428 \pm 38$ & $1153 \pm 50$ & $1488 \pm 49$ & \\
\hline Change & $12 \pm 22$ & $-377 \pm 33^{23}$ & $-21 \pm 20$ & \\
\hline \multicolumn{5}{|l|}{ Lipoprotein(a) (mg/L) } \\
\hline Ruin-in & $165(14$ to 606$)$ & $124(19$ to 986$)$ & $190(21$ to 1123$)$ & \\
\hline Treatment & $167(14$ to 660$)$ & $128(22$ to 1102$)$ & $135(18$ to 4031$)$ & \\
\hline Change & $0(-69$ to 76$)$ & $3(-38$ to 227$)$ & $0(-92$ to 90$)$ & \\
\hline
\end{tabular}

\footnotetext{
"Values are means \pm SEM or medians (range). For experimental details; see Table 2. TRF-RBO, tocotrienol-rich fraction from rice bran oil.

${ }^{2}$ Significantly different from the placebo group: ${ }^{2} p<0,001$

${ }^{34}$ Significantly different from the TRF-RBO group: ${ }^{3} p<0.001,{ }^{4} p<0.01$.
} 


\section{Markers for cholesterol synthesis and absorption}

Serum cholesterol-standardized lathosterol concentrations, an indicator of cholesterol synthesis (33) , decreased by $0.59 \pm 0.07 \mu \mathrm{mol} / \mathrm{mmol}$ cholesterol or $44.3 \pm 3.9 \%$ after pravastatin supplementation, which was significantly different from the changes in both the placebo $(P<0.001)$ and TRF-RBO group $(P<0,001$; Table 4$)$. Changes between the TRF-RBO and placebo groups, however, did not differ significantly ( $95 \%$ $\mathrm{Cl}$ for the difference: -0.12 to $0.17 \mu \mathrm{mol} / \mathrm{mmol}$ cholesterol; $P=0.758)$. In contrast, intestinal cholesterol absorption rose after pravastatin treatment, as indicated by the increase in serum cholesterol-standardized campesterol concentrations of $0.51 \pm$ $0.09 \mu \mathrm{mol} / \mathrm{mmol}$ cholesterol or $16.1 \pm 2.8 \%$ (34). This increment was significantly different from the change in the placebo group $(P=0.005)$, but not from that after TRF-RBO intake $(P=0.134)$. Changes in the campesterol to cholesterol ratios were not significantly different between the TRF-RBO and placebo groups $(95 \% \mathrm{Cl}$ for the difference: -0.06 to $0.39 \mu \mathrm{mol} / \mathrm{mmol}$ cholesterol; $P=0.162$ ). In addition, serum cholesterol-standardized sitosterol concentrations increased in the pravastatin group by $0.29 \pm 0.05 \mu \mathrm{mol} / \mathrm{mmol}$ cholesterol or $21.9 \pm 3.4 \%$, which was significantly more than the changes in both the placebo $(P<0.001)$ and TRF-RBO group $(P=0.005)$.

\section{TABLE 4}

Effects of TRF-RBO or pravastatin supplementation on markers of cholesterol synthesis and absorption after lipid-standardization ${ }^{9}$

\begin{tabular}{|c|c|c|c|}
\hline & Placebo group & Pravastatin group & TRF-RBO group \\
\hline \multicolumn{4}{|c|}{ Lathosterol ( $\mu$ mol $/ \mathrm{mmol}$ cholesterol) } \\
\hline Run-in & $1.22 \pm 0.10$ & $1.27 \pm 0.09$ & $1.25 \pm 0.09$ \\
\hline Treatment & $1.30 \pm 0.13$ & $0.68 \pm 0.06$ & $1.35 \pm 0.10$ \\
\hline Changle & $0.07 \pm 0.05$ & $-0.59 \pm 0.07^{2,3}$ & $0.10 \pm 0.04$ \\
\hline \multicolumn{4}{|c|}{ Campesterol (umol/mmol cholesterol) } \\
\hline Run-in & $3.35 \pm 0.20$ & $3.15 \pm 0.18$ & $3.42 \pm 0.25$ \\
\hline Treatment & $3.51 \pm 0.21$ & $3.66 \pm 0.22$ & $3.75 \pm 0.28$ \\
\hline Change & $0.16 \pm 0.09$ & $0.51 \pm 0.09^{4}$ & $0.33 \pm 0.07$ \\
\hline \multicolumn{4}{|c|}{ Sitosterol (umol/mmol cholesterol) } \\
\hline Run-in & $1.47 \pm 0.11$ & $1.34 \pm 0.07$ & $1.51 \pm 0.13$ \\
\hline Treatment & $1.53 \pm 0.10$ & $1.63 \pm 0.09$ & $1.64 \pm 0.13$ \\
\hline Change & $0.06 \pm 0.04$ & $0.29 \pm 0.05^{2.5}$ & $0.13 \pm 0.03$ \\
\hline
\end{tabular}

\footnotetext{
"Values are means \pm SEM. For experimental details: see Table 2. TRF.RBO, tocotrienol-rich fraction from rice bran oil.

${ }^{2}$ "Significantly different from the placebo group: ${ }^{2} P<0.001,4 P<0.01$

${ }^{35}$ Significantly different from the TRF-RBO group: ${ }^{3} P<0.001,{ }^{5} P<0.01$.
} 


\section{Hemostatic variables}

As listed in Table 5 , neither supplementation with TRF-RBO nor treatment with pravastatin had any effect on $T \times B_{2}$ production of the platelets in clotting blood, on WWF and factor VIIc activities, and on factor VIlla and fibrinogen concentrations.

\section{TABLE 5}

Effects of TRF-RBO or pravastatin supplementation on hemostatic parameters ${ }^{7}$

\begin{tabular}{|c|c|c|c|c|}
\hline 8 & $\%$ & Placebo group & Pravastatin group & TRF-RBO group \\
\hline \multicolumn{5}{|l|}{$T \times B_{a}(n g / m L)$} \\
\hline Runin & & $350.9 \pm 22.7$ & $332.2 \pm 43.1$ & $376.1 \pm 32.9$ \\
\hline Treatment & & $401.2 \pm 25.9$ & $357.4 \pm 48.1$ & $409.5 \pm 30.1$ \\
\hline Change & & $50.3 \pm 14.5$ & $25.2 \pm 22.0$ & $33.4 \pm 17.1$ \\
\hline \multicolumn{5}{|c|}{ WWF ( $\%$ of normal) } \\
\hline Run-in & & $65.3 \pm 3.1$ & $62.6 \pm 3.0$ & $65.2 \pm 3.2$ \\
\hline Treatment & & $63.8 \pm 2.2$ & $61.9 \pm 2.2$ & $64.2 \pm 2.4$ \\
\hline Chainge & & $-1.5 \pm 2.2$ & $-0.7 \pm 2.3$ & $-1.0 \pm 1.6$ \\
\hline \multicolumn{5}{|c|}{ Factor VIlc ( $\%$ of normal) } \\
\hline Runn-in & & $106.0 \pm 1.9$ & $104.9 \pm 2.6$ & $101.8 \pm 2.2$ \\
\hline Treatment & & $100.8 \pm 2.0$ & $102.0 \pm 2.3$ & $100.3 \pm 1.4$ \\
\hline Change & & $-5.2 \pm 2.2$ & $-2.9 \pm 2.3$ & $-1.5 \pm 2.1$ \\
\hline \multicolumn{5}{|c|}{ Factor Vlla (mU/mL) } \\
\hline Run-in & & $32.3 \pm 1.3$ & $32.5 \pm 2.4$ & $32.5 \pm 2.2$ \\
\hline Treatment & & $31.7 \pm 2.0$ & $32.5 \pm 2.7$ & $30.6 \pm 1.7$ \\
\hline Change & & $-0.7 \pm 2.2$ & $0.0 \pm 3.0$ & $-1.9 \pm 2.6$ \\
\hline \multicolumn{5}{|l|}{ Fibrinogen $(\mathrm{g} / \mathrm{L})$} \\
\hline Run-in & & $2.85 \pm 0.07$ & $2.79 \pm 0.05$ & $2.86 \pm 0.06$ \\
\hline Treatment & & $2.77 \pm 0.06$ & $2.85 \pm 0.07$ & $2.85 \pm 0.06$ \\
\hline Change & & $-0.08 \pm 0.04$ & $0.06 \pm 0.04$ & $-0.01 \pm 0.05$ \\
\hline
\end{tabular}

"Values are means \& SEM. For experimental detals: see Table 2. Results of seven subjects were excluded from analyses of serum $T \times B_{2}$ because one subject from the placebo group, four subjects fircm the pravastatin group and two subjects from the TRF-RBO group were prescribed during the study prostaglandin synthetase inhibitors, known to affect the $T \times B_{2}$ production of the platellets in clotting blood. TRF.RBO. tocotrienol-rich fraction from rice bran oll: $T \times B_{2}$, thromboxane $\mathrm{B}_{2}$; WWF, von Willebrand Factor; factor W/Ic factor VIl coagulant; factor Vila activated factor VII. The changes were not significantliy different between the treatments. 


\section{Discussion}

In the present study, daily supplementation with $42 \mathrm{mg}$ of a tocotrienol-rich fraction from rice bran oil for 6 weeks had no beneficial effects on serum lipids and lipoproteins in hypercholesterolemic subjects on a cholesterol-lowering diet. Our findings do therefore contradict the results of Qureshi et al. (19), who reported an $18 \%$ reduction in serum LDL cholesterol in hypercholesterolemic individuals when supplemented daily with $50 \mathrm{mg}$ of a tocotrienol-rich fraction from rice bran oil for 35 days when on an American Heart Association (AHA) step I diet. Such a strong reduction in LDL cholesterol as observed by Qureshi et al. $(18,19)$ is comparable to the decrease that can be achieved with the lipid-lowering drug pravastatin. Like statins, tocotrienols have been suggested to decrease endogenous cholesterol synthesis $(7,9)$. For these reasons, we decided to compare the effects of TRF-RBO with those of pravastatin. The lipid-lowering effects of pravastatin were as expected (35). TRF-RBO supplementation did also not affect cholesterol synthesis and absorption, as indicated by the unchanged cholesterol-standardized concentrations of lathosterol and campesterol. As also observed by others (36), pravastatin decreased cholesterol-standardized lathosterol by $44 \%$, but increased cholesterolstandardized campesterol by $16 \%$. Thus, the agreement of our results on pravastatin treatment with those of other studies, indicate good compliance of our subjects. We therefore conclude that tocotrienols from rice bran oil do not favorably affect cholesterol metabolism in hypercholesterolemic subjects.

It should be noted that the placebo capsules for TRF-RBO contained more tocopherols and tocotrienols than anticipated. Therefore, the difference in TRF-RBO intake between the placebo group and the experimental group was less than planned. However, it is not likely that this explains the lack of effect of our TRF-RBO capsules, as changes for LDL cholesterol in both groups were near zero (Table 3 ). It has been suggested (18-20) that two novel tocotrienol isomers from rice bran oil identified as desmethyl $\left(P_{21}\right)$ and didesmethyl $\left(P_{25}\right)$ tocotrienols, might be responsible for this promising hypocholesterolemic effect. Further, rice bran oil is rich in $\gamma^{4}$ tocotrienol, which may also have a strong inhibiting effect on HMG-CoA reductase activity $(10,23)$. However, the presence of didesmethyl $\left(P_{25}\right)$ tocotrienols could not be confirmed in our preparation.

Results of other human studies (11-13), in which a tocotrienol-rich fraction from palm oil (Palmvitee) were given, are also in contrast with our findings. Tan et al. (12) observed that LDL cholesterol concentrations were reduced between 1 to $37 \%$ in both normocholesterolemic and hypercholesterolemic subjects after daily supplementation with Palmvitee, which contains $\sim 18 \mathrm{mg}$ of tocopherols and $\sim 42 \mathrm{mg}$ 
of tocotrienols. A shortcoming of this study is, however, that it was not placebocontrolled. The group of Qureshi et al. (13) reported that a daily intake of $200 \mathrm{mg}$ of Palmvitee for 4 weeks lowered LDL cholesterol concentrations non-significantly by $8 \%$. When three poor respondents from the in total 15 hypercholesterolemic participants in the tocotrienol group were excluded from the statistical analyses, a significant decrease of $28 \%$ was found. Another trial of Qureshi et al. (11) showed a $13 \%$ decrease in LDL cholesterol in hypercholesterolemic subjects on an AHA step I diet after a daily consumption of $260 \mathrm{mg}$ of Palmvitee for 4 weeks. When $200 \mathrm{mg}$ of -tocotrienol from palm oil per day was supplemented for 4 weeks, serum total cholesterol concentrations were lowered by $13 \%$. Our findings, however, are in agreement with the results of other research groups (14-17). Wahlqvist et al. (16) were the first to demonstrate that tocotrienols from palm oil had no beneficial effects on serum lipids and lipoproteins in hypercholesterolemic subjects who received increasing doses from $60,120,180$ up to $240 \mathrm{mg}$ of Palmvitee per day for 16 weeks. Also Tomeo et al. (17) could not find favorable effects of a tocotrienol-rich fraction from palm oil in increasing doses from 224, 280 up to $336 \mathrm{mg}$ for 18 months on serum lipid concentrations in hyperlipidemic patients with carotid atherosclerosis. In addition, we have earlier reported no change in serum lipids and lipoproteins in mildly hypercholesteralemic men after receiving $220 \mathrm{mg}$ of a tocotrienol-rich fraction from palm oil for 6 weeks (15). Our results also agreed with the findings of a recent study (14), in which $250 \mathrm{mg}$ of purified $\alpha-, \gamma-$, or $\delta$-tocotrienyl acetates from palm oil per day were given for 8 weeks without observing any beneficial effect on the serum lipoprotein profile in hypercholesterolemic subjects on an AHA step I diet.

Qureshi et al. (37) assumed that the observed discrepancy in effects of tocotrienols could be explained by an attenuation of the cholesterol-lowering action of the tocotrienols by $\alpha$-tocopherol as shown in chickens. The authors suggested that the most effective capsules contained 15-20\% $\alpha$-tocopherol and about 60\% $\gamma$ - (and $\delta$-) tocotrienol, whereas less effective capsules consisted of $\geq 30 \% \alpha$-tocopherol and $45 \% \gamma-$ (and $\delta$-) tocotrienol. However, their assumption does not agree with the results of others $(10,38)$, reporting that $\alpha$-tocopherol did not decrease the activity of ytocotrienol in HepG2 cells and rats. Besides, the study of $O^{\prime}$ Byrne et al. (14), in which hypercholesterolemic subjects received tocotrienol supplements, free from $\alpha$ tocopherol, failed to show any reduction in LDL cholesterol concentrations.

Qureshi et al. (18) found favorable effects on platelet function after treatment with a tocotrienol-rich fraction from rice bran oil. They reported decreases in platelet factor 4 and $\mathrm{TxB}_{2}$ of 14 and $31 \%$, respectively, indicating a decreased thrombotic activity. This study (18) was in accordance with the results of Qureshi et al. (13) using 
tocotrienols from palm oil. These findings, hawever, contradict the results of other studies $(15,16)$, which showed that platelet function was unaffected by tocotrienols from palm oil. We did also not observe beneficial effects of TRF-RBO treatment on hemostatic activity. In the literature (39-41), inconsistent effects of pravastatin therapy have been found on factor VII and fibrinogen, whereas WWF remained unaffected. We did not see any effects of pravastatin on these parameters.

In conclusion, supplementation with TRF-RBO had no effect on serum lipoproteins or cholesterol synthesis and absorption in hypercholesterolemic subjects on a cholesterol-lowering diet. The hypocholesterolemic effect of pravastatin was as anticipated. Neither supplementation with TRF-RBO nor pravastatin therapy had any effect on hemostatic function.

\section{Acknowledgements}

We are grateful to the dietary and technical staff of our Department for their excellent support. We would also like to thank all volunteers of the study for their cooperation and interest. The study was supported by Novartis Consumer Health, Nyon, Switzerland. 


\section{References}

1. Kayden HJ, Traber MG. Absorption, lipoprotein transport, and regulation of plasma concentrations of vitamin $E$ in humans. J Lipid Res 1993;34:343-58.

2. Stampfer MJ, Hennekens CH, Manson JE, Colditz GA, Rosner B, Willett WC. Vitamin $E$ consumption and the risk of coronary disease in women. $N$ Engl $\mathrm{J}$ Med $1993 ; 328: 1444-9$.

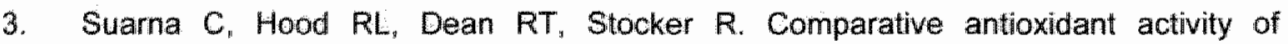
tocotrienols and other natural lipid-soluble antioxidants in a homogeneous system, and in rat and human lipoproteins. Biochim Biophys Acta 1993;1166:163-70.

4. Black TM, Wang P, Maeda N, Coleman RA. Palm tocotrienols protect ApoE $+1-$ mice from diet-induced atheroma formation. J Nutr 2000;130:2420-6.

5. Kesaniemi YA, Grundy SM. Lack of effect of tocopherol on plasma lipids and lipoproteins in man. Am J Clin Nutr 1982;36:224-8.

6. Qureshi AA, Qureshi $N$, Hasler-Rapacz JO, et al. Dietary tocotrienols reduce concentrations of plasma cholesterol, apolipoprotein $B_{\text {, thromboxane }} B_{2}$, and platelet factor 4 in pigs with inherited hyperlipidemias. Am J Clin Nutr 1991;53:1042S-6S.

7. Pearce BC, Parker RA, Deason ME, Qureshi AA, Wright JJK. Hypocholesterolemic activity of synthetic and natural tocotrienols. $\mathbb{N}$ Med Chem 1992;35:3595-606.

8. Qureshi AA, Burger WC, Peterson DM, Elson CE. The structure of an inhibitor off cholesteroll biosynthesis isolated from barley. J Biol Chem 1986;261:10544-50.

9. Parker RA, Pearce BC, Clark RW, Gordon DA. Wright JJK. Tocotrienols regulate cholesterol production in mammalian cells by post-transcriptional suppression of 3 hydroxy-3-methylglutaryl coenzyme A reductase. J Biol Chem 1993;268:11230-8.

10. Theriault A, Wang Q. Gapor A, Adeli K. Effects of $\gamma$-tocotrienol on ApoB synthesis degradation, and secretion in HepG2 cells. Arterioscler Thromb Vasc Biol 1999;19:70412 .

11. Qureshi AA, Bradlow BA, Brace $L$, et al. Response of hypercholesterolemic subjects to administration of tocotrienols. Lipids 1995;30:1171-7.

12. Tan DTS, Khor HT, Low WHS, Ali A, Gapor A. Effect of a palm-oil-vitamin $E$ concentrate on the serum and lipoprotein lipids in humans. Am $J$ Clin Nutr $1991: 53: 1027$ S-30S.

13. Qureshi $A A$, Qureshi $N$, Wright JJK, et al. Lowering of serum cholesterol in hypercholesterolemic humans by tocotrienals (palmvitee). Am J Clin Nutr $1991 ; 53: 1021$ S-6S.

14. O' Byme D, Grundy $S$, Packer $L$, et al. Studies of LDL oxidation following $\alpha-\gamma-$, or $\delta-$ tocotrienyl acetate supplementation of hypercholesterolemic humans. Free Radiac Biol Med 2000;29:834-45.

15. Mensink RP, van Houwelingen AC, Kromhout D, Hornstra G. A vitamin E concentrate rich in tocotrienols had no effect on serum lipids, lipoproteins, or platelet function in men with mildly elevated serum lipid concentrations. Am J Clin Nutr 1999;69:213-9.

16. Wahlquist ML. Krivokuca-Bogetic $Z$, Lo CS, Hage $B$, Smith $R$, Lukito W. Differential serum responses of tocopherols and tocotrienols during vitamin supplementation in hypercholesterolaemic individuals without change in coronary risk factors. Nutr Res 1992:12:S181-S201.

17. Tomeo AC, Geller M, Watkins TR, Gapor A, Bierenbaum ML. Antioxidant effects of tocotrienols in patients with hyperlipidemia and carotid stenosis. Lipids 1995;30:117983. 
18. Qureshi $A A_{\text {n }}$ Bradlow BA, Salser WA, Brace LD. Novel tocotremols of rice bran modulate cardiovascular disease risk parameters of hypercholesterolemic humans. J Nutr Biochem 1997;8:290-8.

19. Qureshi AA, Sami SA, Salser: WA, Khan FA, Synergistic effect of tocotrienol-rich fraction (TRF 25 ) of rice bran and lovastatin on lipid parameters in hypercholesterolemic humans. J Nutr Biochem 2001;12:318-29.

20. Qureshi AA, Mo $H$, Packer $L$, Peterson DM. lsolation and identification of novel tocotrienols from rice bran with hypocholesterolemic, antioxidant and antifumor properties. J Agric Food Chem 2000;48:3130-40.

21. Qureshi AA, Peterson DM. The combined effects of novel tocotrienols and lovastatin on lipid metabolism in chickens. Atherosclerosis 2001,156:39-47.

22. Qureshi AA, Peterson DM, Hasler-Rapacz JO, Rapacz J. Novel tocotrienols of rice bran suppress cholesterogenesis in hereditary hypercholesterolemic swine. I Nutr 2001;131:223-30.

23. Rukmini C, Raghuram TC. Nutritional and biochemical aspects of the hypolipidemic action of rice bran oil: a review. J Am Coll Nutr 1991;10:593-601.

24. Nederlandse Voedingsnormen 1989 (Dutch dietary guidelines 1989) / Commissie Voedingsnormen Voedingsraad, 2e druk. The Hague: Voorlichtingsbureau voor de Voeding 1992 (in Dutch).

25. The Expert Panel. Summary of the second report of the National Cholesterol Education Program (NCEP) Expert Panel on Detection. Evaluation, and Treatment of High Blood Cholesterol in Adults (Adult Treatment Panel II). JAMA 1993;269:3015-23.

26. De Roos B, Katan MB. Possible mechanisms underlying the cholesterol-raising effect of the coffee diterpene cafestol. Curr Opin Lipidiol 1999;10:41-5.

27. Friedewald WT, Levy Rl, Fredrickson DS. Estimation of the concentration of lowdensity lipoprotein cholesterol in plasma, without use of the preparative ultracentrifuge. Clin Chem 1972;18:499-502.

28. Plat J, Mensink RP. Effects of diets enriched with two different plant stanol ester mixtures on plasma ubiquinol-10 and fat-soluble antioxidant concentrations. Metabolism 2001;50:520-9.

29. Cejka J. Performance characteristics of a commercial kit for assay of factor VIII-related antigen. Clin Chem 1984;30:814-5.

30. van Dam-Mieras MCE, Muller AD, et al. Blood coagulation factors $I I, V, V I I, V I I, I X, X$ $X I$ determination by clotting assays. Weinheim: Methods of enzymatic anallysis vol. 5 1984:352-65.

31. Morrissey JH, Macik BG, Neuenschwander PF, Comp PC. Quantitation of activated factor VII levels in plasma using a tissue factor mutant selectively deficient in promoting factor VII activation. Blood 1993;81:734-44.

32. Clauss A. Gerinnungsphysiologische schnellmethode zur bestimmung des fibrinogens. Acta Haematol 1957:17:237-46.

33. Kempen HJM, Glatz JFC, Gevers Leuven JA, van der Voort HA, Katan MB. Serum lathosterol concentration is an indicator of whole-body cholesterol synthesis in humans. $\checkmark$ Lipid Res 1988;29:1149-55.

34. Miettinen TA, Tilvis RS, Kesäniemi YA. Serum plant sterols and cholesterol precursors reflect cholesterol absorption and synthesis in volunteers of a randomly selected male population. Am J Epidemiol 1990;131:20-31.

35. Haria M, McTavish D. Pravastatin. A reappraisal of its pharmacological properties and clinical effectiveness in the management of coronary heart disease. Drugs $1997: 53: 299-336$. 
36. Uusitupa MIJ, Miettinen TA, Happonen P, et al. Lathosterol and other noncholesterol sterols during treatment of hypercholesterolemia with lovastatin alone and with cholestyramine or guar guin. Arterioscler Thromb 1992;12:807-13.

37. Qureshi AA, Pearce BC, Nor RM, Gapor A, Peterson DM, Elson CE. Dietary atocopherol attenuates the impact of $\gamma$-tocotrienol on hepatic 3-hydroxy-3-methylglutary! coenzyme A reductase activity in chickens. I Nuir 1996;126:389-94.

38. Watkins $T$, Lenz $P$, Gapor $A$, Struck $M$, Tomeo A, Blerenbaum $M$. $\gamma$-Tocotrienol as a hypocholesterolemic and antioxidant agent in rats fed atherogenic diets. Lipids 1993;28:1113-8.

39. Wada $H$, Mori $Y$, Kaneko $T$, et al. Elevated plasma levels of vascular endothelial cell markers in patients with hypercholesterolemia. Am J Hematol 1993;44:112-6.

40. Avellone $G$, Di Garbo V, Cordova $R$, Raneli $G$, De Simone R, Bompiani $G$. Changes induced by pravastatin treatment on hemostatic and fibrinolytic patterns in patients with type IIB hyperlipoproteinemia. Curr Ther Res 1994;55:1335-44.

41. Dangas $G$, Badimon $J J$, Smith DA, al. Pravastatin therapy in hyperlipidemia: effects on thrombus formation and the systemic hemostatic profile. J Am Coll Cardiol $1999 ; 33: 1294-1304$. 


\section{Chapter}

The effects of $\beta$-glucan from oat bran in bread and cookies or orange juice on serum lipoproteins in mildly hypercholesterolemic subjects

Daniëlle AJM Kerckhoffs ${ }^{1,2}$, Gerard Hornstra ${ }^{2}$ and Ronald P Mensink ${ }^{1,2}$

${ }^{1}$ Department of Human Biology and ${ }^{2}$ Nutrition and Toxicology Research Institute Maastricht (NUTRIM), Maastricht University, Maastricht, The Netherlands

Submitted for publication 


\section{Abstract}

Objective: To investigate the effects of $\beta$-glucan from oat bran in bread and cookies (Study 1) or orange juice (Study 2) on serum lipoproteins in mildly hypercholesterolemic subjects.

Design: In Study 1,21 men and 27 women first received control bread and cookies rich in wheat fiber for three weeks. Thereafter, volunteers were randomly divided into two groups, consuming control bread and cookies $(n=23)$ or bread and cookies rich in $\beta$-glucan from oat bran $(n=25)$ for four weeks. Mean daily intake of $\beta$-glucan was $5.9 \mathrm{~g}$. The control and experimental products were similar in total dietary fiber content. In Study 2, the same source and daily amount of control fiber and $\beta$-glucan $(5 \mathrm{~g})$ as in Study 1 was provided. During the first two weeks of the trial, 5 men and 8 women consumed wheat fiber with orange juice, while 5 men and 7 women was given $\beta$-glucan from oat bran with orange juice. After a wash-out period of one week. dietary regimens were crossed over.

Results: In Study 1 , no significant effects on the serum lipoprotein profile of $\beta$-glucan from oat bran in bread and cookies were found. Differences in changes in total cholesterol of $-0.16 \mathrm{mmol} / \mathrm{L}(P=0.098)$ and $L D L$ cholesterol concentrations of -0.12 $\mathrm{mmol} / \mathrm{L}(P=0.173)$ were not significantly different between the two groups. In Study 2 , the drink rich in $\beta$-glucan lowered total cholesterol, LDL cholesterol and the total to $\mathrm{HDL}$ cholesterol ratio by $0.22 \pm 0.07 \mathrm{mmol} / \mathrm{L}$ (means $\pm \mathrm{SEM}$ ) or $3.8 \pm 1.3 \%(P=$ $0.006), 0.26 \pm 0.07 \mathrm{mmol} / \mathrm{L}$ or $6.7 \pm 1.8 \%(P=0.001)$ and $0.26 \pm 0.11$ or $5.4 \pm 2.1 \%$ $(P=0.029)$, respectively. Effects on HDL cholesterol and triacylglycerol concentrations were not significant.

Conclusions: Our $\beta$-glucan preparation incorporated into bread and cookies did not significantly affect serum lipids and lipoproteins, whereas it lowered LDL cholesterol concentrations when consumed with a drink. These findings indicate that the food matrix and/or food processing could have detrimental effects on the hypocholesterolemic properties of oat $\beta$-glucan. 


\section{Introduction}

Oats, an important source of water-soluble fibers, have been recognized for long as a potential cholesterol-lowering dietary component (1). Indeed, Ripsin et al. (2) concluded from a meta-analysis of 12 trials that soluble fiber from oat products had a significant effect on total cholesterol concentrations. It was estimated that a daily consumption of about $3 \mathrm{~g}$ of soluble fiber lowered total cholesterol by 0.13 and 0.41 $\mathrm{mmol} / \mathrm{L}$ in normocholesterolemic and hypercholesterolemic individuals, respectively.

The beneficial effects of oat products on the lipoprotein profile are ascribed to their soluble fiber compound, $\beta$-glucan (3). $\beta$-Glucan from oats is a non-starch polysaccharide that is composed of $\beta-(1 \rightarrow 4)$-linked glucose units "which are separated every two to three units by a single $\beta-(1 \rightarrow 3)$-linked glucose (4). Also $\beta$ glucan from barley $(5,6)$ or yeast $(7)$ has been shown to be hypocholesterolemic.

On January 21, 1997, the U.S. Food and Drugs Administration (FDA) approved a health claim on food products that "a diet high in soluble fiber from whole oats (oat bran, oatmeal and oat flour) and low in saturated fat and cholesterol may reduce the risk of heart disease $(8,9)$." In its proposal $(8)$, the FDA reviewed 37 studies, in which oats were consumed as hot and cold cereals or used in a variety of other foods, such as muffins, breads, shakes, and entrees. It was concluded that at least $3 \mathrm{~g}$ of $\beta$ glucan from oats should be consumed daily to achieve a clinically relevant decline in serum total cholesterol concentrations. Such an amount of $\beta$-glucan is provided by as much as $40 \mathrm{~g}$ of oat bran or $60 \mathrm{~g}$ of oatmeal (8). Compliance with this dietary guideline would therefore be greatly improved if common food products rich in oats were available. We, therefore, decided to investigate in mildly hypercholesterolemic subjects the effects on serum lipids and lipoproteins of a daily consumption of at least $5 \mathrm{~g}$ of $\beta$-glucan from oat bran incorporated into bread and cookies (Study 1). No effects, however, were found. To examine in more detail the effects of food processing and the food matrix, we further examined in a second study (Study 2) whether the same source and amount of oat bran as in Study 1 would lower serum $\mathrm{LDL}$ cholesterol concentrations when given with a drink. 


\section{Subjects and methods}

\section{Subjects}

\section{Study 1: Effects of oat $\beta$-glucan in bread and cookies}

Volunteers were recruited from Maastricht and surroundings by advertisements in local newspapers. Also, subjects who had participated in earlier studies at our Department were approached. All subjects were given a detailed written description of the study, before they entered the screening procedure, which consisted of measurements of body weight, height and blood pressure, two fasting blood samples for analysis of serum lipids and lipoproteins, and assessment of the absence of glucose in a morning specimen of urine. Further, all subjects had to fill in a medical questionnaire. Fifty-one participants were selected for the study according to the following inclusion criteria: aged between 18 and $65 \mathrm{y}$, stable body weight (weight gain or loss below $3 \mathrm{~kg}$ in the past three months), body mass index (BMI) below 30 $\mathrm{kg} / \mathrm{m}^{2}$, diastolic blood pressure below $95 \mathrm{mmHg}$, systolic blood pressure below 160 $\mathrm{mmHg}$, concentrations of serum total cholesterol below $8.0 \mathrm{mmol} / \mathrm{L}$, and triacylglycerol below $4.0 \mathrm{mmo} / \mathrm{L}$, no indication for treatment with cholesterol-lowering drugs according to the Dutch Cholesterol Consensus (10), no use of medication known to affect serum lipids, no glucosuria, no pregnancy or breast-feeding, and no history of coronary heart disease. None of the subjects had participated in another biomedical trial or donated blood 30 days before or during the study. The study protocol was approved by the Ethics Committee of the Maastricht University and all subjects gave their written informed consent.

In the first week of the study, one woman dropped out because of stressful personal circumstances and one woman withdrew in the second week of the study because of illness. In the first week of the intervention period, one subject withdrew due to the constraints of the study. The remaining fourty-eight volunteers, 21 men and 27 women, completed the study. The mean age of men was $53 \pm 2$ (SEM) y. They had a mean weight of $79.8 \pm 2.2 \mathrm{~kg}$, a mean height of $1.77 \pm 0.01 \mathrm{~m}$, and a mean BMl of $25.6 \pm 0.6 \mathrm{~kg} / \mathrm{m}^{2}$. For women, these values were $50 \pm 2 \mathrm{y}, 67.1 \pm 1.5 \mathrm{~kg}, 1.66 \pm 0.01$ $\mathrm{m}$, and $24.4 \pm 0.5 \mathrm{~kg} / \mathrm{m}^{2}$, respectively. The mean diastolic and systolic blood pressure was $80 \pm 2 \mathrm{mmHg}$ and $131 \pm 3 \mathrm{mmHg}$ in men, and $75 \pm 1 \mathrm{mmHg}$ and $121 \pm$ $2 \mathrm{mmHg}$ in women. In men, mean fasting concentrations of serum total cholesterol,

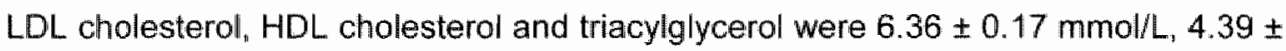
$0.16 \mathrm{mmol} / \mathrm{L}, 1.26 \pm 0.06 \mathrm{mmol} / \mathrm{L}$ and $1.54 \pm 0.15 \mathrm{mmol} / \mathrm{L}$, and in women $5.96 \pm 0.15$ $\mathrm{mmol} / \mathrm{L}, 3.82 \pm 0.14 \mathrm{mmol} / \mathrm{L}, 1.64 \pm 0.08 \mathrm{mmol} / \mathrm{L}$ and $1.09 \pm 0.09 \mathrm{mmol} / \mathrm{L}$, 
respectively. Four men and two women were smokers Four women used oral contraceptives and nine women were postmenopausall.

\section{Study 2: Effects of oat $\beta$ glucan in orange juice}

Twenty-six volunteers agreed to participate in the second study. Inclusion criteria were similar as those for Study 1. All subjects received a detailed written description of the study before they gave their written informed consent. The study protocol was approved by the Ethics Committee of the Maastricht University.

One woman withdrew in the first week of the study because of influenza. Thus, twenty-five volunteers, 10 men and 15 women, completed the trial. The mean age of men was $54 \pm 2 \mathrm{y}$. Their mean body weight, height and $\mathrm{BM} \|$ were $77.0 \pm 2.4 \mathrm{~kg}, 1.76$ $\pm 0.02 \mathrm{~m}$ and $24.9 \pm 0.7 \mathrm{~kg} / \mathrm{m}^{2}$, respectively. For women, these values were $53 \pm 3 \mathrm{y}$, $66.7 \pm 2.0 \mathrm{~kg}, 1.65 \pm 0.02 \mathrm{~m}$, and $24.6 \pm 0.8 \mathrm{~kg} / \mathrm{m}^{2}$, respectively. The mean diastolic and systolic blood pressure was $78 \pm 2 \mathrm{mmHg}$ and $123 \pm 2 \mathrm{mmHg}$ in men, and $73 \pm$ $2 \mathrm{mmHg}$ and $117 \pm 3 \mathrm{mmHg}$ in women. In men, mean fasting concentrations of serum total cholesterol, LDL cholesterol, HDL cholesterol and triacylglycerol were respectively $6.09 \pm 0.23 \mathrm{mmol} / \mathrm{L}, 4.22 \pm 0.22 \mathrm{mmol} / \mathrm{L}, 1.23 \pm 0.09 \mathrm{mmol} / \mathrm{L}$ and $1.39 \pm$ $0.17 \mathrm{mmol} / \mathrm{L}$, and in women $5.94 \pm 0.23 \mathrm{mmol} / \mathrm{L}, 3.83 \pm 0.22 \mathrm{mmol} / \mathrm{L}, 1.67 \pm 0.09$ $\mathrm{mmol} / \mathrm{L}$ and $0.96 \pm 0.08 \mathrm{mmol} / \mathrm{L}$. One man and one woman smoked. One woman used orall contraceptives and six women were postmenopausal.

\section{Experimental design}

\section{Study 1: Effects of oat $\beta$-glucan in bread and cookies}

Study 1 was a randomized, controlled parallel experiment. During the first three weeks of the trial (run-in period), all volunteers were provided with control bread and cooklies rich in wheat fiber. After the run-in period, the subjects were randomly divided into two treatment groups, stratified for age and gender. For the last four weeks of the study, the first group continued consuming control bread and cookies, while the second group received experimental bread and cookies rich in $\beta$-glucan from oat bran (Figure 1). At least five slices of control or experimental bread had to be consumed daily throughout the study, divided over at least two eating moments. One slice of $30 \mathrm{~g}$ of the experimental bread contained $1 \mathrm{~g}$ of $\beta$-glucan and one cookie of $12 \mathrm{~g}$ contained $0.5 \mathrm{~g}$ of $\beta$-glucan from oat bran (Table 1). The subjects were free to replace one slice of bread by two cookies. The aimed daily intake of $\beta$-glucan from oat bran was therefore at least $5 \mathrm{~g}$. 


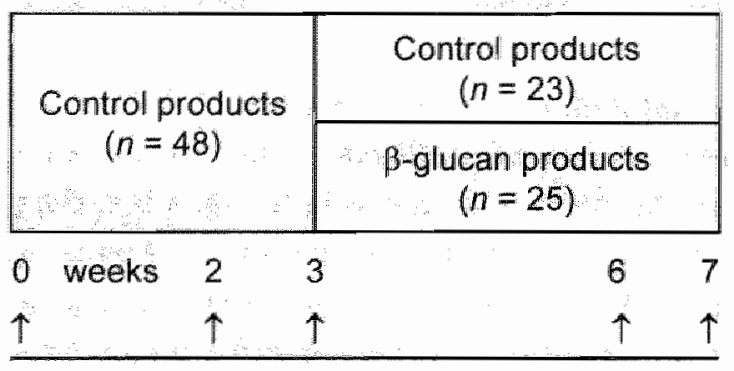

FIGURE 1 Experimental design of Study 1

\section{TABLE 1}

The amount of $\beta$-glucan, total dietary fiber and fat content of a slice of bread and one cookie in Study 1 and of a sachet of fibers in Study $2^{1}$

\begin{tabular}{|c|c|c|c|c|}
\hline & $\begin{array}{l}\text { Slice of bread } \\
\text { (Study 1) }\end{array}$ & $\begin{array}{l}\text { Cookie } \\
\text { (Study } 1 \text { ) }\end{array}$ & $\begin{array}{c}\text { Sachet of fibers } \\
\text { (Study 2) }\end{array}$ & \\
\hline \multicolumn{5}{|l|}{ Control Products } \\
\hline Wheat fiber $(g)$ & 2.0 & 1.0 & 6.0 & \\
\hline Wheat flour $(\mathrm{g})$ & 13.0 & 2.0 & 0.0 & \\
\hline Total dietary fiber $(g)$ & 2.3 & 1.0 & 5.6 & \\
\hline Fat $(g)$ & 1.3 & 3.0 & 0.0 & \\
\hline \multicolumn{5}{|l|}{ Exporimental Products } \\
\hline Oal bran $(g)$ & 5.6 & 2.8 & 14.0 & \multirow{6}{*}{ : } \\
\hline Oat bran concentrate $(\mathrm{g})$ & 2.4 & 1.2 & 6.0 & \\
\hline Wheat flour $(g)$ & 6.6 & 0.0 & 0.0 & \\
\hline$\beta$ - Glucan (g) & 1.0 & 0.5 & 2.5 & \\
\hline Total dietary fiber ( $g$ ) & 2.3 & 1.1 & 5.3 & \\
\hline Fatl (g) & 1.3 & 3.0 & 1.3 & \\
\hline \multicolumn{5}{|c|}{$\begin{array}{l}\text { In Study 1, at least five slices of control or experimental bread had to be consumed daily. The participants were } \\
\text { free to replace one stice of bread by two cookies. The target daily intake of p-glucan from oat bran was } \\
\text { therefore at least } 5 \mathrm{~g} \text {. In Study } 2 \text {, the subjects consumed daily two sachets of wheat fiber ar a mixture of oat } \\
\text { bran and oat bran concentrate, which were similar in total dietary fiber content (about } 5 \mathrm{~g} \text { ), after mixing each } \\
\text { sachet with } 200 \mathrm{ml} \text { of orange juice. }\end{array}$} \\
\hline
\end{tabular}


The total dietary fiber content of the control and the experimental breads and of the control and experimental cookies were similar (one slice of bread: $2 \mathrm{~g}$; one cookie: 1 $g_{i}$ Table 1). Also, the fat content of the control and experimental products was identical (one slice of bread: $1 \mathrm{~g}$, one cookie: $3 \mathrm{~g}$. Table 1 ), but the color and taste differed due to the use of different sources of fiber.

The wheat fiber (VITACEL Wheat Fibre WF 200, Rosenberg, Germany) contained $93.3 \%$ total dietary fiber, of which $98.8 \%$ was water-insoluble fiber, mainly cellulose and hemicellulose. For the bread and cookies rich in $\beta$-glucan, a mixture consisting of 23 parts (w) of oat bran (Melia Oy, Raisio, Finland) and 10 parts of oat bran concentrate (Swedish Oat Fiber, Väröbacka, Sweden) was used. The oat bran consisted of $20.6 \%$ of total dietary fiber, of which $41 \%$ was $\beta$-glucan, whereas the oat bran concentrate contained $40.3 \%$ total dietary fiber, of which $53 \%$ was $\beta$-glucan. The composition of wheat fiber, oat bran and oat bran concentrate is shown in Table 2. Before baking, the oat bran was first soaked in $30^{\circ} \mathrm{C}$ water for one hour in a $36^{\circ} \mathrm{C}$ raising cabin. During soaking, oat bran absorbed water forming a light gel. Thereafter, other ingredients were added. Nearly each week, new batches of bread and cookies were prepared by a local bakery and deep-frozen at $-18{ }^{\circ} \mathrm{C}$. The subjects received bread and cookies at their request once a week.

\section{TABLE 2}

Composition (per $100 \mathrm{~g}$ of product) of wheat fiber, oat bran and oat bran concentrate in Study 1 and $2^{9}$

\begin{tabular}{lccc}
\hline & Wheat fiber & Oat bran & Oat bran concentrate \\
\hline Total dietary fiber (g) & 93.3 & 20.6 & 40.3 \\
$\beta$-Glucan (g) & 0.1 & 8.4 & 21.2 \\
Fat (g) & 0.3 & 7.1 & 4.9 \\
Protein (g) & 0.3 & 20.2 & 22.8 \\
Moisture (g) & 5.3 & 10.6 & 5.3 \\
Ash (g) & 0.7 & 3.1 & 3.9 \\
Carbohydrate (g) & & & \\
(by difference) & 0.1 & 38.4 & 22.8 \\
Energy (Kل) & 17 & 1247 & 950 \\
\hline
\end{tabular}

'Based on chemical analyses $(11-15)$, except for carbohydrates which were calculated by differerice (1) Glucan content was determined by a specific enzymatic kit (Megazyme, Ireland). In Study 1, wheat fiber, oat bran and oat bran concentrate was incorporated imto bread and cookies, whereas in study 2 these produchs were giwen with orange juice. For experimental details: see Table 1. 
The volunteers recorded in diaries any signs of iliness, medication used, menstrual phase, alcohol and fruit consumption and any deviations from the protocol. In addition, the daily annount of bread and cookies consumed were recorded. Subjects were urged not to change their habitual diets, smoking and drinking habits, level of physical activity, or use of oral contraceptives during the study. Body weights without shoes and heavy clothes were recorded once a week. In the last week of the run-in period and at the end of the treatment period, subjects recorded their food intake for the last four weeks by filling in food frequency lists to estimate their intake of energy and nutrients throughout the study. Food frequency lists were checked by a registered dietician in the presence of the subjects.

\section{Study 2: Effects of oat $\beta$-glucan in orange juice}

The follow-up study was a randomized, controlled crossover trial, consisting of two periods of two weeks each, which were interrupted by a wash-out period of one week (Figure 2). In this study, the same source and daily amounts of wheat fiber and of oat bran and oat bran concentrate as in Study 1 were given with orange juice. Wheat fiber, oat bran and oat bran concentrate were from the same batches as used in Study 1.

Before the start of the study, the subjects were randomly allocated to one of the two groups, stratified for age and gender. During the first period of the trial, one group was given the wheat fiber with orange juice (control drink), while the other group consumed $\beta$-glucan from oat with orange juice ( $\beta$-glucan drink). After the wash-out period, volunteers who consumed the control drink in the first period crossed over to the $\beta$-glucan drink in the second period, and vice versa.

During the two periods of the experiment, subjects consumed daily two glasses of orange juice rich in control fiber from wheat or $\beta$-glucan from oat bran, at two separate occasions with an interval of at least three hours. Fifteen sachets filled with wheat fiber or oat bran were provided weekly: two sachets for each day plus one extra sachet as reserve. Each sachet contained wheat fiber $(6 \mathrm{~g})$ or oat bran (a mixture of $14 \mathrm{~g}$ oat bran plus $6 \mathrm{~g}$ oat bran concentrate, in a similar proportion as in Study 1) had to be mixed with $200 \mathrm{ml}$ of orange juice, which was also provided. This mixture had to be consumed immediately since palatability decreased with time. One sachet of oat bran provided $2.5 \mathrm{~g}$ of $\beta$-glucan (Table 1). The aimed daily intake of $\beta$ glucan from oat bran was therefore $5 \mathrm{~g}$. Sachets of wheat fiber and oat bran were comparable in total dietary fiber content but not in color, taste and fat content. Sachets that were left over at the end of each period were collected and counted. Other experimental procedures were the same as for Study 1. 


\begin{tabular}{|c|c|c|c|c|}
\hline \multicolumn{3}{|c|}{$\begin{array}{l}\text { Control drink } \\
(n=13)\end{array}$} & \multirow{2}{*}{$\begin{array}{c}\text { Wash- } \\
\text { out }\end{array}$} & $\begin{array}{l}\text { B-glucan drink } \\
(n=13)\end{array}$ \\
\hline \multicolumn{3}{|c|}{$\begin{array}{c}\beta \text {-glucan drink } \\
(n=12)\end{array}$} & & $\begin{array}{l}\text { Control drink } \\
(n=12)\end{array}$ \\
\hline 0 & days & 12 & & 33 \\
\hline$\uparrow$ & & $\uparrow$ & & $\uparrow$ \\
\hline
\end{tabular}

FIGURE 2 Experimental design of Studly 2

\section{Blood sampling}

The participants of Study 1 and Study 2 fasted overnight, did not use alcohol the previous day and did not smoke on the morning before blood sampling. All venipunctures were generally done by the same person between $8.00 \mathrm{~h}$ and $11.00 \mathrm{~h}$ $A M$, in the same room, and mostly at the same time of the day. Blood was sampled from a forearm vein using vacutainers under minimal stasis with the participant in a supine position for at least 5 minutes. The vacutainers were kept at room temperature before and after blood sampling. For analysis of serum lipids and lipoproteins, $10 \mathrm{ml}$ blood was collected in a serum tube (CORVAC; Sherwood Medical, St. Louis, USA). At least one hour after venipuncture, serum was obtained by centrifuging at $2000 \mathrm{xg}$ for 30 min at $4{ }^{\circ} \mathrm{C}$, which was stored at $-80{ }^{\circ} \mathrm{C}$.

In Study 1, blood samples were taken at the start of the study (day 0), at the end of the run-in period (weeks 2 and 3) and at the end of the treatment period (weeks 6 and 7). In Study 2, blood was sampled at the beginning of the study (day 0), at the end of the first dietary period (days 12 and 14), at the end of the wash-out period (day 21), and at the end of the second period of the trial (days 33 and 35 ).

\section{Analyses}

Concentrations of total cholesterol (CHOD-PAP method; Monotest cholesterol, Boehringer Mannheim GmbH, Mannheim, Germany), HDL cholesterol (precipitation method by adding a mixture of phosphotungstic acid and magnesium ions to the sample, and CHOD-PAP method; Monotest cholesterol, Boehringer Mannheim

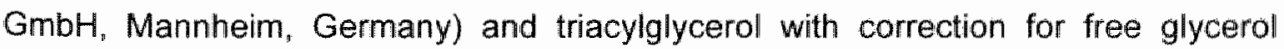


(GPO-Trinder; Sigma Diagnostics; St. Louis, USA) were analyzed in serum enzymatically. LDL cholesterol concentrations were calculated with the Friedewald equation (16). The caefficients of variation within runs for serum total cholesterol, $\mathrm{HDL}$ cholesterol and triacylglycerol of Study 1 were $1.2 \%, 3.9 \%$, and $2.3 \%$, respectively, and those of Study $21.1 \%, 5.0 \%$ and $1.8 \%$, respectively. All samples from one subject were analyzed within one run at the end of each trial.

The molecular weight (MW) distribution of $\beta$-glucan was determined by high performance size exclusion chromatography (HPSEC) (17) in oat bran and oat bran concentrate, after the baking of bread and cookies and after deep-freezing at $-18^{\circ} \mathrm{C}$.

\section{Statistics}

The power of Study 1 as well as of Study 2 to detect a difference in serum LDL concentrations of $8 \%(0.32 \mathrm{mmol} / \mathrm{L})$ between two treatments was $80 \%$. Only the results of the 48 out of 51 subjects who completed Study 1 were included in the analyses. In Study 1, the responses to treatment were calculated for each subject as the change between lipid and lipoprotein values obtained at the end of the treatment period (means of values of weeks 6 and 7) and at the end of the run-in period (means of values of weeks 2 and 3). Differences in changes between the two treatment groups of Study 1 were examined by using the unpaired $t$-test. At the end of the run-in period, all measured variables were not significantly different between the two groups of Study 1 (unpaired $t$-test).

Data of 25 out of 26 participants who completed Study 2 were included in the analyses. First, lipid and lipoprotein values of days 12 and 14 (Period I) and of days 33 and 35 (Period II) were averaged for each subject. Responses to treatment, which were calculated as the difference between values obtained at the end of the $\beta$-glucan drink period and the control drink period, were analyzed by the one-sample $t$-test. Carry-over effects on these responses, which were absent for all variables, were analyzed as described (18). In both trials, a value of $P<0.05$ was considered significant. Variables are presented as means \pm SEM. All statistical analyses were performed with StatVlew 5.0.

\section{Results}

\section{Molecular weight distribution of $\beta$-glucan in the oat products}

The molecular weight (MW) distribution of $\beta$-glucan was determined in oat bran and oat bran concentrate, after the baking of bread and cookies and after frozen storage (Table 3). The MW distribution of $\beta$-glucan in oat bran and in oat bran concentrate 
was very similar. Only 25 to $30 \%$ of the $\beta$-glucan had a MW below $250 \mathrm{kDa}, 50 \%$ of the $\beta$-glucan had a MW between 250 and $1000 \mathrm{kDa}$, whereas 20 to $30 \%$ of the $\beta$ glucan had a MW higher than $1000 \mathrm{kDa}$. In fresh and frozen bread, however, the MW of 55 to $60 \%$ of the $\beta$-glucan was less than $250 \mathrm{kDa}, 30 \%$ of $\beta$-glucan had a MW between 250 and $1000 \mathrm{kDa}$ and the MW of 10 to $15 \%$ of $\beta$-glucan was higher than $1000 \mathrm{kDa}$. $\beta$-Glucan in the frozen cookie had the largest MW and the concentration of $\beta$-glucan ( $4.1 \mathrm{~g} / 100 \mathrm{~g}$ of frozen oat cookie) remained unchanged. Thus, during the bread production the MW of $\beta$-glucan decreased, whereas the concentration of $\beta$ glucan ( $3.3 \mathrm{~g} / 100 \mathrm{~g}$ of fresh oat bread) did not change. Freezing did not have any effect on the MW of $\beta$-glucan or on the concentration of $\beta$-glucan $(3.2 \mathrm{~g} / 100 \mathrm{~g}$ of frozen oat bread).

\section{TABLE 3}

Molecular weight distribution of $\beta$-glucan in the oat bran products

\begin{tabular}{lccc} 
& \multicolumn{3}{c}{ MW } \\
& $>1000 \mathrm{kDa}$ & $250-1000 \mathrm{kDa}$ & $<250 \mathrm{kDa}$ \\
\hline Oat bran & 20 & 50 & 30 \\
Oat bran concentrate & 30 & 50 & $25^{\star}$ \\
Oat bran mix & 23 & 49 & 28 \\
& & & \\
Fresh oat bread & 10 & 30 & 60 \\
Frozen oat bread & 15 & 30 & 55 \\
Frozen oat cookie & 40 & 45 & 15 \\
\hline
\end{tabular}

\footnotetext{
"Values are in percentages. MW, molecular weight.
}

$\Rightarrow 100 \%$ due to rounding of the results.

\section{Dietary intake and body weight}

\section{Study 1: Effects of oat p-glucan in bread and cookies}

As calculated from the diaries, the mean daily consumption of $\beta$-glucan from oat bran during the treatment period was $5.9 \pm 0.2 \mathrm{~g}$ (range $4.3-8.6 \mathrm{~g}$ ), of which $5.1 \pm 0.2 \mathrm{~g}$ (range 3.7-7.5 g) came from bread and only $0.8 \pm 0.1 \mathrm{~g}$ from cookies (range 0.0-1.9 g) (Table 4). Changes in the estimated intake of energy and nutrients were not significantly different between the two groups, except for the percentage of energy $(\mathrm{En} \%)$ from protein and alcohol. The increase in the percentage of energy from protein of $2.1 \pm 0.4 \mathrm{En} \%$ in the $\beta$-glucan group was significantly different from the decrease of $0.5 \pm 0.3 \mathrm{En} \%$ in the control group $(P<0.001)$. For the percentage of 
energy from alcohol, the decrease of $0.5 \pm 0.2 \mathrm{En} \%$ in the $\beta$-glucan group was significantly different from of the increase of $0.1 \pm 0.1 \mathrm{En} \%$ in the control group ( $P=$ 0.043 ). Body weights changed slightly by $0.2 \pm 0.2 \mathrm{~kg}$ (range: $-1.2-2.1 \mathrm{~kg}$ ) in the control group and by $0.0 \pm 0.1 \mathrm{~kg}$ (range: $-1.2-1.5 \mathrm{~kg}$ ) in the $\beta$-glucan group. These changes were not significantly different $(P=0.350)$.

\section{TABLE 4}

Mean daily intake of $\beta-g$ lucan from oat bran in bread and cookies, energy and nutrients during Study $1^{\prime}$

\begin{tabular}{|c|c|c|}
\hline & Control products & $\beta$-Glucan products \\
\hline Total $\beta$-glucan (g) & & $5.9 \pm 0.2$ \\
\hline Of which from bread $(\mathrm{g})$ & & $5.1 \pm 0.2$ \\
\hline Of which from cookies (g) & & $0.8 \pm 0.1$ \\
\hline \multicolumn{3}{|l|}{ Energy $(M J / d)$} \\
\hline Run-in & $9.1 \pm 0.3$ & $8.8 \pm 0.3$ \\
\hline Treatment & $9.3 \pm 0.4$ & $8.6 \pm 0.3$ \\
\hline Change & $0.2 \pm 0.3$ & $-0.3 \pm 0.2$ \\
\hline \multicolumn{3}{|l|}{ Pratein (En\%) } \\
\hline Run-in & $15.9 \pm 0.4$ & $16.3 \pm 0.5$ \\
\hline Treatment & $15.4 \pm 0.4$ & $18.4 \pm 0.7$ \\
\hline Change & $-0.5 \pm 0.3$ & $2.1 \pm 0.4^{z}$ \\
\hline \multicolumn{3}{|l|}{ Fat $(E \cap \%)$} \\
\hline Run-in & $39.2 \pm 1.2$ & $40.4 \pm 1.1$ \\
\hline Treatment & $39.9 \pm 1.2$ & $41.6 \pm 1.1$ \\
\hline Change & $0.8 \pm 0.7$ & $1.2 \pm 0.8$ \\
\hline \multicolumn{3}{|l|}{ SFA $(E n \%)$} \\
\hline Run-in & $14.4 \pm 0.5$ & $15.2 \pm 0.5$ \\
\hline Treatment & $15.0 \pm 0.4$ & $15.6 \pm 0.5$ \\
\hline Change & $0.6 \pm 0.3$ & $0.5 \pm 0.3$ \\
\hline \multicolumn{3}{|l|}{ MUFA (En\%) } \\
\hline Run-in & $13.4 \pm 0.5$ & $13.8 \pm 0.4$ \\
\hline Treatment & $13.7 \pm 0.5$ & $14.9 \pm 0.4$ \\
\hline Change & $0.2 \pm 0.3$ & $1.1 \pm 0.4$ \\
\hline \multicolumn{3}{|l|}{ PUFA (En\%) } \\
\hline Run-in & $8.5 \pm 0.3$ & $8.5 \pm 0.3$ \\
\hline Treatment & $8.6 \pm 0.4$ & $8.4 \pm 0.3$ \\
\hline Change & $0.1 \pm 0.3$ & $-0.1 \pm 0.2$ \\
\hline
\end{tabular}


TABLE 4 Continued

Carbohydrates ( $\mathrm{En} \%$ )

$\begin{array}{lcr}\text { Run-im } & 51.8 \pm 1.4 & 49.0 \pm 1.0 \\ \text { Treatment } & 50.3 \pm 1.3 & 45.6 \pm 1.2 \\ \text { Change } & -1.5 \pm 0.7 & -3.5 \pm 0.7\end{array}$

Alcohol (En\%)

Run-in

$1.7 \pm 0.5$

$2.1 \pm 0.5$

Treatment

$1.8+0.6$

$1.6 \pm 0.5$

Change

$0.1 \pm 0.1$

$-0.5 \pm 0.2^{3}$

Cholesterol (mg/d)

Run-in

$210.6 \pm 13.4$

$220.3 \pm 12.8$

Treatment

$210.5 \pm 12.4$

$240.9 \pm 12.1$

Change

$-0.1 \pm 12.3$

$20.6 \pm 12.7$

Dietary fiber ( $g / M / J)$

Run-in

$3.7 \pm 0.1$

$3.6 \pm 0.1$

Treatment

$3.7 \pm 0.1$

$3.6 \pm 0.1$

Change

$-0.1 \pm 0.1$

$0.0 \pm 0.1$

\footnotetext{
"Walues are means \pm SEM; Fourty-eight participants consumed control bread and cookjes for three weeks (rumiin period). For the next four weeks (treatment period), one group continued consuming their control products (n (23). while the other group consumed bread and cookies rich in $\beta$-glucan from oat bran $(5.9 \mathrm{~g} / \mathrm{d}, n=25)$. Nutrient intake was calculated from a food frequency list filled in at the end of each period. SFA, saturated fatty acids: MUFA, monounsaturated fatty acids; PUFA, polyunsaturated fatty acids.

${ }^{2}{ }^{3}$ Significantly diffefent from the contirol group: ${ }^{2} P<0,001,{ }^{3} P<0.05$.
}

\section{Study 2: Effects of oat $\beta$-glucan in orange juice}

As calculated from the returned sachets, the mean daily intake of $\beta$-glucan from oat bran was $5.00 \pm 0.01 \mathrm{~g}$ (range 4.87-5.07 g). The difference in body weight of $0.0 \pm$ $0.2 \mathrm{~kg}$ between the control and $\beta$-glucan drink period was not significantly different ( $P$ $=0.902$ ).

\section{Lipids and lipoproteins}

\section{Study 1: Effects of oat $\beta$ glucan in bread and cookies}

Serum total cholesterol concentrations increased by $0.03 \pm 0.06 \mathrm{mmol} / \mathrm{L}$ in the control group and declined by $0.13 \pm 0.07 \mathrm{mmol} / \mathrm{L}$ after consumption of bread and cookies rich in $\beta$-glucan (Table 5). Changes in total cholesterol concentrations did not differ significantly between the control and $\beta$-glucan groups ( $95 \%$ confidence interval 
(Ci) for the difference in changes of $-0.16 \mathrm{mmol} / \mathrm{L}$ between the two groups: -0.36 to 0.03 mmoll $\mathrm{F}, P=0.098)$. Also, changes in serum LDL cholesterol $(95 \% \mathrm{Cl}$ for the difference: -0.29 to $0.05 \mathrm{mmol} / \mathrm{L} ; P=0.173)$, $\mathrm{HDL}$ cholesterol $(95 \% \mathrm{Cl}$ for the difference: -0.14 to $0.02 \mathrm{mmol} / \mathrm{L} ; P=0.154)$ and triacylglycerol $(95 \% \mathrm{Cl}$ for the difference: -0.16 to $0.21 \mathrm{mmol} / \mathrm{L} ; P=0.792)$ concentrations and the total to $\mathrm{HDL}$ cholesterol ratio $(95 \% \mathrm{Cl}$ for the difference: -0.19 to $0.23 ; P=0.835)$ were not significantly different between the two groups.

\section{TABLE 5}

Effects of $\beta$-glucan from oat bran in bread and cookies on serum lipid and lipoprotein concentrations in Study $1^{\text {t }}$

\begin{tabular}{|c|c|c|}
\hline & Control products & $\beta$-Glucan products \\
\hline \multicolumn{3}{|c|}{ Total cholesterol (mmol/L) } \\
\hline Rumin & $6.00 \pm 0.16$ & $5.98 \pm 0.16$ \\
\hline Treatment & $6.04 \pm 0.15$ & $5.85 \pm 0.118$ \\
\hline Change & $0.03 \pm 0.06$ & $-0.13 \pm 0.07$ \\
\hline \multicolumn{3}{|c|}{ LDL cholesterol (mmol/L) } \\
\hline Run-in & $4.09 \pm 0.17$ & $3.96 \pm 0.16$ \\
\hline Treatment & $4.11 \pm 0.16$ & $3.86 \pm 0.17$ \\
\hline Change & $0.02 \pm 0.06$ & $-0.10 \pm 0.06$ \\
\hline \multicolumn{3}{|c|}{ HDL cholesterol ( $\mathrm{mmol} / \mathrm{L})$} \\
\hline Run-in & $1.38 \pm 0.09$ & $1.50 \pm 0.09$ \\
\hline Treatment & $1.41 \pm 0.09$ & $1.47 \pm 0.08$ \\
\hline Change & $0.03 \pm 0.03$ & $-0.03 \pm 0.03$ \\
\hline \multicolumn{3}{|c|}{ Triacylglycerol (mmol/L) } \\
\hline Run-in & $1.15 \pm 0.09$ & $1.13 \pm 0.12$ \\
\hline Tréattment & $1.12 \pm 0.10$ & $1.13 \pm 0.14$ \\
\hline Changle & $-0.03 \pm 0.05$ & $-0.01 \pm 0.07$ \\
\hline \multicolumn{3}{|c|}{ Total to HDL cholesterol ratio } \\
\hline Run-in & $4.70 \pm 0.28$ & $4.35 \pm 0.29$ \\
\hline Treatment & $4.62 \pm 0.27$ & $4.29 \pm 0.28$ \\
\hline Change & $-0.08 \pm 0.08$ & $-0.06 \pm 0.07$ \\
\hline
\end{tabular}

'Values are means \pm SEM. For experimental details' see Table 4. The changes were not significantly different between the treatments. 


\section{Study 2: Effects of oat $\beta$-glucan in orange juice}

Consumption of $\beta$-glucan with orange juice lowered serum total cholesteral concentrations by $0.22 \pm 0.07 \mathrm{mmol} / \mathrm{L}$ or $3.8 \pm 1.3 \%$ as compared to the control drink (Table $6 ; 95 \% \mathrm{Cl}$ for the difference: -0.37 to $-0.07 \mathrm{mmol} / \mathrm{L} ; P=0.006$ ). Serum $\mathrm{LDL}$ cholesterol concentrations were also reduced after the $\beta$-glucan drink by $0.26 \pm 0.07$ mmol/L or $6.7 \pm 1.8 \%(95 \% \mathrm{Cl}$ for the difference: -0.41 . to $-0.12 \mathrm{mmol} / \mathrm{L} ; P=0.001)$ and the total to HDL cholesterol ratio by $0.26 \pm 0.11$ or $5.4 \pm 2.1 \%(95 \% \mathrm{Cl}$ for the difference: -0.48 to $-0.03 ; P=0.029)$ versus the control drink. HDL cholesterol $(95 \%$ $\mathrm{Cl}$ for the difference: -0.02 to $0.08 \mathrm{mmol} / \mathrm{L} ; P=0.222)$ and triacylglycerol $(95 \% \mathrm{Cl}$ for the difference: -0.11 to $0.16 \mathrm{mmol} / \mathrm{L} ; P=0.714$ ) were not significantly changed.

\section{TABLE 6}

Effects of $\beta$-glucan from aat bran in orange juice on serum lipid and lipoprotein concentrations in Study $2^{1}$

\begin{tabular}{lccc}
\hline & Control drink & p-Glucan drink & Difference \\
\hline Total cholesterol (mmol/L) & $5.58 \pm 0.13$ & $5.36 \pm 0.13$ & $-0.22 \pm 0.07^{2}$ \\
LDL cholesterol (mmol/L) & $3.77 \pm 0.14$ & $3.50 \pm 0.14$ & $-0.26 \pm 0.07^{2}$ \\
HDL cholesterol (mmol/L) & $1.25 \pm 0.07$ & $1.28 \pm 0.08$ & $0.03 \pm 0.03$ \\
Triacylglycerol (mmol/L) & $1.22 \pm 0.09$ & $1.24 \pm 0.12$ & $0.02 \pm 0.07$ \\
Total to HDL cholesteral ratio & $4.84 \pm 0.31$ & $4.58 \pm 0.32$ & $-0.26 \pm 0.11^{3}$ \\
\hline
\end{tabular}

Walues are means \pm SEM. During the first period of the trial, one group $(n=13)$ consumed wheat fiber with control arange juice, while the other group $(n=12)$ was given $\beta$-glucan from aat bran with orange juice. After the wash-out period, volunteers who consumed the control drink in the first period crossed over to the [3-glucan drink in the second period of the study, and vice versa.

${ }^{2}, 3$ Significantly different from the control drink: ${ }^{2} P<0.01,{ }^{3} P<0.05$.

\section{Discussion}

The present studies demonstrated that a mean daily intake of $5.9 \mathrm{~g}$ of $\beta$-glucan from oat bran administered in bread and cookies had no favorable effects on the serum lipoprotein profile (Study 1). A slight decrease of $0.16 \mathrm{mmol} / \mathrm{L}$ in total cholesterol and of $0.12 \mathrm{mmol} / \mathrm{L}$ in LDL cholesterol concentrations was observed, but these changes did not reach statistical significance. Based on the meta-analysis of Ripsin et al. (2), we expected that a daily intake of at least $3 \mathrm{~g}$ of $\beta$-glucan from oat bran per day would lower serum cholesterol concentrations in our mildly hypercholesterolemic subjects with more than $0.41 \mathrm{mmol} / \mathrm{L}$. When a lower amount of $5 \mathrm{~g}$ of oat $\beta$ mglucan was consumed with a drink, serum total cholesterol concentrations were lowered with 
0.22 mmollL (Study 2). This change, still less than expected, was mainly due to an effect on $L \mathrm{DL}$ cholesterol, which decreased by $0.26 \mathrm{mmol} L$. Consequently, the total to HDL cholesterol ratio decreased by $5 \%$.

Recent studies with oal $\beta$-glucan showed beneficial as well as no effects on the serum lipid profile $(3,19-26)$. It has been suggested that discrepancies between studies could be attributed to the source of the oat used (27). The source of $\beta$-glucan and the method of processing the oat bran or oat bran concentrate in both our studies, however, were similar and can therefore not explain why the drink with oat $\beta$ glucan appeared to be more effective than the bread and cookies enriched with oat Bigucan.

It can be argued that the mode of administration is important. In our first trial $5.1 \mathrm{~g}$ of the oat $\beta$ glucan was provided by bread and only $0.8 \mathrm{~g}$ by the cookies. It is therefore possible that incorporating the oat bran and oat bran concentrate into the bread may be responsible for the lack of effect. Effects of oats administered in bread on the lipid profile are indeed controversial. De Groot et al. (1) demonstrated that consumption of bread that provided $140 \mathrm{~g}$ of rolled oats per day led to a reduction in serum total cholesterol concentrations of $11 \%$. In contrast, other studies did not find any hypocholesterolemic effect of incorporating oats into bread $(22,27-29)$. However also studies that provided oat $\beta$-glucan in a drinkable preparation yielded conflicting results. Lovegrove et al. (26) found that LDL cholesterol concentrations were not affected by the minimal recommended dose by the FDA of $3 \mathrm{~g}$ of oat $\beta$-glucan per day, when consumed with low-fat yogurt or low-fat milk. Also, Beer et al. (23) failed to demonstrate a hypocholesterolemic effect after a daily intake of $9 \mathrm{~g}$ of $\beta$-glucan from oat gum, which was mixed in an instant whip. Other groups, however, observed significant reductions in serum LDL cholesterol concentrations, when the $\beta$-glucan preparation from oat bran was given with a drink $(3,25)$. Therefore, the mode of administration appears not to be a decisive factor.

A possible mechanism of action for the cholesterol-lowering effect of $\beta$-glucan is a decreased bile acid reabsorption caused by fiber binding or by an increased viscosity of intestinal contents $(23,30)$. The viscosity in the intestine may depend, among other things, on the solubility and molecular weight (MW) of $\beta$-glucan. It is, however, also not clear whether the inconsistent results of $\beta$-glucan in the oat products on the lipoprotein profile is due to variation in its MW. The authors of two different studies $(22,23)$ explained their negative results by the poor solubility and low to moderate MW of $\beta$-glucan in their oat products, which, in turn, may lead to a low viscosity in the intestine. In the study of Torroonen et al. (22), the MW of the $\beta$-glucan was low (370 kDa) (31). The MW of $\beta$-glucan used in the study of Beer et al. (23) was substantially 
higher $(1000 \mathrm{kDa})$, but still did not show any beneficial effects on the lipoprotein profile. In the study of Braaten et al. (3), however, consumption of $\beta$-glucan with a MW of $1200 \mathrm{kDa}$ resulted in reduced LDL cholesterol concentrations. Based on the results of these three studies $(3,22,23)$, it can be inferred that a hypocholesterolemic effect can be expected when the MW of $\beta$-glucan from oats is at least $1200 \mathrm{kDa}$. However, comparing these data with our results, it is doubtful that the height of the NW of $\beta$-glucan per se is a strong predictor of its cholesterollowering effect. Only 20 to $30 \%$ of our $\beta$-glucan had a MW above $1000 \mathrm{kDa}$. In fact, most of the $\beta$-glucan (about $75 \%$ ) had a MW that was lower than $1000 \mathrm{kDa}$. Our findings indicate that even though the MW of $\beta$-glucan is lower than $1200 \mathrm{kDa}$, it still has cholesterol-lowering properties when given with a drink. Furthermore, no clear dose-response relationship between the height of the MW of $\beta$-glucan and its cholesterol-lowering effect has been demonstrated in rats (31). $\beta$-Glucan with a MW of $370 \mathrm{kDa}$ resulted in a weak hypocholesterolemic effect, whereas $\beta$-glucan with a MW of $1000 \mathrm{kDa}$ or $1500 \mathrm{kDa}$ lowered total cholesterol concentrations by respectively 30 and $10 \%$. Thus, rats who consumed $\beta$-glucan from oat bran concentrate with the highest MW did not show the greatest cholesterol-lowering response. Therefore, despite the fact that the $M W$ of $\beta$-glucan decreased after incorporating it into bread, there is no clear evidence that only the decreased MW of $\beta$-glucan in the oat bread is responsible for the lack of effect. Besides, yeast-derived $\beta$-glucan also lowers LDL cholesterol concentrations, while it has a low viscosity and its water solubility (4) is much lower as $\beta$-glucan from oats (7). Therefore, the mechanism of action for the hypocholesterolemic effect of yeast-derived $\beta$-glucan can not be explained by its viscosity. These considerations make it questionable whether the cholesterol-lowering effect of $\beta$-glucan from oats depends solely on its viscous properties.

The results of our first study were not confounded by other factors that may influence the serum lipid concentrations, such as body weight or nutrient intake. In our second study, however, the energy content and nutrient composition were not identical when wheat fiber or oat bran was given with a drink. The daily energy intake from $12 \mathrm{~g}$ of wheat fiber was $2 \mathrm{KJ}$, whereas that from the oat bran mixture was $464 \mathrm{KJ}$ of which only $96 \mathrm{KJ}$ came from fat, and $226 \mathrm{KJ}$ and $142 \mathrm{KJ}$ from respectively carbohydrate and protein. However, even if subjects did not compensate for the small differences in energy and fat intake during the two weeks of supplementation, it is not very likelly that these differences have confounded the results (32).

We conclude that our $\beta$-glucan preparation from oat bran administered in bread and cookies is less effective, whereas the same preparation lowered total and LDL cholesterol concentrations and the total to HDL cholesterol ratio when consumed with 
orange juice. This indicates that the food matrix and/or food processing could have detrimental effects on the cholesterol-lowering properties of $\beta$-glucan from oat bran. There is no clear, unequivocal explanation for this difference in effect. Further, the precise mechanism of action for the cholesterol-lowering effect of $\beta$-glucan from oat remains to be elucidated. This raises the question if foods rich in $\beta$-glucan by definition lower $L D L$ cholesterol.

\section{Acknowledgements}

We are grateful to the members of our dietary and technical staff for their excellent support. We would also like to thank all subjects of the studies for their cooperation and interest. The studies were supported by Raisio Group plc, Raisio, Finland. 


\section{References}

1. De Groot AP, Luyken $R_{v}$ Pikaar NA. Cholesterol-lowering effect of rolled oats. Lancet $1963: 2: 303-4$.

2. Ripsin $C M$, Keenan JM, Jacobs $\mathrm{DR}_{\text {w }}$ et al. Oat products and lipid lowering: a metaanalysis. JAMA 1992;267:3317-25.

3. Braaten JT, Wood PJ, Scott FW, et al. Oat $\beta$-glucan reduces blood cholesterol concentration in hypercholesterolemic subjects. Eur J Clin Nutr 1994:48:465-74.

4. Bell S, Goldman VM, Bistrian BR, Arnold AH, Ostroff G, Forse RA. Elfect of B-glucan from oats and yeast on serum lipids. Crit Rev Food Sci Nutr 1999;39:189-202.

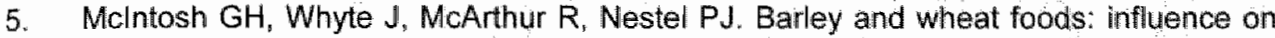
plasma cholesterol concentrations in hypercholesterolemic men. Am J Clin Nutr $1991,53: 1205-9$.

6. Bourdon 1, Yokoyama W, Davis $P$, et al. Postprandiall lipid, glucose, insulin, and cholecystokinin responses in men fed barley pasta enriched with $\beta$-glucan. Am $\mathrm{J}$ Clin Nutr 1999;69:55-63.

7. Nicolosi R, Bell SJ, Bistrian BR, Greenberg I, Forse RA, Blackburn GL. Plasma lipid changes after supplementation with $\beta$-glucan fiber from yeast. Am J Clin Nutr 1999;70:208-12.

8. Food labeling: health claims; oats and coronary heart disease. Food and Drug Administration, HHS. Proposed rule. Fed Regist 1996;61:296-313.

9. FDA Talk Paper. FDA allows whole oat foods to make health claim on reducing the risk of heart disease. January 1997. World Wide Web: http://www.cfsan.fda.gov/ Ird/tpoats.html (accessed 27 April 2001).

10. Centraal Begeleidingsorgaan voor de Intercollegiale Toetsing, in samenwerking met de Nederlandse Hartstichting, et all. Behandeling en preventie van coronaire hartziekten door verlaging van de plasmacholesteralconcentratie (Treatment and prevention of coronary heart disease by lowering plasma cholesterol concentrations). Utrecht: Centraal Begeleidingsorgaan voor de Intercollegiale Toetsing, 1998 (in Dutch).

11. Asp NG, Johansson $C G$, Hallmer $H$, Siljeström M. Rapid enzymatic assay of insoluble and soluble dietary fiber. Journal of Agricultural and Food Chemistry 1983;31:476-82.

12. Fat\% anallysis: AOAC $922.06 / C 112035$ version $0.1,20.08 .1998$.

13. Protein analysis: ICC-Standard no. 105/1.

14. Moisture analysis: ICC-Standard no. 110/1.

15. Ash analysis: ICC-Standard no. 104/1.

16. Friedewald WT, Levy $\mathrm{RI}_{\mathrm{s}}$ Fredrickson DS. Estimation of the concentration of lowdensity lipoprotein cholesterol in plasma, without use of the preparative ultracentrifuge. Clin Chem 1972:18:499-502.

17. Suortiti T. Size-exclusion chromatographic determination of beta-glucan with postcolumn reaction detection. J Chromatogr 1993;632:105-10.

18. Pocock SJ. Clinicals trials: a practical approach. Chichester: John Wiley and Sons, 1987

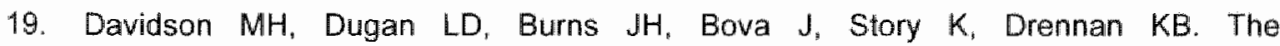
hypocholesterolemic effects of $\beta$-glucan in oatmeal and oat bran. A dose-controlled study. JAMA 1991;265:1833-9

20. Uusitupa MIJ, Ruuskanen $E$, Mäkinen $E_{\text {, }}$ et al. A controlled study on the effect of betaglucam-rich oat bran on serum lipids in hypercholesterolemic subjects: relation to apolipoprotein E phenotype. J Am Coll Nutr 1992;11:651-9. 
21. Mackay $S$, Ball MJ. Do beans and oalt bran add to the effectiveness of a low-fat diel? Eur J Clin Nutr 1992;46:641-8.

22. Torronen $R$, Kansanen L, Uusitupa $M$, et al. Effects of an oat bran concentrate on serum lipids in free-living men with mild to moderate hypercholesterolaemia. Eur $\mathrm{J}$ Clin Nutr 1992;46:621-7.

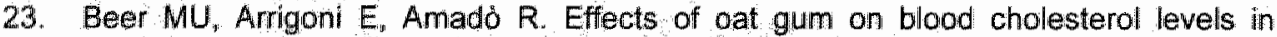
heaithy young men. Eur J Clin Nutr 1995;49:517-22.

24. Behall $\mathrm{KM}$. Scholfield DJ, Hallfisch J. Effect of beta-glucan level in oat fiber extracts on blood lipids in men and women. I Am Coll Nutr 1997;16:46-51.

25. Onning G, Wallmark A, Persson M, Akesson B, Elmstăhl S, Oste R. Consumption of oat milk for 5 weeks lowers serum cholesterol and LDL cholesterol in free-living men with moderate hypercholesterolemia. Ann Nutr Metab 1999;43:301-9.

26. Lovegrove JA, Clohessy $A$, Milon $H$, Williams $C M$. Modest doses of $\beta$-glucan do not reduce concentrations of potentially atherogenic lipoproteins. Am $J$ Clin Nutr $2000 ; 72: 49-55$.

27. Leadbetter J, Ball MJ. Mann Jl. Effects of increasing quantities of oat bran in hypercholesterolemic peoplle. Am J Clin Nutr 1991;54:841-5.

28. Bremer JM, Scott RS, Lintott CJ. Oat bran and cholesterol reduction: evidence against specific effect. Aust NZ J Med 1991;21:422-6.

29. Kestin $M_{1}$ Moss $R$, Clifton PM, Nestel PJ. Comparative effects of three cereal brans on plasma lipids, blood pressure, and glucose metabolism in mildly hypercholesterolemic men. Am J Clin Nutr 1990;52:661-6.

30. Lund EK, Gee JM, Brown JC, Wood PJ, Johnson IT. Effect of oat gum on the physical properties of the gastrointestinal contents and on the uptake of D-galactose and cholesterol by rat small intestine in vitro. Br J Nutr 1989;62:91-101.

31. Mälkki $Y$, Autio $K$, Hănninen $O$, et al. Oat bran concentrates: physical properties of $\beta$ glucan and hypocholesterolemic effects in rats. Cereal Chem 1992;69:647-53.

32. Mensink RP, Katan MB. Effect of dietary fatty acids on serum lipids and lipoproteins: a meta-analysis of 27 trials. Arterioscler Thromb 1992;12:911-9. 


\section{Chapter}

The effects of plant stanol esters, oat $\beta$-glucan and pravastatin on plasma lipid-soluble antioxidants in subjects with increased serum cholesterol concentrations

Daniëlle AJM Kerckhoffs ${ }^{1,2}$, Gerard Hornstra ${ }^{2}$ and Ronald P Mensink $k^{1,2}$

${ }^{\dagger}$ Department of Human Biology and ${ }^{2}$ Nutrition and Toxicology Research Institute Maastricht (NUTRIM), Maastricht University, Maastricht, The Netherlands

Submitted for publication 


\section{Abstract}

Objective: To study effects of two cholesterol-lowering dietary components, plant stanol esters (Study 1) and oat $\beta$-glucan (Study 2), which both act on intestinal sterol metabolism on plasma antioxidants in subjects with increased cholesterol concentrations. Effects were compared with those of pravastatin, an HMG-CoA reductase inhibitor (Study 3).

Design: In Study 1,21 men and 27 women consumed a control margarine for three weeks. Then, subjects were randomly allocated to one of two groups. For another four weeks, one group continued to consume control margarine ( $n=25)$, while the experimental group used a margarine with plant stanol esters $(2.01 \mathrm{~g} / \mathrm{d}$ of plant stanols provided as its fatty acid ester; $n=23$ ). During the first two weeks of Study 2 , 5 men and 8 women received wheat fiber with orange juice, while 5 men and 7 women consumed B-glucan ( $5 \mathrm{~g} / \mathrm{d}$ ) from oat bran with orange juice. After a wash-out period of one week, treatments were crossed over for two weeks. During the first three weeks of Study 3,22 men and 25 women consumed a cholesterol-lowering diet. After that participants were randomly divided into two groups, subjects continued their diets for another six weeks and received either placebo $(n=24)$ or pravastatin ( $40 \mathrm{mg} / \mathrm{d} ; n=23$ ) capsules.

Results: Plant stanol esters, oat $\beta$-glucan and pravastatin lowered the absolute plasma concentrations of the tocopherols (the sum of $\alpha$-tocopherol, $\beta+\gamma$-tocopherol and $\delta$-tocopherol). The hydrocarbon carotenoids (the sum of lycopene, a-carotene and $\beta$-carotene) decreased only by oat $\beta$-glucan and pravastatin, whereas the oxygenated carotenoids (the sum of lutein and $\beta$-cryptoxanthin) were reduced only by pravastatin. After correction for the serum content of total cholesterol plus triacylgllycerols (TC+TG), the hydrocarbon carotenaids decreased by $0.02 \mu \mathrm{mol} / \mathrm{mmol}$ TC+TG or $7.2 \%(P=0.037)$ after oat $\beta$-glucan and the tocopherols increased by 0.38 $\mu \mathrm{mol} / \mathrm{mmol} \mathrm{TC}+\mathrm{TG}$ or $8.7 \%$ with pravastatin $(P=0.002)$. Changes induced by plant stanol ester consumption were no longer significant.

Concllusions: After lipid-standardization, plant stanol esters ( $2 \mathrm{~g}$ plant stanols/d) had only small effects on plasma antioxidants. Oat $\beta$-glucan $(5 \mathrm{~g} / \mathrm{d})$ provided with a drink lowered the hydrocarbon carotenoids, while pravastatin $(40 \mathrm{mg} / \mathrm{d})$ increased the tocopherols. 


\section{Introduction}

$\beta$-Carotene, $\alpha$-carotene, lycopene, lutein and $\beta$-cryptoxanthin are the most common carotenoids in the diet and in the plasma $(1,2)$. Large observational epidemiologic studies have now suggested that these dietary components may lower the risk for chronic diseases, such as cancer, cardiovascular and age-related eye diseases (3). Large-scale intervention trials, however, failed to show a reduction in risk of lung cancer or cardiovascular disease when $\beta$-carotene was supplemented via capsules (4-6). Prospective studies also suggest that vitamin $E$, a generic term for the four forms $(\alpha, \beta, \gamma$ and $\delta$ ) of tocopherols and corresponding tocotrienols, protect against cardiovascular disease and cancer $(7,8)$. Again, however, these findings are not supported by large-scale randomized trials $(4,9-13)$.

Although the role of carotenoids and vitamin $E$ on health is still a matter of debate, there is some concern on the effects of plant sterols and stanols on plasma concentrations of these lipid-soluble antioxidants in humans. Plant sterols and stanols are potent cholesterol-lowering dietary components (14), which not only lower LDL cholesterol, but also plasma lipid-soluble antioxidants (15). For tocopherols and the oxygenated carotenoids (the sum of lutein and $\beta$-cryptoxanthin) this reduction can be explained by the decrease in the number of circulating LDL particles, which transport these antioxidants. Decreases in plasma hydrocarbon carotenoids (the sum of lycopene, $\alpha$-carotene and $\beta$-carotene), however, are related to the reduced cholesterol absorption; as caused by plant sterols and stanols (16).

Not only plant sterols and stanols but also other cholesterol-lowering agents, like the water-soluble dietary fibers (WSDF), may lower plasma concentrations of lipidsoluble antioxidants. In fact, it has been shown that after a meal enriched with the WSDF pectin, guar or alginate together with an antioxidant supplement, the plasma response curves of carotenoids are reduced $(17,18)$, but not those of $\alpha$-tocopherol (18). Information about the effects of the WSDF $\beta$-glucan from oats, which also lower LDL cholesterol concentrations (19), on plasma antioxidants in humans is scarce. The possible mechanism of action for cholesterol lowering of oat $\beta$-glucan differs from that of plant sterols and stanols, which reduce intestinal cholesterol absorption through displacement of intestinal cholesterol from the micelles (20). This reduction results in a compensatory increase in endogenous cholesterol synthesis (21) and in higher LDL-receptor expression (22). Oat $\beta$-glucan may decrease the absorption of bile acids due to fiber binding or to an increased viscosity of intestinal contents ( 23, 24).

We, therefore, decided to examine to what extent two different dietary components with different mechanisms of actions for cholesterol lowering - plant stanol esters and 
B-glucan from oat bran - affect plasma concentrations of carotenoids and tocopherols. Effects were compared with those of a lipid-lowering drug, pravastatin, which does not primarily act on intestinal cholesterol or bile acid absorption; but inhibits the activity of HMG-CoA reductase, the rate-limiting enzyme in the endogenous cholesterol synthesis (25).

\section{Subjects and methods}

\section{Subjects}

All volunteers were recruited from the general population of Maastricht and surroundings via advertisements in local newspapers. In addition, participants of earlier studies at our Department were approached. All subjects received an information brochure about the experimental protocol and purpose of the study before they were invited for a screening program, which consisted of measurements of body weight, height and blood pressure, two fasting blood samples for analyses of serum lipids and lipoproteins, and assessment of the absence of glucose in a morning specimen of urine. Furthermore, all volunteers had to fill in a medical questionnaire. Subjects were enrolled based on the following eligibility criteria: aged between 18 and 65 y (Study 1 and Study 2) or between 40 and 70 y (Study 3), stable body weight (weight gain or loss below $3 \mathrm{~kg}$ in the past three months), bodly mass index (BMI) below $30 \mathrm{~kg} / \mathrm{m}^{2}$, diastolic blood pressure below $95 \mathrm{mmHg}$, systolic blood pressure below $160 \mathrm{mmHg}$, no glucosuria, no history of coronary heart disease, and not pregnant or lactating. None of the subjects was allowed to use food products enriched with plant sterols or stanols, to donate blood or to participate in another biomedical trial within 30 days before or during the trial. For Studies 1 and 2 only, mean fasting concentrations of serum total cholesterol had to be below $8.0 \mathrm{mmol} / \mathrm{L}$, and those of triacylglycerol below $4.0 \mathrm{mmol} / \mathrm{L}$. Further, subjects had no indication for treatment with cholesterol-lowering drugs according to the Dutch Cholesterol Consensus (26), and no use of medication known to affect serum lipids. These latter criteria did not apply for Study 3, which was specifically designed for hypercholesterolemic subjects. The subjects of Study 3 were not allowed to use medication known to affect hemostasis. All study protocols were approved by the Ethics Committee of the Maastricht University and written informed consent was obtained from all subjects.

In all studies, subjects recorded in diaries any signs of illness, medication used, menstrual phase, alcohol consumption and any deviations from the protocol. In addition, subjects were asked not to change their habitual diets, smoking and 
drinking habits; level of physical activity, or use of oral contraceptives during the studies. Body weights without shoes and heavy clothes were recorded once a week and did not change significantly during the studies.

\section{Study 1: Effects of plant stanol esters}

In this study, which was also designed to examine the effects of plant stanol esters on serum lipids and lipoproteins, fifty-one subjects started, but one woman withdrew in the first week of the study because of stressful personal circumstances and one woman dropped out in the second week of the trial because of illness. Before the statistical analysis, one man was excluded due to unexpected high triacylglycerol concentrations ( $>4.5 \mathrm{mmol} / \mathrm{L}$ ) throughout the experiment. Thus, data of fourty-eight participants, 21 men and 27 women, were used. Men had an age of $55 \pm 1$ (mean \pm SEM) y. Their BMI was $25.5 \pm 0.6 \mathrm{~kg} / \mathrm{m}^{2}$. The age of women was $49 \pm 3 \mathrm{y}$. They had a BMI of $24.9 \pm 0.6 \mathrm{~kg} / \mathrm{m}^{2}$. In men, fasting concentrations of serum total cholesterol, LDL cholesterol, HDL cholesterol and triacylglycerol were $6.33 \pm 0.17 \mathrm{mmol} / \mathrm{L}, 4.35 \pm$ $0.16 \mathrm{mmol} / \mathrm{L}, 1.24 \pm 0.07 \mathrm{mmol} / \mathrm{L}$ and $1.61 \pm 0.18 \mathrm{mmol} / \mathrm{L}$, respectively. In women, these values were $6.03 \pm 0.14 \mathrm{mmol} / \mathrm{L}, 3.87 \pm 0.12 \mathrm{mmol} / \mathrm{L}, 1.69 \pm 0.07 \mathrm{mmol} / \mathrm{L}$ and $1.04 \pm 0.08 \mathrm{mmol} / \mathrm{L}$, respectively. Two men and two women smoked, four women used oral contraceptives and thirteen women were postmenopausal.

\section{Study 2: Effects of oat $\beta$-glucan in orange juice}

This study was also designed to test the efficacy of oat $\beta$-glucan on serum lipids and lipoproteins when given with a drink. Characteristics of the subjects have been described in detail elsewhere (Chapter 4). In brief, twenty-six subjects started the study, but one woman dropped out in the first week of the trial because of influenza. The remaining twenty-five subjects, 10 men and 15 women, completed the study. Men were $54 \pm 2 \mathrm{y}$ of age. They had a BMI of $24.9 \pm 0.7 \mathrm{~kg} / \mathrm{m}^{2}$. For women, these values were $53 \pm 3$ y and $24.6 \pm 0.8 \mathrm{~kg} / \mathrm{m}^{2}$, respectively. Fasting concentrations of serum total cholesterol, LDL cholesterol, HDL cholesterol and triacylglycerol were in men $6.09 \pm 0.23 \mathrm{mmol} / \mathrm{L}, 4.22 \pm 0.22 \mathrm{mmol} / \mathrm{L}, 1.23 \pm 0.09 \mathrm{mmol} / \mathrm{L}$ and $1.39 \pm 0.17$ $\mathrm{mmol} / \mathrm{L}$, respectively, and in women $5.94 \pm 0.23 \mathrm{mmol} / \mathrm{L}, 3.83 \pm 0.22 \mathrm{mmol} / \mathrm{L}, 1.67 \pm$ $0.09 \mathrm{mmol} / \mathrm{L}$ and $0.96 \pm 0.08 \mathrm{mmol} / \mathrm{L}$, respectively. One man and one woman were smokers. One woman used oral contraceptives and six women were postmenopausal.

\section{Study 3: Effects of pravastatin}

This study was designed to compare the effects of a tocotrienol-rich fraction from rice bran oil (TRF-RBO) with those of pravastatin on serum lipoproteins, markers for 
cholesterol synthesis and absorption, and hemostatic function in a hypercholesterolemic population (Chapter 3): For the present part of the study, we have selected a subpopulation of fourty-eight volunteers that received either the placebo or pravastatin treatment. The four men and eight women, who were on statin therapy, stopped using their lipid-lowering drugs two weeks before the start of the study. One woman dropped out in the fourth week of the trial because of muscle cramps possibly due to pravastatin therapy. Thus, the study population consisted of fourty-seven volunteers, 22 men and 25 women. Men were $54 \pm 1$ y of age and their BMI was $26.1 \pm 0.5 \mathrm{~kg} / \mathrm{m}^{2}$. For women, these values were $58 \pm 1 \mathrm{y}$ and $25.3 \pm 0.5$ $\mathrm{kg} / \mathrm{m}^{2}$, respectively. At day 0 of the study, fasting concentrations of serum total cholesterol and triacylglycerol in men were $7.37 \pm 0.12 \mathrm{mmol} / \mathrm{L}$ and $1.58 \pm 0.14$ mmol/ $L$, respectively. In women, these values were $7.58 \pm 0.15 \mathrm{mmol} / \mathrm{L}$ and $1.03 \pm$ $0.11 \mathrm{mmol} / L_{\text {, }}$ respectively. Six men and five women were smokers. Two women used oral contraceptives and fifteen women were postmenopausal.

\section{Experimental design}

\section{Study 1: Effects of plant stanol esters}

During the first three weeks of the randomized, double-blind, placebo-controlled parallell trail (run-in period), all subjects were asked to replace their usuall margarine by a sunflower oil-based control margarine. Subjects could choose for the rest of the study to use margarine with $38 \%$ ('light margarine') or $62 \%$ ('regular margarine') absorbable fats. In order to standardize fatty acid intake as much as possible during the study, they were also asked to replace their habitual baking fat by a sunflower oilbased shortening, which contained $99 \%$ absorbable fats. Family members of the participants could use the shortening as well, but not the margarine. After the run-in period, the participants, stratified for age and gender, were randomly assigned to one of two intervention groups for another four weeks. The controll group continued consuming control margarine, while the second group was provided with an experimental margarine with the same amount of absorbable fats $(38$ or $62 \%)$ and with the same fatty acid composition. The experimental margarine further contained $8.2 \mathrm{~g}$ of plant stanols $100 \mathrm{~g}$ product, which were added at the expense of water. The plant stanols, which were derived by hydrogenation from vegetable oil-based plant sterols, consisted of about $71 \%$ sitostanol and $29 \%$ campestanol, and were esterified with fatty acids from rapeseed oil. The composition of the sunflower oil-based margarines is shown in Table 1. The subjects had to consume minimal $20 \mathrm{~g}$ of the 
margarine daily throughout the study, divided over at least two eating moments. The aimed daily intake of plant stanols was therefore at least $1.64 \mathrm{~g}$.

The volunteers had to come to our Department once a week to receive the mangarine and shortening that were packed in 200 and $220 \mathrm{~g}$ tubs, respectively. Parts that were left over at the end of the week were collected and weighed back to estimate the daily intake of the margarine and shortening. For the shortenings, this amount was corrected for the number of persons who had eaten from the shortening. The control and experimental margarines, which were coded with a color label to blind the subjects and the investigators, were similar in color, taste, absorbable fat content, and caloric value. All products were provided by Raisio Group plc, Raisio, Finland.

\section{TABLE 1}

Composition of sunflower oil-margarines $\left(\mathrm{g} / 100 \mathrm{~g}\right.$ of product) in Study $1^{1}$

\begin{tabular}{|c|c|c|c|c|}
\hline & $\begin{array}{c}38 \% \\
\text { Control } \\
\text { margarine }\end{array}$ & $\begin{array}{c}62 \% \\
\text { Control } \\
\text { margarine }\end{array}$ & $\begin{array}{c}46 \% \\
\text { Stanol ester } \\
\text { margarine }\end{array}$ & $\begin{array}{c}70 \% \\
\text { Stanol ester } \\
\text { margarine }\end{array}$ \\
\hline Fat & 38.32 & 62.21 & 46.48 & 70.56 \\
\hline *absorbable fat & 38.32 & 62.21 & $38.31 *$ & $62.41^{*}$ \\
\hline Carbohydrates & 0.18 & 0.25 & 0.18 & 0.25 \\
\hline Protein & 0.14 & 0.20 & 0.14 & 0.20 \\
\hline Total plant stanols & 0.002 & 0.041 & 8.17 & 8.15 \\
\hline Sitostanol & 0.001 & 0.030 & 5.78 & 5.77 \\
\hline Campestanol & 0.001 & 0.011 & 2.39 & 2.38 \\
\hline \multicolumn{5}{|l|}{ Total unsaturated } \\
\hline plant sterols & 0.119 & 0.196 & 0.19 & 0.25 \\
\hline Brassicasterol & 0.005 & 0.008 & 0 & 0 \\
\hline Campesterol & 0.031 & 0.048 & 0.05 & 0.07 \\
\hline Sitosterol & 0.076 & 0.128 & 0.14 & 0.18 \\
\hline Stigmasterol & 0.007 & 0.011 & 0 & 0 \\
\hline $\begin{array}{l}\text { Total stanols plus } \\
\text { unsaturated sterols }\end{array}$ & 0.121 & 0.237 & 8.36 & 8.40 \\
\hline
\end{tabular}

"absorbable fat = total fat - total plant stanols. In this parallel study, fourtymeight subjects received sunflower oilbased control margarine for three weeks (run-in period). During the intervention period of four weeks, one group continued consuming their control margarime $(n=25)$, while the other group consumed sunflower oilloased margarine $(24.57 \mathrm{~g} / \mathrm{d})$ erriched with plant stanol esters $(2.01 \mathrm{~g}$ plant stanols/d: $n=23$ ), 
In the last week of both the run-in and treatment period, subjects recorded their food intake for the previous four weeks by filling in food frequency lists to estimate their energy and nutrient intakes throughout the study. A registered dietician in the presence of the subjects checked the food frequency lists. Changes in the estimated intake of energy and nutrients did not significantly differ between the two groups of Study 1 , except for the percentage of energy $(\mathrm{En} \%)$ from protein. The increase in the percentage of energy from protein of $2.1 \pm 0.4 \mathrm{En} \%$ in the control group was significantly different from the increase of $0.8 \pm 0.4 \mathrm{En} \%$ in the plant stanol ester group $(P=0.026)$.

\section{Study 2: Effects of oat $\beta$-glucan in orange juice}

The design of Study 2 has been described in detail elsewhere (Chapter 4). In brief, this study had a randomized, controlled crossover design. Before the beginning of the trial, the subjects were randomly divided into two groups, stratified for age and gender. During the first period of two weeks, one group received wheat fiber with arange juice (control drink), while the other group was given $\beta$-glucan from oat bran with orange juice ( $\beta$-glucan drink). After a wash-out period of one week, subjects who consumed the control drink in the first two weeks crossed over to the $\beta$-glucan drink in the second period of two weeks, and vice versa.

The wheat fiber (VITACEL Wheat Fibre WF 200, Rosenberg, Germany) contained $93.3 \%$ total dietary fiber, of which $98.8 \%$ was water-insoluble fiber, mainly cellulose and hemicellulose. Oat bran (Melia Oy, Raisio, Finland) consisted of $20.6 \%$ of total dietary fiber, of which $41 \%$ was $\beta$-glucan, whereas oat bran concentrate (Swedish Oat Fiber, Väröbacka, Sweden) contained $40.3 \%$ total dietary fiber, of which $53 \%$ was $\beta$-glucan. A detailed composition of the wheat fiber, oat bran and oat bran concentrate has been given before (Chapter 4).

During the two periods of two weeks each, subjects consumed daily two glasses of orange juice rich in control fiber from wheat or $\beta$-glucan from oat bran, at two separate occasions with an interval of at least three hours. Every week each subject received fifteen sachets of wheat fiber or oat bran: two sachets for each day plus one spare sachet. The subjects were asked to mix each sachet with wheat fiber $(6 \mathrm{~g})$ or oat bran ( $14 \mathrm{~g}$ oat bran plus $6 \mathrm{~g}$ oat bran concentrate) with $200 \mathrm{ml}$ of orange juice, which was also provided. Thereafter, this mixture had to be cansumed immediately as palatability decreased with time. One sachet of oat bran provided $2.5 \mathrm{~g}$ of $\beta$ glucan. Thus, the aimed daily intake of $\beta$-glucan from oat bran was $5 \mathrm{~g}$. The total dietary fiber content of the wheat fiber and the oat bran sachets were comparable (about $5 \mathrm{~g}$ per sachet), but the color, taste and fat content differed due to the use of 
different sources of fiber. At the end of each period, all sachets that were left over were collected and counted.

\section{Study 3: Effects of pravastatin}

Details of the design of this study have been described before (Chapter 3). Briefly, Study 3 had a randomized, double-blind, placebo-controlled parallell design. All volunteers followed a cholesterol-lowering diet during the study period of nine weeks according to the Dutch dietary guidelines (27). In this diet, which is comparable with a National Cholesterol Education Program (NCEP) step I diet (28), the intake of fat is 30-35 En\% and of saturated fat plus trans fatty acids maximal $10 \mathrm{En} \%$. The daily cholesterol intake was restricted to a maximum level of $300 \mathrm{mg}$. Before the start of the study, subjects had to fill in a food frequency list for the last four weeks to estimate their habitual intakes of energy and nutrients. Based on their current dietary habits, individual instructions were given by the dietician to achieve adherence to the recommended diet.

During the run-in period of three weeks, all participants followed the cholesterollowering diet. For another six weeks, the volunteers, stratified for age and gender, were randomly allociated to one of two treatment groups. In adidition to the cholesterol-lowering diet, the control group consumed daily one placebo capsule for pravastatin (cellulose micro cristallinun $\mathrm{Ph} \mathrm{102)} \mathrm{just} \mathrm{before} \mathrm{bedtime.} \mathrm{The} \mathrm{other} \mathrm{group}$ took daily one pravastatin capsule (Bristol-Myers Squibb. The Netherlands) of $40 \mathrm{mg}$ just before bedtime. The participants received their number-coded capsules from the pharmacy of the University Hospital Maastricht at weeks 3 and 6 of the experiment.

In the last week of the run-in period and at the end of the treatment period, subjects recorded their food intake for the last four weeks by filling in food frequency lists to estimate their intake of energy and nutrients throughout the study. Food frequency lists were checked by a registered dietician in the presence of the subjects. Changes in the estimated intake of energy and nutrients were not significantly different between the two groups.

\section{Blood sampling}

Blood was sampled after an overnight fast and after abstinence of drinking alcohol the previous day and smoking on the morning before blood sampling. Venous blood samples were generally taken by the same person between $8.00 \mathrm{~h}$ and $11.00 \mathrm{~h} \mathrm{AM}$, in the same room, and mostly at the same time of the day. Blood was sampled from a forearm vein using vacutainers under minimal stasis with the subject in a supine 
position for at least 5 minutes. The vacutainers were kept at room temperature before and after blood sampling.

First, $10 \mathrm{ml}$ blood was collected in a serum tube (CORVAC; Sherwood Medical, St. Louis, USA) for analyses of serum lipids and lipoproteins. At least one hour after venipuncture, serum was obtained by centrifuging at $2000 \times \mathrm{g}$ for $30 \mathrm{~min}$ at $4{ }^{\circ} \mathrm{C}$, which was stored at $-800^{\circ} \mathrm{C}$.

Thereafter; $10 \mathrm{ml}$ blood was collected in an EDTA tube (Sherwood Medical, Ballymoney, Northern Ireland). Plasma for measurement of tocopherols and carotenoids was obtained by centrifuging the blood at $2000 \times \mathrm{g}$ for $30 \mathrm{~min}$ at $4{ }^{\circ} \mathrm{C}$ within one hour after venipuncture. Plasma samples were frozen in liquid nitrogen and stored at $-80^{\circ} \mathrm{C}$.

In Study 1, blood samples were taken at the start of the study (day 0), at the end of the run-in period (weeks 2 and 3), and at the end of the experimental period (weeks 6 and 7). In Study 2, blood was sampled at day 0 , at the end of the first dietary period (days 12 and 14), at the end of the wash-out period (day 21), and at the end of the second period of the trial (days 33 and 35 ). In Study 3 , blood samples were taken at day 0 , at weeks 2 and 3 (run-in period), and at weeks $4,5,8$ and 9 (treatment period).

\section{Analyses}

\section{Lipids and lipoproteins}

Serum lipids and lipoproteins were determined as described before (Chapter 3 and Chapter 4).

\section{Lipid-soluble antioxidants}

Plasma samples of Stuidy 1 taken at weeks 2 and 3 (run-in period) as well as at weeks 6 and 7 (treatment period)" those of Study 2 taken at days 12 and 14 (Period I) as well as at days 33 and 35 (Period II), and those of Study 3 at weeks 2 and 3 (run-in period) and at weeks 8 and 9 (treatment period) were pooled before analyses of lipid-soluble antioxidants. Retinyl-acetate was used as internal standard for tocopherols ( $\delta$-tocopherol, $\beta+\gamma$-tocopherol and $\alpha$-tocopherol) and various carotenoids (lutein, $\beta$-cryptoxanthin, lycopene, $\alpha$-carotene and $\beta$-carotene). Concentrations of tocopherols and carotenoids were determined simultaneously by reversed-phase high-pressure liquid chromatography (HPLC) as described $(29,30)$. The average recovery's of retinyl-acetate in Study 1 , Study 2 and Study 3 were $102 \pm$ $1 \%, 92 \pm 1 \%$ and $99 \pm 2 \%$, respectively. 
The antioxidant concentrations in all studies were corrected for total cholesterol plus triacylglycerol concentrations (TC+TG) by using mean TC+TG from weeks 2 and 3 and from weeks 6 and 7 (Study 1), from days 12 and 14 and from days 33 and 35 (Study 2), and from weeks 2 and 3 and from weeks 8 and 9 (Study 3).

\section{Statistics}

In Study 1 as well as in Study 3 , the responses to treatment were calculated for each subject as the change between values obtained at the end of the treatment period and at the end of the run-in period. Differences in changes between the two treatment groups of both trials were determined by using the unpaired $t$-test. At the end of the run-in period, all measured variables were not significantly different between the two groups in Study 1 and Study 3 (unpaired t-test). In Study 2, responses to treatment, which were calculated for each subject as the difference between values obtained at the end of the $\beta$-glucan drink period and the control drink period, were analyzed by the one-sample $t$-test. Carry-over effects on these responses, which were absent for all variables, were analyzed as described (31). In all three trials, a value of $P<0.05$ was considiered significant. Variables are presented as means \pm SEM. All statistical analyses were performed with StatView 5.0 .

\section{Results}

\section{Lipids and lipoproteins}

\section{Study1: Effects of plant stanol esters}

During the intervention period, serum total cholesterol concentrations decreased from 5.98 to $5.85 \mathrm{mmol} / \mathrm{L}$ in the control group, and from 5.91 to $5.48 \mathrm{mmol} / \mathrm{L}$ after daily consumption of $2.01 \pm 0.09 \mathrm{~g}$ of plant stanols in ester form (Table 2). The difference in changes of $-0.30 \mathrm{mmol} / \mathrm{L}$ or $-5.0 \%$ between both groups was significant ( $P=$ $0.010)$. In the plant stanol ester group. LDL cholesterol concentrations declined by $0.41 \mathrm{mmol} / \mathrm{L}$, and by $0.10 \mathrm{mmol} / \mathrm{L}$ in the control group. The difference in changes of $0.31 \mathrm{mmol} / \mathrm{L}$ or $-8.0 \%$ between the two groups was significant $(P=0.006)$. The rise of $0.05 \mathrm{mmol} / \mathrm{L}$ in $\mathrm{HDL}$ cholesterol in the plant stanol ester group was also significantly different from the decrease of $0.03 \mathrm{mmol} / \mathrm{L}$ in the control group. The 
difference in changes between the two groups was $0.08 \mathrm{mmol} L \mathrm{~L}$ or $5.1 \%(P=0.021)$. Tracylglycerol concentrations were not significantly changed $(P=0.130)$.

\section{TABLE 2}

Effects of margarine enriched with plant stanol esters on serum lipid and lipoprotein concentrations in Study 1 ?

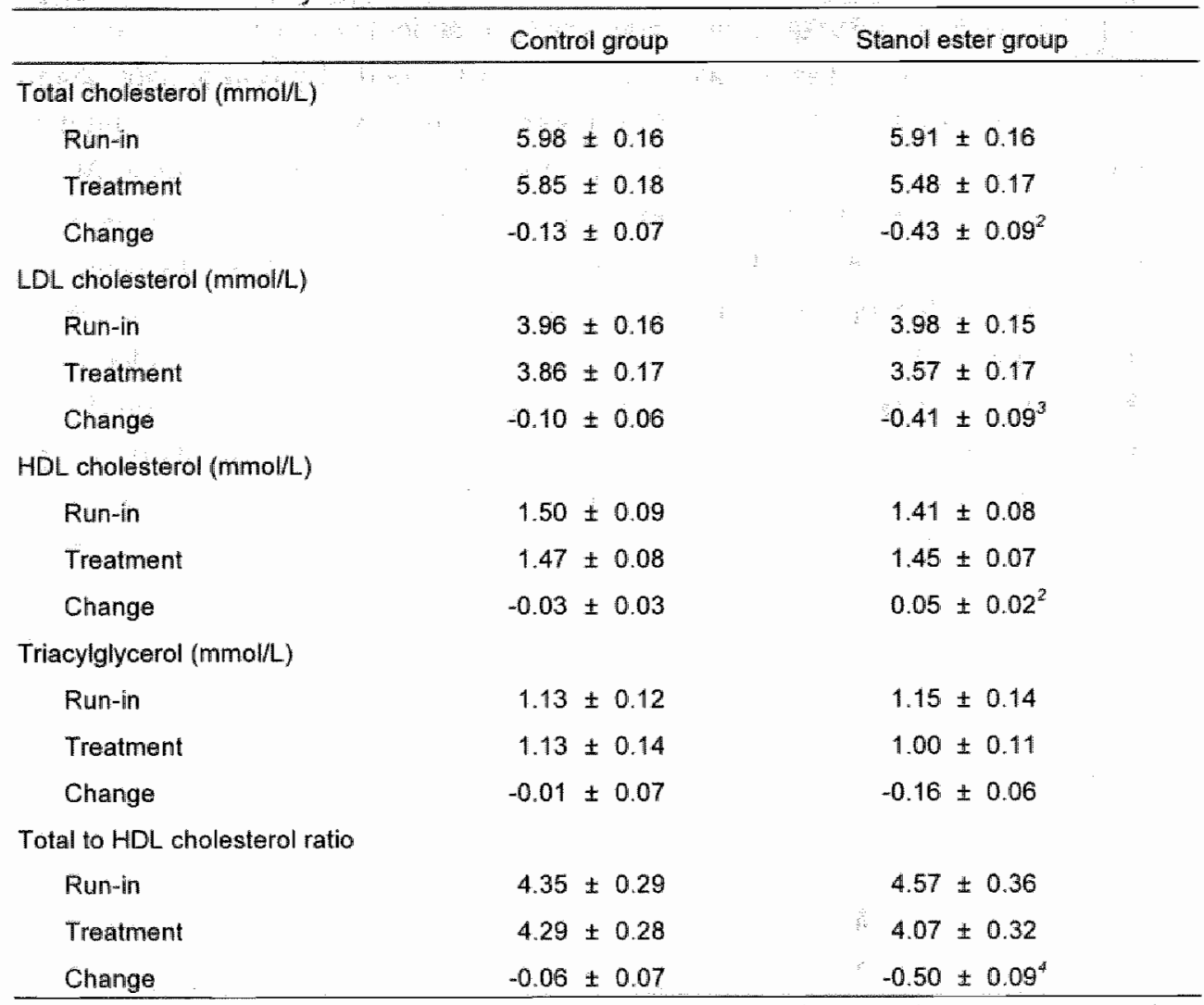

"Values are means \pm SEM. For expmentmental details of this parallel study: see Table 1.

2.3, Significantly different from the control group: ${ }^{2} P<0.05,{ }^{3} p<0.01,{ }^{4} p<0.001$.

\section{Study 2: Effects of oat $\beta$-glucan in orange juice}

As described before (Chapter 4 ), daily consumption of $5.00 \pm 0.01 \mathrm{~g}$ of $\beta$-glucan from oat bran with orange juice reduced serum total cholesterol concentrations by 0.22 mmol/ $L$ or $3.8 \%$ as compared to the control drink $(P=0.006)$. Serum $L D L$ cholesterol concentrations were also lowered by $0.26 \mathrm{mmol} / \mathrm{L}$ or $6.7 \%$ after consumption of the $\beta$-glucan drink as compared to the control drink $(P=0.001)$. HDL cholesterol $(P=$ $0.222)$ and triacylglycerol concentrations $(P=0.714)$ remained unchanged. 


\section{Study 3: Effects of pravastatin}

As described elsewhere (Chapter 3), serum total cholesterol concentrations increased slightly from 7.14 to $7.19 \mathrm{mmo} / \mathrm{L}$ in the placebo group, and declined from 7.39 to $5.54 \mathrm{mmol} / \mathrm{L}$ after treatment with pravastatin $(40 \mathrm{mg} / \mathrm{d})$. The difference in changes of -1.90 mmol/L or $-26.0 \%$ between the two groups was significant $(P<$ $0.001)$. In the pravastatin group, $L D L$ cholesterol concentrations changed from 5.67 to $3.83 \mathrm{mmol} / \mathrm{L}$, and from 5.16 to $5.15 \mathrm{mmol} / \mathrm{L}$ in the placebo group. The difference in changes of $-1.81 \mathrm{mmol} / \mathrm{L}$ or $-32.4 \%$ between both groups was significant $(P<0.001)$. The rise in $\mathrm{HDL}$ cholesterol concentrations in the pravastatin group from 1.08 to 1.24 $\mathrm{mmol} / \mathrm{L}$ was higher than the increase from 1.38 to $1.40 \mathrm{mmol} / \mathrm{L}$ in the placebo group. The difference in changes of $0.14 \mathrm{mmol} / \mathrm{L}$ or $11.9 \%$ between the two groups was significant $(P=0.009)$. The decrease in triacylglycerol in the pravastatin group from 1.40 to $1.01 \mathrm{mmol} / \mathrm{L}$ was significantly different from the increase from 1.31 to 1.41 $\mathrm{mmol} / \mathrm{L}$ in the placebo group. The difference in changes between the two groups was $-0.48 \mathrm{mmol} / \mathrm{L}$ or $-33.0 \%(P<0.001)$.

\section{Lipid-soluble antioxidants}

\section{Study 1: Effects of plant stanol esters}

Figure 1(a) illustrates the changes after consumption of plant stanol esters in the absolute plasma concentrations of the tocopherols (the sum of $\alpha$-tocopherol, $\beta+\gamma$ tocopherol and $\delta$-tocopherol), which are less lipophylic than the oxygenated carotenoids (the sum of lutein and $\beta$-cryptoxanthin), which in turn are less lipophylic than the hydrocarbon carotenoids (the sum of lycopene, $\alpha$-carotene and $\beta$-carotene). The reduction in the plasma concentrations of the sum of the tocopherols after consumption of plant stanol esters was due to decreases in all the tocopherols. For the sum of the tocopherols, the difference in changes between the two groups was $4.95 \mu \mathrm{mol} / \mathrm{L}$ or $-16.6 \%(P=0.008$ for the difference in absolute changes; $95 \%$ confidence interval $(\mathrm{Cl})$ for the difference: -8.53 to $-1.37 \mu \mathrm{mol} / \mathrm{L})$. The differences in changes of $-0.09 \mu \mathrm{mol} / \mathrm{L}$ or $-9.2 \%$ between the two groups for the sum of the oxygenated carotenoids nearly just reached statistical significance $(P=0.050 ; 95 \%$ $\mathrm{Cl}$ for the difference: -0.17 to $0.00 \mu \mathrm{mol} / \mathrm{L}$ ), but those for the hydrocarbon carotenoids did not $(P=0.263 ; 95 \% \mathrm{Cl}$ for the difference: -0.41 to $0.12 \mu \mathrm{mol} / \mathrm{L})$. 
a
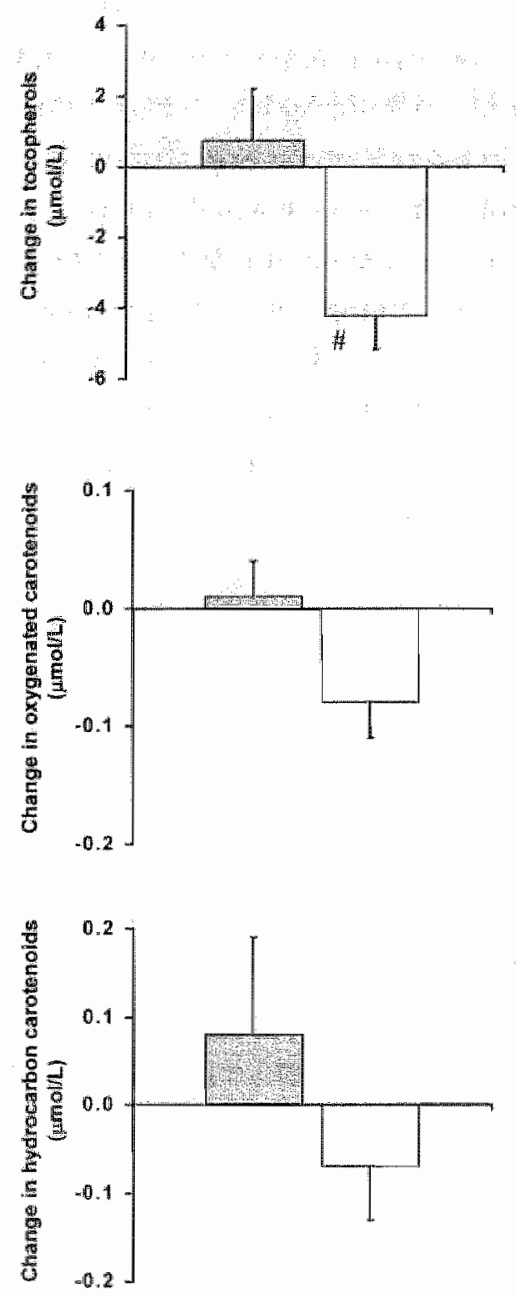

b
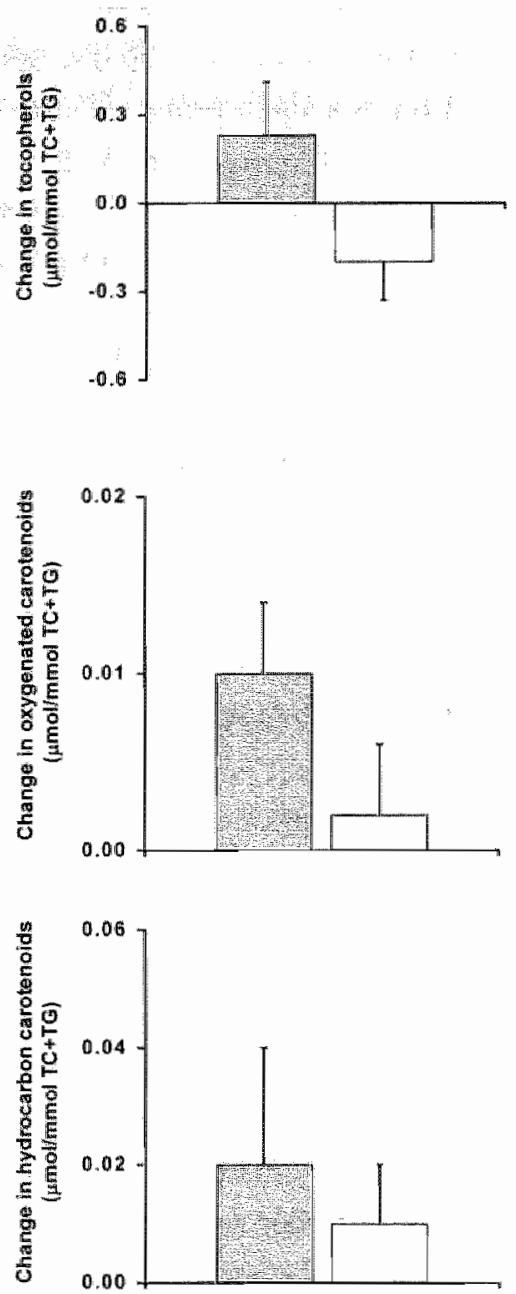

FIGURE 1 Mean ( 1 SEM) changes in the absolute plasma concentrations of the tocopherols. (the sum of $\alpha$ tocopherol, $\beta+\gamma$ tocopherol and 8-tocopherol), the oxygenated carotenoids (the sum of lutein and $\beta-$ cryptoxanthin) and the hydrocarbon carotenoids (the sum of lycopene, $\alpha$-carotene and $\beta$-carotene) (a) as well as the changes after standardization for total cholesterol plus triacylglycerol concentrations (TC+TG) (b) at the end of the treatment period with control margarine (gray bars; $n=25$ ) or surflower oil-based margarine enriched with plant stanol esters (white bars; $2.01 \mathrm{~g}$ plant stanols $/ \mathrm{d}_{1} n=23$ ). "Significantly different from the control group " $P<$ 0.01 . 
When corrected for total cholesterol plus triacylglycerol concentrations (TC+TG), the sum of the tocopherols decreased in the plant stanol ester group from $5.02 \pm 0.16$ to $4.82 \pm 0.23 \mu \mathrm{mol} / \mathrm{mmol} \mathrm{TC}+\mathrm{TG}$ versus the increase in the control group from $4.99 \pm$ 0.24 to $5.23 \pm 0.24 \mu \mathrm{mol} / \mathrm{mmol}$ TC+TG. The difference in changes of -0.43 $\mu \mathrm{mal} / \mathrm{mmol}$ TC+TG or $-11.2 \%$ nearly reached statistical significance $(P=0.065 ; 95 \%$ Ci for the difference: -0.90 to $0.03 \mu \mathrm{mol} / \mathrm{mmol} T \mathrm{TC}+\mathrm{TG}$; Figure $1(\mathrm{~b})$ ). After lipidstandardization, changes between both groups were not significantly different for the oxygenated carotenoids $(P=0.613 ; 95 \% \mathrm{Cl}$ for the difference: -0.02 to 0.01 $\mu \mathrm{mol} / \mathrm{mmol} \mathrm{TC}+\mathrm{TG})$ and for the hydrocarbon carotenoids $(P=0.603 ; 95 \% \mathrm{Cl}$ for the difference: -0.05 to $0.03 \mu \mathrm{mol} / \mathrm{mmol} \mathrm{TC}+\mathrm{TG}$ ). Comparable effects were found after the antioxidant concentrations were standardized for total cholesterol or for LDL cholesterol concentrations, although for the tocopherols the difference in changes reached statistical significance after correction for total cholesterol concentrations ( $P$ $=0.039$ ).

\section{Study 2: Effects of oat $\beta$-glucan in orange juice}

For the sum of the tocopherols, the difference between the control drink and oat $\beta$ glucan drink was $-1.77 \mu \mathrm{mol} / \mathrm{L}$ or $-4.1 \%(P=0.041$ for the absolute difference; $95 \%$ $\mathrm{Cl}$ for the difference: -3.46 to $-0.08 \mu \mathrm{mol} / \mathrm{L})$, and for the sum of the hydrocarbon carotenoids $-0.15 \mu \mathrm{mol} / \mathrm{L}$ or $-10.4 \%(P=0.002 ; 95 \% \mathrm{Cl}$ for the difference: -0.23 to $0.06 \mu \mathrm{mol} / \mathrm{L} ;$ Figure 2(a)). The decreases were due to reductions in all the tocopherols and hydrocarbon carotenoids. The oxygenated carotenoids were not affected $(P=0.853 ; 95 \% \mathrm{Cl}$ for the difference: -0.10 to $0.08 \mu \mathrm{mol} / \mathrm{L}$ ).

When the absolute concentrations of the sum of the hydrocarbon carotenoids were standardized for $\mathrm{TC}+\mathrm{TG}$, the difference between the control drink and oat $\beta$-glucan drink of $-0.02 \mu \mathrm{mol} / \mathrm{mmol}$ TC + TG or $-7.2 \%$ remained significant $(P=0.037 ; 95 \% \mathrm{Cl}$ for the difference: -0.03 to $0.00 \mu \mathrm{mol} / \mathrm{mmol} T C+T G$; Figure $2(\mathrm{~b})$ ). The lipidstandardized concentrations of the tocopherols $(P=0.252 ; 95 \% \mathrm{Cl}$ for the difference: -0.36 to $0.10 \mu \mathrm{mol} / \mathrm{mmol} \mathrm{TC}+\mathrm{TG})$ and of the oxygenated carotenoids $(P=0.507$; $95 \% \mathrm{Cl}$ for the difference: -0.01 to $0.02 \mu \mathrm{mol} / \mathrm{mmol} \mathrm{TC}+\mathrm{TG}$ ) were not significantly affected. When the antioxidant concentrations were corrected for total cholesterol or for LDL cholesterol concentrations, the effects were comparable, although for the hydrocarbon carotenoids the difference was not significant after LDL cholesterolstandardization $(P=0.246)$. 
a
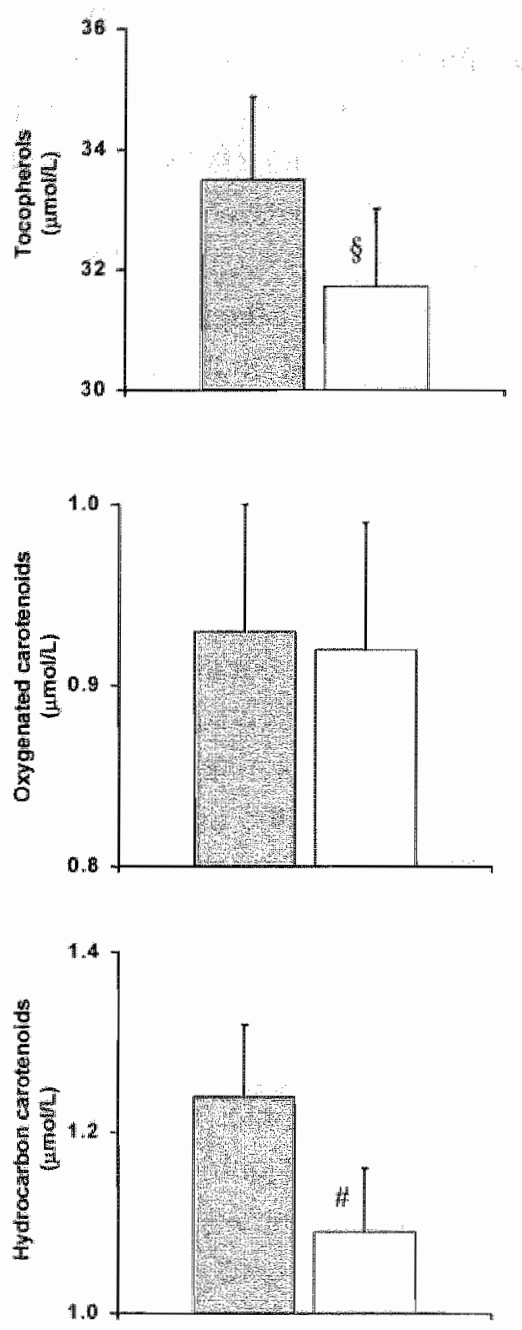

b
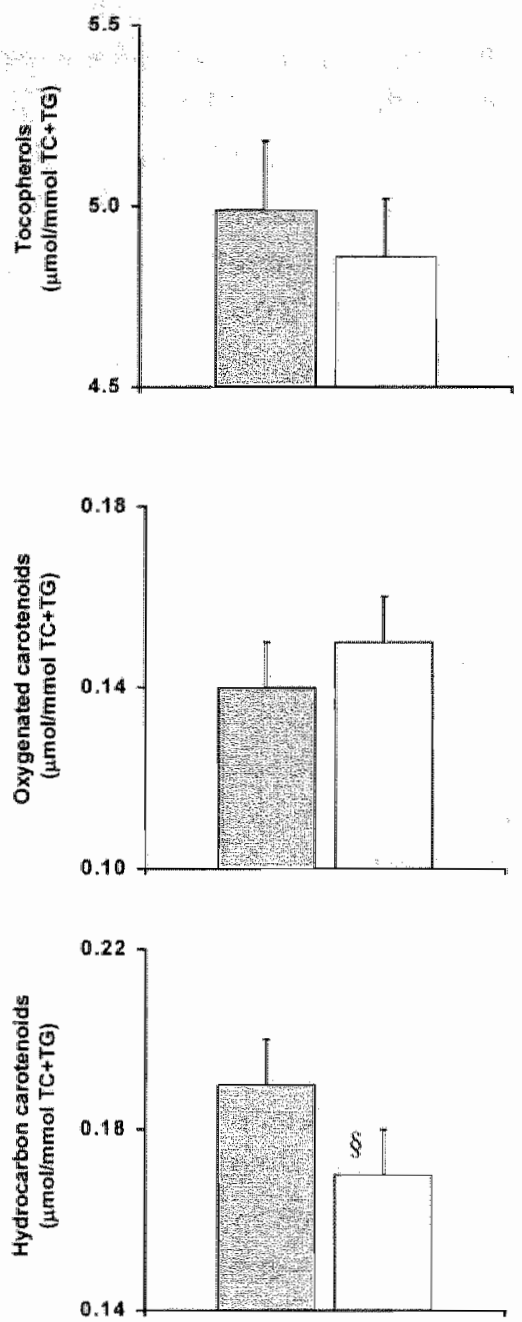

FIGURE 2 Mean ( \pm SEM) absolute plasma concentrations of the tocopherols (the sum of $\alpha$-tocopherol, $3+$ $\gamma$-tocophenol and s-tocopherol), the oxygenated carotenoids (the sum of lutein and $\beta$-cryptoxanthim) and the hydrocarbon carotenoids (the sum of lycopene, $\alpha$-carotene and $\beta$-carotere) (a) as well as the values after stiandandization for total cholesterol plus triacylglycerol concentrations (TC+TG) (b) after consumption of the wheat fiber (gray bars) and oat $\beta-g l u c a n$ (white bars; $5 \mathrm{~g} / \mathrm{d}$ ) with orange juice. "Significantly different from the control drink: $p<0.01,8 p<0.05$. 


\section{Study 3: Effects of pravastatin}

Treatment with pravastatin lowered the absolute concentrations of the sum of the tocopherols and of the oxygenated and hydrocarbon carotenoids (Figure $3(a)$ ). These reductions were due to decreases in all the tocopherols and carotenoids. For the sum of the tocopherols, the difference in changes between the two groups was -10.2 umol/L or $-23.9 \%(P<0.001 ; 95 \% \mathrm{Cl}$ for the difference: -12.78 to $-7.61 \mu \mathrm{mol} / \mathrm{L})$, for the sum of the oxygenated carotenoids $-0.19 \mu \mathrm{mol} / \mathrm{L}$ or $-19.9 \%(P=0.002 ; 95 \% \mathrm{Cl}$ for the difference: -0.30 to $-0.08 \mu \mathrm{mol} / \mathrm{L})$, and for the hydrocarbon carotenoids -0.31 $\mu \mathrm{mol} / \mathrm{L}$ or $-25.9 \%(P<0.001 ; 95 \% \mathrm{Cl}$ for the difference: -0.47 to $-0.16 \mu \mathrm{mol} / \mathrm{L})$.

As illustrated in Figure $3(\mathrm{~b})$, the observed decreases in absolute antioxidant concentrations caused by pravastatin did not remain significant, when corrected for TC+TG. In fact, the sum of the lipid-standardized tocopherols rose in the pravastatin group from $4.67 \pm 0.09$ to $5.51 \pm 0.11 \mu \mathrm{mol} / \mathrm{mmol} T C+T G$ versus the increase in the placebo group from $4.96 \pm 0.13$ to $5.43 \pm 0.14 \mu \mathrm{mol} / \mathrm{mmol} T C+T G$. The difference in changes of $0.38 \mu \mathrm{mol} / \mathrm{mmol}$ TC+TG or $8.7 \%$ between the two groups was significant $(P=0.002 ; 95 \% \mathrm{Cl}: 0.15$ to $0.61 \mu \mathrm{mol} / \mathrm{mmol} \mathrm{TC}+\mathrm{TG})$. Besides, the lipid-standardized oxygenated carotenoids tended to increase from $0.10 \pm 0.01$ to $0.12 \pm 0.01$ $\mu \mathrm{mol} / \mathrm{mmol} \mathrm{TC}+\mathrm{TG}$ versus the change in the placebo group from $0.11 \pm 0.01$ to 0.12 $\pm 0.01 \mu \mathrm{mol} / \mathrm{mmol}$ TC+TG $(P=0.061 ; 95 \% \mathrm{Cl}$ for the difference: 0.00 to 0.03 $\mu \mathrm{mol} / \mathrm{mmol} \mathrm{TC}+\mathrm{TG})$. However, changes between the two groups were not significantly different for the hydrocarbon carotenoids after lipid-standardization ( $P=$ $0.979 ; 95 \% \mathrm{Cl}$ for the difference: -0.02 to $0.02 \mu \mathrm{mol} / \mathrm{mmol} \mathrm{TC}+\mathrm{TG})$. The lipidstandardized concentrations of lycopene, $\alpha$-carotene and $\beta$-carotene did also not change after intake of pravastatin. Comparable effects were found after the antioxidant concentrations were corrected for total cholesterol or for LDL. cholesterol concentrations, although for the oxygenated carotenoids the difference in changes was significant after LDL cholesterol-standardization $(P=0.007)$, but not after correction for total cholesterol concentrations $(P=0.127)$. 
a
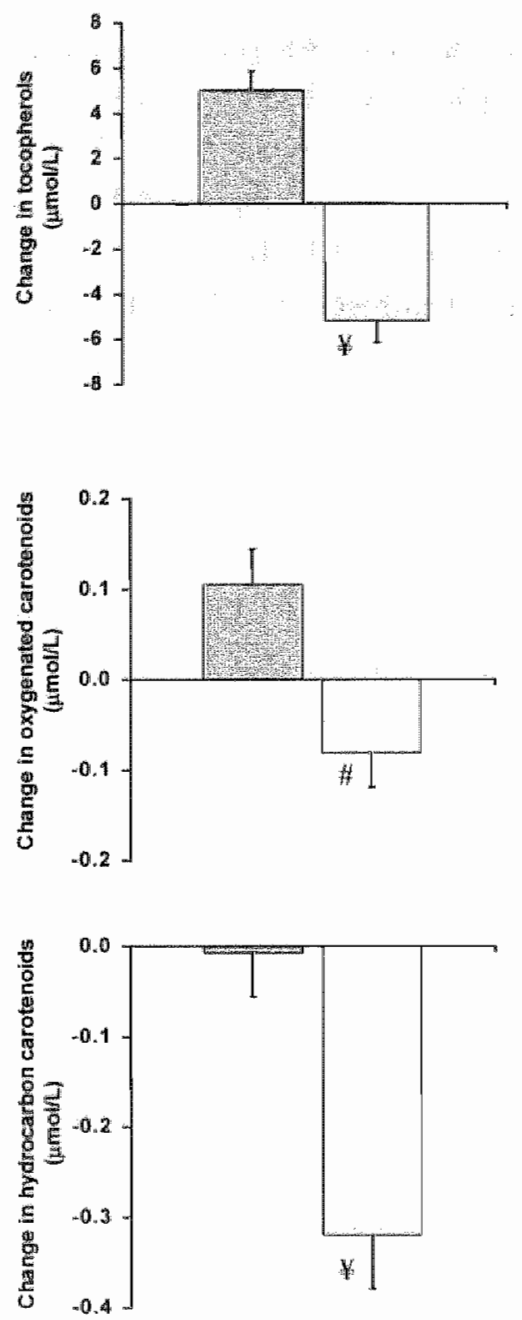

b
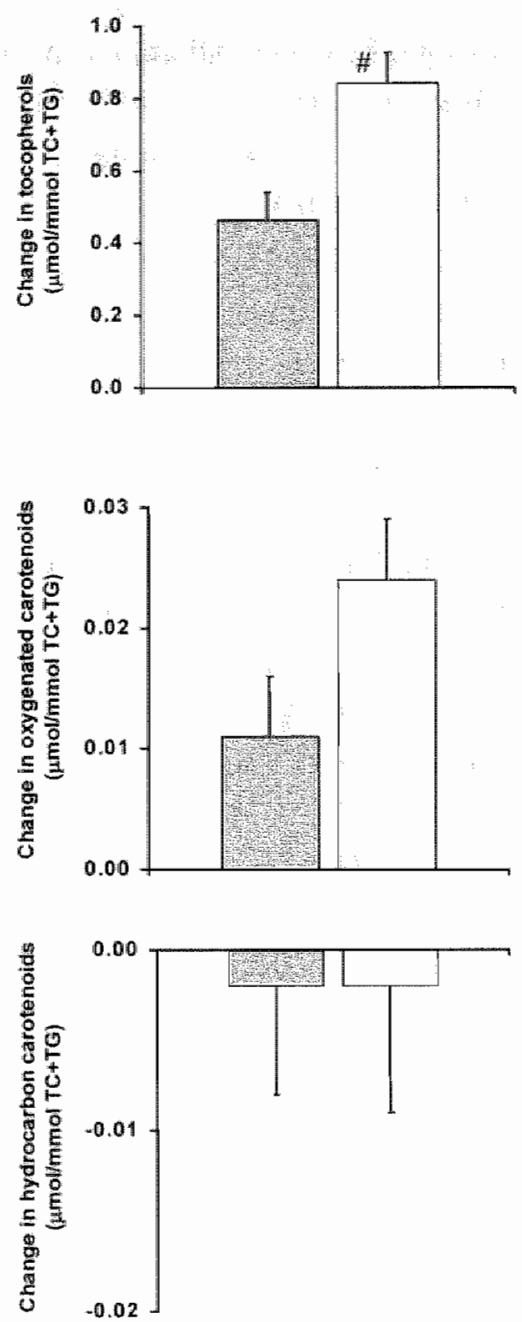

FIGURE 3 Mean ( $t$ SEM) changes in the absolute plasma concentrations of the tocopherols (the sum of $\alpha$ " tocopherol, $p+\gamma$-tocopheroll and 8 -tocopherol), the oxygenated carotenoids (the sum of lutein and $\beta$ cryptoxanthin) and the hydrocarbon carotenoids, (the sum of lycopene, $\alpha$-carotene and ( $\beta$-carotene) (a) as well as the changes after standardization for total cholesterol plus triacylglycerol concentrations (TC+TG) (b) at the end of the treatment period with placebo (gray bars $n=24$ ) or pravastatin (white bars: $40 \mathrm{mg} / \mathrm{d}, n=23$ ) supplementation. "Significantly different from the placebo group: $P<0.001, " P<0.01$. 


\section{Discussion}

The present studies examined the effects of two different LDL cholesterol-lowering dietary components (plant stanol esters and $\beta$-glucan from oat bran) and of a frequently prescribed lipid-lowering drug (pravastatin) on various plasma lipid-soluble antioxidants. It is known that consumption of functional foods rich in plant sterols and stanols may lower absolute plasma concentrations of carotenoids and vitamin $E$ (15). This has raised some concern, because of the potential health benefits of these lipidsoluble antioxidants. However, little is known how these effects compare with those of oat $\beta$-glucan, a dietary component from whole oat foods with an approved health claim for reducing the risk of heart disease $(32,33)$, and of pravastatin.

Our studies now showed that plant stanol esters, $\beta$-glucan from oat bran and pravastatin all lowered the absolute plasma concentrations of the tocopherols (the sum of $\alpha$-tocopherol, $\beta+\gamma$-tocopherol and $\delta$-tocopherol) in volunteers with increased cholesterol concentrations. The absolute concentrations of the hydrocarbon carotenoids (the sum of lycopene, $\alpha$-carotene and $\beta$-carotene), however, were only lowered by both oat $\beta$-glucan and pravastatin but not by plant stanol esters, whereas those of the oxygenated carotenoids (the sum of lutein and $\beta$-cryptoxanthin) were reduced only after pravastatin treatment. Since lipoprotein particles transport lipidsoluble antioxidants in the plasma, a part of the decrease in plasma antioxidant concentrations can be explained by the decreased number of lipoprotein particles as caused by these cholesterol-lowering agents. For this reason, antioxidant concentrations are usually standardized for serum lipid or lipoprotein concentrations. However, no uniformity exists. In some studies antioxidants were standardized for concentrations of serum total cholesterol (34), while in others for those of LDL cholesterol (16) or serum total cholesterol plus triacylglycerol concentrations (35). We also decided to standardize for total cholesterol plus triacylglycerol concentrations $(\mathrm{TC}+\mathrm{TG})$, because our study with pravastatin suggested that concentrations of all antioxidant-carrying lipoproteins (VLDL, LDL and HDL) were changed. For reasons of uniformity, the same method was used for the other two studies. It should be noted, however, that the way of standardization did not substantially change the results. After correction for TC+TG, only significant increases in the tocopherols were observed after pravastatin treatment and significant decreases in the hydrocarbon carotenoids after the consumption of oat $\beta$-glucan.

Most studies have found that plant sterols and stanols, which inhibit intestinal cholesterol absorption through displacement of intestinal cholesterol from the micelles, lower the absolute concentrations of tocopherols and carotenoids (15). After 
lipid-standardization, however, these effects on the tocopherols disappeared, whereas the carotenolds ( $\alpha$ - plus $\beta$-carotene) remained reduced (15). As reported by Plat \& Mensink (16) decreases in plasma hydrocarbon carotenoids after daily consumption of $4 \mathrm{~g}$ of plant stanols as esters were related to the reduced cholesterol absorption, suggesting that plant stanol esters may lower the absorption of other lipid-soluble components than cholesterol as well. The reductions in the tocopherols and the oxygenated carotenoids were only associated with the decrease in the number of circulating LDL particles. In contrast with some other studies (15), our present study did not show a significant decrease in the oxygenated or hydrocarbon carotenoids, also not after correction for serum lipids. It should be noted, however, that the daily intake of $2.0 \mathrm{~g}$ of plant stanols as esters in our present study where the effect on LDL cholesterol may be near maximum (14), was not as high as in many other studies (15). Under these conditions, it could be possible that plant stanols affect the incorporation of cholesterol into mixed micelles, but hardly that of the carotenoids. Indeed, results from several randomized placebo-controlled studies with plant sterol or stanol intakes ranging from 0.7 to $3.2 \mathrm{~g}$ per day (15) suggest that a daily consumption of $2.2 \mathrm{~g}$ or less reduces the lipid-standardized carotenoid concentrations only minimally. A recent study of Raeinini-Sarjaz et al. (36) also suggested that the absolute and lipid-standardized serum carotenoids were not reduced after a daily intake of $1.92 \mathrm{~g}$ of plant sterols as esters or $1.76 \mathrm{~g}$ of stanols as esters. Taken together, these findings indicate that the daily recommended intake of about 2 to $2.5 \mathrm{~g}$ of plant sterols or stanols have minor effects on lipid-standardized plasma lipid-soluble antioxidants.

Also other hypocholesterolemic dietary components, like water-soluble dietary fibers (WSDF) have been reported to affect plasma lipid-soluble antioxidants in humans $(17,18,37)$. A rich source of WSDF is oats. Based on a meta-analysis of 12 trials, Ripsin et al. (38) estimated that a daily intake of about $3 \mathrm{~g}$ of WSDF from oat products lowers total cholesterol concentrations by about $0.13 \mathrm{mmol} / \mathrm{L}$. The WSDF $\beta$ glucan appears to be the hypocholesterolemic ingredient in oats (19). In fact the U.S. Food and Drug Administration approved the registration of oat products as cholesterol-lowering foods, with a minimum recommended dose of $3 \mathrm{~g}$ of $\beta$-glucan from oats per day $(32,33)$. The precise mechanism of action for the cholesterollowering effect of WSDF has not yet been clarified. It has been suggested that WSDF may decrease the absorption of bile acids due to fiber binding or to an increased viscosity of intestinal contents $(23,24)$. It could also be possible that WSDF may disturb the formation of micelles, which are necessary for the absorption of lipidsoluble substances. Since WSDF may change the physical characteristics of the 
contents of the small intestine, WSDF may affect plasma antioxidant concentrations. However, information about the effects of oat $\beta$-glucan on plasma antioxidants in humans is limited. In Study 2 , the daily consumption of $5 \mathrm{~g}$ of oat $\beta$-gluean with orange juice for two weeks lowered serum total and LDL cholesterol concentrations by 4 and $7 \%$, respectively. However, also the absolute plasma concentrations of the tocopherols and the hydrocarbon carotenoids decreased by oat $\beta$-glucan; while the latter were still reduced after lipid-standardization. A lowering effect of WSDF on the absolute vitamin $E$ concentrations has also been demonstrated in rats fed pectin for 8 weeks (39) as well as in diabetic subjects who received a test meal with konjac mannan (glucomannan) and vitamin $E$ (37). However, Riedl et al (18) found that the plasma response curves of carotenoids were reduced, but not those of $\alpha$-tocopherol, when subjects received supplements consisting of carotenoids and $\alpha$-tocopheral together with a test meal enriched with the WSDF pectin, guar or alginate. Furthermore, Rock \& Swendseid (17) showed that the plasma $\beta$-carotene response to a $\beta$-carotene supplement was inhibited after subjects consumed a test meal with pectin. Based on these findings, it can be concluded that oat $\beta$-glucan as well as other WSDF lower the plasma lipophylic hydrocarbon carotenoids. Note, however, that in our study the decrease of $7 \%$ in lipid-standardized hydrocarbon concentrations was observed at a daily intake of $5 \mathrm{~g}$ of oat $\beta$-glucan administered in orange juice, which is higher than the minimum recommended dose of $3 \mathrm{~g} / \mathrm{d}$ of $\beta$ glucan from oats. Furthermore, not all human studies showed a lowering effect on LDL cholesterol of products rich in oat $\beta$-glucan $(40)$. The food matrix of the oat products and/or food processing may influence the cholesterol-lowering potential of $\beta$-glucan from oats $(40)$. It remains to be determined whether our results can be extrapolated to lower doses or to other oat $\beta$-glucan-containing food products. It is clear, however, that not only relatively high intakes of plant sterols and stanols may lower serum lipid-standardized hydrocarbon carotenoids concentrations, but also relatively high intakes of oat $\beta$-glucan. This suggests that these decreases are related to the actions of serum cholesterol-lowering agents that change intestinal sterol metabolism.

Statins inhibit the activity of HMG-CoA reductase, the rate-limiting enzyme in the endogenous cholesterol synthesis. This results in an increased LDL receptor activity leading to an increased removal of $L D L$ cholesterol from the circulation (25). In Study 3 , the beneficial effects of daily supplementation with $40 \mathrm{mg}$ of pravastatin for 6 weeks on serum LDL cholesterol, HDL cholesterol and triacylglycerols were as expected (25). The observed decreases in the absolute concentrations of the tocopherols and carotenoids by pravastatin corresponds with the results of Julia et al. 
(44) who have used simvastatin as lipid-lowering agent. The observed increase in lipid-standardized tocopherol concentrations agrees with the results of both short term and long term studies with pravastatin $(45,46)$. Laaksonen et al. (47) demonstrated that simvastatin treatment resulted in reduced concentrations of $\alpha$ tocopherol, $\beta$-carotene and lycopene in LDL in hypercholesterolemic subjects. After lipid-standardization, the total antioxidant (the sum of $\alpha$-tocopherol, ubiquinone, $\beta$ carotene and lycopene) concentrations were not affected. The increases in lipidstandardized tocopherol concentrations in our study after pravastatin treatment suggest that the lipoprotein particles became enriched with tocopherols: At the moment, there is no clear explanation why the lipid-standardized the hydrocarbon carotenoid concentrations did not increase after pravastatin treatment, while those of the tocopherols did.

In conclusion, our findings show that two different hypocholesterolemic dietary components, plant stanol esters and oat $\beta$-glucan, that affect intestinal sterol metabolism in a different way, lowered absolute plasma tocopherol concentrations in subjects with increased cholesterol concentrations. Oat $\beta$-glucan, which was provided with orange juice, also lowered the absolute concentrations of the hydrocarbon carotenoids, even after these antioxidants were corrected for serum lipids. At daily intakes of about $2 \mathrm{~g}$, plant stanols had only small effects on lipidstandardized plasma lipid-soluble antioxidant concentrations. It should be noted, however, that the daily intake of oat $\beta$-glucan, was relatively, but not exceptional, high. Future studies should elucidate if our results also apply to lower intakes and other food matrices. After treatment with pravastatin, which does not primarily act on intestinal sterol metabolism, but inhibits the activity of HMG-CoA reductase, all absolute antioxidant concentrations decreased. After lipid-standardization, however, the tocopherols increased, whereas the oxygenated and hydrocarbon carotenoids were not affected. Our findings suggest that at relatively high intakes, cholesterollowering components that change intestinal sterol metabolism may have the greatest impact on lipid-standardized plasma hydrocarbon carotenoid concentrations.

\section{Acknowledgements}

We are grateful to the members of our dietary and technical staff for their excellent support. We would also like to thank all participants of our studies for their cooperation and interest. Study 1 and Study 2 were supported by Raisio Group plc, Raisio, Finland. Study 3 was supported by Novartis Consumer Health, Nyon, Switzerland. 


\section{References}

1. Rock CL. Carotenoids: biology and treatment. Pharmacol Ther 1997;75:185-97.

2. Parker RS. Bioavailabilty of carotenoids. Eur J Clin Nutr 1997; $1:$ S86-S90.

3. Cooper DA. Eldridge AL, Peters JC. Dietary carotenoids and certain cancers, heart disease, and agie-related macular degeneration: a review of recent research. Nutr Rev 1999:57:201-14.

4. The Alpha-Tocopherol, Beta Carotene Cancer Prevention Study Group. The effect of vitamin $E$ and beta carotene on the incidence of lung cancer and other cancers in male smokers. N Engl J Med 1994;330:1029-35.

5. Omenn GS, Goodman GE. Thornquist MD, et al. Effects of a combination of beta carotene and vitamin $\mathrm{A}$ on lung cancer and cardiovascular disease. $\mathrm{N}$ Engl J Med 1996;334:1150-5.

6. Hennekens $\mathrm{CH}$, Buring JE, Manson JE, et al. Lack of effect of long-term supplementation with beta carotene on the incidence of malignant neoplasms and cardiovascular disease. N Engl J Med 1996;334:1145-9.

7. Rimm EB, Stampfer MJ, Ascherio A, Giovannucci E, Colditz GA, Willett WC. Vitamin E consumption and the risk of coronary heart disease in men. $N$ Engl $J$ Med 1993;328:1450-6.

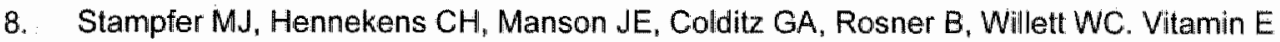
consumption and the risk of coronary disease in women. IN Engl J Med 1993;328:14449.

9. Virtamo J, Rapola $J M_{*}$ Ripatti $S$, et al. Effect of vitamin $E$ and beta carotene on the incidence of primary nonfatal myocardial infarction and fatal coronary heart disease. Arch Intern Med 1998;158:668-75.

10. Stephens NG, Parsons A, Schofield PM, et al. Randomised controlled trial of vitamin E in patients with coronary disease: Cambridge Heart Antioxidant Study (CHAOS). Lancet 1996;347:781-6.

11. GISSI-Prevenzione Investigators (Gruppo Italiano per lo Studio della Sopravvivenza nell'Infarto miocardico). Dietary supplementation with $n-3$ polyunsaturated fatty acids and vitamin $E$ after myocardial infarction: results of the GISSI-Prevenzione trial. Lancet $1999 ; 354: 447-55$.

12. The Heart Outcomes Prevention Evaluation Study Imvestigators Vitamin $E$ supplementation and cardiovascular events in high-risk patients. $\mathrm{N}$ Engl J Mad 2000;342:154-60.

13. Collaborative Group of the Primary Prevention Project (PPP). Low-dose aspirin and vitamin $E$ in people at cardiovascular risk: a randomised trial in general practice. Lancel 2001;357:89-95.

14. Law M. Plant sterol and stanol margarines and health. BMJ 2000;320:861-4.

15. Plat J, Kerckhoffs DAJM, Mensink RP. Therapeutic potential of plant sterols and stanols. Curr Opin Lipidol 2000;11:571-6.

16. Plat $J$, Mensink RP. Effects of diets enriched with two different plant stanol ester mixtures on plasma ubiquinol-10 and fat-soluble antioxidant concentrations. Metabolism 2001;50:520-9.

17. Rock CL, Swendseid ME. Plasma $\beta$-carotene response in humans after meals supplemented with dietary pectin. Am J Clin Nutr 1992;55:96-9.

18. Riedl J, Linseisen J, Hoffmann J, Wolfram G. Some diletary fibers reduce the absorption of carotenoids in women. J Nutr 1999;129:2170-6. 
19. Braaten JT, Wood PJ, Scott FW, et al. Dat $\beta$-glucan reduces blood cholesterol concentration in hypercholesterolemic subjects. Eur J Clin Nutr 1994;48:465-74.

20. Plat J, Mensink RP. Effects of plant sterols and stanols on lipid metabolism and cardiovascular risk. Nutr Metab Cardiovasc Dis 2001;11:31-40.

21. Miettinen TA, Gylling $\mathrm{H}$. Regulation of cholesterol metabolism by dietary plant sterols. Curr Opin Lipidol 1999;109-14.

22. Plat $d$ Mensink RP. Effects of plant stanol esters on LDL receptor protein expression and on LDL receptor and HMG-COA reductase mRNA expression on mononuclear blood cells of healthy men and women. FASEB J 2002;16:258-60.

23. Lund EK, Gee JM, Brown JC, Wood PJ, Johnson IT. Effect of oat gum on the physical properties of the gastrointestinal contents and on the uptake of D-galactose and cholesterol by ral small intestine in vitro. $\mathrm{Br} J \mathbb{N}$ Nutr 1989;62:91-101.

24. Beer MU, Arrigoni E. Amadò R. Effects of oat gum on blood cholesterol levels in healthy young men. Eur J Clin Nutr 1995:49:517-22.

25. Haria M, McTavish D. Pravastatin. A reappraisal of its pharmacological properties and clinical effectiveness in the management of coronary heart disease. Drugs 1997;53:299-336.

26. Centraal Begeleidingsorgaan voor de Intercollegiale Toetsing, in samenwerking met de Nederlandse Hartstichting, et al. Behandeling en preventie van coronaire hartziekten door verlaging van de plasmacholesterolconcentratie (Treatment and prevention of coronary heart disease by lowering plasma cholesterol concentrations). Utrecht: Centraal Begeleidlingsorgaan voor de Intercollegiale Toetsing, 1998 (in Dutch).

27. Nederlandse Voedingsnormen 1989 (Dutch dietary guidelines 1989) / Commissie Voedingsnormen Voedingsraad, 2e druk. The Hague: Voorlichtingsbureau voor de Voeding 1992 (in Dutch).

28. The Expert Panel. Summary of the second report of the National Cholesterol Education Program (NCEP) Expert Panell on Detection, Evaluation, and Treatment of High Blood Cholesterol in Adults (Adult Treatment Panel II). JAMA 1993;269:3015-23.

29. Hess $D$, Keller HE, Oberlin B, Bonfanti $R$, Schüep $W$. Simultaneous determination of retinol, tocopherols, carotenes and lycopene in plasma by means of high-performance liquid chromatography on reversed phase. Internat J Vit Nutr Res 1991;61:232-8.

30. Oostenbrug GS, Mensink RP, Hardeman MR, De Vries T, Brouns F, Hornstra G. Exercise performance, red blood cell deformability, and lipid peroxidation: effects of fish oil and vitamin E. J Appl Physiol 1997;83:746-52.

31. Pocock S.J. Clinicals trials: a practical approach. Chichester: John Wiley and Sons, 1987.

32. Food labeling: health claims; aats and coronary heart disease. Food and Drug Administration, HHS. Proposed rule. Fed Regist 1996;61:296-313.

33. FDA Talk Paper. FDA allows whole oat foods to make health claim on reducing the risk of heart disease. January 1997. World Wide Web: http://www.cfsan,fda.gov/ Ird/poats.html (accessed 27 Aprill 2001).

34. Hallikainen MA, Uusitupa MIJ. Effects of 2 low-fat stanol ester-containing margarines on serum cholesterol concentrations as part of a low-fat diet in hypercholesterolemic subjects. Am J Clin Nutr 1999:69:403-10.

35. Sierksma A, Weststrate JA, Meijer GW. Spreads enriched with plant sterols, either esterified 4,4-dimethylsterols or free 4-desmethylsterols, and plasma total- and LDLcholesterol concentrations. Bir J Nutr1999;82:273-82.

36. Raeini-Sarjaz M, Ntanios FY, Vanstone CA, Jones $P$ J. No changles in serum fat-soluble vitamin and carotenoid concentrations with the intake of plant sterolsstanol esters in the context of a controlled diet. Metabolism 2002;51:652-6. 
37. Doi $K$, Matsuura $M$. Kawara $A$, Tanaka $T$, Baba $S$. Influence of dietary fiber (konjac mannan) on absorption of vitamin $B 12$ and vitamin $E$. Tohoku $J$ Exp Med $1983 ; 141: 677-81$.

38. Ripsin CM, Keenan $\mathrm{JM}_{\mathrm{r}}$ Jacobs $\mathrm{DR}$, et al. Oat products and lipid lowering: a metaanalysis. JAMA $1992 ; 267: 3317-25$.

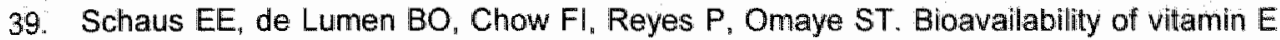
in rats fed graded levels of pectin. $J$ Nutr 1985;115:263-70.

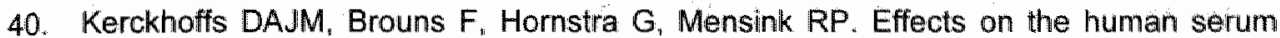
lipoprotein profile of $\beta$-glucan, soy protein and isoflavones, plant sterols and stanols, garlic and tocotrienols. J Nutr 2002;132:2494-505.

41. Koonsvitsky BP, Berry DA, Jones MB, et al. Olestra affects serum concentrations of $\alpha-$ tocopherol and carotenoids but not vitamin D or vitamin $K$ status in free-living subjects. J Nutr 1997:127:1636S-45S.

42. Schäfer Elinder L, Hådell $\mathbb{K}$, Johansson J, et al. Probucol treatment decreases serum concentrations of diet-derived antioxidants. Arterioscler Thromb Vasc Biol 1995:15:1057-63.

43. Ayres EJ, Hoeg JM, Bailey KR, Bieri JG. The effect of neomycin on plasma alpha tocopherol levels in type II hyperlipoproteinemia. Drug Nutr Interact 1986;4:325-31.

44. Jula A, Mamiemi J, Huupponen R, Virtanen A, Rastas M, Rönnemaa T. Effects of diet and simvastatin on serum lipids, insulin, and antioxidants in thypercholesterolemic men. JAMA 2002;287:598-605.

45. Bláha $V$, Zadák $Z$, Solichová D, Brátová $M$, Havel $\mathbb{E}$. Hypocholesterolemic effect of pravastatin is associated with increased content of antioxidant vitamin-E in cholesterol fractions. Acta Medica Hradec Králové 1998;41:87-90.

46. Salonen $R$, Nyyssönen $K$, Porkkala-Sarataho $E$, Salonen JT. The Kuopio Atherosclerosis Prevention Study (KAPS): effect of pravastatin treatment on lipids, oxidation resistance of lipoproteins, and atherosclerotic progression. Am J Cardiol 1995:76:34C-9C.

47. Laaksonen $R$, Jokelainen $K$, Laakso $d$, et al. The effect of simvastatin treatment on natural antioxidants in low-density lipoproteins and high-energy phosphates and ubiquinone in skeletal muscle. Am J Cardiol 1996;77:851-4. 
APPENDIX 1

Effects of margarine enriched with plant stanol esters on plasma lipid-soluble antioxidant concentrations in Study 1 ?

\begin{tabular}{|c|c|c|}
\hline & Control group & Stanol ester group \\
\hline \multicolumn{3}{|l|}{ a-Tocopherol } \\
\hline Run-im & $33.52 \pm 2.21$ & $33.15 \pm 1.58$ \\
\hline Treatment & $34.03 \pm 2.10$ & $29.09 \pm 1.75$ \\
\hline Change & $0.51 \pm 1.44$ & $-4.05 \pm 0.93^{2}$ \\
\hline \multicolumn{3}{|l|}{$\beta * y$-Tocopherol } \\
\hline Runi-in & $2.03 \pm 0.20$ & $2.08 \pm 0.15$ \\
\hline Treatment & $2.24 \pm 0.22$ & $1.93 \pm 0.15$ \\
\hline Change & $0.22 \pm 0.10$ & $-0.14 \pm 0.08^{3}$ \\
\hline \multicolumn{3}{|l|}{ S-Tocopherol } \\
\hline Rum-in & $0.15 \pm 0.02$ & $0.16 \pm 0.01$ \\
\hline Treatment & $0.17 \pm 0.01$ & $0.15 \pm 0.01$ \\
\hline Change & $0.02 \pm 0.02$ & $-0.01 \pm 0.01$ \\
\hline \multicolumn{3}{|c|}{ Total tocopherols } \\
\hline Rum-in & $35.70 \pm 2.22$ & $35.38 \pm 1.68$ \\
\hline Treatment & $36.45 \pm 2.17$ & $31.17 \pm 1.84$ \\
\hline Change & $0.74 \pm 1.46$ & $-4.21 \pm 0.96^{3}$ \\
\hline \multicolumn{3}{|l|}{ Lutein } \\
\hline Run-in & $0.52 \pm 0.03$ & $0.53 \pm 0.04$ \\
\hline Treatment & $0.54 \pm 0.04$ & $0.49 \pm 0.03$ \\
\hline Change & $0.03 \pm 0.02$ & $-0.04 \pm 0.02$ \\
\hline \multicolumn{3}{|l|}{$\beta$-Cryptoxanthin } \\
\hline Run-in & $0.49 \pm 0.05$ & $0.46 \pm 0.05$ \\
\hline Treatment & $0.48 \pm 0.05$ & $0.42 \pm 0.05$ \\
\hline Change & $-0.02 \pm 0.02$ & $-0.03 \pm 0.02$ \\
\hline \multicolumn{3}{|c|}{ Oxygenated carotenoilds } \\
\hline Run-in & $1.01 \pm 0.07$ & $0.99 \pm 0.07$ \\
\hline Treatment & $1.02 \pm 0.07$ & $0.92 \pm 0.07$ \\
\hline Change & $0.01 \pm 0.03$ & $-0.08 \pm 0.03$ \\
\hline \multicolumn{3}{|l|}{ Lycopene } \\
\hline Run-in & $0.66 \pm 0.05$ & $0.61 \pm 0.04$ \\
\hline Treatment & $0.72 \pm 0.05$ & $0.62 \pm 0.04$ \\
\hline Change & $0.06 \pm 0.05$ & $0.01 \pm 0.03$ \\
\hline
\end{tabular}


APPENDIX 1 Continued

$\begin{array}{lll}\text { a-Carotene } & & \\ \text { Run-in } & 0.17 \pm 0.02 & 0.18 \pm 0.03 \\ \text { Treatment } & 0.18 \pm 0.02 & 0.16 \pm 0.01 \\ \text { Change } & 0.00 \pm 0.01 & -0.02 \pm 0.02 \\ \beta \text {-Carotene } & & \\ \text { Run-in } & 0.80 \pm 0.15 & 0.61 \pm 0.05 \\ \text { Treatment } & 0.82 \pm 0.16 & 0.55 \pm 0.04 \\ \text { Change } & 0.02 \pm 0.08 & 0.06 \pm 0.02 \\ \text { ot- plus } \beta \text {-Carotene } & & \\ \text { Run-in } & 0.97 \pm 0.16 & 0.79 \pm 0.06 \\ \text { Treatment } & 0.99 \pm 0.17 & 0.71 \pm 0.05 \\ \text { Change } & 0.02 \pm 0.08 & -0.08 \pm 0.03 \\ \text { Hydrocarbon carotenoids } & 1.64 \pm 0.19 & 1.40 \pm 0.09 \\ \text { Run-in } & 1.72 \pm 0.20 & 1.33 \pm 0.07 \\ \text { Treatment } & 0.08 \pm 0.11 & -0.07 \pm 0.06 \\ \text { Change } & & \end{array}$

Values are means \pm SEM. Concentrations are expressed in Hmol/L. For experimental details of this parallal study: see Table 1.

${ }^{2,3}$ Significantly different from the control group: ${ }^{2} P<0.05,{ }^{3} P<0.01$ 


\section{APPENDIX 2}

Effects of margarine enriched with plant stanol esters on lipid-standardized antioxidant concentrations in Study ${ }^{1}$

\begin{tabular}{|c|c|c|}
\hline & Control group & Stanol ester group \\
\hline \multicolumn{3}{|l|}{ a-Tacopherol } \\
\hline Run-in & $4.69 \pm 0.25$ & $4.71 \pm 0.15$ \\
\hline Treatment & $4.88 \pm 0.23$ & $4.50 \pm 0.22$ \\
\hline Change & $0.19 \pm 0.18$ & $-0.21 \pm 0.12$ \\
\hline \multicolumn{3}{|l|}{$\beta+\gamma$-Tocopherol } \\
\hline Run-in & $0.28 \pm 0.03$ & $0.30 \pm 0.02$ \\
\hline Treatment & $0.32 \pm 0.03$ & $0.30 \pm 0.02$ \\
\hline Change & $0.04 \pm 0.02$ & $0.01 \pm 0.01$ \\
\hline \multicolumn{3}{|l|}{ 8-Tocopherol } \\
\hline Run-in & $0.02 \pm 0.00$ & $0.02 \pm 0.00$ \\
\hline Treatment & $0.02 \pm 0.00$ & $0.02 \pm 0.00$ \\
\hline Change & $0.00 \pm 0.00$ & $0.00 \pm 0.00$ \\
\hline \multicolumn{3}{|c|}{ Totall tocopherols } \\
\hline Run-in & $4.99 \pm 0.24$ & $5.02 \pm 0.16$ \\
\hline Treatment & $5.23 \pm 0.24$ & $4.82 \pm 0.23$ \\
\hline Change & $0.23 \pm 0.18$ & $-0.20 \pm 0.13$ \\
\hline \multicolumn{3}{|l|}{ Lutein } \\
\hline Run-in & $0.07 \pm 0.00$ & $0.08 \pm 0.01$ \\
\hline Treatment & $0.08 \pm 0.00$ & $0.08 \pm 0.01$ \\
\hline Changle & $0.00 \pm 0.00$ & $0.00 \pm 0.00$ \\
\hline \multicolumn{3}{|l|}{ B-Cryptoxanthin } \\
\hline Run-in & $0.07 \pm 0.01$ & $0.07 \pm 0.01$ \\
\hline Treatment & $0.07 \pm 0.01$ & $0.07 \pm 0.01$ \\
\hline Change & $0.00 \pm 0.00$ & $0.00 \pm 0.00$ \\
\hline \multicolumn{3}{|c|}{ Oxygenated carotenoids } \\
\hline Rum-in & $0.14 \pm 0.01$ & $0.14 \pm 0.01$ \\
\hline Treatment & $0.15 \pm 0.01$ & $0.14 \pm 0.01$ \\
\hline Change & $0.01 \pm 0.00$ & $0.00 \pm 0.00$ \\
\hline \multicolumn{3}{|l|}{ Lycopene } \\
\hline Run-in & $0.09 \pm 0.01$ & $0.09 \pm 0.01$ \\
\hline Treatment & $0.11 \pm 0.01$ & $0.10 \pm 0.01$ \\
\hline Change & $0.01 \pm 0.01$ & $0.01 \pm 0.01$ \\
\hline
\end{tabular}




\section{APPENDIX 2 Continued}

a-Carotene

Run-in

$0.02 \pm 0.00$

$0.03 \pm 0.00$

Treatment

$0.03 \pm 0.00$

$0.03 \pm 0.00$

Change

$0.00 \pm 0.00$

$0.00 \pm 0.00$

$\beta$-Carotene

Run-in

$0.12 \pm 0.02$

$0.09 \pm 0.01$

Treatment

$0.12 \pm 0.02$

$0.09 \pm 0.01$

Change

$0.01 \pm 0.01$

$0.00 \pm 0.00$

$\alpha$ - plus $\beta$-Carotene

$\begin{array}{lll}\text { Run-in } & 0.14 \pm 0.02 & 0.12 \pm 0.01 \\ \text { Treatment } & 0.15 \pm 0.02 & 0.11 \pm 0.01 \\ \text { Change } & 0.01 \pm 0.01 & 0.00 \pm 0.00\end{array}$

Hydracarbon carotenoids

$\begin{array}{lll}\text { Run-in } & 0.23 \pm 0.03 & 0.20 \pm 0.02 \\ \text { Treatment } & 0.25 \pm 0.03 & 0.21 \pm 0.02 \\ \text { Change } & 0.02 \pm 0.02 & 0.01 \pm 0.01\end{array}$

"Values are means \pm SEM. Concentrations are expressed in $4 \mathrm{~mol} / \mathrm{mmol}$ total cholesterol plus triacylglycerol (TC+TG). For experimental details of this parallel study: see Table 1. 


\section{APPENDIX 3}

Effects of $\beta$-glucan from oat bran in orange juice on plasma lipid-soluble antioxidant concentrations in Study $2^{\prime}$

\begin{tabular}{|c|c|c|c|}
\hline & Control drink & $\beta$-Glucan drink & Difference \\
\hline a-Tocopherol & $30.89 \pm 1.30$ & $29.31 \pm 1.19$ & $-1.58 \pm 0.78$ \\
\hline$\beta+\gamma$-Tocopherol & $2.44 \pm 0.14$ & $2.28 \pm 0.14$ & $-0.16 \pm 0.08$ \\
\hline g-Tocopherol & $0.17 \pm 0.01$ & $0.14 \pm 0.01$ & $-0.03 \pm 0.01^{2}$ \\
\hline Total tocopherols & $33.50 \pm 1.37$ & $31.73 \pm 1.28$ & $-1.77 \pm 0.82^{2}$ \\
\hline Lutein & $0.49 \pm 0.04$ & $0.48 \pm 0.03$ & $-0.01 \pm 0.02$ \\
\hline$\beta-$ Cryptoxanthin & $0.44 \pm 0.05$ & $0.45 \pm 0.04$ & $0.01 \pm 0.04$ \\
\hline Oxygenated carotenoids & $0.93 \neq 0.07$ & $0.92 \pm 0.07$ & $-0.01 \pm 0.04$ \\
\hline Lycopene & $0.59 \pm 0.04$ & $0.49 \pm 0.03$ & $-0.09 \pm 0.04^{2}$ \\
\hline$\alpha$-Carotene & $0.16 \pm 0.02$ & $0.15 \pm 0.02$ & $-0.01 \pm 0.01$ \\
\hline$\beta$-Carotene & $0.49 \pm 0.05$ & $0.45 \pm 0.05$ & $-0.04 \pm 0.02^{2}$ \\
\hline a- plus $\beta$-Carotene & $0.65 \pm 0.06$ & $0.60 \pm 0.06$ & $.0 .05 \pm 0.02^{2}$ \\
\hline Hydracarbon carotenoids & $1.24 \pm 0.08$ & $1.09 \pm 0.07$ & $-0.15 \pm 0.04^{3}$ \\
\hline
\end{tabular}

'Values are means \pm SEM. Concentrations are expressed in jimal/L. During the first period of two weeks of this cross-over trial, one group $(n=13)$ consumed wheat fiber with control orange juice, while the other group $(n=$ 1.2) was given ph-glucam from oat bran with orange juice. After a wash-out periad of one week volunteers who consumed the control drink in the first period crossed over to the p-glucan drink in the second period of two weeks, and vice versa.

${ }^{2.3}$ Significantly different from the control drink: ${ }^{2} P<0.05,{ }^{3} P<0.01$. 


\section{APPENDIX 4}

Effects of $\beta$-glucan from oat bran in orange juice on lipid-standardized antioxidant concentrations in Study $2^{y}$

\begin{tabular}{lccc}
\hline & Control drink & $\beta$-Glucan drink & Difference \\
\hline$\alpha$-Tocopherol & $4.60 \pm 0.18$ & $4.49 \pm 0.15$ & $-0.11 \pm 0.11$ \\
$\beta+\gamma$-Tocopherol & $0.36 \pm 0.02$ & $0.35 \pm 0.02$ & $-0.02 \pm 0.01$ \\
$\delta$-Tocopherol & $0.03 \pm 0.00$ & $0.02 \pm 0.00$ & $0.00 \pm 0.00$ \\
Total tocopherols & $4.99 \pm 0.19$ & $4.86 \pm 0.16$ & $-0.13 \pm 0.11$ \\
Lutein & $0.07 \pm 0.01$ & $0.08 \pm 0.01$ & $0.00 \pm 0.00$ \\
$\beta$-Cryptoxanthin & $0.07 \pm 0.01$ & $0.07 \pm 0.01$ & $0.00 \pm 0.00$ \\
Oxygenated carotenoids & $0.14 \pm 0.01$ & $0.15 \pm 0.01$ & $0.00 \pm 0.01$ \\
Lycopene & $0.09 \pm 0.01$ & $0.08 \pm 0.01$ & $-0.01 \pm 0.01$ \\
$\alpha$-Carotene & $0.02 \pm 0.00$ & $0.02 \pm 0.00$ & $0.00 \pm 0.00$ \\
$\beta-$ Carotene & $0.07 \pm 0.01$ & $0.07 \pm 0.01$ & $0.00 \pm 0.00$ \\
$\alpha$ - plus $\beta$-Carotene & $0.10 \pm 0.01$ & $0.09 \pm 0.01$ & $0.00 \pm 0.00$ \\
Hydrocarbon carotenoids & $0.19 \pm 0.01$ & $0.17 \pm 0.01$ & $-0.02 \pm 0.01^{2}$ \\
\hline
\end{tabular}

Values are means \pm SEM. Concentrations are expressed in $\mu$ mol/mmol total cholesterol plus triacyiglycerol (TC+TG). For experimental details of this cross-over trial: see Appendix 3.

2Significantly different from the control drink: ${ }^{2} p<0.05$. 


\section{APPENDIX 5}

Eftects of pravastatin on plasma lipid-soluble antioxidant concentrations in Study 3 ?

\begin{tabular}{|c|c|c|c|}
\hline & Placebo group & Pravastatin group & \\
\hline \multicolumn{4}{|l|}{ a-Tocopherol } \\
\hline Riun-fin & $38.49 \pm 1.41$ & $38.16 \pm 1.28$ & 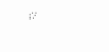 \\
\hline Treatment & $43.00 \pm 1.87$ & $33.19 \pm 1.22$ & \\
\hline Change & $4.51 \pm 0.74$ & $-4.97 \pm 0.92^{2}$ & \\
\hline \multicolumn{4}{|c|}{$\beta+y$-Tocopherol } \\
\hline Run-in & $3.28 \pm 0.37$ & $2.74 \pm 0.17$ & \\
\hline Treatment & $3.77 \pm 0.49$ & $2.55 \pm 0.15$ & \\
\hline Change & $0.49 \pm 0.24$ & $-0.19 \pm 0.17^{3}$ & \\
\hline \multicolumn{4}{|l|}{ 8-Tocopherol } \\
\hline Run-in & $0.16 \pm 0.01$ & $0.13 \pm 0.01$ & \\
\hline Treatment & $0.18 \pm 0.03$ & $0.13 \pm 0.01$ & \\
\hline Change & $0.02 \pm 0.02$ & $-0.01 \pm 0.01$ & \\
\hline \multicolumn{4}{|c|}{ Total tocopherols } \\
\hline Run-in & $41.93 \pm 1.71$ & $41.04 \pm 1.31$ & \\
\hline Treatment & $46.95 \pm 2.28$ & $35.87 \pm 1.25$ & \\
\hline Change & $5.03 \pm 0.85$ & $-5.17 \pm 0.97^{2}$ & \\
\hline \multicolumn{4}{|l|}{ Lutein } \\
\hline Run-in & $0.59 \pm 0.05$ & $0.54 \pm 0.04$ & \\
\hline Treatment & $0.63 \pm 0.04$ & $0.47 \pm 0.02$ & \\
\hline Change & $0.04 \pm 0.02$ & $-0.07 \pm 0.02^{4}$ & \\
\hline \multicolumn{4}{|l|}{$\beta$-Cryptoxanthin } \\
\hline Run-in & $0.33 \pm 0.04$ & $0.32 \pm 0.03$ & \\
\hline Treatment & $0.40 \pm 0.04$ & $0.31 \pm 0.04$ & \\
\hline Change & $0.06 \pm 0.02$ & $-0.01 \pm 0.03$ & \\
\hline \multicolumn{4}{|c|}{ Oxygenated carotenoids } \\
\hline Run-in & $0.92 \pm 0.06$ & $0.86 \pm 0.06$ & \\
\hline Treatment & $1.03+0.06$ & $0.78 \pm 0.05$ & \\
\hline Change & $0.10 \pm 0.04$ & $-0.08 \pm 0.04^{4}$ & \\
\hline \multicolumn{4}{|l|}{ Lycopene } \\
\hline Run-in & $0.65 \pm 0.05$ & $0.64 \pm 0.06$ & \\
\hline Treatment & $0.64 \pm 0.05$ & $0.46 \pm 0.04$ & \\
\hline Change & $-0.01 \pm 0.03$ & $-0.18 \pm 0.03^{2}$ & \\
\hline
\end{tabular}




\section{APPENDIX 5 Continued}

a-Carotene

Run-in

$0.08 \pm 0.01$

$0.07 \pm 0.01$

Treatment

$0.08 \pm 0.01$

$0.05 \pm 0.00$

Change

$0.00 \pm 0.01$

$-0.02 \pm 0.01$

$\beta$-Carotene

Run-in

$0.48 \pm 0.06$

$0.43 \pm 0.04$

Treatment

$0.48 \pm 0.06$

$0.31 \pm 0.04$

Change

$0.00 \pm 0.03$

$-0.12 \pm 0.03^{4}$

$\alpha$-plus $\beta$-Carotene

$\begin{array}{lll}\text { Run-in } & 0.56 \pm 0.06 & 0.50 \pm 0.04 \\ \text { Treatment } & 0.56 \pm 0.06 & 0.36 \pm 0.04 \\ \text { Change } & 0.00 \pm 0.04 & .0 .14 \pm 0.04^{4}\end{array}$

Hydrocarbon carotenoids

Run-in

$\begin{array}{rlr}1.21 & \pm 0.07 & 1.14 \pm 0.09 \\ 1.20 \pm 0.07 & 0.82 \pm 0.07 \\ -0.01 \pm 0.05 & -0.32 \pm 0.06^{2}\end{array}$

$-0.01 \pm 0.05$

$0.32 \pm 0.06^{2}$

\footnotetext{
"Values are means \pm SEM. Concentrations, are expressed in $\mu$ molih. In this parallel study, fourty-seven subjects followed a cholesterol-lowering diet for three weeks (run-in period). For another six weeks (treatment period), volunteers continued their diets and consumed placebo $(n=24)$ ) or pravastatin ( $40 \mathrm{mg} / \mathrm{d}, n=23)$ capsules. ${ }^{2,3,4}$ Significantly different from the placebo group: ${ }^{2} P<0.001{ }^{3}{ }^{3} P<0.05,{ }^{4} P<0.01$.
} 


\section{APPENDIX 6}

Effects of pravastatin on lipid-standardized antioxidant concentrations in Study $3^{7}$

\begin{tabular}{|c|c|c|}
\hline & Placebo group & Pravastatin group \\
\hline \multicolumn{3}{|l|}{ 2-Tocopheral } \\
\hline Run-in & $4.56 \pm 0.11$ & $4.34 \pm 0.09$ \\
\hline Treatment & $4.98 \pm 0.12$ & $5.10 \pm 0.10$ \\
\hline Change & $0.42 \pm 0.07$ & $0.76 \pm 0.07^{2}$ \\
\hline \multicolumn{3}{|c|}{$\beta+\gamma-$ Tocopheral } \\
\hline Run-in & $0.38 \pm 0.04$ & $0.32 \pm 0.02$ \\
\hline Treatment & $0.42 \pm 0.04$ & $0.40 \pm 0.03$ \\
\hline Change & $0.04 \pm 0.03$ & $0.08 \pm 0.02$ \\
\hline \multicolumn{3}{|l|}{ 8-Tocopherol } \\
\hline Run-in & $0.02 \pm 0.00$ & $0.02 \pm 0.00$ \\
\hline Treatment & $0.02 \pm 0.00$ & $0.02 \pm 0.00$ \\
\hline Change & $0.00 \pm 0.00$ & $0.00 \pm 0.00$ \\
\hline \multicolumn{3}{|c|}{ Tolal tocopherols } \\
\hline Run-in & $4.96 \pm 0.13$ & $4.67 \pm 0.09$ \\
\hline Treatment & $5.43 \pm 0.14$ & $5.51 \pm 0.11$ \\
\hline Change & $0.46 \pm 0.08$ & $0.84 \pm 0.09^{2}$ \\
\hline \multicolumn{3}{|l|}{ Lutein } \\
\hline Run-in & $0.07 \pm 0.00$ & $0.06 \pm 0.00$ \\
\hline Treatment & $0.07 \pm 0.00$ & $0.07 \pm 0.00$ \\
\hline Change & $0.00 \pm 0.00$ & $0.01 \pm 0.00^{3}$ \\
\hline \multicolumn{3}{|l|}{ B-Cryptoxanthin } \\
\hline Run-in & $0.04 \pm 0.01$ & $0.04 \pm 0.00$ \\
\hline Treatment & $0.05 \pm 0.01$ & $0.05 \pm 0.01$ \\
\hline Change & $0.01 \pm 0.00$ & $0.01 \pm 0.00$ \\
\hline \multicolumn{3}{|c|}{ Oxyglenated carotenoids } \\
\hline Rum-in & $0.11 \pm 0.01$ & $0.10 \pm 0.01$ \\
\hline Treatment & $0.12 \pm 0.01$ & $0.12 \pm 0.01$ \\
\hline Change & $0.01 \pm 0.00$ & $0.02 \pm 0.00$ \\
\hline \multicolumn{3}{|l|}{ Lycopene } \\
\hline Run-in & $0.08 \pm 0.01$ & $0.07 \pm 0.01$ \\
\hline Treatment & $0.08 \pm 0.01$ & $0.07 \pm 0.01$ \\
\hline Change & $0.00 \pm 0.00$ & $0.00 \pm 0.00$ \\
\hline
\end{tabular}




\section{APPENDIX 6 Continued}

a-Carotene

Run-in

Treatment

Change

$\beta$-Carotene

Run-in

Treatment

Change

$\alpha$ - plus $\beta$-Carotene

Run-in

Treatment

Change

Hydrocarbon carotenoids

Run-in

$0.15 \pm 0.01$

$0.14 \pm 0.01$

$0.00 \pm 0.01$

Treatment

Change

$$
\begin{aligned}
& 0.01 \pm 0.00 \\
& 0.01 \pm 0.00 \\
& 0.00 \pm 0.00 \\
& 0.05 \pm 0.00 \\
& 0.05 \pm 0.01 \\
& 0.00 \pm 0.01
\end{aligned}
$$

$0.06 \pm 0.01$

$0.06 \pm 0.01$

$0.00 \pm 0.00$

$0.07 \pm 0.01$

$0.06 \pm 0.00$

$0.07 \pm 0.01$

$0.06 \pm 0.01$

$0.00 \pm 0.00$

$0.00 \pm 0.01$

$0.13 \pm 0.01$

$0.13 \pm 0.01$

$0.00 \pm 0.01$

\footnotetext{
"Values are means \pm SEM. Concentrations are expressed in umalmmol total chalesterol plus triacylglycerol (TC+TG). For experimental details of this parallel study: see Appendix 5 .

${ }^{2.3}$ Significantly different from the control group: ${ }^{2} P<0.01,{ }^{3} P<0.05$.
} 


\section{Chapter}

C-reactive protein and interleukin-6 in mildly and hypercholesterolemic subjects: effects of plant stanol esters and pravastatin, and relationships with plasma antioxidants

Daniëlle AJM Kerckhoffs ${ }^{1,2}$, Marja $P$ van Dieijen-Visser ${ }^{3}, G$ Gerard Hornstra ${ }^{2}$ and Ronald P Mensink ${ }^{1,2}$

${ }^{1}$ Department of Human Biology and ${ }^{2}$ Nutrition and Toxicology Research Institute Maastricht (NUTRIM), Maastricht University, Maastricht, ${ }^{3}$ Department of Clinical Chemistry, University Hospital Maastricht, Maastricht, The Netherlands 


\section{Abstract}

Objective: To examine effects of plant stanol esters (Study 1) and pravastatin (Study 2) on circulating markers of inflammation (C-reactive protein (CRP) and interleukin-6 (IL-6)) in subjects with increased cholesterol concentrations. Furthermore, relationships were studied between these inflammation markers with plasma tocopherol and carotenoid concentrations.

Design: In Study 1, 21 men and 27 women consumed a control margarine for three weeks. After the subjects were randomly divided into two groups, one group ( $n=25$ ) continued to use control margarine, while the other group $(n=23)$ consumed a margarine with plant stanols $(2.01 \mathrm{~g} / \mathrm{d}$ of plant stanols provided as its fatty acid ester) for the next four weeks. In Study 2,22 men and 25 women consumed a cholesterollowering diet for three weeks. Thereafter, participants were randomly allocated to one of two groups. For another six weeks, subjects continued their diets and received placebo $(n=24)$ or pravastatin $(40 \mathrm{mg} / \mathrm{d} ; n=23)$ capsules. For the cross-sectional study, data obtained after the run-in periods of Study 1 and Study 2 were combined.

Results: Plant stanols and pravastatin effectively lowered LDL cholesterol, but did not affect serum CRP and plasma IL-6 concentrations. After adjustment for serum LDL cholesterol, HDL cholesterol and triacylglycerols, the tocopherols (the sum of $\alpha$ tocopherol, $\beta+\gamma$-tocopherol and $\delta$-tocopherol), the oxygenated carotenoids (the sum of lutein and $\beta$-cryptoxanthin) and hydrocarbon carotenoids (the sum of lycopene, $\alpha$ carotene and $\beta$-carotene) were not significantly related to serum log-transformed CRP concentrations. In these multiple regression models, triacylglycerol was significantly and positively associated with CRP. The hydrocarbon carotenoids were significantly and inversely associated with IL-6 concentrations, whereas the tocopherols and oxygenated carotenoids showed no significant relations with IL-6. HDL cholesterol showed a significant inverse relationship with IL-6.

Conclusions: Short-term plant stanol ester consumption or pravastatin treatment did not affect circulating CRP and IL-6 concentrations in subjects with increased cholesterol concentrations. An inverse relationship was found between the hydrocarbon carotenoids and IL-6, whereas the oxygenated carotenoids and tocopherols were not related with $\mathrm{IL}-6$ in this group of mildly and hypercholesterolemic subjects. 


\section{Introduction}

The hepatic synthesis of the acute phase reactant C-reactive protein (CRP), a sensitive marker of an ongoing inflammatory process, is primarily regulated by the proinflammatory cytokine interleukin-6 (IL-6) $(1,2)$. As atherosclerosis is considered as a chronic inflammatory disease $(3,4)$, it is not unexpected that plasma concentrations of these two components are significant predictors of the risk of future cardiovascular events (5). This may suggest that decreasing atherosclerotic risk goes together with lower plasma CRP and IL-6 concentrations. Indeed, several studies have shown that statins decrease CRP and $1 L-6$ concentrations (6-12). It is known that plant sterols and stanols - like the statins - lower serum concentrations of the atherogenic LDL (13). Therefore, we decided to compare the effects of plant stanol esters with those of pravastatin on CRP and IL-6 concentrations in subjects with increased cholesterol concentrations.

Also plasma concentrations of antioxidants are related with cardiovascular risk (14). An early event in the development of atherosclerotic plaque is the increased expression of proinflammatory cytokines and adhesion molecules initiated by oxidized LDL. These oxidized LDL particles play a crucial role in vascular endothelial cell damage. Dietary antioxidants that prevent oxidative stress may therefore protect against disease processes in which endothelial dysfunction is involved (15). It has already been demonstrated in humans that circulating concentrations of CRP (16, 17) or IL-6 (18) are inversely associated with carotenoid concentrations. Therefore, we have now examined in the same subjects with increased cholesterol concentrations the relations between circulating markers of inflammation (CRP and IL-6) and plasma lipid-soluble antioxidants (the tocopherol isomers and various carotenoids).

\section{Subjects and methods}

\section{Subjects}

The volunteers were recruited from Maastricht and surroundings through advertisements in local newspapers (Chapter 3 and Chapter 5). Also subjects from earlier studies at our Department were approached. All participants were given a detailed description of the experimental protocol and purpose of the study before they gave their written informed consent. They were invited for a screening program, which consisted of measurements of body weight, height and blood pressure, two fasting blood samples for analyses of serum lipids and lipoproteins, and assessment 
of the absence of glucose in a morning specimen of urine. In addition, all subjects had to fill in a medical questionnaire. Participants were selected for the trials according to the following inclusion criteria: aged between 18 and 65 y (Study 1) or between 40 and 70 y (Study 2), stable body weight (weight gain or loss below $3 \mathrm{~kg}$ in the past three months), body mass index (BMI) below $30 \mathrm{~kg} / \mathrm{m}^{2}$, diastolic blood pressure below $95 \mathrm{mmHg}$, systolic blood pressure below $160 \mathrm{mmHg}$, no glucosuria, no history of coronary heart disease, and no pregnancy or breast-feeding. The use of food products enriched with plant sterols or stanols; blood donation or participation in another biomedical trial was not allowed within 4 weeks before or during the studies. For the subjects of Study 1 , mean fasting concentrations of serum total cholesterol had to be below $8.0 \mathrm{mmol} / \mathrm{L}$, and those of triacylglycerol below $4.0 \mathrm{mmol} / \mathrm{L}$. These subjects had no indication for treatment with cholesterol-lowering drugs according to the Dutch Cholesterol Consensus (19), and no use of medication known to affect serum lipids. These latter inclusion criteria did not apply for Study 2, which was specifically designed for hypercholesterolemic subjects: In addition, subjects of Study 2 were not allowed to use medication known to affect hemostasis. Both study protocols were approved by the Ethics Committee of the Maastricht University.

In both studies, participants recorded in diaries any signs of illness, medication used, menstrual phase, alcohol consumption and any deviations from the protocol. The subjects were urged not to change their habitual diets, smoking and drinking habits, level of physical activity, or use of oral contraceptives during the studies. Body weights without shoes and heavy clothes were recorded once a week and did not change during the studies. In the last week of both the run-in and treatment period, subjects recorded their food intake for the previous four weeks by filling in food frequency lists to estimate their energy and nutrient intakes throughout the study. A registered dietician in the presence of the subjects checked the food frequency lists. As already reported in Chapter 5, changes in the estimated intake of energy and nutrients were not significantly different between the two groups of both studies, except for the percentage of energy (En\%) from protein in Study 1 , which increased slightly by $1.3 \mathrm{En} \%$ in the control group $(P=0.026)$.

\section{Study 1: Effects of plant stanol esters}

This study was also designed to examine the efficacy of plant stanol esters on serum lipoproteins and plasma lipid-soluble antioxidants. Characteristics of the subjects have been described before in detail (Chapter 5). In brief, fifty-one volunteers were selected for the study. One woman dropped out in the first week of the trial because of stressful personal circumstances and one woman withdrew in the second week because of illness. Before the statistical analysis " one man was excluded because of 
unexpected high serum triacylglycerol concentrations $(>4.5 \mathrm{mmol} / \mathrm{L})$ throughout the study. Data of the remaining fourty-eight subjects, 21 men and 27 women, were used. Men were $55 \pm 1$ (mean \pm SEM) y of age and their BMl was $25.5 \pm 0.6 \mathrm{~kg} / \mathrm{m}^{2}$. For women, these values were $49 \pm 3$ y and $24.9 \pm 0.6 \mathrm{~kg} / \mathrm{m}^{2}$, respectively. Fasting concentrations of serum total cholesterol, LDL cholesterol, HDL cholesterol and triacylglycerol were in men $6.33 \pm 0.17 \mathrm{mmol} / \mathrm{L}, 4.35 \pm 0.16 \mathrm{mmol} / \mathrm{L}, 1.24 \pm 0.07$ $\mathrm{mmol} / \mathrm{L}$ and $1.61 \pm 0.18 \mathrm{mmol} / \mathrm{L}$, respectively. In women, these values were $6.03 \pm$ $0.14 \mathrm{mmol} / \mathrm{L}, 3.87 \pm 0.12 \mathrm{mmol} / \mathrm{L}, 1.69 \pm 0.07 \mathrm{mmol} / \mathrm{L}$ and $1.04 \pm 0.08 \mathrm{mmol} / \mathrm{L}$, respectively. Two men and two women were smokers. Four women used oral contraceptives and thirteen women were postmenopausal.

\section{Study 2: Effects of pravastatin}

This study, which was carried out to compare the effects of a tocotrienol-rich fraction from rice bran oil (TRF-RBO) with those of pravastatin on serum lipoproteins, markers for cholesteral synthesis and absorption, and hemostatic function in a hypercholesterolemic population (Chapter 3 ), was also designed to examine the effects of pravastatin on plasma lipid-soluble antioxidants in a subpopulation of fourty-eight subjects that received either the placebo or pravastatin capsules (Chapter 5). Characteristics of this study population have been described in detail before (Chapter 5). Briefly, four men and eight women, who were on lipid-lowering therapy, stopped using their statins two weeks before the beginning of the trial. One woman withdrew in the fourth week of the study because of muscle cramps possibly attributable to pravastatin treatment. Thus, the study population comprised fourtyseven participants, 22 men and 25 women. Men were $54 \pm 1$ y of age. They had a $\mathrm{BMl}$ of $26.1 \pm 0.5 \mathrm{~kg} / \mathrm{m}^{2}$. Women were $58 \pm 1 \mathrm{y}$ of age and their BMI was $25.3 \pm 0.5$ $\mathrm{kg} / \mathrm{m}^{2}$. At day 0 of the study, fasting concentrations of serum total cholesterol and triacylglycerol in men were $7.37 \pm 0.12 \mathrm{mmol} / \mathrm{L}$ and $1.58 \pm 0.14 \mathrm{mmol} / \mathrm{L}$, respectively, and in women, these values were $7.58 \pm 0.15 \mathrm{mmol} / \mathrm{L}$ and $1.03 \pm 0.11 \mathrm{mmo} / \mathrm{L}$, respectively. Six men and five women smoked, two women used oral contraceptives and fifteen women were postmenopausal.

\section{Cross-sectional study}

To examine the relations between markers of inflammation (CRP and IL-6) and plasma lipid-soluble antioxidants (tocopherols and carotenoids), data obtained during the run-in periods of Study 1 and Study 2 were combined. Ninety-five volunteers, 43 men and 52 women, were included in this cross-sectional study. Of these subjects, $\|$ IL-6 values of 2 women could not be measured. Furthermore, data of 3 women with CRP values of $\geq 10 \mathrm{mg} / \mathrm{L}$ and data of 4 participants ( 3 men and 1 woman) with IL-6 
values of $\geq 3 \mathrm{pg} / \mathrm{mL}$ caused non-normality of the residuals from the regression models (see statistics), which could not be corrected by log-transformation. These outliers were therefore excluded from the analyses of the relationships between markers of inflammation and antioxidants. Thus, the final cross-sectional study group consisted of 86 subjects ( 40 men and 46 women).

\section{Experimental design}

\section{Study 1: Effects of plant stanol esters}

Details of the design of Study 1 have been described elsewhere (Chapter 5). Briefly, Study 1 was a randomized double-blind, placebo-controlled parallel trail. During the first three weeks of the study (run-in period), all subjects replaced their usual margarine by a sunflower oil-based control margarine. At the start of the study, they had to choose for the rest of the study between a margarine with $38 \%$ ("light margarine') or $62 \%$ ('regular margarine') absorbable fats. To standardize fatty acid intake as much as possible during the trial, the volunteers were also provided with a sunflower oil-based shortening, which contained $99 \%$ absorbable fats, to replace their habitual baking fat. After the run-in period, subjects were randomly allocated to one of two treatment groups, stratified for age and gender. For another four weeks, the control group continued to use control margarine, while the second group consumed an experimental sunflower oil-based margarine with 38 or $62 \%$ absorbable fats containing $8.2 \mathrm{~g}$ of plant stanols $/ 100 \mathrm{~g}$ product. The plant stanol mixture consisted of $71 \%$ sitostanols and $29 \%$ campestanols, which were derived from vegetable oil-derived plant sterols by saturation of plant sterols. The plant stanols were esterified with fatty acids from rapeseed oil. A detailed composition of the margarines has been presented before (Chapter 5 ). All subjects had to use daily minimal $20 \mathrm{~g}$ of the margarine throughout the study, divided over at least two eating moments. Thus, the aimed daily intake of plant stanols was at least $1.64 \mathrm{~g}$. Mean daily consumption of plant stanols was $2.01 \mathrm{~g}$.

The control and experimental margarines, which were similar in color, taste, absorbable fat content and caloric value, were coded with a color label to blind the subjects and the investigators. All products were provided by Raisio Group plc, Raisio, Finland. Subjects came to the Department once a week to receive a new supply of products. 


\section{Study 2: Effects of pravastatin}

The design of this study has been described in detail before (Chapter 3 and Chapter 5). In brief, all subjects consumed a cholesterol-lowering diet during the randomized; double-blind, placebo-controlled parallel study for nine weeks according to the Dutch dietary guidelines (20). This diet, in which the intake of fat is $30-35 \mathrm{En} \%$ and of saturated fat plus trans fatty acids maximal $10 \mathrm{En} \%$, is comparable with a National Cholesterol Education Program (NCEP) step I diet (21). The daily cholesterol intake was restricted to a maximum level of $300 \mathrm{mg}$. Before the beginning of the trial; subjects had to fill in a food frequency list for the last four weeks to estimate their habitual intakes of energy and nutrients. Based on their current dietary habits individual instructions were given by the dietician to achieve adherence to the recommended diet.

During the first three weeks of Study 2 (run-in period), all subjects consumed the cholesterol-lowering diet. Then, subjects were randomly divided into two treatment groups for another six weeks, stratified for age and gender. In addition to the cholesterol-lowering diet, the control group took daily one placebo capsule for pravastatin (cellulose micro cristallinun $\mathrm{Ph}$ 102) just before bedtime, whereas the experimental group used daily one pravastatin capsule (Bristol-Myers Squibb, The Netherlands) of $40 \mathrm{mg}$. The number-coded capsules were provided by the pharmacy of the University Hospital Maastricht at weeks 3 and 6 of the experiment.

\section{Blood sampling}

The subjects of Study 1 and Study 2 fasted overnight and were not allowed to use alcohol the day preceding or to smoke on the morning before blood sampling. All venipunctures were generally taken by the same person between $8.00 \mathrm{~h}$ and $11.00 \mathrm{~h}$ $A M$, in the same room, and mostly at the same time of the day of the week. Blood samples were taken from a forearm vein using vacutainers under minimal stasis with the subject in a supine position for at least 5 minutes. The vacutainers were kept at room temperature before and after blood sampling.

First, $10 \mathrm{ml}$ blood was collected in a serum tube (CORVAC; Sherwood Medical, St. Louis, USA) for analyses of serum lipids and lipoproteins, and high sensitivity (hs)CRP. At least one hour after venipuncture, serum was obtained by centrifuging at $2000 \times \mathrm{g}$ for $30 \mathrm{~min}$ at $4{ }^{\circ} \mathrm{C}$, which was stored at $-80^{\circ} \mathrm{C}$.

Then, $10 \mathrm{ml}$ blood was collected in an EDTA tube (Sherwood Medical, Ballymoney, Northern Ireland). Plasma for measurement of hs-IL- 6 was obtained by centrifuging the blood at $2000 \times \mathrm{g}$ for $30 \mathrm{~min}$ at $4{ }^{\circ} \mathrm{C}$ within one hour after venipuncture. Plasma samples were frozen in liquid nitrogen and stored at $-80^{\circ} \mathrm{C}$. 
In Study 1 and Study 2, blood was sampled at the start of the study (day 0), at weeks 2 and 3 (run-in period), and at weeks 6 and 7 (treatment period; Study 1) and weeks $4,5,8$ and 9 (treatment period, Study 2 ).

\section{Analyses}

\section{Lipids and lipoproteins}

Concentrations of lipids and lipoproteins in serum were determined as described elsewhere (Chapter 3, Chapter 4 and Chapter 5).

\section{C-reactive protein and interleukin-6}

Before analyses of CRP and IL-6, samples obtained at weeks 2 and 3 of the run-in period (Study 1 and Study 2), at weeks 6 and 7 (treatment period, Study 1) as well as of weeks 8 and 9 (treatment period, Study 2) were pooled. Serum concentrations of CRP were measured by a high sensitivity chemiluminescent sandwich enzyme immunoassay using the IMMULITE ${ }^{-1}$ Automated Analyzer (Diagnostics Products

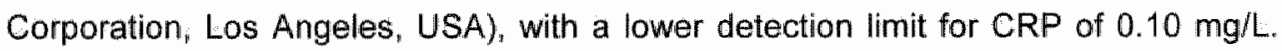
The coefficient of variation between runs for CRP was 3-5\% for values below 10 $\mathrm{mg} / \mathrm{L}$ (22). IL-6 concentrations in plasma were determined using a high sensitivity sandwich enzyme immunoassay (Quantikine ${ }^{(i)}$ HS, R\&D Systems Europe Ltd, Abingdon, United Kingdom), with a lower detection limit of $0.094 \mathrm{pg} / \mathrm{mL}$ for IL-6. The coefficient of variation within runs for IL-6 was $8.5 \%$.

\section{Lipid-soluble antioxidants}

Concentrations of tocopherols and carotenoids were determined simultaneously by reversed-phase high-pressure liquid chromatography (HPLC) as described before in Chapter 5. Plasma samples taken at weeks 2 and 3 of the run-in period (Study 1 and Study 2), at weeks 6 and 7 (treatment period, Study 1) as well as of weeks 8 and 9 (treatment period, Study 2) were pooled before analyses of lipid-soluble antioxidants. Values obtained during the run-in period of both studies were used for the crosssectional dlata analysis. 


\section{Statistics}

\section{Intervention studies}

In Study 1 and Study 2, the responses to treatment were calculated for each subject as the change between values obtained at the end of the treatment period and at the end of the run-in period. Differences in changes between the two treatment groups of both trials were determined by using the unpaired $t$ test. At the end of the run-in period, all measured variables were not significantly different between the two groups in both trials (unpaired $t$ test). The non-normally distributed CRP and IL-6 values were log-transformed. CRP values $\geq 10 \mathrm{mg} / \mathrm{L}$ (the cut-off level reflecting possible intervening acute infection (23)) during the run-in and/or treatment periods were excluded from the statistical analyses of CRP from Study 1 (control group: $n=2$; plant stanol ester group: $n=1$ ) and Study 2 (pravastatin group: $n=1$ ). Effects were essentially similar when these values were not excluded. In both studies, a value of $P$ $<0.05$ was considered significant. Normally distributed values are presented as means \pm SEM and non-normally distributed variables as medians with ranges in parentheses. The statistical analyses were done with StatView 5.0.

\section{Cross-sectional study}

The relations between markers of inflammation (CRP and IL-6) and plasma lipidsoluble antioxidants (tocopherols and carotenoids) were examined by multiple linear regression analyses after adjustment for serum concentrations of LDL cholesterol, HDL cholesterol and triacylglycerol after the run-in periods of Study 1 and Study 2. For this multiple regression analysis, the non-normally distributed CRP and IL-6 values were log-transformed. Three multiple regression models were used to examine the relationships of CRP or IL-6 with respectively the total tocopherols (the sum of $\alpha$-tocopherol, $\beta+\gamma$-tocopherol and $\delta$-tocopherol), with the oxygenated carotenoids (the sum of lutein and $\beta$-cryptoxanthin), and with the hydrocarbon carotenoids (the sum of lycopene, $\alpha$-carotene and $\beta$-carotene). A value of $P<0.05$ was considered significant. All statistical analyses were performed with StatView 5.0. 


\section{Results}

\section{Lipids and lipoproteins}

\section{Study 1: Effects of plant stanol esters}

For serum total, LDL- and HDL cholesteral concentrations, the differences in changes between the plant stanol ester and control groups were $-0.30 \mathrm{mmol} / \mathrm{L}$ or $5.0 \%(P=0.010),-0.31 \mathrm{mmol} / \mathrm{L}$ or $-8.0 \%(P=0.006)$, and $0.08 \mathrm{mmol} / \mathrm{L}$ or $5.1 \%(P=$ 0.021), respectively, as presented elsewhere (Chapter 5). Triacylglycerol concentrations were unaffected $(P=0.130)$.

\section{Study 2: Effects of pravastatin}

For serum total-, LDL- and HDL cholesterol, and triacylglycerol concentrations, the differences in changes between the pravastatin and placebo groups were -1.90 $\mathrm{mmol} / \mathrm{L}$ or $-26.0 \%(P<0.001),-1.81 \mathrm{mmol} / \mathrm{L}$ or $-32.4 \%(P<0.001), 0.14 \mathrm{mmol} / \mathrm{L}$ or $11.9 \%(P=0.009)$ and $-0.48 \mathrm{mmol} / \mathrm{L}$ or $-33.0 \%(P<0.001)$, as described before (Chapter 3 and Chapter 5 ).

\section{C-reactive protein and interleukin-6}

\section{Study 1: Effects of plant stanol esters}

As shown in Table 1, changes in serum concentrations of CRP were not significantly different between the plant stanol ester and control groups $(P=0.766$ for the difference in changes). Also, changes in plasma IL-6 concentrations did not significantly differ between the two groups $(P=0.222)$.

\section{Study 2: Effects of pravastatin}

As llisted in Table 2, changes in serum concentrations of CRP did not significantly differ between the pravastatin and placebo groups $(P=0.397)$. Changes in plasma IL $\omega 6$ concentrations were also not significantly different between both groups $(P=$ $0.710)$ 


\section{TABLE 1}

Effects of margarine enriched with plant stanol esters on serum CRP and plasma IL-6 concentrations in Study $y^{*}$

\begin{tabular}{lcc}
\hline & Control group & Stanol ester group \\
\hline CRP (mg/L) & $0.83(0.27$ to 5.85$)$ & $0.75(0.24$ to 6.78$)$ \\
$\quad$ Run-in & $1.08(0.25$ to 4.30$)$ & $0.84(0.24$ to 6.75$)$ \\
$\quad \begin{array}{l}\text { Treatment } \\
\text { Change }\end{array}$ & $-0.06(-1.65$ to 3.74$)$ & $0.06(-4.25$ to 3.51$)$ \\
IL-6 (pg/mL) & $1.20(0.23$ to 3.01$)$ & $0.96(0.60$ to 3.00$)$ \\
Run-in & $1.14(0.27$ to 4.54$)$ & $1.05(0.63$ to 2.13$)$ \\
Treatment & $0.03(-0.74$ to 3.22$)$ & $-0.02(-2.01$ to 0.70$)$ \\
\hline
\end{tabular}

"Values are medians (range). Fourty-eight volunteers consumed sunflower oil-based control margarine for thres weeks (run-in period). During the treatment period of four weeks, one group continued consuming their control margarine $(n=25)$, while the other group received sunflower oil-based margarine $(24.57 \mathrm{~g} / \mathrm{d})$ enriched with plant stanol esters (2.01 g plant stanols/d; $n=23$ ).

\section{TABLE 2}

Effects of pravastatin on serum CRP and plasma IL-6 concentrations in Study $2^{\Uparrow}$

\begin{tabular}{lcc}
\hline & Placebo group & Pravastatin group \\
\hline CRP (mg/L) & $1.10(0.33$ to 9.26$)$ & $1.08(0.29$ to 6.03$)$ \\
$\quad$ Run-in & $1.00(0.20$ to 6.04$)$ & $1.29(0.16$ to 7.04$)$ \\
Treatment & $-0.02(-8.74$ to 3.40$)$ & $0.01(-3.77$ to 5.26$)$ \\
$\quad$ Change & & \\
IL-6 (pg/mL) & $1.08(0.37$ to 2.39$)$ & $1.10(0.42$ to 3.05$)$ \\
$\quad$ Run-in & $1.28(0.50$ to 2.30$)$ & $1.12(0.31$ to 4.20$)$ \\
$\quad$ Treatment & $0.16(-1.02$ to 1.07$)$ & $0.02(-1.17$ to 2.54$)$ \\
Change &
\end{tabular}

Values are medians (range). Fourty-seven participants consumed a cholesteroltowering diet for three weeks (run-in period). For another six weeks (treatment period), volunteers continued their diets and received placebo $(n=24)$ or pravastatin $\left(40 \mathrm{mg} / \mathrm{d}_{4} n=23\right)$ capsules. 


\section{Cross-sectional study}

Table 3 presents the concentrations of CRP and IL-6, plasma tocopherols and carotenoids, and serum lipids and lipoproteins in the study population $(n=86)$ as used in the multiple regression analyses.

\section{TABLE 3}

Serum CRP, plasma IL-6, tocopherols and carotenoids, and serum lipids and lipoproteins in the cross-sectional study population as used in the multiple regression analyses ${ }^{1}$

\begin{tabular}{|c|c|}
\hline & $(n=86)$ \\
\hline CRP (mg/L) & $0.81(0.24$ to 6.78$)$ \\
\hline $1 \mathrm{~L}-6(\mathrm{pg} / \mathrm{mL})$ & $1.08(0.23$ to 2.39$)$ \\
\hline$\alpha$-Tocopherol $(\mu \mathrm{mol} / \mathrm{L})$ & $35.74 \pm 0.91$ \\
\hline$p+\gamma$ Tocopherol (umollL) & $2.57 \pm 0.14$ \\
\hline S-Tocopherol ( $\mu$ molnL) & $0.15 \pm 0.01$ \\
\hline Total tocopherols ( $\mu \mathrm{mol} / \mathrm{L}$ ) & $38.46 \pm 0.97$ \\
\hline Lutein ( $\mu$ molll $)$ & $0.55 \pm 0.02$ \\
\hline B-Cryptoxanthin ( $\mu \mathrm{mol} / \mathrm{L})$ & $0.41 \pm 0.02$ \\
\hline Oxygenated carotenoids $\left(\mu \mathrm{mol} / \mathrm{L}_{\mathrm{L}}\right)$ & $0.96 \pm 0.03$ \\
\hline Lycopene (umal/L) & $0.64 \pm 0.02$ \\
\hline$\alpha$-Carotene $(\mu \mathrm{mol} / \mathrm{L})$ & $0.12 \pm 0.01$ \\
\hline$\beta$-Carotene $(\mu \mathrm{mol} / \mathrm{L})$ & $0.56 \pm 0.04$ \\
\hline Hydrocarbon carotenoids ( $\mu$ mol/L) & $1.32 \pm 0.06$ \\
\hline LDL cholesterol (mmol/L) & $4.68 \pm 0.12$ \\
\hline HDL cholesterol (mmal/L) & $1.36 \pm 0.06$ \\
\hline Triacylglycerol (mmol/L) & $1.25 \pm 0.07$ \\
\hline
\end{tabular}

Table 4 shows the relationship between serum log-normalized CRP as dependent variable and plasma lipid-soluble antioxidants after adjustment for serum LDL cholesteral, HDL cholesterol and triacylglycerol concentrations. None of the plasma antioxidants were significantly related to serum CRP. Triacylglycerol was positively associated with CRP. Comparable relationships were found between CRP with the tocopherol isomers and individual carotenoids (data not shown). 


\section{TABLE 4}

Relationships between serum CRP and plasma lipid-soluble antioxidants after adjustment for serum LDL cholesterol, HDL chalesterol and triacylglycerol ${ }^{3}$

\begin{tabular}{lll}
\hline & Regression coefficient \pm SEM & P-value \\
\hline
\end{tabular}

Dependent variable:

CRP

Independent variables:

$\begin{array}{lcc}\text { Total tocopherols } & -0.004 \pm 0.006 & 0.519 \\ \text { LDL cholesterol } & -0.040 \pm 0.042 & 0.344 \\ \text { HDL cholesterol } & 0.078 \pm 0.089 & 0.382 \\ \text { Triacylglycerol } & 0.280 \pm 0.092 & 0.003\end{array}$

Dependent variable:

CRP

Independent variables:

$\begin{array}{lcc}\text { Oxygenated carotenoids } & -0.159 \pm 0.114 & 0.169 \\ \text { LDL cholesteral } & -0.051 \pm 0.036 & 0.161 \\ \text { HDL cholesterol } & 0.079 \pm 0.084 & 0.348 \\ \text { Triacylglycerol } & 0.259 \pm 0.066 & <0.001\end{array}$

Dependent variable:

CRP

Independent variables:

Hydrocarbon carotenoids

$\begin{array}{ll}-0.074 \pm 0.067 & 0.271 \\ -0.056 \pm 0.036 & 0.127 \\ 0.072 \pm 0.084 & 0.394 \\ 0.243 \pm 0.064 & <0.001\end{array}$

LDL cholesterol

HDL cholesterol

Triacylglycerol

'CRP walues were log-transformed. Three multiple regression madels were calculated for the relations of CRP'

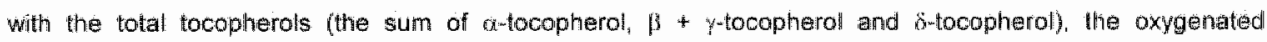
carotenoids (the sum of Jutein and B-cryptoxanthin), and the hydrocarbon carotenoids (the sum of lycopens, a carotene and $(1$-carotene). Concentrations of the antioxiclants were expressed in $\mu$ moll L.

The hydrocarbon carotenoids were inversely related to log-transformed IL-6, whereas the tocopherols and oxygenated carotenoids showed no significant associations with IL-6 (Table 5). HDL cholesterol showed an inverse relationship with IL-6. Comparable effects were found for the relations between IL-6 with the individual tocopherols and various carotenoids (data not shown). When the multiple regression models for CRP and IL-6 (Table 4 and Table 5, respectively) were also adjusted for age and/or BMI, relationships were essentially similar. 


\section{TABLE 5}

Relationships between plasma $\mathrm{LL}-6$ and lipid-soluble antioxidants after adjustment for serum LDL cholesterol, HDL cholesterol and triacylglycerol ${ }^{4}$

\begin{tabular}{lcc}
\hline & Regression coefficient \pm SEM & P-value \\
\hline Dependent variable: & & \\
IL-6 & & \\
Independent wariables: & & \\
Total tocopherols & $-0.001 \pm 0.004$ & 0.820 \\
LDL cholesterol & $-0.017 \pm 0.024$ & 0.485 \\
HDE cholesterol & $-0.107 \pm 0.050$ & 0.035 \\
Triacylglycerol & $0.018 \pm 0.052$ & 0.730
\end{tabular}

Dependent variable:

IL 6

Independent variables:

Oxygenated carotenoids

$\begin{array}{rl}-0.035 \pm 0.065 & 0.587 \\ -0.019 \pm 0.020 & 0.362 \\ -0.106 \pm 0.047 & 0.028 \\ 0.014 \pm 0.037 & 0.703\end{array}$

LDL cholesterol

HDL cholesterol

Triacylglycerol

$0.014 \pm 0.037$

0.703

Dependent variable:

$\| L-6$

Independent variables:

Hydrocarbon carrotenoids

$$
\begin{array}{rr}
-0.086 \pm 0.036 & 0.021 \\
-0.021 \pm 0.020 & 0.285 \\
-0.095 \pm 0.046 & 0.041 \\
0.015 \pm 0.035 & 0.671
\end{array}
$$

LDL cholestero:

Triacylglycerol

'IL.6 values were log-transformed. The multiple regression models were calculated for the relations of llL-6 with the total tocopherols (the sum of a-tocopherd, *y-tocopherol and s-tocopherol), the oxygenated carotenoids (the sum of lutein and p-cryptoxanthini), and the hydrocarbon carotenoids (the sum of lycopene, $\alpha$-carotene and j) carotene". Concentrationg of the antioxidants were expressed in $\mu$ mol/h.

\section{Discussion}

In the present studies, we have studied in mildly and hypercholesterolemic subjects the effects of a cholesterol-lowering dietary component, plant stanol esters, and those of a lipid-lowering drug, pravastatin, on circulating CRP and IL-6 concentrations. As these inflammation markers may reflect the severity of the atherosclerotic process (5), it was hypothesized that cholesterol lowering by 
pravastatin or plant stanol esters may lower circulating concentrations of these components. Our findings, however, showed that daily consumption of $2.01 \mathrm{~g}$ of plant stanols as esters for 4 weeks or pravastatin treatment of $40 \mathrm{mg} / \mathrm{d}$ for 6 weeks had no effects on CRP and IL-6 concentrations in subjects with increased cholesterol concentrations, despite significant reductions in serum LDL cholesterol of 8 and $32 \%$, respectively. In contrast, two placebo-controlled trials $(6,10)$ found that pravastatin (40 mg/d) for respectively 5 years and 24 weeks lowered CRP concentrations by $22 \%$ in patients who remained free of recurrent coronary events and by $17 \%$ in subjects with mildly elevated cholesterol concentrations. Also after short-terim treatment for 4 up to 8 weeks with pravastatin as well as with other statins, such as simvastatin, atorvastatin and cerivastatin, comparable reductions in CRP have been reported in participants with markedly elevated cholesterol concentrations $(7,12,24)$. A limitation of these latter studies, however, was the absence of a placebo group. As for plasma IL-6, two trials, which also lacked a placebo group, found reductions only in hypercholesterolemic subjects after simvastatin treatment for 3 months (8) or 36 weeks (25). Not all studies, however, demonstrated reductions in plasma concentrations of CRP or IL-6 after statin therapy. In two placebo-controlled trials with hypercholesterolemic individuals, pravastatin $(40 \mathrm{mg} / \mathrm{d})$ did not affect CRP or IL6 after long- or short-term treatment $(26,27)$. In two studies that lacked control groups $_{n}$ a comparison of the short-term effects of pravastatin . simvastatin and atorvastatin in subjects with markedly elevated cholesterol concentrations showed comparable decreases in CRP and no changes in IL-6 in one study (24), while CRP was not affected in the other study (28). In addition, fluvastatin therapy for 24 weeks had no effect on circulating CRP in coronary artery disease patients with mixed hyperlipidemia (29). Taken together, these findings suggest that the effects of statins on CRP and IL-6 are not consistent. It seems that the lack of effect of pravastatin in our present study cannot be explained by the class of statin drug used. It should be noted, however, that several trials $(7,8,12,24,25,28,29)$ lacked a control group. which makes it more difficult to interpret the results properly. Furthermore, it has been demonstrated that changes in CRP by statins were not associated with changes in LDL cholesterol $(6,7,10,12,24)$. In other words, effects of statins on CRP may be independent of statin-induced lipid lowering. It is therefore possible that lipid lowering per se does not affect CRP. which may explain the lack of effect by plant stanol esters. It could also be that the intervention period was too short. Another reason for the lack of effect could be that reduction in CRP occurs especially in persons with increased CRP concentrations (26). It is therefore possible that the mildly and hypercholesterolemic subjects of our present study were at minor risk of 
developing cardiovascular disease, as suggested by low CRP values at the start of the sturdy.

No human studies so far have examined the effects of consumption of functional foods enriched with plant sterois or stanols on CRP or IL-6 concentrations. However, effects of other potential beneficial dietary regimes with regard to the prevention of cardiovascular disease, such as consumption of tea polyphenols (18) and soy isoflavones (30) or caloric restriction (31), on these inflammation markers have been studied. It has been shown that tea polyphenol consumption for 4 weeks did not affect plasma concentrations of CRP and IL-6 in smokers (18). In contrast, high intakes of soy isoflavones for one month increased serum IL-6 in postmenopausa women, whereas CRP concentrations remained unchanged (30). On the other hand, a recent study (31) showed that weight loss by caloric restriction decreased plasma CRP concentrations in obese postmenopausal women. As adipocytes secrete IL-6 (2), which in turn stimulates the CRP production, it is very likely that these findings (31) are due to a reduction in fat mass.

Since dietary antioxidants may lower the risk for cardiovascular disease (14), we also investigated in the group of mildly and hypercholesterolemic subjects the relationships between markers of inflammation (CRP and IL-6) with plasma tocopherol and carotenoid concentrations. Antioxidants may protect against damage by oxygen free radicals, which play a role in pathological processes, such as atherosclerosis, cancer and the aging process (15). In addition, plasma carotenoid concentrations have not only been associated with cardiovascular disease risk (14) but also with other inflammatory conditions. In fact, in the general population $(16,17$, 32,33 ) but also in patients with lung cancer (34) or acute pancreatitis (35), concentrations of CRP are inversely related to carotenoid concentrations. With regard to $\alpha$-tocopherol, no significant correlation was found with CRP in older women (32), whereas negative correlations with CRP were observed in patients with lung cancer (34) or acute pancreatitis (35), and a remarkable positive relation with CRP in subjects from the general population (33). Our findings are not in line with these inverse relationships between carotenoids, $\alpha$-tocopherol and CRP. Thus, in our cross-sectional study group of mildly and hypercholesterolemic subjects, we found that none of the plasma tocopherols or carotenoids were significantly related to serum CRP. However, we observed an inverse relation between the hydrocarbon carotenoids (the sum of lycopene, $\alpha$-carotene and $\beta$-carotene) and IL- 6 , whereas the oxygenated carotenoids (the sum of lutein and $\beta$-cryptoxanthin) and the tocopherols (the sum of $\alpha$-tocopherol, $\beta+\gamma$-tocopherol and $\delta$-tocopherol) were not associated with IL-6. In our multiple regression models, we also found that triacyliglycerol was positively related with CRP and that HDL cholesterol was inversely associated with 
IL-6. De Maat et al. (18) showed a negative correlation between plasma $1 \mathrm{~L}-6$ and 3 carotene concentrations in smoking individuals, but found a remarkable positive correlation with $\alpha$-tocopherol. In agreement with our findings, no significant correlations were observed between these antioxidants and CRP (18). The importance of the finding that the hydrocarbon carotenoids are related to $1 L-6$ is that this inflammation marker is a significant predictor of the risk of future cardiovascular events (5). It could be possible that these carotenoids may prevent the oxidative stress in the vessel wall. However, the cross-sectional design of our study does not permit conclusions about causal relationships.

In conclusion, circulating CRP and IL-6 concentrations were not affected after shortterm plant stanol ester consumption or pravastatin treatment in mildly and hypercholesterolemic volunteers. Placebo-controlled randomized trials in persons with higher risks of cardiovascular disease with longer treatment periods are needed, especially for plant stanol esters, to investigate effects on these inflammation markers. In mildly and hypercholesterolemic subjects, the hydrocarbon carotenoids were inversely related to $\mathbb{L L}-6$, while the oxygenated carotenoids and tocopherols were not associated with IL-6. Intervention studies, however, are needed to test causality.

\section{Acknowledgements}

We wish to thank the members of our dietary and technical staff of our Department and the technicians of the Department of Clinical Chemistry of the University Hospital Maastricht for their excellent support. We would also like to thank all subjects for their cooperation and interest. Study 1 was supported by Raisio Group plc, Raisio, Finland. Study 2 was supported by Novartis Consumer Health, Nyon, Switzerland. 


\section{References}

1. Tracy RP. Inflammation markers and coronary heart disease. Curr Opin Lipidol $1999 ; 10: 435-41$.

2. Yudkin JS, Kumari M, Humphries SE, Mohamed-Ali V. Inflammation, obesity, stress and coronary heart disease: is interleukin-6 the link? Atherosclerosis 2000; 148:209-14.

3. Ross R. Atherosclerosis - an inflammatory disease. N Engl J Med 1999;340:115-26.

4. Patrick $L_{\text {. }}$ Uzick M. Cardiovascular disease: $C$-reactive protein and the inflammatory disease paradigm: HMG-CoA reductase inhibitors, alpha-tocopherol, red yeast rice, and olive oil polyphenols. A review of the literature. Altern Med Rev 2001;6:248-71.

5. Ridker PM, Hennekens CH, Buring JE, Rifai N. C-reactive protein and other markers of inflammation in the prediction of cardiovascular disease in women. N Engl J Med $2000,342: 836-43$.

6. Ridker PM, Rifai N, Pfeffer MA, Sacks F, Braunwald E. Long-term effects of pravastatin on plasma concentration of C-reactive protein. Circulation 1999;100:230-5.

7. Ridker PM, Rifai N, Pitman Lowenthal S. Rapid reduction in C-reactive protein with cerivastatin among 785 patients with primary hypercholesterolemia. Circulation 200*:103:1191-3.

8. Musial J, Undas A, Gajewski P, Jankowski M, Sydor W, Szczekllik A. Anti-inflammatory effects of simwastatin in subjects with hypercholesterolemia. Int J Cardiol 2001;77:24753.

9. Bickel $C$, Rupprecht HJ, Blankenberg $S$, et al. Influence of HMG-CoA reductase inhibitors on markers of coagulation, systemic inflammation and soluble cell adhesion. Int ل ال Cardiol 2002;82:25-31.

10. Albert MA, Danielson E, Rifai NI, Ridker PM. Effect of statin therapy on C-reactive protein levels. The Pravastatin Inflammation/CRP Evaluation (PRINCE): a randomized trial and cohort study. JAMA $2001 ; 286: 64-70$.

11. Ridker PM, Rifai $N$, Clearfield $M$, et al. Measurement of C-reactive protein for the targeting of statin therapy in the primary prevention of acute coronary events. $\mathrm{N}$ Engl J Med 2001:344:1959-65.

12. Riesen WF, Engler $H_{4}$, Risch $M$, Korte W, Noseda $G$. Short-tem effects of atorvastatin on C-reactive protein. Eur Heart $\mathbb{J} 2002 ; 23: 794-9$.

13. Law M. Plant sterol and stanol margarines and health. BMJ 2000;320:861-4.

14. Cooper DA, Eldridge AL, Peters JC. Dietary carotenoids and certain cancers, heart disease, and age-related macular degeneration: a review of recent research. Nutr Rev 1999;57:201-14.

15. Berry EM. The effects of nutrients on lipoprotein susceptibility to oxidation. Curr Opin Lipidol 1992;3:5-11.

16. Ellinger TP, Guallar E, Miller III ER, Stolzenberg-Solomon $R$, Appel LJ. Relationship between systematic markers of inflammation and serum $\beta$-carotene levels. Airch intern Med 2001:161:1903-8.

17. Kritchevsky SB, Bush AJ, Pahor M, Gross MD. Serum carotenoids and markers of inflammation in nonsmokers. Am J Epidemiol 2000;152:1065-71.

18. De Maat MP, Pijl H, Kluft C, Princen HM. Consumption of black and green tea had no effect on inflammation, haemostasis and endothelial markers in smoking healthy individuals. Eur J Clin Nutr 2000;54:757-63.

19. Centraal Begeleidingsorgaan voor de Intercollegilale Toetsing, in samenwerking met de Nederlandse Hartstichting, et al. Behandeling en preventie van coronaire hartziekten door verlaging van de plasmacholesterolconcentratie (Treatment and prevention of 
coronary heart disease by lowering plasma cholesterol concentrations). Utrecht: Centraal Begeleidingsorgaan voor de Intercollegiale Toetsing, 1998 (in Dutch).

20. Nederlandse Voedingsnomen 1989 (Dutch dietary guidelines 1989) / Commissie Voedingsnormen Voedingsraad, 2e druk. The Hague: Voorlichtingsbureau voor de Voeding 1992 (in Dutch).

21. The Expert Panel. Summary of the second report of the National Cholesteroll Education Program (NCEP) Expert Panel on Detection, Evaluation, and Treatment of High Blood Cholesterol in Adults (Adult Treatment Panel ll). JAMA 1993;269:3015-23.

22. Rothkrantz-Kos $S$, Schmitz MPJ, Bekers O, Menheere PPCA van Dieijen-Visiser MP High-sensitivity C-reactive protein methods examined. Clin Chem 2002;48:359-62.

23. Strandberg TE, Tilvis RS. C-reactive protein, cardiovascullar risk factors, and mortality in a prospective study in the elderly. Arterioscier Thromb Vasc Biol 2000;20:1057-60.

24. Jialal 1, Stein D, Balis D, Grundy $\mathrm{SM}_{8}$ Adams-Huet B, Devaraj S. Effect of hydroxymethyl glutaryl coenzyme A reductase inhibitor therapy on high sensitive $C$ reactive protein levels. Circulation 2001;103:1933:5.

25. Wiklund O, Mattsson-Hultén L. Hurt-Camejo E, Oscarsson J. Effects of simvastatin and atorvastatin on inflammation markers in plasma. J Intern Med 2002;251:338 47.

26. Kluft C, De Maat MPM, Gevers Leuven JA, Potter van Loon BJ, Mohrschladt M. Statins and $\mathrm{C}$-reactive protein. The Lancet 1999;353:1274.

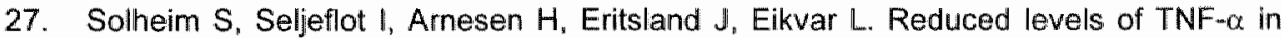
hypercholesteralemic individuals after treatment with pravastatin for 8 weeks. Atherosclerosis 2001:157:411-5.

28. Joukhadar $C_{\text {, Klein }} \mathbb{N}$, Prinz $N$, et al, Similar effects of atorvastatin, simvastatin and pravastatin on thrombogenic and inflammatory parameters in patients with hypercholesterolemia. Thromb Haemost 2001;85:42-6.

29. Cortellaro $M_{1}$ Cofrancesco $E$, Boschetti $C_{n}$ et al. Effects of fluvastatin and bezafibrate combination on plasma fibrinogen, t-plasminogen activator inhibitor and C-reactive protein levels in coronary artery disease patients with mixed hyperlipidaemia (FACT Study). Thromb Haemost 2000;83:549-53.

30. Jenkins DJ, Kendall CW, Connelly PW, et al. Effects of high- and low-isoflavone (phytoestrogen) soy foods on inflammatory biomarkers and proinflammatory cytokines in middle-aged men and women. Metabolism 2002;51:910-24.

31. Tchernof A, Nolan A, Sites $C_{4}$, Ades PA, Poehiman ET. Weight loss reduces $C_{-}$ reactive protein levels in obese postmenopausal women. Circulation 2002;105:564-9.

32. Boosalis MG, Snowdon DA, Tully CL. Gross MD. Acute phase response and plasma carotenoid concentrations in older women: findings from the nun study. Nutrition $1996 ; 12 ; 475-8$.

33. Broekmans WMR, Klöpping Ketelaars IAA, Bots ML, et al. Serum carotenoids and vitamins in relation to biomarkers of endothelial function and inflammation. Thesis Wageningen University, Carotenoid status in man: effects on biomarkers of eye, skin and cardiovascular health 2002 ;SBN 90-5808-631-3.

34. Taiwar D, Ha TKK, Scott HR, et al. Effect of inflammation on measures of antioxidant status in patients with non-small cell lung cancer. Am J Clin Nutr 1997;66:1283-5.

35. Curran FJM, Sattar N. Talwar D, Baxter JN, Imrie CW. Relationship of carotenoid and vitamin $A$ and $E$ with the acute inflammatory response in acute pancreatitis. Br J Surg $2000 ; 87: 301-5$. 


\title{
Chapter
}

\author{
General discussion
}




\section{General Discussion}

The studies described in the present thesis were focused on effects of the dietary components, tocotrienols, $\beta$-glucan and plant stanol esters on cardiovascular risk markers in individuals with increased serum cholesterol concentrations. The first study described in Chapter 3 was a double-blind, placebo-controlled parallel trial, in which effects of a tocotrienol-rich fraction from rice bran oil (TRF-RBO) on serum lipids and hemostatic parameters were compared with those of a lipid-lowering drug. pravastatin. To investigate effects on serum lipids and lipoproteins of $\beta$-glucan from oat bran in different food matrices "we carried out our second and third study (Chapter 4). The effects of oat $\beta$-glucan incorporated into bread and cookies were examined in a controlled parallel designed study. In our third trial, which had a crossover design, the same source and daily amount of oat $\beta$-glucan was given with orange juice. Plasma lipid-soluble antioxidants were studied not only in our third study with oat $\beta$-glucan, but also in a subpopulation of our first study that received either placebo or pravastatin treatment, as well as in a double-blind, placebocontrolled parallel study in which plant stanol esters were consumed (Chapter 5). In the subpopulation of our first study and in the study with plant stanol esters, effects on inflammation markers were also examined (Chapter 6). Furthermore, relationships were studied between inflammation markers and plasma lipid-soluble antioxidants in a cross-sectional study group of mildly and hypercholesterolemic subjects (Chapter 6).

\section{Serum lipids and lipoproteins}

The major aim of the in Chapter 3 described study was to investigate whether a tocotrienol-rich fraction from rice bran oil (TRF-RBO) changed serum cholesterol concentrations in hypercholesterolemic humans consuming a cholesterol-lowering diet. So far, results of tocotrienals from palm oil on serum lipids were highly controversial (1-7) and except for Qureshi et al. (8-10), no other research groups have ever studied the effects of tocotrienols from rice bran oil in humans before. Since tocotrienols have been suggested to decrease endogenous cholesterol synthesis like statins, we also examined how the effects of TRF-RBO on serum lipids compared with those of a statin, namely pravastatin. The rate-limiting step in the biosynthesis of cholesterol is the conversion of 3-hydroxy-3-methylglutaryl-coenzyme A (HMG-CoA) to mevalonic acid by the enzyme HMG-CoA reductase. The class of drugs named HMG-CoA reductase inhibitors, or statins, inhibits this enzyme. As a 
result, intracellular cholesterol concentrations decreases, which increases the expression of LDL receptors on cell surfaces leading to an increased clearance of LDL cholesterol from the circulation. Statins may also inhibit hepatic synthesis of VLDL, which is a precursor of LDL, thereby inhibiting the production of LDL (11). The proposed mechanism of action for cholesteroll lowering of tocotrienols differs from that of statins. Like statins, tocotrienols have been suggested to lower endogenous cholesterol synthesis by an inhibition of the activity of HMG-CoA reductase as demonstrated in animals $(12-15)$. However, statins competitively inhibit HMG-CoA reductase (11), whereas tocotrienols may inhibit the activity of this enzyme by a posttranscriptional mechanism, which may involve a reduced HMG-COA reductase protein synthesis rate and an increased degradation rate as found in human hepatoma HepG2 cells (16). It has been suggested that the different tocotrienol subtypes exert various degrees of cholesterol-lowering activity. In fact, the inhibitory effects of $\delta$-tocotrienol and $\gamma$-tocotrienol on HMG-CoA reductase activity are claimed to be greater than of $\alpha$-tocotrienol, whereas $\beta$-tocotrienol has a very low effect ( 14 , 17).

In our first study, all subjects were instructed to consume a cholesterol-lowering diet according to the Dutch dietary guidelines (18). We decided to choose for cholesterollowering dietary therapy throughout the study since a low intake of saturated fatty acids and cholesterol increases the activity of HMG-CaA reductase and the LDL receptors (19), and under these conditions, the inhibitors of cholesterol biosynthesis, tocotrienols and pravastatin, are likely to be most effective. Furthermore, TRF-RBO capsules were given after supper and at bedtime divided into two daily doses and pravastatin was administered once daily at bedtime because the biosynthesis of cholesterol in humans is highest during the night (11).

Our first study demonstrated that a daily intake of $42 \mathrm{mg}$ of TRF-RBO for 6 weeks had no favorable effects on serum lipid and lipoprotein concentrations in hypercholesterolemic volunteers. In addition, we have examined the effects of TRFRBO and pravastatin on markers for cholesterol synthesis and absorption. After tocotrienol supplementation, no changes were found in serum cholesterolstandardized concentrations of lathosterol, which reflect the endogenous cholesterol synthesis (20), and in those of campesterol, which reflect the intestinal cholesterol absorption (21). These findings indicate that TRF-RBO did not affect cholesterol metabolism in hypercholesterolemic subjects on a cholesterol-lowering diet.

On the other hand, a daily use of $40 \mathrm{mg}$ of pravastatin decreased serum total cholesterol, LDL cholesterol and triacylglycerol concentrations and the total to HDL cholesterol ratio by $25,32,25$ and $34 \%$, respectively, versus changes in the placebo and TRF-RBO groups. Pravastatin tended to increase serum HDL concentrations 
compared with the placebo group. Neither apo A-l nor $L p(a)$ concentrations were affected by pravastatin. Changes in serum apo $B$ concentrations paralleled those in LDL cholesterol, which indicates that the number of the LDL particles was decreased with pravastatin. In agreement with others (22), endogenous cholesterol synthesis was also reduced by pravastatin as indicated by a $44 \%$ decline in the cholesterolstandardized lathosterol concentrations versus changes in the placebo and TRFRBO groups, whereas those of campesterol were increased by $16 \%$ versus changes in the placebo group, which suggests a compensatory increase in the intestinal cholesterol absorption with pravastatin. The beneficial effects of pravastatin on the serum lipid and lipoprotein profile were as expected (11) and the use of pravastatin can therefore be regarded as a good positive control indicating good compliance of our participants.

Results of three studies $(1-3)_{i}$ in which tocotrienols from palm oil reduced serum LDL cholesterol concentrations, do not support our findings: A shortcoming of the study by Tan et al. (1) is that it lacked a control group. Another problem in interpreting the results is that in the study of Qureshi et al. (2), a significant decrease in serum LDL cholesterol concentrations was only achieved when three poor responders from 15 subjects in the tocotrienol group were excluded from the statistical analysis. The exclusion of these subjects from the statistical analysis makes the validity doubtful. Our findings, however, agreed with results from other studies (4-7) in which a tocotrienol-rich fraction from palm oil was supplemented in doses ranging from 60 to $336 \mathrm{mg}$ per day. Also, even after daily consumption of $250 \mathrm{mg}$ of purified $\alpha-, \gamma-$, or $\delta-$ tocotrienyl acetates from palm oil, $O^{\prime}$ Byrne et al. ( 7 ) found no effects on serum lipids and lipoproteins.

Rice bran oil is a rich source of $\gamma$-tocotrienol, which is claimed to possess a strong hypocholesterolemic activity (23). Besides; Qureshi et al. $(8,9)$ suggested that tocotrienols from rice bran oill were even more effective in lowering serum LDL cholesterol concentrations than the tocotrienols from palm oil. It has been postulated that these promising effects were attributed to two novel subtypes of tocotrienols. They isolated these tocotrienols from rice bran oil and identified them as desmethyl $\left(P_{21}\right)$ and didesmethyl $\left(P_{25}\right)$ tocotrienols $(8)$. Our results, however, are not consistent with the findings of Qureshi et al. $(8,9)$, who conducted two human studies in which a daily intake of 50 or $200 \mathrm{mg}$ of a tocotrienol-rich fraction from rice bran oil lowered LDL cholesteral concentrations by 18 and $23 \%$, respectively. When comparing these results of Qureshi et al. $(8,9)$ with our findings, it should be taken into account that our placebo capsules contained more tocopherols and tocotrienols than anticipated, but, the changes in serum LDL cholesterol concentrations in both the placebo and TRF-RBO groups were near zero. Qureshi et al (9), however, observed a strong LDL 
cholesterol-lowering effect of $18 \%$ after a daily use of $50 \mathrm{mg}$ of a tocotrienol-rich fraction from rice bran oil. Based on the fact that this hypocholesterolemic effect of tocotrienols follows a dose-response relationship (10), it might be expected that a daily intake of $42 \mathrm{mg}$ of our TRF-RBO capsules should result in a hypocholesterolemic effect as well.

Although studies in various animal species have demonstrated that tocotrienols not only decrease cholesterol concentrations (12-14); but also diet-induced atherosclerotic lesions (24), the claimed hypocholesterolemic effect by Qureshi et al. $(2,3,8-10)$ of tocotrienols from either palm oil or rice bran oil is highly controversial in humans. Based on studies with cell cultures and animals $(14,16,17)$, it seems that tocotrienols inhibit the activity of HMG-CoA reductase. Such mechanistic studies have the advantage to gain more insight into the mechanism of action, but the limitation of these studies, however, is the extrapolation of the results to humans. Except for one study that was not well controlled (1), no other human intervention trials have verified the promising results of Qureshi and his colleagues. Furthermore, no other research groups have ever detected the presence of the rare $P_{25}$-tocotrienol. In conclusion, it is not very likely that tocotrienols have favorable effects on the human lipid and lipoprotein profile. Based on scientific evidence from well-designed placebo-controlled human studies, it is therefore not very likely that a health claim for tocotrienols will be approved on reducing the risk of heart disease.

The main purpose of our second intervention study described in Chapter 4 was to examine the effects of $\beta$-glucan from oat bran incorporated into bread and cookies on serum lipids and lipoproteins in mildly hypercholesterolemic subjects. In the early 1960 s, the cholesterol-lowering effect of oats was demonstrated in men for the first time (25). It appeared that this beneficial effect of oat products could be ascribed to their main water-soluble fiber compound, $\beta$-glucan (26). In 1997, the U.S. Food and Drugs Administration (FDA) approved a health claim on food products that "a diet high in soluble fiber from whole oats (oat bran, oatmeal and oat flour) and low in saturated fat and cholesterol may reduce the risk of heart disease $(27,28)$ ". The FDA concluded that at least $3 \mathrm{~g}$ of $\beta$-glucan from oats should be consumed daily to achieve a clinically relevant decline in serum total cholesterol concentrations. Since compliance with this dietary guideline increases when common food products rich in oats are available on the market, we investigated whether a hypocholesterolemic effect could be achieved after consumption of bread and cookies enriched with $\beta$ glucan from oat bran. 
The results of our second study showed that a mean daily intake of $5.9 \mathrm{~g}$ of $\beta$-glucan from oat bran administered in bread and cookies for 4 weeks had no significant effects on the serum lipoprotein profile in mildly hypercholesterolemic subjects. To avoid possible detrimental effects of food processing and/or the food matrix on the cholesterol-lowering activity of oat $\beta$-glucan, we further studied in our third trial, described in Chapter 4, whether $\beta$-glucan from oat bran would decrease serum LDL cholesterol concentrations when given with a drink. In this third study, the same source from the same batches and daily amounts of wheat fiber (control fiber), oat bran and oat bran concentrate ( $5 \mathrm{~g} / \mathrm{dl} \beta$-glucan) as in our second study were provided with orange juice. The study followed a cross-over design, in which all subjects used both the control and experimental fiber and in which less subjects were needed than in our second parallel-designed study to reach the same statistical power. It should be noted that carry-over effects were not present in our third study.

The third study demonstrated that the daily consumption of $5 \mathrm{~g}$ of $\beta$-glucan from oat bran with a drink for two weeks lowered serum total cholesterol and LDL cholesterol concentrations and the total to HDL cholesterol ratio by 4,7 and $5 \%$, respectively. Serum HDL cholesterol and triacylglycerol concentrations were not affected.

Based on a meta-analysis of 12 trials, Ripsin et al. (29) estimated that a daily consumption of $3 \mathrm{~g}$ of soluble fiber from oat products resulted in a modest reduction of total cholesterol concentrations of about $0.13 \mathrm{mmol} / \mathrm{L}$ or $3 \%$. This reduction appeared to be greater in persons with higher initial total cholesterol concentrations. In fact, serum total cholesterol concentrations were lowered by $0.41 \mathrm{mmol} / \mathrm{L}$ or $7 \%$ in individuals with increased cholesterol concentrations ( $\geq 5.9 \mathrm{mmol} / \mathrm{L})$. Our mildly hypercholesterolemic subjects received daily $5 \mathrm{~g}$ of oat $\beta$-glucan with a drink, which was higher than the daily dose of $3 \mathrm{~g}$ from the meta-analysis. Based on these data, it can be predicted that a daily intake of $5 \mathrm{~g}$ of oat $\beta$-glucan would reduce serum total cholesterol concentrations of our subjects by more than $0.41 \mathrm{mmol} / \mathrm{L}$ or $7 \%$. In this third study, however, total cholesterol concentrations decreased by $0.22 \mathrm{mmol} / \mathrm{L}$ or $4 \%$, which was less than anticipated.

The lack of effect of $\beta$-glucan in bread and cookies observed in our second study could not be attributed to the type of the oat used, since the source of $\beta$-glucan and the method of processing the oat bran or oat bran concentrate were the same in both our studies. Furthermore, the findings of our second trial were not confounded by body weight or nutrient intake.

Despite the fact that other studies, in which oats were administered in bread $(25,30$ 33 ) or oat $\beta$-glucan was provided in a drinkable form $(26,34-36)$, yielded controversial results, it seems that the mode of administration is of importance in explaining the discrepancies between both our studies. As the mean daily intake of 
oat $\beta$-glucan from bread was $5.1 \mathrm{~g}$ and that from cookies only $0.8 \mathrm{~g}$, it is possible that the lack of effect can be ascribed to the incorporation of oat bran and oat bran concentrate into the bread. One of the suggested mechanisms of action of oat $\beta$ glucan is that it increases the viscosity of the intestinal contents, thereby increases the unstirred water layer adjacent to the mucosa and thus decreases the bile acid reabsorption $(35,37)$. As such, it can be suggested that the food matrix of the oat bread may influence the viscosity in the gastrointestinal tract. However, the mechanism of action for the cholesterol-lowering effect of yeast-derived $\beta$-glucan cannot be explained by its viscosity since this type of $\beta$-glucan has a low viscosity and its solubility in water is much lower than $\beta$-glucan from oats (38). Therefore, it is questionable whether the cholesterol-lowering effect of oat $\beta$-glucan depends solely on its viscous properties.

In conclusion, our oat $\beta$-glucan preparation incorporated into bread and cookies did not significantly change serum lipids and lipoproteins, whereas it lowered serum total and LDL cholesterol concentrations and the total to $\mathrm{HDL}$ cholesterol ratio when consumed with orange juice. Although there is no unequivocal explanation for the lack of effect, the food matrix and/or food processing could have negative effects on the hypocholesterolemic activity of oat $\beta$-glucan. Research should focus on the role of the food matrix to explain the observed discrepancy in effects. Therefore, more human intervention trials are needed to examine the effects on serum lipoproteins of oat $\beta$-glucan in different food forms. Furthermore, it is interesting to investigate how the effects on the serum lipoprotein profile of $\beta$-glucan from oats - also in different food matrices - compare with those of $\beta$-glucan from barley or yeast. With regard to the possible influence of the food matrix on the cholesterol-lowering potential of $\beta$ glucan from oats, it is questionable whether a health claim should be made on each specific food enriched with a bioactive compound or on the specific bioactive compound itself. In fact, before health claim approval for a specific bioactive compound, such as $\beta$-glucan from oats, the efficacy of a variety of foods enriched with this bioactive compound should be tested first.

The cholesterol-lowering effects of plant sterols and stanols have been well established. The major objectives of our study with plant stanol esters in the present thesis were their effects on plasma lipid-soluble antioxidants (Chapter 5) and on inflammation markers (Chapter 6). Therefore, their efficacy on serum lipids and lipoproteins will not be discussed in this chapter. 


\section{Plasma lipid-soluble antioxidants}

The main purpose of our studies described in Chapter 5 was to investigate in subjects with increased serum cholesterol concentrations the effects of two different hypocholesterolemic dietary components, plant stanol esters and oat $\beta$-glucan, and of a lipid-lowering drug, pravastatin, on plasma concentrations of lipid-soluble antioxidants (the tocopherol isomers and various carotenoids). Although the role of vitamin $E$ and carotenoids on health is still a matter of debate, there is some concern with respect to decreased absolute plasma concentrations of these antioxidants after consumption of plant sterols and stanols (39). Also water-soluble dietary fibers (WSDF) have been shown to lower plasma antioxidants (40-42). However, information about the effects of the WSDF oat B-glucan on plasma tocopherol and carotenoid concentrations in humans is limited. The proposed mechanism for cholesteroll lowering of oat $\beta$-glucan differs from that of plant sterols and stanols, which reduce intestinal chollesterol absorption through displacement of intestinal cholesterol from the micelles. Oat $\beta$-glucan may decrease the absorption of bille acids due to fiber binding or to an increased viscosity of intestinal contents $(35,37)$. Furthermore, little is known about how the effects on plasima antioxidants of plant stanol esters and oat $\beta$-glucan, which both act on intestinal sterol metabolism, compare with those of pravastatin, which does not primarily act on intestinal cholesterol or bile acid absorption, but inhibits the activity of HMG-CoA reductase.

Because lipid-soluble antioxidants are transported by lipoprotein particles in the plasma, a part of the decrease in plasma antioxidant concentrations can be attributed to the decreased number of lipoprotein particles as caused by the hypocholesterolemic agents. Therefore, antioxidant concentrations are generally standardized for serum lipid or lipoprotein concentrations, but no uniformity exists. (43-45). We chose to standardize for serum total cholesterol plus triacylglycerol concentrations (TC+TG), because our study with pravastatin suggested that concentrations of all antioxidant-carrying lipoproteins (VLD, LDL and HDL) were affected. For reasons of uniformity, we used the same method of standardization in the other studies with plant stanol esters and oat $\beta$-glucan.

Our study with plant stanol esters $(2.01 \mathrm{~g} / \mathrm{d}$ of plant stanols provided as its fatty acid ester) described in Chapter 5 showed that the absolute plasma concentrations of the tocopherols (the sum of $\alpha$-tocopherol, $\beta+\gamma$-tocopherol and $\delta$-tocopherol) were lowered, whereas those of the oxygenated carotenoids (the sum of lutein and $\beta$. cryptoxanthin) and the hydrocarbon carotenoids (the sum of lycopene, $\alpha$-carotene and $\beta$-carotene) were not affected. After lipid-standardization, plant stanol esters had only small nonsignificant effects on plasma antioxidants. Most studies demonstrated 
that the absolute concentrations of the tocopherols and carotenoids decreased after consumption of plant sterols and stanols (39). After lipid-standardization, however, these effects on the tocopherols disappeared, whereas the carotenoids ( $\alpha$ - plus $\beta$ carotene) remained decreased (39): It has been reported (44) that decreases in plasma tocopherols and oxygenated carotenoids after daily consumption of $4 \mathrm{~g}$ of plant stanols as esters were associated with decreases in the number of circulating LDL particles, whereas the decreases in hydrocarbon carotenoids were related to the reduced cholesterol absorption. This latter finding suggests that plant stanols at daily intakes of $4 \mathrm{~g}$ may lower the absorption of other lipid-soluble components than cholesterol as well. Decreases in the absolute and lipid-standardized plasma carotenoids as found in some trials (39) are not in line with our findings. It should be realized, however, that the daily consumption of $2 \mathrm{~g}$ of plant stanols as esters in our study was not as high as in many other trials (39). Under these conditions, it could be that plant stanols affect the incorporation of cholesterol into mixed micelles, but hardly that of the carotenoids. In fact, it seems that daily intakes of $2.2 \mathrm{~g}$ or less lowers the lipid-standardized carotenoid concentrations only minimally as based on results from several randomized placebo-controlled studies with plant sterol or stanol intakes ranging from 0.7 to $3.2 \mathrm{~g} / \mathrm{d}(39)$. To summarize, these findings indicate that the recommended intake of about 2 to $2.5 \mathrm{~g} / \mathrm{d}$ of pllant sterols or stanols have only minor effects on lipid-standardized plasma antioxidants.

In our study with oat $\beta$-glucan described in Chapter 5 , we found that the absolute plasma concentrations of the tocopherols and hydrocarbon carotenoids decreased, whereas those of the oxygenated carotenoids did not change. After correction for $\mathrm{TC}+\mathrm{TG}$, only the hydrocarbon carotenoids were still lowered. Also another WSDF, konjac mannan (glucomannan), has been shown to lower the absolute vitamin $E$ concentrations in diabetic subjects (42). Furthermore, it has been demonstrated that the plasma response curves of carotenoids were reduced $(40,41)$, but not those of $\alpha$-tocopherol (41), after a test meal enriched with the WSDF pectin, guar or alginate together with an antioxidant supplement. Thus, these findings indicate that oat $\beta$ glucan as well as other WSDF reduces the lipophylic hydrocarbon carotenoids. It should be noted, however, that the lipid-standardized hydrocarbon carotenoids decreased by $7 \%$ in our study after a daily consumption of $5 \mathrm{~g}$ of Dat $\beta$-glucan provided with orange juice, which is higher than the minimum recommended intake by the FDA of $3 \mathrm{~g} / \mathrm{d}$ of $\beta$-glucan from oats $(27,28)$. Therefore, human intervention trials are needed to investigate whether our results can be extrapolated to lower intakes or to other oat $\beta$-gllucan-containing foods with different food matrices.

Our study with pravastatin ( $40 \mathrm{mg} / \mathrm{d}$ ) described in Chapter 5 showed that the absolute plasma concentrations of all the tocopherols and carotenoids were lowered. 
which was confirmed by a study with simvastatin (46). After lipid-standardization, only the tocopherols increased by $9 \%$, which is in agreement with other studies with pravastatin $(47,48)$. This latter finding suggests that the lipoprotein particles became enriched with tocopherols after pravastatin treatment.

Taken together, plant stanol esters at daily intakes of about $2 \mathrm{~g}$ had only small and nonsignificant effects on lipid-standardized plasma lipid-soluble antioxidant concentrations in subjects with increased cholesterol concentrations. It is clear, however, that not only relatively high intakes of plant sterols and stanols may lower plasma lipid-standardized hydrocarbon carotenoids; but also relatively high intakes of oat $\beta$-glucan ( $5 \mathrm{~g} / \mathrm{d}$ ) administered in a drink. After treatment with pravastatin, which does not primarily act on intestinal sterol metabolism but inhibits the activity of HMGCoA reductase, the tocopherols increased after lipid-standardization. Our results suggest that at relatively high intakes, cholesterol-lowering agents that change intestinal sterol metabolism may have the greatest impact on lipid-standardized plasma hydrocarbon carotenoid concentrations.

\section{Hemostatic and inflammatory parameters}

Except for effects on serum lipids and lipoproteins, we have also investigated the effects of a tocotrienol-rich fraction from rice bran oil (TRF-RBO) on some hemostatic variables. Effects of TRF-RBO were compared with those of pravastatin. Like results on serum lipids and lipoproteins, the findings on platelet function of human studies using tocotrienols from either palm oil $(2,4,6)$ or rice bran oil $(8)$ are not consistent. Effects of pravastatin on factor VII and fibrinogen have also been controversial (4951), whereas VWF remained unaffected. In our first study described in Chapter 3 , we found that TRF-RBO as well as pravastatin had no effect on $\mathrm{TXB}_{2}$ production in clotting blood, WWF and factor VIlc activities, and factor VIla and fibrinogen concentrations in hypercholesterolemic subjects.

A major objective of our studies described in Chapter 6 was to compare in mildly and hypercholesterolemic subjects the effects of plant stanol esters with those of pravastatin on circulating inflammation markers (C-reactive protein (CRP) and interleukin-6 (IL-6)). It is evident that plant sterols and stanols - like statins potentially lower serum concentrations of the atherogenic LDL, which may reduce the risk of cardiovascular disease. Atherosclerosis is now considered as a chronic inflammatory disease $(52,53)$. Actually, CRP and IL- 6 have been shown to predict the risk of future cardiovascular events in women (54). Since these markers of 
ongoing inflammation may reflect the severity of the atherosclerotic process; we hypothesized that cholesterol lowering by plant stanol esters or pravastatin would lower circulating concentrations of CRP and IL-6.

Several studies found that CRP and IL-6 concentrations were lowered after statin therapy (55-58). It has also been shown that dietary regimes affect these circulating inflammation markers $(59,60)$. So far, information about the effects of functional foods enriched with plant sterols and stanols on CRP and IL-6 concentrations is lacking. Our studies described in Chapter 6, however, demonstrated that consumption of plant stanol esters ( $2.01 \mathrm{~g}$ plant stanols $/ \mathrm{d})$ for 4 weeks or treatment with pravastatin ( $40 \mathrm{mg} / \mathrm{d})$ for 6 weeks did not affect CRP and IL-6 concentrations in mildly and hypercholesterolemic volunteers, despite significant decreases in serum LDL cholesterol concentrations of 8 and $32 \%$, respectively. Our findings with pravastatin are not in line with a placebo-controlled study of Albert et al. (57) in which long-term treatment with pravastatin lowered CRP concentrations by $17 \%$ in subjects with mildly elevated cholesterol concentrations. Also short-term treatment with pravastatin and other statins, such as simvastatin, atorvastatin and cerivastatin, has been shown to reduce CRP concentrations in individuals with markedly elevated cholesterol concentrations $(55,58,61)$. This suggests that the lack of effect of pravastatin in our trial was not attributable to the short treatment period or by the class of statin used. It should be taken into account, however, that these latter studies $(55,58,61)$ had no placebo group, which makes it more impossible to interpret these findings properly. With regard to the effects of statins on IL-6, two trials with simvastatin, which also lacked a placebo group, showed reductions in hypercholesterolemic subjects after short- (56) and long-term therapy (62). In contrast, placebo-controlled studies $(63,64)$ reported that CRP or IL-6 concentrations were not affected by pravastatin after long- and short-term treatment in hypercholesterolemic subjects. In two studies that lacked a placebo group "a comparison of short-term effects of pravastatin, simvastatin and atorvastatin in subjects with markedly elevated cholesterol concentrations showed similar reductions in CRP and no changes in IL-6 in one study (61), whereas CRP was not affected in the other trial (65). Thus, the effects of statins on circulating CRP and IL-6 concentrations are not consistent.

Possible reasons for the lack of effect of plant stanol esters could be that the intervention period was too short or that reductions in CRP occur preferably in individuals with high CRP levels (63). It could be that the subjects of our study were at minor risk of developing cardiovascular disease as suggested by their low CRP levels at the start of the study. Whether circulating inflammation markers after long- 
term treatment are affected in persons at higher risk of cardiovascular disease needs further study.

Dietary antioxidants that may prevent oxidative stress have been shown to be associated with a lower risk for cardiovascular disease $(66,67)$. In our crosssectional study described in Chapter 6 we studied in mildly and hypercholesterolemic participants the relationships between circulating inflammation markers (CRP and IL6) with plasma lipid-soluble antioxidants (the tocopherol isomers and various carotenoids). The cross-sectional data were obtained after the run-in periods of the in Chapter 6 described studies with plant stanol esters and pravastatin. Three multiple regression models were used to study the relations of CRP or IL-6 with, respectively, the total tocopherols (the sum of $\alpha$-tocopherol, $\beta+\gamma$-tocopherol and $\delta$-tocopherol), the axygenated carotenoids (the sum of lutein and $\beta$-cryptoxanthin), and the hydrocarbon carotenoids (the sum of lycopene, $\alpha$-carotene and $\beta$-carotene). After adjustment for serum LDL cholesterol, HDL cholesterol and triacylglycerols, we found that none of these plasma antioxidants were significantly related to serum logtransformed CRP concentrations. In our multiple regression models, we also found that triacyliglycerol was positively associated with CRP. Also de Maat et al. (68) found that $\beta$-carotene concentrations were not correlated with CRP in smoking persons. Our findings, however, are not in agreement with the inverse relationships between carotenoids and CRP in subjects from the general population (69-72). Plasma carotenoid concentrations have not only been studied with regard to cardiovascular disease risk (67) but also in other inflammatory conditions. In fact, it has also been shown in patients with lung cancer (73) or acute pancreatitis (74) that circulating concentrations of CRP are inversely related to carotenoid concentrations. As for $\alpha$ tocopherol, no significant correlation was observed with CRP - like in our study - in elderly women (71) and smoking subjects (68), whereas negative correlations with CRP were found in patients with lung cancer (73) or acute pancreatitis (74), and a remarkable positive association with CRP in persons from the general population (72).

On the other hand, we found an inverse relationship between the hydrocarbon carotenoids and log-transformed IL-6, whereas the oxygenated carotenoids and the tocopherols were not related with IL-6. In our regression models, we also observed that HDL cholesterol was inversely associated with IL-6. In agreement with our results, de Maat et al. (68) observed a negative correlation between plasma IL-6 and $\beta$-carotene concentrations in smoking individuals, but showed a remarkable positive correlation with $\alpha$-tocopherol. Since the cross-sectional design of our study does not permit conclusions about causal associations, intervention trials are needed to test causality. 


\section{Conclusions and recommendations}

The present thesis shows that a tocotrienol-rich fraction from rice bran oil had no favorable effects on serum lipids and lipoproteins or hemostatic parameters in hypercholesterolemic subjects on a cholesterol-lowering diet. It is not very likely that tocotrienols from palm oil or rice bran oil have a cholesterollowering effect in humans. With regard to $\beta$-glucan from oat bran, we found that our $\beta$-glucan preparation administered in bread and cookies did not significantly affect serum lipids and lipoproteins in mildly hypercholesterolemic participants, whereas it lowered serum total and LDL cholesterol concentrations and the total to HDL cholesterol ratio when consumed with orange juice. These findings indicate that the food matrix and/or food processing may influence the hypocholesterolemic properties of oat $\beta$ glucan. This raises the question whether each food enriched with oat $\beta$-glucan needs to be tested before being put on the market. To explain the observed discrepancy in effects, it is necessary to gain more insight into the mechanisms of action for the hypocholesterolemic effect of oat $\beta$-glucan.

With regard to the lipid-soluble antioxidants as cardiovascular risk markers, we found that plant stanol esters at daily intakes of about $2 \mathrm{~g}$ had only small and nonsignificant effects on lipid-standardized plasma antioxidant concentrations in subjects with increased cholesterol concentrations. The lipid-standardized hydrocarbon carotenoids, however, were lowered after a daily consumption of $5 \mathrm{~g}$ of oat $\beta$-glucan provided with orange juice, which is higher than the minimal recommended intake by the U.S. FDA of $3 \mathrm{~g} / \mathrm{d}$ of $\beta$-glucan from oats $(27,28)$. Future studies are needed to elucidate if our results also apply to lower intakes or to other oat $\beta$-glucan-containing foods. On the other hand, the lipid-standardized tocopherols increased after treatment with pravastatin, which does not primarily act on intestinal sterol metabolism but inhibits the activity of HMG-CoA reductase. These findings suggest that at relatively high intakes, cholesterol-lowering agents that influence intestinal sterol metabolism may have the greatest impact on lipid-standardized hydrocarbon carotenoids.

For CRP and IL-6 as risk markers for cardiovascular disease, we showed that consumption of plant stanol esters or pravastatin treatment did not affect these circulating inflammation markers in mildly and hypercholesterolemic subjects, despite decreases in serum LDL cholesterol concentrations. It remains to be determined whether long-term treatment affects circulating CRP and $\| L-6$ concentrations in persons at high risk of cardiovascular disease. In our cross-sectional study group of mildy and hypercholesterolemic subjects, none of the tocopherols or carotenoids were significantly associated with CRP. However, an inverse relationship was 
observed between the hydrocarbon carotenoids and IL-6, whereas the oxygenated carotenoids and the tocopherols were not associated with IL-6. Future intervention trials are needed to test causality. 


\section{References}

1. Tan DTS, Khor HT, Low WHS, Ali A, Gapor A. Effect of a palm-oil-vitamin $E$ concentrate on the serum and lipoprotein lipids in humans. Am $J$ Clin Nuti 1991; 53:1027S-30S.

2. Qureshi AA, Qureshi N, Wright JJK, et al. Lowering of serum cholesterol in hypercholesteralemic humans by tocotrienols (palmvitee). Am $J$ Clin Nutr 1991;53:1021S-6S.

3. Qureshi AA, Bradllow BA, Brace $L$, et al. Response of hypercholesterolemic subjects to administration of tocotrienols. Lipids 1995;30:1171-7.

4. Wahlquist $M L$, Krivokuca-Bogetic $Z_{*}$ Lo CS, Hage $B$, Smith $R$, Lukito $W$. Differential serum responses of tocopherols and tocotrienols during vitamin supplementation in hypercholesterolaemic individuals without change in coronary risk factors. Nutr Res 1992;12:S181-S201.

5. Tomeo AC, Geller M, Watkins TR, Gapor A, Bierenbaum ML. Antioxidant effects of tocotrienols in patients with hyperlipidemia and carotid stenosis. Lipids 1995;30:1179. 83.

6. Mensink RP, van Houwelingen AC, Kromhout D, Hornstra G. A vitamin E concentrate rich in tocotrienols had no effect on serum lipids, lipoproteins, or platelet function in men with mildly elevated serum lipid concentrations. Am J Clin Nutr 1999:69:213-9.

7. O' Byrne D, Grundy S, Packer $L_{\text {, }}$ et al. Studies of LDL oxidation following $\alpha-, \gamma-$, or $\delta^{-}$ tocotrienyl acetate supplementation of hypercholesterolemic humans. Free Radiac Biol Med 2000;29:834-45.

8. Qureshi AA, Bradllow BA, Salser WA, Brace LD. Novell tocotrienols of rice bran modulate cardiovascular disease risk parameters of hypercholesterolemic humans. J Nutr Biochem 1997;8:290-8.

9. Qureshi AA, Sami SA, Salser WA, Khan FA. Synergistic effect of tocotrienol-rich fraction ( $\mathrm{TRF}_{25}$ ) of rice bran and lovastatin on lipid parameters in hypercholesterolemic humans. J Nutr Biochem 2001;12:318-29.

10. Qureshi AA, Sami SA, Salser WA, Khan FA. Dose-dependent suppression of serum cholesterol by tocotrienol-rich fraction $\left(\mathrm{TRF}_{25}\right.$ ) of rice bran in hyperchollesterolemic humans. Atherosclerosis 2002;161:199-207.

11. Haria $M_{3}$ McTavish D. Pravastatin. A reappraisal of its pharmacological properties and clinical effectiveness in the management of coronary heart disease. Drugs 1997:53:299-336.

12. Qureshi AA, Burger WC, Peterson DM, Elson CE. The structure of an inhibitor of cholesterol biosymthesis isolated from barley. $₫$ Biol Chem 1986;261:10544-50.

13. Qureshi AA, Qureshi N, Hasler-Rapacz JO, et al. Dietary tocotrienols reduce concentrations of plasma cholesterol, apolipoprotein $B$, thromboxane $B_{2}$, and platelet factor 4 in pigs with inherited hyperlipidemias. Am J Clin Nutr 1991;53:1042S-6S.

14. Pearce BC, Parker RA, Deason ME, Qureshi AA, Wright JJK. Hypocholesterolemic activity of synthetic and natural tocotrienols. J Med Chem 1992;35:3595-606.

15. Khor HT, $\mathrm{Ng} \mathrm{TT}$. Effects of administration of $\alpha$-tocopherol and tocotrienols on serum lipids and liver HMG CoA reductase activity. Int J Food Sci Nutr 2000;51:S3-S11.

16. Parker RA, Pearce BC, Clark RW, Gordon DA, Wright JJK. Tocotrienois regulate cholesterol production in mammalian cells by post-transcriptional suppression of 3hydroxy-3-methylglutaryl coenzyme A reductase. J Biol Chem 1993;268:11230-8. 
17. Pearce BC, Parker RA, Deason ME, et al. Inthibitors of cholesterol biosynthesis. 2. Hypocholesterolemic and antioxidant activities of benzopyran and letrahydronaphthalene analogues of the tocotrienols. J Med Chem 1994;37:526-41.

18. Nederlandse Voedinglsnormen 1989 (Dutch dietary guidelines 1989) / Commissie Voedingsnormen Voedingsraad, $2 e$ druk. The Hague: Voorlichtingsbureau voor de Voeding 1992 (in Dutch).

19. Jones PJH. Regulation of cholesterol biosynthesis by diet in humans. Am J Clin Nutr $1997 ; 66: 438-46$.

20. Kempen HJM, Glatz JFC, Gevers Leuven JA, van der Voort HA, Katan MB. Serum lathosterol concentration is an indicator of whole-body cholesterol synthesis in humans. $J$ Lipid Res 1988;29:1149-55.

21. Miettinen TA, Tilvis RS, Kesäniemi YA. Serum plant sterols and cholesterol precursors. reflect cholesteral absorption and synthesis in valunteers of a randomly selected male population. Am J Epidemiol 1990;131:20-31.

22. Uusitupa MIJ, Miettinen TA, Happonen $P_{\text {" }}$ et al. Lathosterol and other noncholesterol sterols during treatment of hypercholesteralemia with lovastatin alone and with cholestyramine or guar gum. Arterioscler Thromb 1992;12:807-13.

23. Rukmini $\mathrm{C}$, Raghuram TC. Nutritional and biochemical aspects of the hypolipidemic action of rice bran oil: a review. J Am Coll Nutr 1991;10:593-601.

24. Black TM, Wang P. Maeda $N$, Coleman RA. Paim tocotrienols protect ApoE $+/$-mice from diet-induced atheroma formation. J Nutr 2000;130:2420-6.

25. De Groot $A P$, Luyken $R$, Pikaar NA. Cholesterol-lowering effect of rolled oats. Lancet $1963 ; 2: 303-4$

26. Braaten JT, Wood PJ, Scott FW, et al. Oat $\beta$-glucan reduces blood cholesterol concentration in hypercholesterolemic subjects. Eur J Clin Nutr 1994:48:465-74.

27. Food labeling: health claims; oats and coronary heart disease. Food and Drug Administration, HHS. Proposed rule. Fed Regist 1996;61:296-313.

28. FDA Talk Paper. FDA allows whole oat foods to make health claim on reducing the risk of heart disease. January 1997. World Wide Web: http://www.cfsan.fda.gov/ Ird/tpoats.html (accessed 27 April 2001).

29. Ripsin $C M$, Keenan $J M$, Jacobs $D R$, et al. Oat products and lipid lowering: a metaanalysis. JAMA 1992;267:3317-25.

30. Törrönen $R$, Kansanen $L$, Uusitupa $M$, et al. Effects of an oat bran concentrate on serum lipids in free-living men with mild to moderate hypercholesterolaemia. Eur J Clin Nutr 1992:46:621-7.

31. Leadbetter J, Ball MJ, Mann Jl. Effects of increasing quantities of oat bran in hypercholesterolemic people. Am J Clin Nutr 1991:54:841-5.

32. Bremer JM. Scott RS, Lintott CJ. Oat bran and cholesterol reduction: evidence against specific effect. Aust NZ J Med 1991;21:422-6.

33. Kestin $M$. Moss $R_{v}$ Clifton PM, Nestel PJ. Comparative effects of three cereal brans on plasma lipids, blood pressure, and glucose metabolism in mildly hypercholesterolemic men. Am J Clin Nutr 1990;52:661-6.

34. Lovegrove $\Downarrow A$, Clohessy $A$, Milon $H$, Williams $C M$. Modest doses of $\beta$-glucan do not reduce concentrations of potentially atherogenic lipoproteins. Am $J$ Clin Nutr 2000;72:49-55.

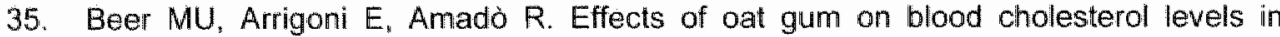
healthy young men. Eur J Clin Nutr 1995;49:517-22.

36. Önning $G$, Wallmark A, Persson $M$, Akesson B, Elmståhl S, Öste R, Consumption of oat milk for 5 weeks lowers serum cholesterol and LDL cholesterol in free-living men with moderate hypercholesterolemia. Ann Nutr Metab 1999;43:301-9. 
37. Lund EK, Gee JM, Brown JC, Wood PJ, Johnson IT. Effect of oat gun on the physical properties of the gastrointestinal contents and on the uptake of D-gallactose and cholesterol by rat small intestine in witro. Br J Nutr 1989;62:91-101.

38. Bell $S$, Goldman VM, Bistrian BR, Amold $A H$, Ostroff $G$, Forse RA. Effect of $B$-glucan from oats and yeast on serum lipids. Crit Rev Food Soi Nutr $1999 ; 39: 189-202$.

39. Plat J, Kerckhoffs DAJM, Mensink RP. Therapeutic potential of plant sterols and stanols. Curr Opin Lipidol 2000;11.571-6.

40. Rock $\mathrm{CL}$, Swendseid ME. Plasma $\beta$-carotene response in humans after meals supplemented with dietary pectin. Am J Clin Nutr 1992;55:96-9.

41. Riedl J, Linseisen J, Hoffmann J, Wolfram $G$. Some dietary fibers reduce the absorption of carotenoids in women. J Nutr 1999;129:2170-6.

42. Doi $K$, Matsuura $M$, Kawara $A$, Tanaka $T$, Baba $S$. Influence of dietary fiber (konjac mannan) on absorption of vitamin $B 12$ and vitamin $E$. Tohoku $J$ Exp Med $1983: 141: 677-81$.

43. Hallikainen MA, Uusitupa MIJ. Effects of 2 low-fat stanol ester-containing margarines on serum cholesterol concentrations as part of a low-fat diet in hypercholesterolemic subjects. Am J Clin Nutr 1999;69:403-10.

44. Plat J, Mensink RP. Effects of diets enriched with two different plant stanol ester mixtures on plasma ubiquinol-10 and fat-soluble antioxidant concentrations. Metabolism 2001;50:520-9.

45. Sierksma A, Weststrate JA, Meijer GW. Spreads enriched with plant sterols, either esterified 4,4-dimethylsterols or free 4-desmethylsterols, and plasma total- and LDLcholesterol concentrations. $\mathrm{Br}$ I Nutr1999;82:273-82.

46. Jula A, Marniemi J, Huupponen R, Virtanen A, Rastas M, Rönnemaa T. Effects of diet and simvastatin on serum lipids, insulin, and antioxidants in hypercholesterolemic men. JAMA 2002;287:598-605.

47. Bläha $V$, Zadák $Z$, Sollichová $D$, Brátová M, Havel E. Hypocholesterolemic effect of pravastatin is associated with increased content of antioxidant vitamin- $E$ in cholesterol fractions. Acta Medica Hradlec Králové 1998;41:87-90.

48. Salonen R, Nyyssönen $K$, Porkkala-Sarataho $E$, Salonen JT. The Kuopio Atherosclerosis Prevention Study (KAPS): effect of pravastatin treatment on lipids, oxidation resistance of lipoproteins, and atherosclerotic progression. Am $\mathrm{J}$ Cardiol 1995;76:34C-9C.

49. Wada $H_{s}$ Mori $Y$, Kaneko $T$, et al. Elevated plasma levels of vascular endothelial cell markers in patients with hypercholesterolemia. Am J Hematol 1993:44:112-6.

50. Avellone G, Di Garbo V, Cordova R, Raneli G, De Simone R, Bompiani G. Changes induced by pravastatin treatment on hemostatic and fibrinolytic patterns in patients with type IIB hyperlipoproteinemia. Curr Ther Res 1994;55:1335-44.

51. Dangas $G$, Badimon $J J$, Smith $D A$, et al. Pravastatin therapy in hyperlipidemia: effects on thrombus formation and the systemic hemostatic profile. J Am Coll Cardiol 1999;33:1294-1304

52. Ross R. Atherosiclerosis - an inflammatory disease. N Engl J Med 1999;340:115-26.

53. Patrick $L$, Uzick M. Cardiovascular disease: C-reactive protein and the inflammatory disease paradigm: HMG-CoA reductase inhibitors, alpha-tocopherol, red yeast rice. and olive oil polyphenols. A review of the literature. Altern Med Rev 2001;6:248-71.

54. Ridker PM, Hennekens CH, Buring JE, Rifai N. C-reactive protein and other markers of inflammation in the prediction of cardiovascular disease in women. $N$ Engl $J$ Med $2000 ; 342: 836-43$. 
55. Ridker PlM, Rifal N, Pitman Lowenthal S. Rapid reduction in C-reactive protein with cerivastatin among 785 patients with primary hypercholesterolemia. Circulation 2001;103:1191-3.

56. Musial J, Undas A, Gajewski P, Jankowski M, Sydor W, Szczeklik A. Anti-inflammatory effects of simvastatin in subjects with hypercholesterolemia. Int $\mathrm{J}$ Cardiol 2001;77:24753.

57. Albert MA, Danielson $E$, Rifai $N$, Ridker PM. Effect of statin therapy on C-reactive protein levels. The Pravastatin Inflammation/CRP Evaluation (PRINCE): a randomized trial and cohort study. JAMA 2001:286:64-70.

58. Riesen WF, Engler H. Risch M, Korte W, Noseda G. Short-tem effects of atorvastatin on C-reactive protein. Eur Heart J 2002:23:794-9.

59. Jenkins DJ, Kendall CW, Connelly $P W_{v}$ et al. Effects of high- and low-isoflavone (phytoestrogen) soy foods on inflammatory biomarkers and proinflammatory cytokines in middle-aged men and women. Metabolism 2002;51:919-24.

60. Tchernof $A$, Nolan $A$, Sites $C K$, Ades PA, Poehiman ET. Weight loss reduces $C$. reactive protein levels in obese postmenopausal women. Circulation 2002;105:564-9.

61. Jialal I, Stein D, Balis D, Grundy SM, Adams-Huet B, Devaraj S. Effect of hydroxymethyl glutaryl coenzyme A reductase inhibitor therapy on high sensitive $\mathrm{C}$ reactive protein levels: Circulation 2001:103:1933:5.

62. Wiklund O, Mattsson-Hultén L, Hurt-Camejo E, Oscarsson J. Effects of simvastatin and atorvastatin on inflammation markers in plasma. J Intern Med 2002;251:338-47.

63. Kluft C, De Maat MPM, Gevers Leuven JA, Potter van Loon BJ, Mohrschladt M. Statins and C-reactive protein.. The Lancet 1999;353:1274.

64. Solheim S, Seljeflot I, Arnesen H, Eritsland J, Eikvar L. Reduced levels of TNF- $\alpha$ in hypercholesterolemic individuals after treatment with pravastatin for 8 weeks. Atherosclerosis 2001;157:411-5.

65. Joukhadar $\mathrm{C}$, Klein $\mathrm{N}$, Prinz $\mathrm{N}$, et al. Similar effects of atorvastatin, simvastatin and pravastatin on thrombogenic and inflammatory parameters in patients with hypercholesterolemia. Thromb Haemost 2001;85:42-6.

66. Stampfer MJ , Hennekens $\mathrm{CH}$, Manson JE, Colditz GA, Rosner B, Willett WC. Vitamin E consumption and the risk of coronary disease in women. $\mathrm{N}$ Engl J Med 1993;328:14449.

67. Cooper DA, Eldridge AL. Peters JC. Dietary carotenoids and certain cancers, heart disease, and age-related macular degeneration: a review of recent research. Nutr Rev $1999: 57: 201-14$.

68. De Maat MP, Pijl H, Kluft C. Princen HM. Consumption of black and green tea had no effect on inflammation, haemostasis and endothelial markers in smoking healthy Individuals. Eur J Clin Nutr 2000;54:757-63.

69. Erlinger TP, Guallar E, Miller III ER, Stolzenberg-Solomon R, Appel LJ. Rellationship between systematic markers of inflammation and serum $\beta$-carotene levels. Arch Intern Med 2001:161:1903-8.

70. Kritchevsky SB, Bush AJ, Pahor M, Gross MD. Serum carotenoids and markers of inflammation in nonsmokers. Am J Epidemiol 2000;152:1065-71.

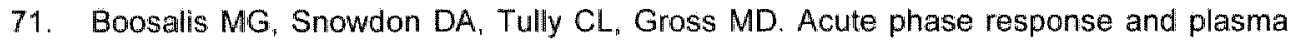
carotenoid concentrations in older women: findings from the nun study. Nutrition $1996 ; 12: 475-8$.

72. Broekmans WMR, Klöpping-Ketelaars IAA, Bots ML, et al. Serum carotenoids and vitamins in relation to biomarkers of endothelial function and inflammation. Thesis Wageningen University, Carotenoid status in man: effects on biomarkers of eye, skin and cardiovascular health 2002; ISBN 90-5808-631-3. 
73. Talwar D, Ha TKK, Scott $\mathrm{HR}_{\mathrm{w}}$ et al. Effect of inflammation on measures of antioxidanl status in patients with non-small cell lung cancer. Am J Clin Nutr 1997;66:1283-5.

74. Curran FJM, Sattar N. Talwar D, Baxter JN, Imrie CW. Relationship of carotenoid and vitamin $A$ and $E$ with the acute inflammatory response in acute pancreatitis. $B r J$ Surg $2000 ; 87: 301-5$ 



\section{Summary}

The composition of the diet may play an important role in lowering the risk of coronary heart disease (CHD), for instance by improving an unfavorable serum lipoprotein profile. Therefore, much interest has not only been given to general dietary advices, but also to the role of specific foods and food components in the control of lipid and lipoprotein metabolism. Also plasma concentrations of antioxidants are related with cardiovascular risk. An early event in the development of CHD is the formation of oxidized LDL in the intima of vessel walls, which may ultimately lead to the development of an atherosclerotic plaque. Antioxidants that prevent $\mathrm{LDL}$ oxidation may therefore protect against $\mathrm{CHD}$. Also $\mathrm{C}$-reactive protein (CRP) and interleukin-6 (IL-6), two markers of ongoing inflammation, are significant predictors of the risk of future cardiovascular events. As atherosclerosis is considered as a chronic inflammatory disease, this may suggest that decreasing atherosclerotic risk goes together with lower plasma CRP and IL-6 concentrations.

This thesis describes the effects of the dietary components "tocotrienols, $\beta$-glucan and plant stanol esters on various cardiovascular risk markers in subjects with increased serum cholesterol concentrations. For comparison with a lipid-lowering drug, effects of pravastatin were also studied.

\section{Serum lipids and lipoproteins}

Vitamin $E$ is the generic term for the four subtypes $(\alpha, \beta, \gamma$ and $\delta)$ of tocopherols and corresponding tocotrienols. Unlike tocopherols, tocotrienols have been suggested to lower serum LDL cholesterol concentrations, possibly by reducing the activity of 3hydroxy-3-methylglutaryl-coenzyme A (HMG-COA) reductase, the rate-limiting enzyme in the endogenous cholesterol synthesis. It has been suggested that especially tocotrienols from rice bran oil have a strong cholesteral-|lowering activity. In our first study with 71 hypercholesterolemic volunteers consuming a cholesterollowering diet, however, we have demonstrated that the daily intake of $42 \mathrm{mg}$ of a tocotrienol-rich fraction from rice bran oil (TRF-RBO) for 6 weeks had no beneficial effects on the serum lipoprotein profile. Furthermore, no changes were found in serum cholesterol-standardized concentrations of lathosterol, which reflect endogenous cholesterol synthesis, and in those of campesterol, which reflect intestinal cholesterol absorption. On the other hand, the daily use of $40 \mathrm{mg}$ of pravastatin, an HMG-COA reductase inhibitor, lowered serum LDL cholesterol concentrations by $32 \%$. Pravastatin also decreased cholesterol-standardized lathosterol concentrations by $44 \%$, but increased cholesterol-standardized 
campesterol by $16 \%$. Based on these results, it is concluded that TRF-RBO supplementation does not favorably affect cholesterol metabolism in hypercholesterolemic subjects.

Dietary fibers can be classified into two groups based on water solubility. In contrast to water-insoluble fibers, most soluble fibers lower serum LDL cholesterol concentrations. A rich source of soluble fiber is oats. It has been demonstrated that the cholesterol-lowering effect of oats can be ascribed to the water-soluble fiber, $\beta$ glucan. The U.S. Food and Drug Administration (FDA) has concluded that at least 3 $g$ of $\beta$-glucan from oats should be consumed daily to achieve a clinically relevant decrease in serum total cholesterol concentrations. Since compliance with this dietary guideline may increase when common food products rich in oat $\beta$-glucan are avallable, the second intervention trial examined the effects of bread and cookies enriched with $\beta$-glucan from oat bran on serum lipids and lipoproteins in 48 mildly hypercholesterolemic volunteers. It was shown that a mean daily intake for 4 weeks of $5.9 \mathrm{~g}$ of 3 -glucan from oat bran incorporated into bread and cookies had no statistically significant effects on the serum lipoprotein profile. To investigate the potential effects of food processing and the food matrix, in our third study the same source and daily amounts of wheat fiber (control fiber) and oat bran as in our second study was provided with orange juice. We found that the daily intake of $5 \mathrm{~g}$ of $\beta$ glucan from oat bran with a drink for two weeks lowered serum total cholesterol and LDL cholesterol concentrations and the total to HDL cholesterol ratio in 25 subjects by 4,7 and $5 \%$, respectively. Based on these findings, it is suggested that the food matrix and/or food processing may have detrimental effects on the cholesterollowering activity of oat $\beta$-glucan.

\section{Plasma lipid-soluble antioxidants}

There is some concern on the decreases in plasma antioxidants after consumption of plant stanol esters: Little is known, however, about the effects of other cholesterollowering agents, such as oat $\beta$-glucan and pravastatin. Therefore, plasma lipidsoluble antioxidants were examined not only in our third study with oat $\beta$-glucan, and also in a trial with 48 subjects in which plant stanol esters were consumed for 4 weeks, as well as in volunteers of our first study who received either placebo or pravastatin treatment. In subjects with increased serum cholesterol concentrations, we have now demonstrated that absolute plasma concentrations of the tocopherols ( $\alpha$-tocopherol, $\beta+\gamma$-tocopherol and $\delta$-tocopherol) were lowered by a daily intake of 2 $\mathrm{g}$ of plant stanols - which were provided as its fatty acid esters - and oat $\beta$-glucan. The hydracarbon carotenoids (lycopene, $\alpha$-carotene and $\beta$-carotene) were also 
lowered by oat $\beta$-glucan $(5 \mathrm{~g} / \mathrm{d})$ provided with orange juice, even after these antioxidants were corrected for serum concentrations of total cholesterol plus triacylglycerols. After lipid-standardization, plant stanols had only small and statistically nonsignificant effects on plasma lipid-soluble antioxidant concentrations. After treatment with pravastatin ( $40 \mathrm{mg} / \mathrm{d})$ ), absolute plasma concentrations of the tocopherols, oxygenated carotenoids (lutein and $\beta$-cryptoxanthin) and hydrocarbon carotenoids decreased. After lipid-standandization, however, the tocopherols increased.

\section{Hemostatic and inflammatory parameters}

In our first intervention trial, it was shown that TRF-RBO as well as pravastatin had no effect on thromboxane $B_{2}\left(T \times B_{2}\right)$ production in clotting blood, von Willebrand Factor (VWF) and factor VII coagulant (factor VIIc) activities, and activated factor VII (factor VIla) and fibrinogen concentrations in hypercholesterolemic subjects.

With regard to inflammatory parameters as cardiovascular risk markers, we examined the effects of plant stanol esters and pravastatin on circulating concentrations of C-reactive protein (CRP) and interleukin-6 (IL-6). As these markers of ongoing inflammation may reflect the severity of the atherosclerotic process, we hypothesized that cholesterol lowering by plant stanol esters or pravastatin may lower circulating concentrations of CRP and IL-6. In our first study with subjects who received either placebo or pravastatin treatment and in the study with plant stanol esters, however, it was found that daily intakes of $2 \mathrm{~g}$ plant stanols for 4 weeks or 40 $\mathrm{mg}$ of pravastatin for 6 weeks did not affect CRP and IL- 6 concentrations in mildly and hypercholesterolemic volunteers, despite significant reductions in serum LDL cholesterol concentrations of 8 and $32 \%$, respectively. Furthermore, in the subjects of these studies cross-sectional relationships were examined between concentrations of inflammation markers and plasma lipid-soluble antioxidants. For this, three multiple regression models were used to study the relations of CRP or IL-6 with, respectively, the tocopherols, oxygenated carotenoids and hydrocarbon carotenoids. After adjustment for serum concentrations of LDL cholesterol, HDL cholesterol and triacylglycerol, it was found that none of the plasma tocopherols or carotenoids was significantly related to serum CRP concentrations. However, an inverse relation between the hydrocarbon carotenoids and IL- 6 was observed, whereas the oxygenated carotenoids and the tocopherols were not related with IL-6. We also found that triacyiglycerol was positively associated with CRP and that HDL cholesterol was inversely related with IL-6. 


\section{Main conclusions}

This thesis shows that a tocotrienol-rich fraction from rice bran oil does not favorably affect cholesterol metabolism or hemostatic parameters in hypercholesterolemic subjects. Oat B-glucan has been shown to have a cholesterol-fowering effect in mildly hypercholesterolemic volunteers when provided with a drink but not when incorporated into bread and cookies. The food matrix and/or food processing may therefore have detrimental effects on the hypocholesterolemic activity of oat $\beta$ glucan. To better understand these differential effects, it is necessary to further clarify the cholesterol-Howering mechanism of action of oat $\beta$-glucan. Of the lipid-soluble antioxidants investigated, lipid-standardized hydrocarbon carotenoids were only lowered after relatively high intakes of oat $\beta$-glucan $(5 \mathrm{~g} / \mathrm{d}$ ) provided with a drink, while plant stanols at daily intakes of about $2 \mathrm{~g}$ had only small effects on lipidstandardized plasma antioxidants in subjects with increased cholesterol concentrations. Whether our results can be extrapolated to lower intakes or to other oat $\beta$-glucan-containing foods needs to be elucidated. For CRP and IL-6 as cardiovascular risk markers, these circulating inflammation parameters were not affected after short-term consumption of plant stanol esters or after pravastatin treatment in mildly and hypercholesterolemic subjects, despite decreases in serum LDL cholesterol concentrations. It remains to be determined whether long-term treatment affects circulating CRP and IL-6 concentrations. 


\section{Samenvatting}

De samenstelling van de voeding kan een belangrijke rol spelen bij het verlagen van het risico op hart- en vaatziekten (HVZ), onder andere door verbetering van een ongunstig lipoproteïnenprofiel. Vandaar dat er niet alleen veel aandacht wordt besteed aan algemene voedingsadviezen, maar ook aan specifieke voedingsmiddelen en voedingscomponenten die het lipiden- en lipoproteïnenmetabolisme beïnvloeden. Tevens zijn concentraties van antioxidanten in het plasma geassocieerd met het risico op HVZ. Een vroege gebeurtenis in de ontwikkeling van HVZ is de vorming van geoxideerd $L D L$ in de vaatwand, hetgeen uiteindelijk kan leiden tot de ontwikkeling van een atherosclerotische plaque. Antioxidanten die LDL oxidatie voorkomen, kunnen dus van belang zijn bij de bescherming tegen HVZ. Verder zijn C-reactief proteïne (CRP) en interleukine-6 (IL6), twee markers voor ontsteking, significante voorspellers van het krijgen van cardiovasculaire aandoeningen. Aangezien atherosclerose wordt gezien als een chronische ontsteking van de vaatwand, suggereert dit dat een verlaging in atherosclerotisch risico samengaat met lagere CRP en IL-6 concentraties.

Dit proefschrift beschrijft de effecten van de voedingscomponenten, tocotriënolen. $\beta$ glucan en plantaardige stanolesters op diverse risicoindicatoren voor hart- en vaatziekten bij proefpersonen met een verhoogd cholesterolgehalte in het bloed. $\mathrm{Om}$ een vergelijking te maken met een lipidenverlagend geneesmiddel, werden de effecten van pravastatine eveneens bestudeerd.

\section{Serum lipiden en lipoproteïnen}

Vitamine $E$ is de algemene term voor de vier vormen $(\alpha, \beta, \gamma$ en $\delta)$ van tocoferolen en tocotriënolen. In tegenstelling tot tocoferolen werd gesuggereerd dat tocotrienolen het LDL cholesterolgehalte verlagen, mogelijk door verlaging van de activiteit van 3hydroxy-3-methylglutaryl-coënzym A (HMG-CoA) reductase. Dit is het snelheidsbepalende enzym voor de cholesterolsynthese in het lichaam. Het is gesuggereerd dat vooral tocotriënolen afkomstig uit rijstzemelenolie een sterke cholesterolverlagende werking hebben. In onze eerste studie, waaraan 71 vrijwilligers met hypercholesterolemie deelnamen die een cholesterolverlagend dieet volgden, hebben wij echter aangetoond dat de dagelijkse inname van $42 \mathrm{mg}$ van een tocotriënolen-rijke fractie uit rijstzemelenolie (TRF-RBO) gedurende 6 weken geen gunstig effect had op het lipoproteïnenprofiel. Bovendien werden geen veranderingen gevonden in serum chollesterolgestandaardiseerde concentraties van lathosterol (indicator voor de cholesterolsynthese in het lichaam) en campesterol (indicator voor 
cholesterolabsorptie). Daarentegen bleek dat een dagelijks gebruik van $40 \mathrm{mg}$ pravastatine, een HMG-COA reductase-remmer, het LDL cholesterolgehalte verlaagde met $32 \%$. Pravastatine verlaagde eveneens de cholesterolgestandaardiseerde lathosterolconcentraties met $44 \%$, maar verhoogde het cholesterolgestandaardiseerde campesterol met $16 \%$. Op basis van deze resultaten is geconcludeerd dat TRF-RBO-supplementatie geen gunstig effect heeft op het cholesterolmetabolisme bij mensen met hypercholesterolemie.

Voedingsvezels kuninen worden onderverdeeld in twee groepen op basis van thun wateroplosbaarheid. In tegenstelling tot wateronoplosbare vezels verlagen de meeste wateroplosbare vezels $L D L$ cholesterolconcentraties in serum. Haver is rijk aan wateroplosbare vezels. Aangetoond is dat het cholesterolverlagend effect van haver kan worden toegeschreven aan de wateroplosbare vezel, $\beta$-glucan. De 'Food and Drug Administration" (FDA) in de V.S. heeft geconcludeerd dat tenminste $3 \mathrm{~g} \beta$ glucan afkomstig uit haver dagelijks genuttigd dient te worden om een klinisch relevante daling in serum totaalcholesterolconcentraties te bereiken. Aangezien de dieettrouw met deze voedingsrichtlijn zal toenemen wanneer alledlaagse voedingsmiddelen rijk aan $\beta$-glucan uit haver beschikbaar zijn, werden in de tweede interventiestudie de effecten bestudeerd van brood en koekjes verrijkt met $\beta$-glucan uit haverzemelen op lipiden- en lipoproteïnenconcentraties bij 48 vrijwilligers met matige hypercholesterolemie. Het bleek dat een gemiddelde dagelijkse inname gedurende 4 weken van $5,9 \mathrm{~g} \beta$-glucan uit haverzemelen dat verwerkt was in brood en koekjes, geen statistisch significant effect had op het lipoproteïnenprofiel. Om de mogelijke effecten van voedselbereiding en de voedselmatrix nader te onderzoeken, werd in onze derde studie dezelfde bron en dagelijkse hoeveelheid tarwevezel (controlevezel) en haverzemelen als in onze tweede studie verstrekt met sinaasappelsap. Wij vonden dat de dagelijkse inname van $5 \mathrm{~g} \beta$-glucan uit haverzemelen met een drank gedurende twee weken serum totaalcholesterol- en LDL cholesterolconcentraties en de totaalcholesterol/HDL cholesterol verhouding verlaagden bij 25 personen met respectievelijk 4,7 en $5 \%$. Op basis van deze bevindingen is gesuggereerd dat de voedselmatrix en/of voedselbereiding nadelige effecten hebben op de cholesterolverlagende werking van $\beta$-glucan uit haver.

\section{Plasma vetoplosbare antioxidanten}

Er bestaat enige bezorgdheid over de verlaging in antioxidantenconcentraties in plasma door de consumptie van plantaardige stanolesters. Er is echter nog weinig bekend over de effecten van andere cholesterolverlagende stoffen, zoals $\beta$-glucan uit haver en pravastatine. Daarom werden de vetoplosbare antioxidanten niet alleen in 
onze derde studie met $\beta$-glucan uit haver bestudeerd, en ook in een studie met 48 vrijwilligers waarin plantaardige stanolesters werden genuttigd gedurende 4 weken, en in personen uit onze eerste studie die hetzij placebo of pravastatine kregen Bij proefpersonen met een verhoogd cholesterolgehalte is aangetoond dat de concentraties van de tocoferolen ( $\alpha$-tocoferol, $\beta+\gamma$-tocoferol en $\delta$-tocoferol) daialden door dagelijkse inname van $2 \mathrm{~g}$ plantaardige stanolen - welke werden aangeboden als hun vetzuuresters - en $\beta$-glucan uit haver. De hydrocarbon carotenoilden (lycopeen, $\alpha$-caroteen en $\beta$-caroteen) daalden eveneens door het nuttigen van $\beta$ glucan uit haver (5 g/dag) met sinaasappelsap "zelfs nadat de concentraties van deze antioxidanten waren gecorrigeerd voor de hoeveelheid cholesterol plus triacylglycerol in het bloed. Na standaardisatie voor lipiden hadden plantaardigie stanolen slechts kleine en niet-significante effecten op vetoplosbare antioxidanten. $\mathrm{Na}$ behandeling met pravastatine ( $40 \mathrm{mg} / \mathrm{dag}$ ) daalden de concentraties van de tocoferolen, geoxygeneerde carotenoïden (luteïne en $\beta$-cryptoxanthine) en hydrocarbon carotenoïden. Echter na standaardisatie voor lipiden namen de tocoferolenconcentraties toe.

\section{Hemostase en ontstekingsparameters}

In onze eerste studie bleek dat zowel TRF-RBO als pravastatine geen effect had op de hoeveellheid tromboxaan $\mathrm{B}_{2}\left(T \times B_{2}\right)$ in gestold bloed, von Willebrand-Factor (WWF) en factor $V \| l$ coagulant (factor $V I I c$ ) activiteit, en concentraties van geactiveerd factor VII (factor VIlia) en fibrinogeen bij personen met hypercholesterolemie.

Wat betreft de ontstekingsparameters als risicoindicatoren voor hart- en vaatziekten hebben wij de effecten van plantaardige stanolesters en pravastatine op C-reactief proteine (CRP) en interleukine-6 (IL-6) concentraties onderzocht. Aangezien deze markers voor chronische ontsteking een afspiegeling zijn van het atherosclerotische proces, was onze hypothese dat cholesterolverlaging door plantaardige stanolesters of pravastatine gepaard zou gaan met verlaagde concentraties van CRP en IL-6. In onze eerste studie met personen die hetzij placebo of pravastatine kregen en in de studie met plantaardige stanolesters vonden wij echter dat na dagelijkse inname van $2 \mathrm{~g}$ plantaardige stanolen gedurende 4 weken of $40 \mathrm{mg}$ pravastatine gedurende 6 weken CRP en IL-6 concentraties onveranderd bleven bij vrijwilligers met matig en sterk verhoogde cholesterolconcentraties, ondanks significante dalingen in LDL cholesterol van respectievelijk 8 en $32 \%$. Verder werden bij de mensen uit deze studies cross-sectionele relaties bestudeerd tussen de concentraties van de ontstekingsmarkers en vetoplosbare antioxidanten. Hiervoor werden drie meervoudige regressiemodellen gebruikt om de verbanden te bestuderen van CRP 
of L-6 met respectievelijk de tocoferolen, geoxygeneerde carotenoïden en hydrocarbon carotenoiden. $N$ a correctie voor de hoeveelheid $L D L$ cholesterol, $\mathrm{HDL}$ chollesterol en triacylglycerol in het bloed bleek dat geen van de tocoferolen of carotenoilden significant gerelateerd was met CRP concentraties. Er werd echter een inverse relatie gevonden ussen de hydrocarbon carotenoiden met $\mathbb{L}-6$, terwijl de geoxygeneerde carotenoíden en de tocoferolen niet gerelateerd waren met IL-6. Verder bleek dat triacylglycerol positief geassocieerd was met CRP en dat HDL cholesterd invers gerelateerd was met $1 \mathrm{~L}-6$.

\section{Conclusies}

Dit proefschrift laat zien dat een tocotriënolen-rijke fractie uit rijstzemelenolie (TRFRBO) geen gunstig effect heeft op het cholesterolmetabolisme en parameters betrokken bij hemostase bij personen met hypercholesterolemie. $\beta$-Glucan uit haver verlaagt het cholesterolgehalte bij mensen met matig en sterk verhoogde cholesterolconcentraties, wanneer deze genuttigd wordt met een drank maar niet wanneer deze verwerkt is in brood en koekjes. De voedselmatrix en/of voedselbereiding kan daarom nadelige effecten hebben op de cholesterolverlagende werking van $\beta$-glucan uit haver. Om de discrepantie in effecten beter te kunnen begrijpen " is het van belang meer inzicht te krijgen in het cholesterolverlagend mechanisme van $\beta$-glucan uit haver. Wat betreft de effecten van vetoplosbare antioxidanten, daalden de lipidengestandaardiseerde hydrocarbon carotenoïden na relatief hoge innamen van $\beta$-glucan uit haver $(5 \mathrm{~g} / \mathrm{dag})$ met vruchtensap, terwijl $2 \mathrm{~g}$ plantaardige stanolen per dag slechts geringe effecten hadden op lipidengestandaardiseerde antioxidanten bij mensen met een verhoogd cholesterolgehalte. Of onze resultaten ook gelden voor de inname van kleinere hoeveetheden of voor andere voedingsmiddelen verrijkt met $\beta$-glucan uit haver, dient verder onderzocht te worden. Andere risicoindicatoren voor hart- en vaatziekten, zoals de ontstekingsparameters CRP en IL-6, bleven onveranderd na kortdurige consumptie van plantaardige stanolesters of na behandeling met pravastatine bij milde en hypercholesterolemische personen, ondanks het feit dat het LDL cholesterolgehalte daalde. Het lange termijn effect op de concentraties van CRP en $\mathrm{IL}-6$ in het bloed dient te worden bekeken. 


\section{Dankwoord}

Promoveren doe je niet in je eentje. Vandaar dat ik in de komende twee bladzijden van dit proefschrift gelukkig alle mensen kan bedanken die daar een steentje aan hebben bijgedragen. Zonder jullie was dit boekje immers nooit tot stand gekomen.

Allereerst wil ik graag mijn beide promotoren, Prof. Dr. Ir. R.P. Mensink en Prof. Dr. G. Hornstra, hartelijk bedanken. Beste Ronald, bij jou kon ik altijd binnenlopen voor de broodnodige begeleiding tijdens het opzetten en uitvoeren van de voedingsinterventiestudies. Ook wil ik je danken voor je aandachtige en vooral precieze manier waarop je mijn manuscripten hebt doorgelezen, en van commentaar hebt voorzien. Ronald, bedankt voor de prettige samenwerking. Voor Gerard heb ik bewondering vanwege zijn brede wetenschappelijke blik op het voedingsonderzoek. Beste Gerard, bedankt voor de kritische opmerkingen en suggesties bij het doornemen van mijn manuscripten.

Ik zou graag de leden wan de beoordelingscommissie, Prof. Dr. Ir. W.H.M. Saris, Prof. Dr. A. Bast, Prof. Dr. T.W.A. de Bruin, Prof. Dr. M.H. Hofker en Dr. Ir. P.L. Zock, willen bedanken voor het beoordelen van dit proefschrift.

Dr. F. Brouns, beste Fred, bedankt voor je intensieve betrokkenheid bij het verrichten van de uitgebreide literatuurstudie op de voormalige Novartis Unit. Ik ben blij dat dit literatuuronderzoek heeft geleid tot de totstandkoming van dit promotieproject. Eva en Michiel, als toenmalige kamergenoten maakten jullie de sfeer achter die stapels artikelen vele malen leuker. Ook was het vaak gezellig vertoeven rond het espressoapparaat van de Unit tezamen met Martina, Martine, Nicky, Rien, Eric, Peter, Dean, Bert, Anne-Marie en Ellen. Dr. Elke Trautwein waardeer ik vanwege haar grote vakkennis en enthousiasme.

Verder verdienen alle proefpersonen op zijn minst een bloemetje. Zonder hun deelname aan de studies had ik dit proefschrift niet kunnen schrijven. Er zijn in de afgelopen jaren al heel wat ontbijtjes verorberd! Ik wil de proefpersonen van harte bedanken voor hun inzet en interesse voor het voedingsonderzoek.

Tevens gaat mijn dank uit naar Prof. Dr. Tjerk de Bruin voor zijn betrokkenheid als internist bij de eerste interventiestudie. Tijdens deze studie heeft Margriet een hoop werk verzet. Margriet, bedankt. Ook de 'priksters', Lucie, Anita en Renate, dank ik voor het goede verloop van de vele bloedafnames en het verwerken van de buisjes bloed. Bij jullie voelden de proefpersonen zich goed op hun gemak. Tijdens het verzamelen van bloedmonsters zijn de cupjes onmisbaar. Jo ${ }^{\dagger}$, ik zie je nog voor me zitten, verstopt achter een gigantische berg cupjes die je aan het nummeren en plakken was voor al die grootschalige studies. Bedankt $\mathrm{Jo}^{\dagger}$. 
De diëtisten, Marjolien, Ilse, Heidi, Elke, Sacha en Mirjam wil ik met alle plezier bedanken voor hun uitstekende begeleiding van de proefpersonen en het uitwerken van de voedingsvragenlijsten.

Voor de onmisbare ondersteuning op het lab dank ik graag de analisten, Frank, Martijn, Puck en Sjoerd. Door de aanwezigheid van Jos, Joan en Adje werd het Cobassen voor mij een afwisselende bezigheid. Prof. Dr. Marja van Dieijen-Visser, bedankt voor het mogelijk maken van de CRP bepalingen op de afdeling Klinische Chemie van het AZM.

Paul en Loek, jullie stonden altijd paraat wanneer de computer weer eens bleef hangen (dit was nog voor het iMac tijdperk) of vanwege mijn roze beeldscherm. Ook zijn de mensen van ons secretariaat net zo onmisbaar, bedankt llona, Claudia, Marion, Désirée, Peggy, Marco, en last but not least Truus.

Dear members from Raisio Group in Finland. Ingmar Wester, Annu Hopia and Paula Virtanen, I would like to thank you for your scientific interest and support.

De dagelijkse lunchhalfuurtjes had ik beslist niet willen missen tijdens mijn AlO periode. Om klokslag 12 uur begaven wij ons dan richting de Mensa voor soep of andere versnaperingen. Riëtte, Karin, Jo ${ }^{\dagger}$, Frank, Dennis en Jogchum (mijn vroegere kamergenoten!), Marjolien, Susan, Yvette, Esther, Patrick R., Petra, Wilhelmine, Annemarie, Myriam, Sandra, Mirjam, Martijn, Maurice, Sjoerd, Angelina en Julian, bedankt allemaal voor jullie gezelligheid (ook buiten de lunches natuurlijk!) en de momenten van stoom afblazen. Elke en Ariënne, ik vond het erg leuk om jullie als allerlaatste kamergenoten om me heen te hebben.

Omdat we als (ex-) leden van het tijdelijk WP allen in hetzelfde schuitje zaten, will ik jullie eveneens in dit dankwoord noemen. Niet alleen vanwege jullie collegialiteit, maar ook voor de plezierige momenten: Annelies, Annemiek, Chris, Cyriel, Dorien, Eefje, Erica, Erwin M. Erwin T., Freddy, Guy, Joost, Kristof, Luc, Manuela, Marco, Margriet, Marieke, Marije, Marleen, Patrick S., Renate, Roosje "Suzie en Tanja. Natuurlijk dank ik ook de rest van Humane Biologie voor hun collegialiteit.

Beste Jozet en Lavienja, we zijn vriendinnen vanaf het begin van onze studententijd en nu zijn jullie mijn paranimfen. Ik vind het heel fijn dat jullie samen met mij op het podium staan tijdens mijn verdediging van het proefschrift.

Familie, vrienden en kennissen wil ik met name bedanken voor de nodige afleiding en ontspanning. Heerlijk om op jullie te kunnen terugvallen. Vooral mijn vader en moeder", broer Maurice tezamen met Ingrid en mijn neefje Luc draag ik een warm hart toe.

De mooiste afsluiting van dit dankwoord dat ben jii. Lieve Ron, "miene leve sjattepoemel': omdat je er altijd voor me bent! 


\section{Curriculum Vitae}

Daniëlle Kerckhoffs was born on June 6, 1970, in Maastricht. After graduating from secondary school at the Trichter College in Maastricht, she studied Biological Health Sciences at the Faculty of Health Sciences, Maastricht University (1992-1997). Her first internship was performed from January until September 1996 at the Department of Human Biology Maastricht University, in which defects in sympathetically mediated fat utilization in the etiology of non-insulin dependent diabetes mellitus were studied. Before graduating, she spent her second internship from October 1996 until April 1997 at the Department of Medicine, Center of Metabolism \& Endocrinology, Huddinge University Hospital, Karolinska Institute, Stockholm. During this time, she investigated lipolysis and lactate production in human adipose tissue and skeletal muscle by use of the microdialysis technique.

From June 1997 until June 1998, she worked as a research assistant at the Novartis Nutrition Research Unit in Maastricht. She performed a comprehensive literature study on effects of dietary components on lipid and lipoprotein metabolism in humans, which resulted in a research proposal for her PhD project (1998-2002) at the Department of Human Biology, Maastricht University. She conducted dietary intervention studies with subjects with increased serum cholesterol concentrations to examine the effects of the dietary components, tocotrienols, $\beta$-glucan and plant stanol esters on various cardiovascular risk markers, such as lipoproteins, lipidsoluble antioxidants, and hemostatic and inflammatory parameters. From September 2002 until January 2003, she worked as a Medical Writer at Clinical Documentation, N.V. Organon, Oss. 


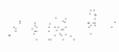

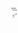

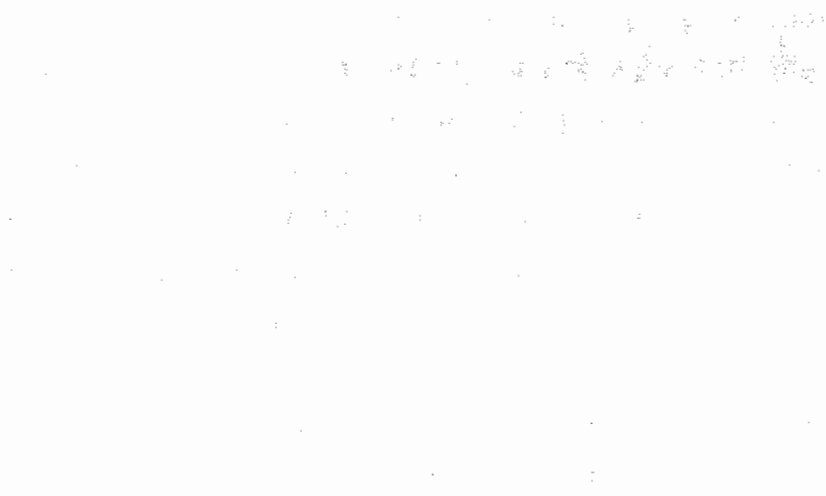




\section{List of publications}

\section{Full papers}

Kerckhoffs DA.IM, Arner P. Bolinder J. Lipolysis and lactate production in human skeletal muscie and adipose tissue following glucose ingestion. Clin Sci 1998;94:71-7.

Kerckhoffs DAJM, Blaak EE, van Baak MA, Saris WHM. Effect of aging on $\beta$-adrenergically mediated thermogenesis in men. Am J Physioll (Endocrinol Metab 37) 1998:274:E1075-E9.

Kerckhoffs DA.JM, Brouns F. Mensink RP. Effects of dietary components on lipid and lipoprotein metabolism in humans. Internal Report to Novartis for Recommendations to Marketing, 1998.

Bolinder J, Kerckhoffs DAJM, Moberg E, Hagström-Toft E, Arner P. Rates of skeletal muscle and adipose tissue glycerol release in nonobese and obese subjects. Diabetes $2000 ; 49: 797-802$.

Plat J, Kerckhoffs DAJM, Mensink RP. Therapeutic potential of plant sterols and stanols. Curr Opin Lipidol 2000;11:571-6.

Kerckhoffs DAJM, Brouns F, Hornstra G, Mensink RP. Effects on the human serum lipoprotein profile of $\beta$-glucan, soy protein and isoflavones, plant sterols and stanols, garlic and tocotrienols. J Nutr 2002;132:2494-505.

Kerckhoffs DAJM, Mensink RP, de Bruin TWA, Trautwein EA, Brouns F, Hornstra $G$. Effects af a tocotrienol-rich fraction from rice bran oil on serum lipoproteins, markers for cholesterol synthesis and absorption, and hemostatic parameters in hypercholesterolemic subjects. Submitted for publication.

Kerckhoffs DAJM, Hornstra G, Mensink RP. The effects of $\beta$-glucan from oat bran in bread and cookies or orange juice on serum lipoproteins in milldy hypercholesterolemic subjects. Submitted for publication.

Kerckhoffs DAJM, Hornstra G, Mensink RP. The effects of plant stanol esters, oat \$ 1 -glucan and pravastatin on plasma lipid-soluble antioxidants in subjects with increased serum cholesterol concentrations. Submitted for publication. 
Kerckhoffs DA.M, van Diejen-Visser MP, Hornstra G, Mensink RP. C-reactive protein and interleukin-6 in mildly and hypercholesterolemic subjects: effects of plant stanol esters and pravastatin, and relationships with plasma antioxidants. In preparation.

\section{Abstracts}

Blaak EE, Kerckhoffs DAJM, van Baak MA. Saris WHM. Impact of aging on the sympathetically mediated thermogenic and heart rate responses, VIII ${ }^{\text {th }}$ European Congress on Obesity. Dublin, Int J Obesity 1997;21:S89.

Mensink RP, Kerckhoffs DAJM, Plat J. Review on plant sterol and stanol esters. $3^{\text {rd }}$ Meeting of the European Section of AOCS - Oils, Fats, from Basic Research to Industrial Applications, Helsinki, 2000.

Kerckhoffs DAJM, Mensink RP, de Bruin TWA, Trautwein EA, Brouns F, Hornstra $G$. Tocotrienols from rice bran oil have no effects on levels of LDL cholesterol and markers for cholesterol synthesis and absorption. XII ${ }^{\text {th }}$ Unternational Symposium on Atherosclerosis, Stockholm, Atherosclerosis 2000;151:114.

Kerckhoffs DAJM, Hornstra G, Mensink RP. B-Glucan from oat bran has a cholesterollowering effect in mildly hypercholesterolemic subjects when consumed in orange juice but not in bread and cookies. International Symposium on Functional Foods - Scientific and Global Perspectives, Paris, 2001.

Naumann E, Luiking YC, Plat J "Kerckhoffs DAJM, Mensink RP. Effects of different ratios of palmitic and linoleic acids in the diet on palmitic acid oxidation. Atherosclerosis supplements. Abstracts, $73^{\text {rid }}$ Congress of the European Atherosclerosis Society, Salzburg, 2002. 